\title{
Materiales macroporosos \\ biodegradables basados en quitosano para la ingeniería tisular
}

Tesis presentada por

\section{Dunia Mercedes García Cruz}

\author{
Para obtener el título de Doctora \\ por la Universidad Politécnica de Valencia, \\ Valencia, 2008
}

Directores de Tesis: Dr. José Luís Gómez Ribelles

Dr. Manuel Salmerón Sánchez 


\section{Miembros del tribunal}

\section{Presidente del tribunal}

Dr. Manuel Monleón Pradas, Catedrático de Universidad, Departamento de Termodinámica Aplicada, Universidad Politécnica de Valencia, España.

\section{Secretaria}

Dra. Gloria Gallego Ferrer, Profesora Titular de Escuela Universitaria, Departamento de Termodinámica Aplicada, Universidad Politécnica de Valencia, España.

\section{Vocal}

Dr. Manuel Doblaré Castellano, Catedrático de Universidad, Instituto de Ingeniería de Aragón, Universidad de Zaragoza.

Director científico del Centro de Investigaciones Biomédicas en Red en Bioingeniería, Biomateriales y Nanomedicina (CIBER-BBN), España.

\section{Vocal}

Dra. Carmen Carda Batalla, Catedrática de Universidad, Departamento de Patología, Facultad de Medicina y Odontología, Universidad de Valencia, España.

\section{Vocal}

Dr. Joan Carles Monllau García, Asociado Universitario, Departamento de Cirugía Ortopédica y Traumatología, Facultad de Medicina, Universidad Autónoma de Barcelona, UDIMAS, Hospital del Mar, España. 


\section{Agradecimientos}

Agradecer a la Generalitat Valenciana por su financiación a través de una beca FPI (CTBPRB/2005/078).

Agradecer al Ministerio de Educación y Ciencia, por la financiación del proyecto de investigación científica y desarrollo tecnológico "MCYT MAT2004-04980-C02-01", concedido al profesor José Luis Gómez Ribelles y con el cual se apoyó mi candidatura a la beca FPI de la Generalitat Valenciana. Agradecer a los investigadores del 3B's Research Group in Biomaterials, Biodegradables and Biomimetics, de la universidad de Minho en Braga, Portugal y en especial al Profesor Joao F. Mano, por la ayuda y guía profesional durante mi estancia en dicho centro.

Agradecer a mis compañeros y profesores del Centro de Biomateriales e Ingeniería Tisular y en especial a mis directores de tesis José Luis Gómez Ribelles y Manuel Salmerón Sánchez por su ayuda, experiencia y profesionalidad.

Agradecer al equipo de técnicos de microscopía confocal del Centro de Investigaciones Príncipe Felipe y al grupo de microscopía electrónica de la Universidad Politécnica de Valencia.

Agradecer al Instituto Municipal de Investigaciones Médicas (IMIM) de Barcelona por el suminstro de condrocitos.

Agradecer a Ana, Gema, Juanchi y Josafat por acogernos en el seno de sus familias, por vuestro cariño y por ser lo que somos, muy buenos amigos.

Agradecer a mi familia en general y en especial a mis abuelos, a mis padres y a mis hermanos por su cariño, apoyo y confianza.

Por último y en especial a Jorge por su amor, cariño, entrega, confianza y por ser todo un ejemplo para mí. 
A mi hija, Isabela 


\section{Índice}

Resumen..................................................... 15

1. Introducción................................................ $\quad 25$

1.1. Objetivos................................................... $\quad 26$

1.2. Polímeros naturales............................................. 28

1.3. Polisacáridos................................................... 30

1.3.1. Polisacáridos de origen humano........................... 31

1.3.1.1. Ácido hialurónico................................. 31

1.3.1.2. Sulfato de condroitina............................. 33

1.3.2. Polisacáridos de origen no-humano........................ 35

1.3.2.1. El dextrano.................................... 35

1.3.2.2. La agarosa.................................... 37

1.3.2.3. La carragenina.................................. 38

1.3.2.4. La celulosa.......................................... 40

1.3.2.5. El ácido algínico................................. 41

1.3.2.6. La quitina y el quitosano............................. 44

1.4. Quitosano................................................... 45

1.4.1. Método de obtención de la quitina y el quitosano............. 45

1.4.2. Propiedades físico-químicas............................. 46 
1.4.3. Características biológicas y/o farmacológicas...............

1.4.4. Biodegradación........................................... 50

1.4.5. Caracterización físico-química.......................... 53

1.4.5.1. Determinación del grado de desacetilación.......... 53

1.4.5.2. Determinación de la distribución de pesos 54 moleculares.

1.5. Derivados y reacciones químicas del quitosano.................. 55

1.5.1. Reacciones de cuaternización............................ 56

1.5.2. Reacciones de entrecruzamiento.......................... 59

1.5.3. Formación de policomplejos........................... 63

1.6. Mezclas de quitosano con otros polímeros........................................ 64

1.6.1. Principales características de la policaprolactona............ 66

1.7. Ingeniería tisular............................................ 68

1.7.1. Scaffolds, como material soporte en el cultivo celular....... 69

1.7.1.1. Esponjas de quitosano........................... 70

1.7.1.2. Micropartículas de quitosano..................... 71

1.7.1.3. Características de los scaffolds de quitosano.......... 72

1.7.2. Aplicaciones de los scaffolds de quitosano en la ingeniería 74 de tejidos. 
1.7.2.2. El tejido cartilaginoso...........................

2. Parte Experimental......................................... 83

2.1. Materiales................................................. 84

2.1.1. Polímeros.............................................. 84

2.1.2. Otros reactivos........................................ 86

2.1.3. Solventes................................................ 86

2.1.4. Tipo de células y medios de cultivo utilizados en los 86 ensayos biológicos

2.2. Experimentos realizados..................................... 88

2.2.1. Caracterización físico-química y evaluación de la respuesta 88 biológica de mezclas poliméricas biodegradables de policaprolactona y quitosano.

2.2.1.1. Preparación de mezclas de policaprolactona y 88 quitosano.

2.2.2. Cultivo in vitro de condrocitos humanos sobre mezclas 89 biodegradables de policaprolactona y quitosano.

2.2.2.1. Aislamiento celular de condrocitos......

2.2.2.2. Cultivo primario de condrocitos................... 90

2.2.3. Materiales 3D con estructura porosa basados en redes 90 poliméricas semi-interpenetradas (semi-IPNs) de policaprolactona $y$ quitosano.

2.2.3.1. Preparación de las redes poliméricas semi- 90 
interpenetradas de policaprolactona y quitosano.

2.2.3.2. Preparación de scaffolds a partir de las semi-IPNs...

2.2.4. Diferenciación osteogénica de células madre de medula ósea 92 de cabra (GBMSCs) cultivadas en scaffolds de quitosano.................

2.2.4.1. Preparación de los scaffolds de quitosano........... 92

2.2.5. Cultivo in vitro de GBMSCs y su diferenciación osteogénica 93 en estructuras $3 \mathrm{D}$ porosas de quitosano.

2.2.5.1. Aislamiento de las GBMSCs

2.2.5.2. Cultivo y osteoinducción de las GBMSCs en 93 scaffolds de quitosano

2.2.6. Materiales tridimensionales porosos a base de quitosano para 94 la regeneración de cartílago articular.

2.2.6.1. Preparación de scaffolds de quitosano.

2.2.6.2. Cultivo primario de condrocitos en scaffolds de quitosano. Ensayos estáticos y dinámicos

2.2.7. Scaffolds a base de micropartículas de quitosano como 95 soporte en el cultivo celular de GBMSCs.

2.2.7.1 Preparación de micropartículas de quitosano 95 entrecruzadas con genipin

2.2.7.2. Cultivo in vitro de GBMSCs sobre micropartículas 96 de quitosano entrecruzadas con genipin

2.3. Técnicas experimentales. 97

2.3.1. Técnicas y métodos de caracterización de materiales 97

2.3.2. Técnicas de caracterización biológica.... 
3.1. Propiedades físico-químicas de filmes poliméricos biodegradables de policaprolactona de bajo peso molecular y quitosano. Cinética de cristalización.

3.2. Morfología, propiedades y evaluación biológica de mezclas poliméricas biodegradables de policaprolactona de alto peso molecular y quitosano.

3.3. Preparación de scaffolds macroporosos a partir de la formación de 145 redes semi-interpenetradas de policaprolactona y quitosano....

3.4. Scaffolds porosos de quitosano. Proliferación y diferenciación de las GBMSCs

3.4.1. Caracterización de los scaffolds

3.4.2. Ensayos de biodegradación "in vitro" de los scaffolds de 163 quitosano.

3.4.3. Determinación de las propiedades mecánicas de los scaffolds mediante ensayos de compresión.

3.4.4. Cultivo"in vitro” de GBMSCs, viabilidad celular, adhesión, 167 proliferación y producción de la matriz extracelular.

3.4.5. Cultivo “in vitro" de condrocitos en condiciones estáticas y 175 dinámicas en scaffolds de quitosano.

3.5. Proliferación y adhesión de GBMSCs sobre las micropartículas de 188 quitosano 
Abreviaturas................................................ 201

Referencias.................................................. 205

Apéndice..................................................... 223 


\section{Resumen}

La ingeniería tisular es una ciencia que aplica los principios de la ingeniería y las ciencias de la vida para desarrollar sustitutos biológicos que reparen o mejoren la función biológica de un tejido u órgano (según la definición de Langer y Vacanti). Para ello, el enfoque más común se basa en el uso de tres elementos fundamentales las células, las biomoléculas y los scaffolds poliméricos. A pesar de los muchos avances alcanzados, los investigadores de este campo aún nos enfrentamos a importantes retos en la reparación o la sustitución de los tejidos que cumplen predominantemente funciones biomecánicas como es el caso del tejido óseo y el tejido cartilaginoso y en específico el cartílago articular. En este sentido, los materiales tridimensionales (scaffolds) desempeñan un papel muy importante por lo que deben cumplir una serie de requisitos tales como: deben tener una estructura de poros interconectados con el fin de favorecer la integración y vascularización del tejido, deben ser biocompatibles, biodegradables, tener adecuadas propiedades mecánicas y una superficie química apropiada que favorezca la adhesión, diferenciación y proliferación celular.

En este contexto, el quitosano es un candidato con un gran potencial, utilizado en una amplia gama de aplicaciones, ya que posee propiedades biológicas únicas, entre las que se incluyen su biocompatibilidad, su biodegradación, su marcada actividad antibacterial, entre otras y además posibilita el desarrollo de materiales en una gran variedad de formas, como son polvos, micropartículas, scaffolds y filmes. La selección del quitosano como material soporte en cultivos celulares es de gran interés debido a la posibilidad de modular y controlar sus propiedades químicas, físicas y biológicas bajo suaves condiciones de reacción. Es por ello, que el gran reto de este trabajo es 
el desarrollo de materiales basados en quitosano para la ingeniería tisular, entre los cuales podemos mencionar la formación de mezclas poliméricas de policaprolactona y quitosano, scaffolds implantables de quitosano y el desarrollo de un nuevo modelo de scaffolds inyectables basados en micropartículas entrecruzadas de quitosano.

En la preparación de las mezclas de policaprolactona y quitosano, ambos polímeros han sido disueltos en un solvente adecuado y haciendo uso de la técnica de evaporación de solvente se han obtenido filmes con diferentes composiciones. Se ha estudiado la influencia del componente hidrófilo sobre algunas propiedades, tales como la capacidad de absorción de agua, la energía superficial, la cristalinidad y las propiedades mecánicas entre otras. Por otro lado, se evaluó la respuesta biológica de los materiales en cultivos primarios "in vitro" de condrocitos, llegando a la conclusión de que la hidrofilicidad, en este caso, no está directamente relacionada con la respuesta biológica y las mezclas de PCL/CHT que contienen un $20 \%$ de quitosano muestran mejores resultados que las demás mezclas con respecto a la viabilidad y proliferación de los condrocitos.

Por otra parte, se han preparado scaffolds de quitosano con micro y macroporos de geometría esférica y con una estructura interconectada mediante la combinación de la técnica de freeze-gelation y la utilización de micropartículas de porógeno. Se han realizado estudios biológicos con células madre de médula ósea de cabra (GBMSCs) que se han diferenciado a osteoblastos, las células del tejido óseo. También se han realizado cultivos "in vitro" de condrocitos humanos en condiciones estáticas y en un bioreactor de flujo con agitación intermitente. Los condrocitos cultivados en condiciones estáticas proliferan, tienen una morfología plana y tienden a cubrir la superficie del scaffold, mientras que los condrocitos cultivados en el bioreactor tienen una 
forma redondeada y tienden a agruparse dentro de los poros, en el interior del scaffold.

También hemos propuesto un nuevo modelo de scaffold inyectable basado en micropartículas de quitosano entrecruzadas con genipin para ser utilizado en la ingeniería de tejidos mediante procedimientos mínimamente invasivos. Hemos evaluado la respuesta biológica de las micropartículas en los cultivos "in vitro" de GBMSCs llegando a la conclusión que las células se extienden sobre las micropartículas, uniéndolas entre sí formando un constructo tri-dimensional donde las micropartículas actúan como soporte del tejido. 


\section{Summary}

Tissue engineering is an interdisciplinary science that applies the principles of engineering and life sciences to develop biological substitutes to restore, maintain or improve tissue function. The most common approach for engineering biological substitutes is based on living cells, biochemical factors and polymer scaffolds. Despite many advances, tissue engineers still face significant challenges in repairing or replacing tissue that serve predominantly biomechanical functions such as bone tissue and articular cartilage. In this sense, the tri-dimensional materials (scaffolds) play an important role and should meet the following requirements: the scaffold should possess interconnecting pores to favour tissue integration and vascularization, should be biocompatible with the tissue, biodegradable at the ideal rate corresponding to the new tissue formation, and possess optimal mechanical properties and adequate chemistry surface to favour cellular attachment, differentiation and proliferation.

In this context, chitosan has been found a fascinating candidate in a wide range of applications along with unique biological properties including biocompatibility, biodegradability to harmless product, non-toxicity and can be formulated in a variety of forms including powders, microparticles, scaffolds, and films. The choice of chitosan as a tissue support material is governed among others by multiple ways by which its biological, physical and chemical properties can be controlled under mild conditions. That is why; the great challenge of this work is the development of different materials based in chitosan for tissue engineering (polycaprolactone/chitosan blends, implantable chitosan scaffolds and a model of injectable scaffolds from crosslinked chitosan microparticles). 
Blends of polycaprolactone and chitosan (prepared by casting from the mixture of solution of both components in suitable solvents) were prepared with different compositions of both components, and also we study the behaviour of different properties (water absorption capacity, surface energy, mechanical properties, cristalinity, etc.) with the content of hydrophilic component. On the other hand, we studied the cell response on the materials, concluding that the hydrophilicity in this case is not directly related with the biological response and the samples with $20 \mathrm{wt} \%$ of chitosan shows better results than the other blends with respect to chondrocyte viability and proliferation.

The chitosan scaffolds with interconnected and spherical pore were prepared by combine the freeze-gelation and leaching out techniques. The biological response of these materials was evaluated seeding in its "Goat Bone Marrow Stromal Cell (GBMSCs)" differentiated to osteoblastic cells. Also, primary chondrocytes was seeding into the scaffolds and experiments were conducted for four times at static conditions and in an intermittent stirred flow bioreactor. In static conditions, the cells proliferated well and covered the surface of chitosan scaffolds by dense layer of cells, while the chondrocytes grown in the bioreactor has a rounded shape and tend to form cell cluster inside the pores.

Finally, a novel injectable scaffold model from crosslinked chitosan microparticles was proposed for tissue engineering through minimally invasive surgical procedures. Genipin crosslinked chitosan microparticles were prepared by water/oil crosslinking emulsion technique. Its biological response were analysed seeding GBMSCs on chitosan particles; the obtained results shows that the cell spread on their surface joining them to form a $3 \mathrm{D}$ construct in which microparticles play the role of the scaffolds. 


\section{Resum}

L'enginyeria tissular és una ciència que aplica els principis de l'enginyeria i les ciències de la vida per a desenvolupar substituts biològics que reparen o milloren la funció biològica d'un teixit o òrgan. Per a això, l'enfocament més comú es basa en l'ús de tres elements fonamentals: les cèlllules, les biomolècules i els esquelets (scaffolds) polimèrics. A pesar dels molts avanços a què s'ha arribat, els investigadors d'aquest camp encara ens enfrontem a importants reptes en la reparació o la substitució dels teixits que compleixen predominantment funcions biomecàniques, com és el cas del teixit ossi i el teixit cartilaginós i, específicament, el cartílag articular. En aquest sentit, els materials tridimensionals (esquelets) ocupen un paper molt important i per això han de complir una sèrie de requisits, com ara els següents: han de tenir una estructura de porus interconnectats, amb la finalitat d'afavorir la integració i vascularització del teixit; han de ser biocompatibles, biodegradables, tenir propietats mecàniques adequades i una superfície química apropiada que afavorisca l'adhesió, la diferenciació i la proliferació cel-lular.

En aquest context, el quitosan és un candidat amb un gran potencial, utilitzat en una àmplia gamma d'aplicacions, ja que posseeix propietats biològiques úniques, entre les quals s'inclouen la biocompatibilitat, la biodegradació, la marcada activitat antibacteriana, entre altres i, a més, possibilita el desenvolupament de materials en una gran varietat de formes, com ara pólvores, micropartícules, esquelets i films. La selecció del quitosan com a material de suport en cultius cel-lulars és de gran interès a causa de la possibilitat de modular i controlar les seues propietats químiques, físiques i biològiques sota suaus condicions de reacció. És per això que el gran repte d'aquest treball és el desenvolupament de materials basats en el quitosan per a 
l'enginyeria tissular, entre els quals podem esmentar la formació de barreges polimèriques de policaprolactona i quitosan, esquelets implantables de quitosan i el desenvolupament d'un nou model d'esquelets injectables basats en micropartícules entrecreuades de quitosan.

En la preparació de les barreges de policaprolactona i quitosan, ambdós polímers han estat dissolts en una solució adequada, i fent ús de la tècnica d'evaporació de solucions s'han obtingut films amb diferents composicions. S'ha estudiat la influència del component hidròfil sobre algunes propietats, com ara la capacitat d'absorció d'aigua, l'energia superficial, la cristal-linitat i les propietats mecàniques, entre altres. D'altra banda, es va avaluar la resposta biològica dels materials en cultius primaris in vitro de condròcits, i es va arribar a la conclusió que la hidrofilicitat, en aquest cas, no està directament relacionada amb la resposta biològica, i les barreges de PCL/CHT que contenen un $20 \%$ de quitosan mostren millors resultats que les altres barreges pel que fa a la viabilitat i proliferació dels condròcits.

D’altra banda, s'han preparat esquelets de quitosà amb microporus i macroporus de geometria esfèrica i amb una estructura interconnectada mitjançant la combinació de la tècnica de congelació-gelificació (freeze-gelation) i la utilització de micropartícules de porífer. S'han realitzat estudis biològics amb cèlllules mare de medullla òssia de cabra (GBMSCs) i s'han diferenciat en teixit ossi. També s'han realitzat cultius primaris in vitro de condròcits en condicions estàtiques i en un bioreactor de flux amb agitació intermitent. Els condròcits conreats en condicions estàtiques proliferen, tenen una morfología plana i tendeixen a cobrir la superfície del esquelet, mentre que els condròcits conreats en el bioreactor tenen una forma arrodonida i tendeixen a agrupar-se dins dels porus, en l'interior del esquelet. 
També hem proposat un nou model d'esquelets injectables basats en micropartícules de quitosan entrecreuades amb genipin per a utilitzar-les en l'enginyeria de teixits mitjançant procediments mínimament invasius. Hem avaluat la resposta biològica de les micropartícules en els cultius in vitro de GBMSCs i hem arribat a la conclusió que les cèlllules s'estenen sobre les micropartícules, unint-les entre si formant un constructe tridimensional on les micropartícules actuen com a suport del teixit. 
Capítulo 1

Introducción 


\subsection{Objetivos}

En este documento se describe la obtención de materiales biodegradables basados en quitosano para su utilización en la ingeniería tisular. Para ello nos hemos planteado lo siguientes objetivos:

1. La preparación de mezclas de policaprolactona (PCL) y quitosano (CHT) con el fin de obtener nuevos materiales.

2. Analizar la influencia del contenido de quitosano sobre las propiedades físico-químicas y mecánicas de las mezclas.

3. Estudiar la respuesta biológica de las mezclas de PCL/CHT en cultivos primarios "in vitro" de condrocitos.

Una vez obtenidas dichas mezclas, se procedió a desarrollar materiales macroporosos a partir de de ambos componentes por lo que los objetivos en este apartado son los siguientes:

1. Obtención de scaffolds macroporosos a partir de la formación de redes poliméricas semi-interpenetradas de policaprolactona y quitosano (semiIPN $\mathrm{PCL} / \mathrm{CHT})$.

2. Analizar la miscibilidad y las interacciones de ambos polímeros durante la formación de la semiIPN.

3. Caracterizar tanto las semiIPN como los scaffolds de PCL y CHT y estudiar la influencia de la porosidad y del contenido de quitosano sobre las propiedades físico-químicas y mecánicas.

Otro de los desafíos del trabajo fue la obtención de materiales tridimensionales con estructura de poros interconectados a partir del quitosano 
como un futuro material implantable, por lo que los objetivos en esta parte del trabajo fueron:

1. Desarrollo de materiales tridimensionales (scaffolds) con estructura de poros interconectados de quitosano, además del estudio de su respuesta biológica en el cultivo de células madre provenientes de médula ósea de cabra (GBMSCs) y su posterior diferenciación a células de tejido óseo.

2. Estudiar el comportamiento biológico de condrocitos humanos cultivados "in vitro" en scaffolds de quitosano en condiciones estáticas y dinámicas (bioreactor).

Por último, otra de las propuestas en relación a la obtención de materiales que puedan ser utilizados en la ingeniería biomédica fue el desarrollo de un posible scaffold inyectable a base de micropartículas de quitosano por lo que los objetivos a seguir fueron los siguientes:

1. Síntesis de micropartículas de quitosano entrecruzadas con genipin mediante el método de emulsión de agua en aceite (W/O).

2. Realizar cultivos "in vitro" de GBMSCs sobre las micropartículas y valorar la respuesta celular. 


\subsection{Polímeros naturales}

Los polímeros naturales procedentes de las plantas y los animales han sido utilizados a lo largo de cientos de años, casi desde los mismos orígenes de la tierra. Entre estos materiales se incluyen la lana, el caucho, la seda, la madera, las proteínas, los polisacáridos, los polinucleótidos, las enzimas, entre otros [1].

Los polímeros naturales tienen la ventaja de ser muy similares a las sustancias macromoleculares que el medio biológico está preparado para reconocer y metabolizar. Con la utilización de materiales naturales se puede evitar en principio los problemas de estimulación de una reacción inflamatoria crónica y toxicidad asociada frecuentemente al uso de muchos polímeros sintéticos, además la similitud con sustancias naturales introduce la interesante posibilidad de diseñar biomateriales con una función biológica a nivel molecular en vez de macroscópica. Sin embargo, los polímeros naturales son frecuentemente bastante inmunogénicos (especialmente las proteínas). Asimismo, debido a que son estructuralmente más complejos que los polímeros sintéticos su manipulación tecnológica es más delicada.

Los polímeros naturales se degradan en medios fisiológicos por la acción de enzimas naturales, por lo que debe esperarse que el implante sea degradado y metabolizado por mecanismos fisiológicos. No obstante, existe la posibilidad de controlar en cierta medida la velocidad de degradación y el tiempo de vida medio del implante en el organismo [1], a través de modificaciones químicas de los polímeros de partida, por ejemplo variando la concentración del agente reticulante.

Muchos de los biomateriales naturales o biológicos utilizados hoy en día en diversas aplicaciones biomédicas [2] están constituidos por polímeros 
presentes en la matriz extracelular de muchos tejidos tales como el tejido óseo, el tejido cartilaginoso, la piel, los tendones, los ligamentos, etc. Dentro de ellos, los polisacáridos y sus derivados han sido ampliamente utilizados en aplicaciones farmacéuticas y biomédicas. Los polisacáridos de origen nohumano como la carboximetilcelulosa, la agarosa, el quitosano y el alginato han sido empleados para la inmovilización celular así como material soporte, en el diseño de sistemas de liberación controlada de moléculas activas y en la preparación de membranas para hemodiálisis. Por otra parte, los polisacáridos de origen humano tales como el ácido hialurónico, la heparina, el sulfato de condroitina, entre otros han encontrado numerosas aplicaciones en el campo de la ingeniería de tejido (TE) y en la medicina regenerativa [3].

En la tabla 1.1 se resumen las propiedades generales de algunos polímeros naturales.

Tabla 1.1. Propiedades generales de algunos polímeros naturales.

\begin{tabular}{|c|c|c|c|}
\hline & Polímeros & Presencia & Propiedades \\
\hline \multirow{4}{*}{ Proteínas } & Colágeno & $\begin{array}{c}\text { Tejido } \\
\text { conectivo }\end{array}$ & Soporte mecánico \\
\hline & Albúmina & Plasma & $\begin{array}{l}\text { Transporte de } \\
\text { ácidos grasos }\end{array}$ \\
\hline & Actina & Músculos & $\begin{array}{l}\text { Movilidad y } \\
\text { contracción }\end{array}$ \\
\hline & Fibrinógeno & Sangre & $\begin{array}{l}\text { Coagulante } \\
\text { sanguíneo }\end{array}$ \\
\hline $\begin{array}{c}\text { Poli } \\
\text { nucleótidos }\end{array}$ & DNA y RNA & $\begin{array}{l}\text { Núcleos } \\
\text { celulares }\end{array}$ & $\begin{array}{c}\text { Biosíntesis directa } \\
\text { de proteínas }\end{array}$ \\
\hline
\end{tabular}




\begin{tabular}{|c|c|c|c|}
\hline \multirow{7}{*}{ Polisacáridos } & $\begin{array}{c}\text { Ácido } \\
\text { hialurónico }\end{array}$ & Fluido sinovial & $\begin{array}{c}\text { Proporciona } \\
\text { viscoelasticidad a } \\
\text { los tejidos }\end{array}$ \\
\cline { 2 - 4 } & Agarosa & Algas rojas & $\begin{array}{c}\text { Geles para } \\
\text { electrofóresis }\end{array}$ \\
\cline { 2 - 4 } & Quitina & $\begin{array}{c}\text { Insectos y } \\
\text { crustáceos }\end{array}$ & $\begin{array}{c}\text { Proporciona } \\
\text { configuración y } \\
\text { forma }\end{array}$ \\
\cline { 2 - 4 } & $\begin{array}{c}\text { Glicosaminogli } \\
\text { canos }\end{array}$ & Tejido & $\begin{array}{c}\text { Contribuye al } \\
\text { conectivo }\end{array}$ \\
\cline { 2 - 4 } & soporte mecánico \\
\hline
\end{tabular}

\subsection{Polisacáridos}

Los polisacáridos son una clase de biopolímeros formados por la unión de una gran cantidad de monosacáridos a través de enlaces glucosídicos [4] entre el grupo hidroxilo $(\mathrm{OH})$ de cada unidad monosacarídica; lo cual le confiere la habilidad de formar biopolímeros lineales o ramificados. En los últimos tiempos, la aplicación de éstos como biomateriales en la ingeniería de tejidos, en la biomedicina y la biotecnología ha despertado un gran interés debido a su actividad biológica en el reconocimiento celular y a la posibilidad de fabricar estructuras apropiadas para cada aplicación en específico [5]. Estas características conjuntamente con la posibilidad de modificar sus propiedades físico-químicas mediante rutas sintéticas hacen que los polisacáridos naturales sean uno de los biomateriales más importantes. 


\subsubsection{Polisacáridos de origen humano}

\subsubsection{Acido hialurónico}

El ácido hialurónico (HA) es un polisacárido lineal perteneciente a la familia de los glicosaminoglicanos, constituido por unidades alternadas de $\mathrm{N}$ acetil glucosamina y ácido glucurónico (ver figura 1.1). El ácido hialurónico está formado por más de 50000 unidades disacarídicas por lo que se estima que su peso molecular oscile entre 2 y 4 millones. Es un biopolímero capaz de retener grandes cantidades de agua y en disolución adopta una conformación extendida producto al gran número de grupos hidroxilo $(\mathrm{OH})$ y cargas negativas presente en su estructura, lo que permite, por el establecimiento de fuerzas de repulsión, que se conserven relativamente separadas entre si las cadenas del polímero.

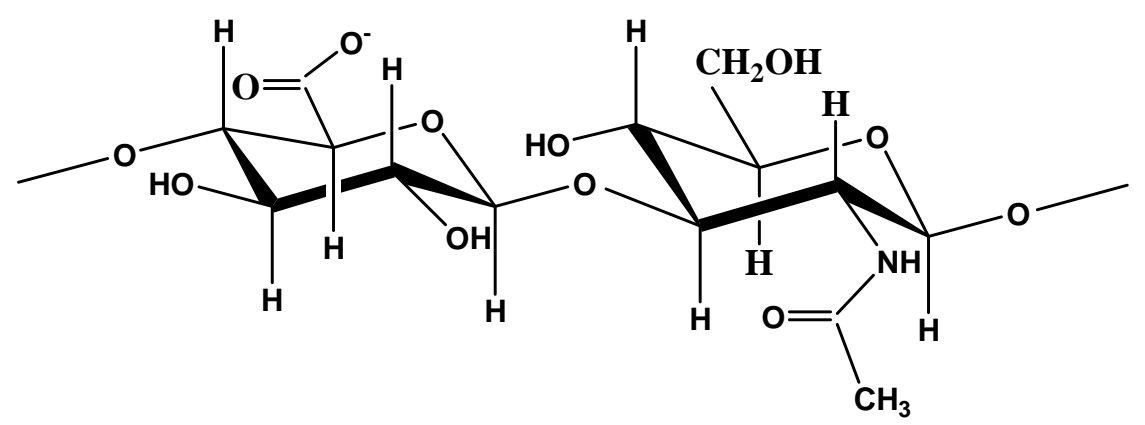

Figura 1.1 Estructura química del ácido hialurónico.

El ácido hialurónico es el único glicosaminoglicano no sulfatado, in vivo se encuentra en forma de poli-anión [6] y es el mayor componente de la matriz extracelular del cartílago, el cordón umbilical, el humor vítreo, el fluido sinovial y del tejido conectivo [6] de numerosos organismos. El HA ha sido 
utilizado ampliamente como sistema de liberación controlada de moléculas bioactivas por vía nasal, pulmonar, dermal, parenteral así como vehículo implantable para la liberación de genes [6]. En la ingeniería de tejido se ha aplicado esencialmente en el cartílago, hueso y en sistemas osteocondrales, donde se ha obtenido resultados muy alentadores, debido principalmente a la similitud de este compuesto con los componentes de la matriz extracelular. Las aplicaciones más relevantes en este tema se resumen en la tabla 1.2.

Tabla 1.2. Matrices a base de HA utilizadas en diferentes aplicaciones.

\begin{tabular}{|c|c|c|c|c|c|}
\hline $\begin{array}{l}\text { Polímero/ } \\
\text { scaffold }\end{array}$ & $\begin{array}{c}\text { Aplicaciones } \\
\text { en TE }\end{array}$ & $\begin{array}{c}\text { Biomolécula } \\
\text { activa }\end{array}$ & Tipo de célula & $\begin{array}{l}\text { Modelo } \\
\text { animal }\end{array}$ & Ref. \\
\hline $\begin{array}{c}\text { Scaffold de } \\
\text { nanofibras } \\
\text { de HA }\end{array}$ & No definido & $\begin{array}{c}\text { Fibronectin } \\
\text { a }\end{array}$ & $\begin{array}{c}\text { Fibroblastos } \\
\text { NIH 3T3 }\end{array}$ & - & {$[7]$} \\
\hline $\begin{array}{c}\text { Scaffolds } \\
\text { HA-alginato }\end{array}$ & No definido & bFGF & - & - & [8] \\
\hline Gel de HA & $\begin{array}{l}\text { Hueso/ } \\
\text { Cartílago }\end{array}$ & Gen BMP-2 & $\begin{array}{l}\text { Células de } \\
\text { médula ósea }\end{array}$ & $\begin{array}{l}\text { Músculo } \\
\text { femoral de } \\
\text { ratón }\end{array}$ & [9] \\
\hline $\begin{array}{c}\text { Hidrogel de } \\
\text { HA }\end{array}$ & Cartílago & - & $\begin{array}{l}\text { Condrocito } \\
\text { articular }\end{array}$ & $\begin{array}{c}\text { Implante } \\
\text { subcutáneo } \\
\text { en ratones }\end{array}$ & {$[10]$} \\
\hline $\begin{array}{c}\text { Membranas } \\
\text { de HA }\end{array}$ & Piel & - & Queratinocitos & - & [11] \\
\hline $\begin{array}{c}\text { Esponjas de } \\
\text { HA } \\
\left(\text { Hyaff }^{\circledR} 11\right)\end{array}$ & $\begin{array}{c}\text { Tejido } \\
\text { adiposo }\end{array}$ & & Pre-adipocitos & $\begin{array}{c}\text { Implante } \\
\text { subcutáneo } \\
\text { en ratones }\end{array}$ & [12] \\
\hline
\end{tabular}




\subsubsection{Sulfato de condroitina}

El sulfato de condroitina (CS) es uno de los glicosaminoglicanos (GAG) más importantes que componen la matriz extracelular. A excepción del ácido hialurónico, los GAG, se encuentran unidos covalentemente a las proteínas formando los proteoglicanos. El CS está constituido por unidades disacáridas de ácido glucurónico y sulfato de $\mathrm{N}$-acetil galactosamina en la posición 4 y 6 ó 2 y 6 según el tipo de CS (ver figura 1.2). Las enzimas responsables de esta modificación son las sulfotransferasas de condroitina.

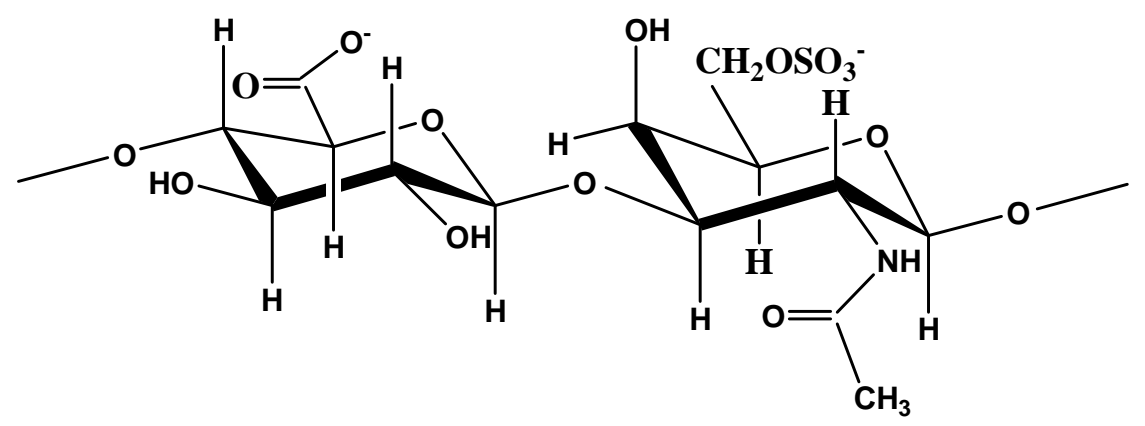

Figura 1.2. Estructura química del sulfato de condroitina.

El CS se encuentra en el fluido sinovial, en el hueso, en las válvulas del corazón y como componente mayoritario de los agrecanos, el GAG más abundante del cartílago articular. En las últimas décadas estudios realizados revelan el enorme potencial de ésta macromolécula como biomaterial en aplicaciones biomédicas como vehículo en sistemas de liberación controlada y esencialmente en la ingeniería de tejido de cartílago [13]. Desde el punto de vista biológico, el CS proporciona al cartílago elasticidad producto a la formación de una red de agrecanos altamente hidrófila, además de ser una macromolécula de reconocimiento celular que interviene en la conexión de los 
componentes de la matriz extracelular con las glicoproteínas superficiales de la célula.

Además del potencial biológico del CS, otro factor a tener en cuenta son las propiedades físico-químicas del biopolímero, por lo que numerosos investigadores han centrado su atención en desarrollar métodos de entrecruzamiento tanto físico como químico con el fin de obtener hidrogeles y matrices poliméricas que permitan la formación de scaffolds para diferentes aplicaciones biomédicas $\left[\begin{array}{lll}14 & \text { y } & 15\end{array}\right]$. En la tabla 1.3 se resumen las aplicaciones de scaffolds de CS en TE y como sistema de liberación de moléculas bioactivas.

Tabla 1.3 Matrices poliméricas a base de CS utilizadas en aplicaciones biomédicas.

\begin{tabular}{|c|c|c|c|c|c|}
\hline $\begin{array}{c}\text { Polímero/ } \\
\text { scaffold }\end{array}$ & $\begin{array}{c}\text { Aplicaciones en } \\
\text { TE }\end{array}$ & $\begin{array}{c}\text { Biomolécula } \\
\text { activa }\end{array}$ & $\begin{array}{l}\text { Tipo de } \\
\text { célula }\end{array}$ & $\begin{array}{l}\text { Modelo } \\
\text { animal }\end{array}$ & Ref. \\
\hline $\begin{array}{l}\text { Membranas } \\
\text { de colágeno } \\
\text { y CS }\end{array}$ & Hueso & rhBMP-2 & - & $\begin{array}{c}\text { Implante } \\
\text { óseo en rata }\end{array}$ & [16] \\
\hline $\begin{array}{c}\text { Scaffolds de } \\
\text { CS/CHT }\end{array}$ & Hueso & PDGF-BB & $\begin{array}{c}\text { Células } \\
\text { faciales de } \\
\text { rata }\end{array}$ & - & {$[17]$} \\
\hline $\begin{array}{l}\text { Scaffolds de } \\
\text { CS/colágeno } \\
\text { /CHT y } \\
\text { MCP de } \\
\text { CHT }\end{array}$ & Cartílago & TGF- $\beta 1$ & $\begin{array}{c}\text { Condrocitos } \\
\text { de conejo }\end{array}$ & - & [18] \\
\hline $\begin{array}{c}\text { Hidrogel de } \\
\text { CS }\end{array}$ & Vascularización & bFGF & $\begin{array}{c}\text { Fibroblastos } \\
\text { NIH 3T3 }\end{array}$ & $\begin{array}{c}\text { Implante } \\
\text { subcutáneo } \\
\text { en ratones }\end{array}$ & [19] \\
\hline
\end{tabular}




\begin{tabular}{|c|c|c|c|c|c|}
\hline $\begin{array}{c}\text { Scaffolds de } \\
\text { PLGA- } \\
\text { CS/gelatina }\end{array}$ & Cartílago & - & $\begin{array}{c}\text { Células } \\
\text { madre de } \\
\text { conejo }\end{array}$ & $\begin{array}{c}\text { Defecto } \\
\text { cartílago } \\
\text { articular }\end{array}$ & [20 $]$ \\
\hline $\begin{array}{c}\text { Scaffolds de } \\
\text { gelatina/CS } \\
\text { /HA }\end{array}$ & Cartílago & - & $\begin{array}{c}\text { Defecto } \\
\text { de cerdo }\end{array}$ & $\begin{array}{c}\text { y cartílago } \\
\text { articular }\end{array}$ & $\begin{array}{c}\text { 22 }] \\
\end{array}$ \\
\hline
\end{tabular}

Otros polisacáridos de origen humano tales como el sulfato de queratán, el sulfato de dermatán, entre otros han sido utilizados como biomateriales en aplicaciones biomédicas.

\subsubsection{Polisacáridos de origen no-humano}

Los polisacáridos de origen no-humano se pueden clasificar en dos clases: una clase la forman aquellas biomoléculas de naturaleza aniónica y/o neutra tales como; la celulosa, el dextrano, la pectina, el ácido algínico, el agar, la agarosa, la carragenina, entre otras y otra segunda clase a la que pertenecen la quitina y el quitosano como polisacáridos catiónicos.

\subsubsection{El dextrano}

El dextrano es un polisacárido complejo, de estructura ramificada formado por muchas moléculas de glucosa unidas a través de enlaces glucosídicos $\alpha 1-6$, mientras que las ramificaciones pueden empezar en uniones $\alpha$ 1-4 y en algunos casos también por uniones $\alpha$ 1-2 y $\alpha$ 1-3 (ver figura 1.3). Generalmente el grado de ramificación es aproximadamente de un $5 \%$. 


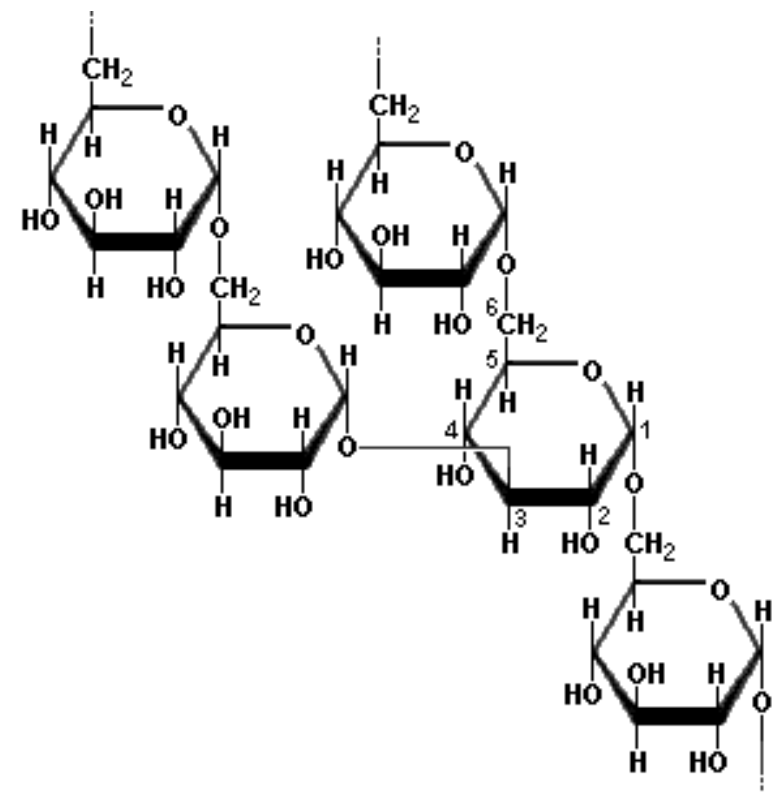

Figura 1.3. Estructura química del dextrano.

El dextrano es obtenido mediante un proceso de fermentación a partir de la sacarosa bajo la acción de ciertas bacterias ácido-lácticas, de las cuales las más conocidas son la leuconostoc mesenteroides y el streptococcus mutans [23]. Es un polímero de alto peso molecular, disponible comercialmente en un amplio rango de pesos moleculares entre 1 y $2000 \mathrm{kDa}$, es soluble en agua y en soluciones electrolíticas, así como en algunos solventes orgánicos, excepto en alcoholes y cetonas.

El dextrano es un polímero biocompatible, biodegradable enzimaticamente por las enzimas dextranasas dando lugar a la formación de azúcares de bajo peso molecular como por ejemplo la glucosa e isomaltosa. En cuanto a sus aplicaciones podemos decir que es comúnmente utilizado en 
biotecnología, en la industria alimenticia y en aplicaciones clínicas debido a sus propiedades antitrombogénicas.

\subsubsection{La agarosa}

La agarosa es un polisacárido lineal formado por moléculas de galactosa unidas a través de enlaces $\alpha$ 1-4 y $\beta$ 1-3 que se extrae de la pared celular de varias especies de algas rojas (ver figura 1.4).

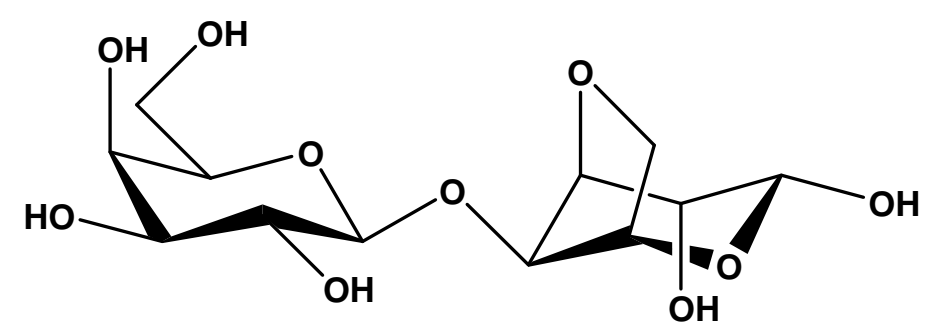

Figura 1.4. Estructura química de la agarosa.

La agarosa es soluble en agua a temperaturas superiores a $65^{\circ} \mathrm{C}$ en dependencia del grado de sustitución hidroxietílica de su cadena lateral, es insoluble en solventes orgánicos y tiene la capacidad de formar geles termoreversibles [24 y 25]. Debido a sus características, la agarosa, es un producto indispensable en una gran cantidad de técnicas de biología molecular, bioquímica, cultivos celulares, microbiología y biología celular para la preparación de geles que permitan separar moléculas de ADN u otros compuestos mediante electrofóresis, además de ser utilizada para fijar moléculas en su estructura como antígenos o anticuerpos. 


\subsubsection{La carragenina}

La carragenina es un polisacárido de alto peso molecular formado por unidades alternadas de galactosa y 3,6-anhidro-galactosa unidas a través de enlaces glucosídicos $\alpha$ 1-3 y $\beta$ 1-4 (ver figura 1.5). Éste polímero natural pertenece a la familia de los polisacáridos sulfatados y se extrae de las algas rojas marinas. La posición y el número de grupos sulfato, así como el contenido de unidades 3,6-anhidro-galactosa determinan las diferencias entre los tipos de carragenina (kappa, iota y lambda) y sus propiedades.

\section{Kappa}
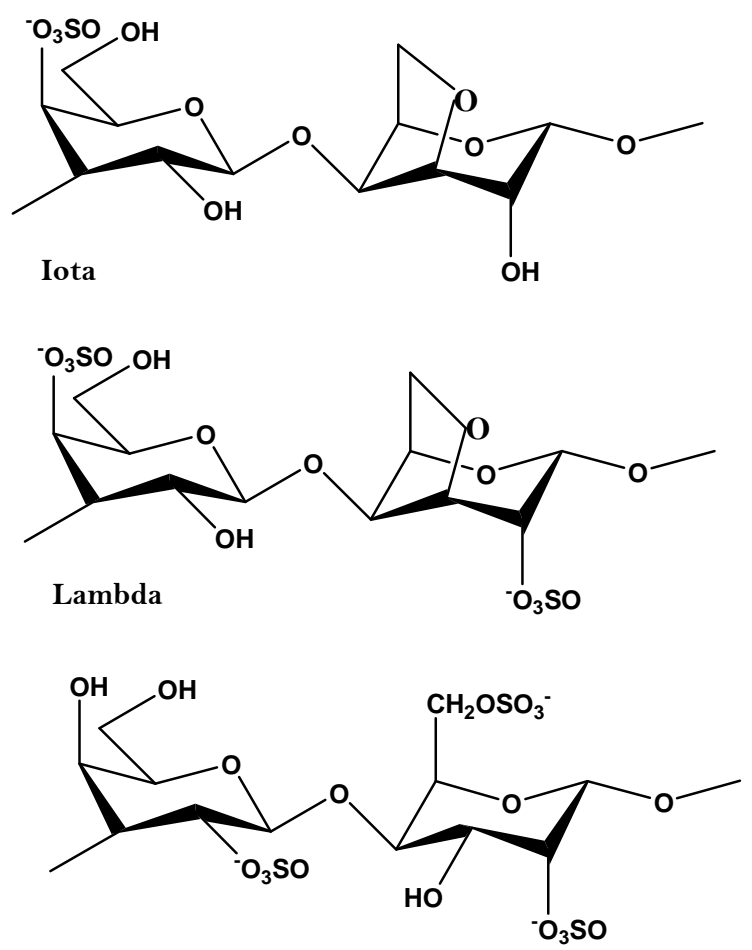

Figura 1.5. Estructura química de los diferentes tipos de carragenina. 
La carragenina posee una habilidad exclusiva de formar una amplia variedad de texturas de gel a temperatura ambiente [26]: gel firme o elástico; transparente o turbio; fuerte o débil; termo-reversible o estable al calor; alta o baja temperatura de fusión/gelificación. En la tabla 1.4 se resumen las propiedades físico-químicas de los diferentes tipos de carragenina.

Tabla 1.4. Propiedades físico-químicas de los diferentes tipos de carragenina.

\begin{tabular}{|l|l|}
\hline Tipo de carragenina & Propiedades físico-químicas \\
\hline Carragenina kappa & $\begin{array}{l}\text { Forma un gel rígido, quebradizo, } \\
\text { termo-reversible y presenta } \\
\text { sinéresis (extrusión espontánea de } \\
\text { agua a través de la superficie del gel } \\
\text { en reposo). }\end{array}$ \\
\hline Carragenina iota & $\begin{array}{l}\text { Forma un gel elástico, termo- } \\
\text { reversible, con propiedades } \\
\text { tixotrópicas y no presenta sinéresis }\end{array}$ \\
\hline Carragenina lambda & $\begin{array}{l}\text { Es soluble en frío, no forma geles y } \\
\text { sus disoluciones presentan altas } \\
\text { viscosidades. }\end{array}$ \\
\hline
\end{tabular}

Las aplicaciones de la carragenina se concentran en la industria alimentaria, donde puede ser utilizado como agente de suspensión, retención de agua, gelificación, emulsificación y estabilización de emulsiones o proteínas entre otras diversas aplicaciones industriales. Sin embargo, actualmente se empiezan a utilizar en forma de micropartículas para la liberación controlada de fármacos o compuestos bioactivos [27-29]. 


\subsubsection{La celulosa}

La celulosa es un homopolisacárido compuesto por moléculas de glucosa unidas entre si por enlaces glucosídicos $\beta$ 1-4 (ver figura 1.6) y es referida como la biomolécula orgánica más abundante en la naturaleza, ya que forma la mayor parte de la biomasa terrestre [30].

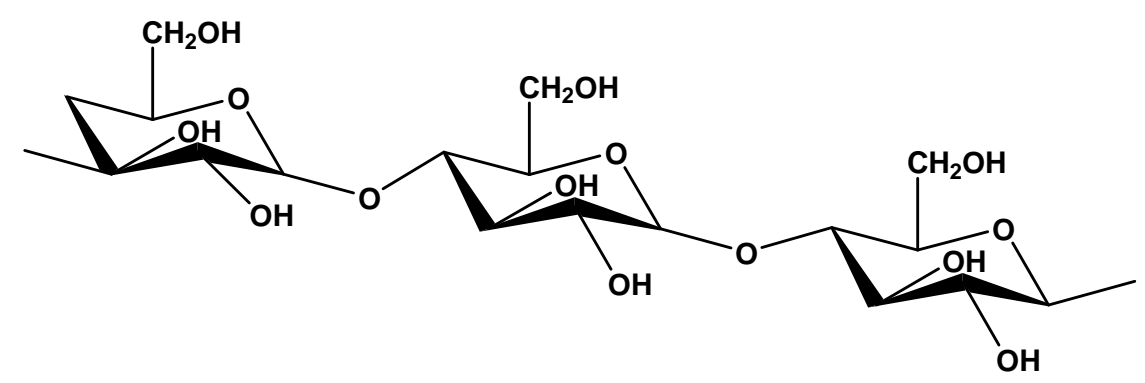

Figura 1.6. Estructura química de la celulosa.

La celulosa es un polímero lineal en el que se establecen múltiples puentes de hidrógeno entre los grupos hidroxilo de las distintas cadenas yuxtapuestas de glucosa, haciéndolas impenetrables al agua y originando fibras compactas que constituyen la pared celular de las células vegetales [31]. Aunque sus principales aplicaciones se concentran en la industria del papel y en la industria textil, scaffolds de celulosa han sido evaluados en la formación de hueso obteniéndose resultados no muy alentadores debido a que es preciso periodos de tiempo muy largos para que se lleve a cabo la regeneración ósea [32], sin embargo al combinar el material con factores de crecimiento se obtiene buenos resultados. Por otra parte, también las esponjas de celulosa han sido utilizadas en la ingeniería de tejido del cartílago [33 y 34], hueso [35 y 36] y en aplicaciones cardíacas [37]. 


\subsubsection{El ácido algínico}

El ácido algínico es un polisacárido lineal, de naturaleza aniónica, constituido por dos unidades monoméricas, el ácido manurónico $(\mathrm{M})$ y el ácido gulurónico $(\mathrm{G})$, los cuales se agrupan en bloques de secuencias MM o MG, unidos por enlaces glucosídicos $\beta$ 1-4; y bloques GG o GM, unidos por enlaces glucosídicos $\alpha$ 1-4 [38]. En la figura 1.7 se muestran las configuraciones espaciales que adoptan los bloques $\mathrm{M}$ y $\mathrm{G}$ debido a los diferentes enlaces glucosídicos entre los carbonos $\mathrm{C}-1$ y C-4 de las unidades monoméricas. Las regiones de bloques $\mathrm{M}$ corresponden a cadenas lineales, mientras que los bloques $\mathrm{G}$ presentan una estructura en forma de bucle.

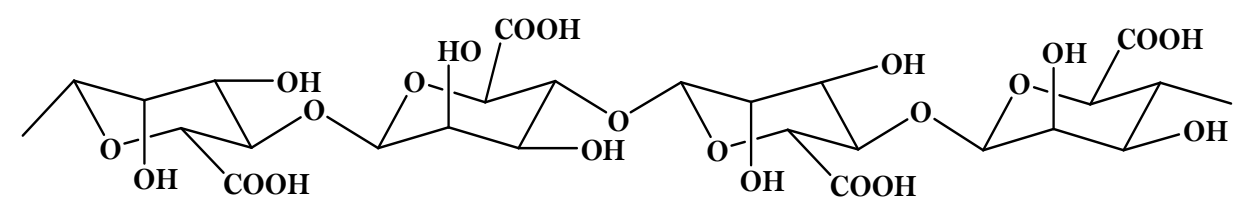

\section{Bloque MM}

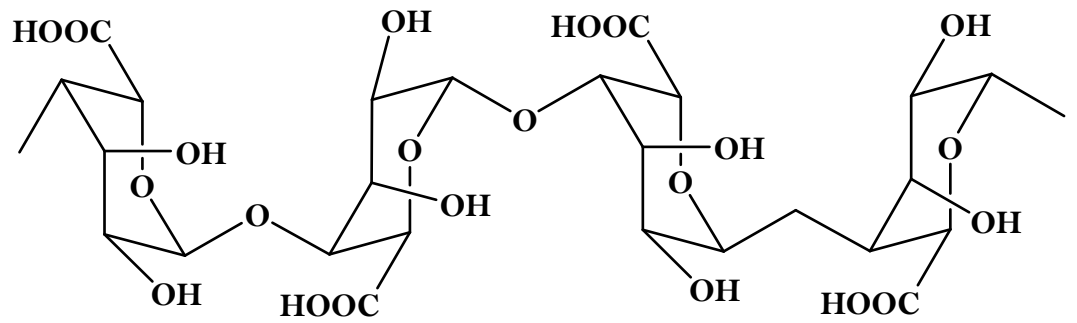

\section{Bloque GG}

Figura 1.7. Configuraciones espaciales de los bloques MM y GG. 
Cuando dos cadenas de bloques $\mathrm{G}$ se alinean una al lado del otro, resulta un hueco en forma de diamante, el cual tiene la dimensión ideal para acomodar en su interior un ión calcio, formándose una estructura dimérica que obedece al modelo propuesto por Grant, conocido como el modelo de la caja de huevos (egg-box model) [39] para explicar las propiedades gelificantes de los alginatos al reaccionar con sales cálcicas.

Las algas pardas de la familia de las "feofíceas"[40] constituyen la materia prima principal en la producción de alginato, el cual es un componente de la pared celular de tales organismos y se encuentra formando un complejo insoluble de ácido algínico y sus sales cálcica, magnésica y de metales alcalinos en varias proporciones.

En cuanto a sus aplicaciones, los alginatos constituyen un insumo de gran importancia para la industria alimenticia, farmacéutica y química en general, debido a su propiedad hidrocoloide, es decir, a la capacidad de hidratarse en agua caliente o fría para formar soluciones viscosas [41], dispersiones o geles. Resulta válido destacar que, según los porcentajes de bloques G y M, que varían en las distintas especies de alga, serán las características de los geles de alginato. Por ejemplo, el alginato obtenido de la Laminaria hyperborea, con un alto porcentaje de segmentos poli-gulurónicos, forma geles rígidos, con baja capacidad de unión de agua y tendencia a la sinéresis (pérdida de agua por proceso de exudación del gel, que produce su contracción). Por el contrario, el alginato extraído del Macrocystis pyrifera o Ascophyllum, forma geles elásticos, con baja tendencia a la sinéresis y baja capacidad de sufrir deformación. 
Los alginatos disponibles en el mercado se comercializan, en su mayoría, en forma de sales hidrosolubles, libres de celulosa, blanqueadas y purificadas, entre las que se incluyen: el alginato de sodio, el alginato de potasio y el alginato de calcio, entre otros.

Los geles y materiales a base de alginato son utilizados en el desarrollo de sistemas "inteligentes" de liberación controlada de compuestos bioactivos [42 y 43], debido a que en condiciones ácidas el gel se contrae, reduciendo la liberación y en condiciones básicas se hincha y el compuesto bioactivo es liberado al medio. Micropartículas, hidrogeles y scaffolds tri-dimensionales (3D) de alginatos pueden ser preparados de una manera sencilla depositando o manteniendo la solución de alginato de sodio en una solución que contiene cationes divalentes como el calcio, el bario o el estroncio, los cuales actúan como agente entrecruzante del alginato e induce la formación del gel. Sin embargo, los cationes monovalentes y el magnesio, aunque es un catión divalente, no inducen la formación de geles [39].

En los últimos años, éstos materiales han sido utilizados en la ingeniería de tejidos, principalmente en cultivos celulares tri-dimensional de condrocitos, debido a sus bio-características y a la habilidad de formar geles, micropartículas (MCP) y estructuras tri-dimensionales e incluso considerando la posibilidad de encapsular células y biomléculas que pueden ser liberados al medio de cultivo en función del tiempo. En la tabla 1.5 se resumen las principales aplicaciones de los materiales a base de alginato en la ingeniería de tejidos. 
Tabla 1.5. Materiales a base de alginato y sus aplicaciones en la ingeniería de tejidos.

\begin{tabular}{|c|c|c|c|c|c|}
\hline $\begin{array}{l}\text { Polímero/ } \\
\text { scaffold }\end{array}$ & $\begin{array}{c}\text { Aplicaciones } \\
\text { en TE }\end{array}$ & $\begin{array}{c}\text { Biomolécula } \\
\text { activa }\end{array}$ & $\begin{array}{l}\text { Tipo de } \\
\text { célula }\end{array}$ & $\begin{array}{c}\text { Modelo } \\
\text { animal }\end{array}$ & Ref. \\
\hline $\begin{array}{l}\text { MCP de } \\
\text { alginato }\end{array}$ & Cartílago & BMP-2 & $\begin{array}{c}\text { Condrocito } \\
\text { articular } \\
\text { humano }\end{array}$ & - & [44] \\
\hline $\begin{array}{l}\text { Fibras de } \\
\text { CHT y } \\
\text { alginato }\end{array}$ & No-definido & $\begin{array}{c}\text { Dexametaso } \\
\text { na, PDGF- } \\
\text { BB }\end{array}$ & - & - & [45] \\
\hline $\begin{array}{l}\text { Hidrogel de } \\
\text { alginato }\end{array}$ & $\begin{array}{l}\text { Hueso/ } \\
\text { cartílago }\end{array}$ & Gen BMP-2 & $\begin{array}{c}\text { Células } \\
\text { madre de } \\
\text { médula ósea }\end{array}$ & $\begin{array}{l}\text { Músculo } \\
\text { femoral de } \\
\text { ratón }\end{array}$ & [46] \\
\hline $\begin{array}{l}\text { MCP de } \\
\text { alginato }\end{array}$ & Cartílago & TGF $-\beta$ & - & $\begin{array}{c}\text { Defecto } \\
\text { osteocondral } \\
\text { en conejo }\end{array}$ & {$[47]$} \\
\hline $\begin{array}{l}\text { Hidrogel de } \\
\text { alginato }\end{array}$ & $\begin{array}{c}\text { Discos } \\
\text { intervertebr } \\
\text { ales }\end{array}$ & $\mathrm{TGF}-\beta_{1}$ & $\begin{array}{c}\text { Células de } \\
\text { discos } \\
\text { intervente } \\
\text { brales } \\
\text { humanas }\end{array}$ & - & $\begin{array}{l}{[48-} \\
50]\end{array}$ \\
\hline $\begin{array}{l}\text { MCP de } \\
\text { alginato }\end{array}$ & $\begin{array}{c}\text { Nervio } \\
\text { periférico }\end{array}$ & BDNF & - & $\begin{array}{l}\text { Nervio } \\
\text { siático de } \\
\text { ratas }\end{array}$ & {$\left[\begin{array}{ll}5 & 1\end{array}\right]$} \\
\hline
\end{tabular}

\subsubsection{La quitina y el quitosano}

La quitina y el quitosano son polisacáridos que se obtienen a partir de fuentes renovables y ampliamente utilizados en la industria farmacéutica, cosmética, en la agricultura, en aplicaciones biomédicas, biotecnológicas , en la industria alimenticia y en diferentes procesos industriales para el tratamiento de aguas, de papel y en la industria textil [52]. En los últimos años, 
numerosos estudios han centrado su atención en el desarrollo de materiales a base de estos biopolímeros debido a su actividad biológica, a su excelente biocompatibilidad, biodegradabilidad y a su baja toxicidad. A continuación dedicaremos un apartado a los aspectos y características principales de la quitina y el quitosano, siendo este último, el biopolímero que nos ocupa en este estudio.

\subsection{Quitosano}

\subsubsection{Método de obtención de la quitina y el quitosano}

La quitina es un heteropolímero linear de naturaleza catiónica, compuesto por unidades de N-acetilglucosamina y glucosamina unidas a través de enlaces glucosídicos $\beta$ 1-4, distribuidas aleatoriamente a lo largo de la cadena polimérica (ver figura 1.8). La quitina es el segundo biopolímero natural más abundante en la naturaleza, presente en el exoesqueleto de los crustáceos y en la pared celular de hongos e insectos [53]. Mediante procesos consecutivos de descalcificación, desproteinización y decoloración la quitina es obtenida en forma de polvo con un peso molecular promedio en peso que oscila entre $1 \mathrm{y}$ $2.5 \times 10^{6}$ Da correspondiente a un grado de polimerización entre 5000 y 10000 y con un grado de desacetilación mínimo de un 10\%.

El quitosano (CHT) se obtiene a partir de la quitina a través de un proceso de desacetilación, llevado a cabo en soluciones básicas concentradas, que puede ser total o parcial. Los valores que comúnmente se obtienen del grado de desacetilación en el quitosano, se encuentran entre un 40 y un $98 \%$ y el rango de pesos moleculares entre 50 y $2000 \mathrm{kDa}$ [54] (ver figura 1.8). 

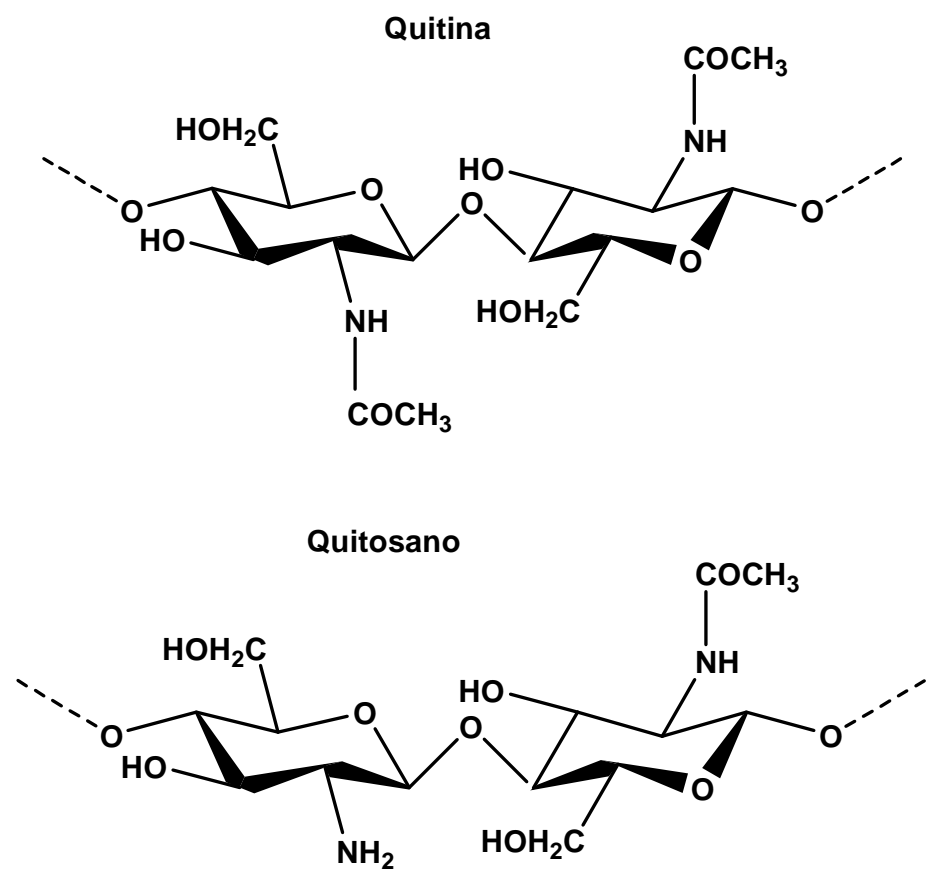

Figura 1.8. Estructura química de la quitina y el quitosano.

Dos parámetros importantes a tener en cuenta son el grado de desacetilación como hemos comentado anteriormente y el grado de polimerización (DP), los cuales deciden en gran medida el peso molecular del polímero y por consiguiente dictamina la aplicación del quitosano.

\subsubsection{Propiedades físico-químicas}

La quitina $y$ el quitosano presentan estructuras muy similares sin embargo, sus características físicas y las reacciones químicas que pueden tener lugar son sorprendentemente diferentes. Ambos polímeros presentan grupos funcionales reactivos (el grupo hidroxilo y el grupo amino). El quitosano es 
menos cristalino que la quitina de ahí que sea más susceptible frente a varios solventes. En cuanto a las propiedades térmicas, ambos polímeros no tienen punto de fusión y se descomponen antes de fundir. Otra de las grandes diferencias entre ambos radica en la solubilidad [55]. En la tabla 1.6 se resume el perfil de solubilidad de cada uno por separado.

Tabla 1.6. Perfil de solubilidad de la quitina y el quitosano.

\begin{tabular}{|c|c|}
\hline La quitina es soluble en & El quitosano es soluble en \\
\hline $\begin{array}{c}\text { Di-metilacetamida o di- } \\
\text { etilacetamida con un } 5 \% \text { de } \\
\text { cloruro de litio }(\mathrm{LiCl}) .\end{array}$ & $\begin{array}{c}\text { Soluciones acuosas diluidas de ácidos } \\
\text { minerales u orgánicos }(\mathrm{pH}<6.5)\end{array}$ \\
\hline $\begin{array}{r}\text { Solución saturada de tiocianato } \\
\text { de litio. }\end{array}$ & Dimetilsulfóxido \\
\hline N-metil-2-pirrolidona con LiCl & Ácido p-toluensulfónico \\
\hline
\end{tabular}

Existen relativamente pocos solventes para la quitina, mientras que el quitosano se disuelve en soluciones diluidas de ácidos, siendo el ácido acético y el ácido fórmico los más comúnmente utilizados. El quitosano es soluble en presencia de un ácido debido a la protonación de la multitud de grupos amino presente en su estructura a lo largo de la cadena polimérica, lo cual genera un incremento en la polaridad y en las repulsiones electrostáticas. Entre las sales de quitosano solubles en agua podemos mencionar: el formato, el acetato, el lactato, el maleato, el citrato, el tártrato, el piruvato y el ascorbato. La solubilidad del quitosano depende en gran medida del grado de desacetilación y 
del peso molecular. Estudios realizados demuestran que los quitosanos comerciales de alto peso molecular con un grado de desacetilación aproximadamente entre un o y un 20\% son solubles en soluciones ácidas diluidas a un $\mathrm{pH}$ por debajo de su valor aparente de pKa que es aproximadamente de 6.5 [ 56 y 57$]$ donde las cadenas del polímero se encuentran con una alta densidad de carga positiva. Sin embargo, estudios realizados por Sannan y colaboradores [58] han comprobado que los quitosanos de alto peso molecular con grados de desacetilación entre un 40 y un $60 \%$ son solubles en condiciones de pH neutro, incluso investigaciones más recientes han demostrado que la solubilidad de quitosano en condiciones neutras de $\mathrm{pH}$ se logra mediante un control estricto y adecuado de su composición química ya sea, su grado de desacetilación y su peso molecular [59].

\subsubsection{Características biológicas y/o farmacológicas}

Una de las características que presenta el quitosano desde el punto de vista biológico es su efecto hipocolesterolemiante (disminución de colesterol en sangre), el cual es independientemente de su peso molecular. Estudios realizados por Sugano y colaboradores [60] demuestran que al aumentar el grado de desacetilación dicho efecto se incrementa debido a que se produce una menor absorción de grasa. Las condiciones de pH es otro de los factores que influyen en el carácter hipocolesterolemiante del quitosano; en condiciones de pH ácido (en el estómago) existe una gran densidad de carga positiva y la formación de polielectrólitos complejos con los lípidos se ve favorecida por lo que disminuye la absorción de las grasas. 
También se ha comprobado que el quitosano presenta características hemostáticas. Klokkevod y colaboradores [61] han estudiado el efecto del quitosano sobre el proceso de coagulación, observándose como disminuye el tiempo de coagulación de la sangre mediante el uso tópico de quitosano sobre heridas causadas en lenguas de conejos heparinizados. Dicha disminución según los autores fue debida a posibles interacciones que tienen lugar entre el quitosano y la membrana celular de los eritrocitos.

La acción antibacteriana del quitosano es otra de las características que hacen de este biopolímero un candidato con un gran potencial en diversas aplicaciones. Estudios realizados comprueban la actividad del quitosano frente a determinados microorganismo tales como la Escherichia coli, la Candida albicans, el Enterococcus faecalis, el Staphylococcus aureus, el Streptococcus pyogenes, entre otros [62-64]. Aimin y colaboradores [65] estudiaron la eficacia del tratamiento con quitosano en conejos infectados experimentalmente de osteomielitis causada por el Staphylococcus aureus, obteniendo una reducción de la infección. La naturaleza catiónica del quitosano debido a su grupo amino es relacionado con los aniones presentes en las paredes celulares de las bacterias. Dicha interacción permite la fuga de constituyentes intracelulares; por ejemplo, la unión del quitosano con las moléculas del DNA, inhibe la síntesis del ácido ribonucleico mensajero (mRNA) producto a la penetración del quitosano en el núcleo de los microorganismos, lo cual trae consigo una interferencia en la síntesis de las proteínas y del mRNA.

El quitosano inhibe el crecimiento de una gran variedad de hongos, levaduras y bacterias; la explicación de este comportamiento viene dado producto a las interacciones de tipo electrostáticas que tienen lugar entre los sitios catiónicos del quitosano y los sitios aniónicos de las macromoléculas presentes en la superficie celular de los microorganismos. Dicha interacción no 
confiere una estabilidad dimensional, sino que debilita y produce una pérdida de integridad a la membrana bacteriana [66].

El quitosano es un biopolímero no tóxico, biodegradable, biocompatible, presenta propiedades bioadhesivas y promueve la curación de las heridas. Su bioadhesividad [67-69] se debe en gran medida a su naturaleza catiónica ya que puede interactuar con macromoléculas cargadas negativamente incluidas las proteínas, los ácidos nucleicos, los polisacáridos aniónicos, los lípidos, etc. Por otra parte se ha demostrado que promueve la curación de las heridas [70] y reduce la formación de cicatrices ya que promueve la síntesis de colágeno [71] e incrementa la acción de los leucocitos poli-morfonucleares, los queratinocitos, los fibroblastos, los neutrófilos y los macrófagos [72].

La biocompatibilidad y la biodegradación son una de las características biológicas mas importantes de ahí que en la actualidad sea un biopolímero ampliamente utilizado en la ingeniería de tejido y en la medicina regenerativa. Su biocompatibilidad se debe principalmente a la conformación de su estructura ya que las unidades de $\mathrm{N}$-acetilglucosamina y glucosamina están presentes en la estructura de la mayoría de las biomoléculas que conforman los tejidos del cuerpo humano [ 73 y 74$]$. A continuación abordaremos en detalle la biodegradación del quitosano.

\subsubsection{Biodegradación}

La degradación de los materiales poliméricos depende en gran medida de las propiedades físico-químicas del material. En el caso específico del quitosano la degradación ocurre mediante la hidrólisis de los enlaces glucosídicos que unen las unidades de N-acetilglucosamina y glucosamina. Dicha hidrólisis puede ser catalizada por enzimas conocidas como las hidrolasas entre las que se 
incluyen la quitosanasa, la quitinasa, la lipasa, la glicosidasa, la lisozima, la fosfatasa entre otras.

Las enzimas son catalizadores biológicos que aceleran los tiempos de reacción en los organismos vivos, de hecho muchas de las reacciones metabólicas celulares no ocurrirían sin la presencia de las enzimas. Existen muchos factores que afectan la actividad de las enzimas [75], entre los cuales podemos citar el $\mathrm{pH}$, la temperatura, la fuerza iónica, la presencia de activadores y/o inhibidores, etc. Los perfiles de la actividad enzimática están caracterizados por las condiciones óptimas del $\mathrm{pH}$ y la temperatura bajo las cuales las enzimas exhiben su máxima actividad. Por otro lado, las enzimas son moléculas que pueden ser fácilmente desactivadas y/o desnaturalizadas bajo la acción de condiciones extremas de $\mathrm{pH}$, el contacto con temperatura elevadas o mediante la presencia de agentes caotrópicos o surfactantes iónicos. Teniendo en cuenta estas consideraciones las reacciones enzimáticas necesitan unas condiciones estrictamente controladas en términos de $\mathrm{pH}$, temperatura $\mathrm{y}$ concentraciones de sales con el objetivo de asegurar un máximo de actividad enzimática y evitar su desactivación (ejemplo: El uso de una solución buffer para mantener el $\mathrm{pH}$ constante).

La actividad enzimática es expresada normalmente en términos de unidades $(\mathrm{U})$, la cual define la cantidad de enzimas que produce $1 \mu \mathrm{mol}$ de sus productos de reacción o la cantidad de enzima que cataliza la transformación de $1 \mu \mathrm{mol}$ de substrato en 1 minuto bajo condiciones específicas de reacción. La actividad específica también puede ser definida como U por unidad de peso de la enzima $(\mathrm{U} / \mathrm{mg})$.

Las enzimas presentes en el suero pueden ser divididas en dos categorías, las enzimas específicas del plasma y las que no lo son. Las primeras son las enzimas cuya función está relacionada con la coagulación sanguínea y el 
metabolismo de las lipoproteínas. Las segundas, son enzimas que no tienen funciones fisiológicas en el plasma. En ésta categoría se incluyen las enzimas que son secretadas por los tejidos (ejemplo: amilasa, lipasa, fosfatasa, etc.) y que están presente en niveles muy bajos en el suero, pero que su presencia puede acelerar los procesos de degradación de los polímeros biodegradables.

La biodegradación del quitosano es catalizada por la enzima lisozima, la cual está presente en varios fluidos y tejidos del cuerpo humano. En el suero sanguíneo dicha enzima se encuentra en un intervalo de concentración de 4 a $13 \mathrm{mg} / \mathrm{L}[76]$ sin embargo, en las lágrimas la concentración oscila entre 450 y $1230 \mathrm{mg} / \mathrm{L}[77]$.

En los estudios de degradación in vitro del quitosano se utiliza la lisozima procedente de los huevos de las gallinas blancas (HEW) [78 y 79], la cual es muy similar a la lisozima humana [ 80 y 81$]$. La acción de ésta sobre la estructura química del quitosano se basa en la escisión de los enlaces glucosídicos (ver figura 1.9), dando lugar a la formación de quito-oligómeros de $\mathrm{N}$-acetilglucosamina y glucosamina como productos de degradación [82]; los cuales son a su vez no tóxicos y eliminados mediante los ciclos metabólicos celulares que normalmente tienen lugar en el organismo.

Según estudios realizados por Hirano y colaboradores [83] la lisozima no sólo actúa sobre los enlaces glucosídicos sino también sobre los residuos acetilados. La velocidad de degradación del quitosano es inversamente proporcional al grado de cristalinidad, la cual está controlada principalmente por el grado de desacetilación (DD). Quitosanos con altos grados de desacetilación (DD > 85\%) exhiben una degradación relativamente lenta que puede durar varios meses, mientras que quitosanos con bajos grados de desacetilación degradan mucho más rápido [84-86]. 


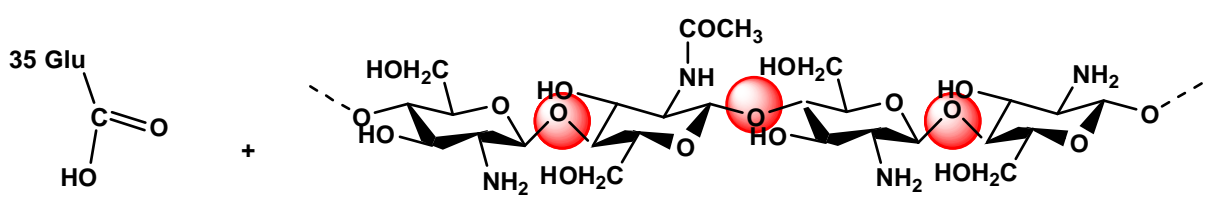

Lisozima
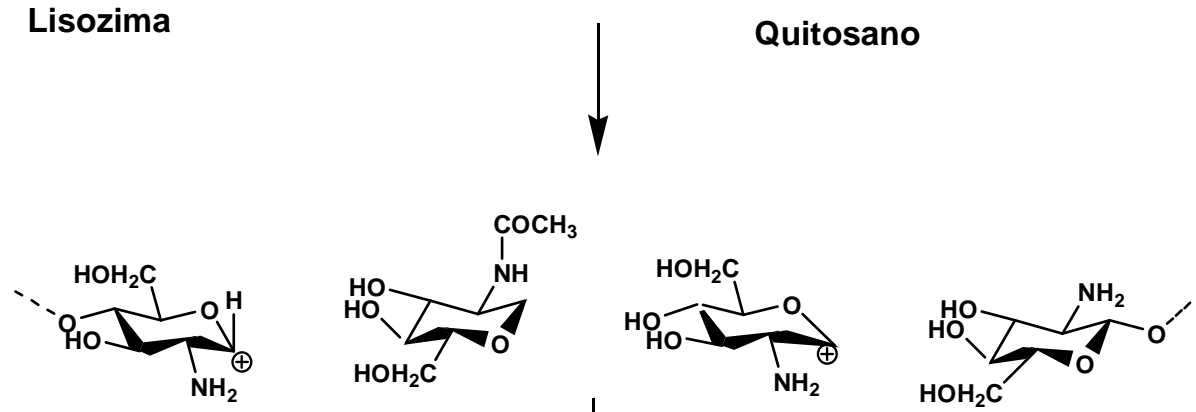

$\mathrm{H}_{2} \mathrm{O}$
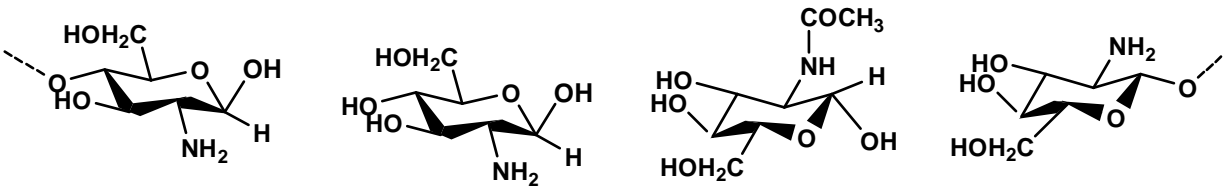

Glucosamina

$\mathrm{N}$-acetilglucosamina

Figura 1.9. Degradación enzimática del quitosano.

\subsubsection{Caracterización físico-química}

\subsubsection{Determinación del grado de desacetilación}

Los estudios de caracterización del quitosano se centran fundamentalmente en la determinación del grado de desacetilación y su distribución de pesos moleculares. Para la determinación del grado de 
desacetilación existen varios métodos que ya se han hecho rutinarios para este propósito incluyendo estudios de resonancia magnética nuclear de protones $\left({ }^{1} \mathrm{H}\right)$ y carbono $\left({ }^{13} \mathrm{C}\right)$ en estado sólido [87], mediante espectroscopía infrarroja (IR) [88], cromatografía de permeación de gel (GPC), espectroscopía ultravioleta (UV) y su primera derivada [89], además de valoraciones potenciométricas [90], hidrólisis ácida y cromatografía líquida de alta resolución (HPLC) [91] y espectroscopía del infrarrojo cercano [92].

\subsubsection{Determinación de la distribución de pesos moleculares}

Varios autores han determinado la distribución de pesos moleculares del quitosano utilizando la técnica de HPLC [93] y la dispersión de la luz [94]. Sin embargo, la viscosimetría es un método simple y rápido para la determinación del peso molecular. Teniendo en cuenta las constantes $\alpha$ y $\mathrm{K}$, determinadas a partir de una mezcla de solventes de ácido acético $0.1 \mathrm{M} \mathrm{y}$ cloruro de sodio $0.2 \mathrm{M}$ y las medidas de la viscosidad intrínseca, el peso molecular promedio viscosimétrico puede determinarse a través de la ecuación de Mark-Houwink [95].

$$
[\eta]=K M^{\alpha}=1.81 \times 10^{-3} M^{0.93}
$$

El peso molecular promedio viscosimétrico para el quitosano oscila entre 50 y $2000 \mathrm{kDa}$, por lo que en ocasiones la alta viscosidad de sus soluciones hacen que este biopolímero sea excluido en muchas aplicaciones biológicas. A continuación se describen algunas modificaciones químicas que hacen posible la obtención de derivados del quitosano con un amplio espectro de aplicaciones. 


\subsection{Derivados y reacciones químicas del quitosano.}

Las reacciones químicas en el quitosano tienen lugar a partir de sus tres grupos funcionales activos: el grupo amina primaria y los grupos hidroxilo primario y secundario (ver figura 1.10).

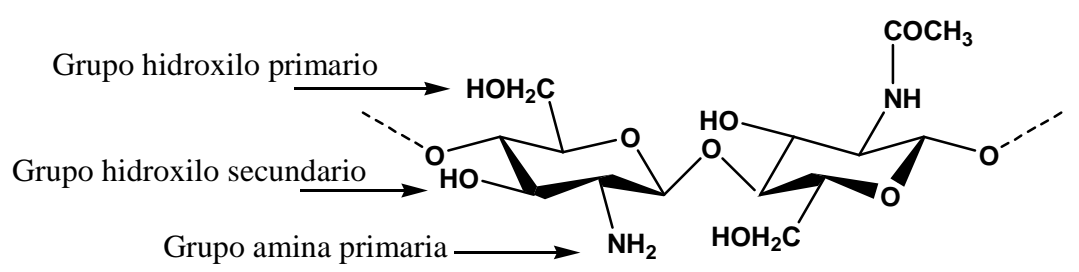

Figura 1.10. Grupos funcionales activos en la molécula de quitosano.

En la tabla 1.7 se describen varios ejemplos de los principales compuestos derivados del quitosano.

Tabla 1.7. Principales compuestos derivados del quitosano.

\begin{tabular}{|l|l|}
\hline Derivados del quitosano & Ejemplos \\
\hline $\begin{array}{l}\text { Quitosano metilado y alquil- } \\
\text { quitosano }\end{array}$ & $\begin{array}{l}\text { Cloruro de trimetil quitosano, N-propil- } \\
\mathrm{N}, \mathrm{N} \text {-dimetil } \\
\text { dietilmetilamino quitosano }\end{array}$ \\
\hline $\mathrm{N}$-acil quitosano & $\begin{array}{l}\text { Formal, acetil, propionil, butiril, } \\
\text { hexanoil, octanoil, benzoil, succinil, entre } \\
\text { otros. }\end{array}$ \\
\hline $\begin{array}{l}\text { N-carboxi-alquil/aril } \\
\text { quitosano }\end{array}$ & $\begin{array}{l}\text { N-carboximetil quitosano (Glisina } \\
\text { glucano), N-carboxipropil quitosano, N- } \\
\text { carboxibencil quitosano, entre otros }\end{array}$ \\
\hline
\end{tabular}




\begin{tabular}{|l|l|}
\hline O-carboxi-alquil quitosano & $\begin{array}{l}\text { O-carboximetilo, y O-carboximetilo } \\
\text { reticulado }\end{array}$ \\
\hline Quitosano tiolado & $\begin{array}{l}\text { Conjugado quitosano-cisteína, quitosano- } \\
\text { ácido tioglicólico, quitosano-4-tio- } \\
\text { butilamidina. }\end{array}$ \\
\hline
\end{tabular}

\subsubsection{Reacciones de cuaternización}

El quitosano posee un valor del pKa aproximadamente de 6.5, siendo soluble sólo en soluciones ácidas con valores de $\mathrm{pH}<6$. Con el objetivo de extender el intervalo de $\mathrm{pH}$ donde se pueda utilizar dicho biopolímero en solución, surge la cuaternización del quitosano ya que una molécula con una mayor densidad de cargas generaría una mayor solubilidad.

La cuaternización es un proceso de alquilación exhaustiva del grupo amina presente en la cadena polimérica del quitosano. Para llevar a cabo esta reacción existen varios métodos [96], en los cuales se utiliza el yoduro de metilo, como agente alquilante, en una solución alcalina de $\mathrm{N}$-metil pirrolidona o hidróxido de sodio. El método más comúnmente utilizado se basa en la formación de un intermediario mono-alquilado tipo una base de Schiff y en una segunda etapa de reacción tiene lugar la alquilación exhaustiva con el yoduro de metilo (ver figuras 1.11 y 1.12). 

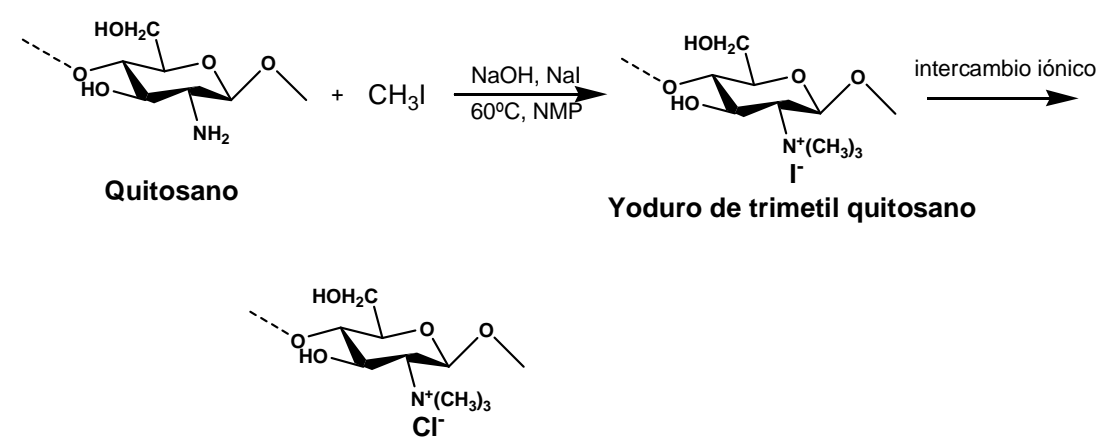

Cloruro de trimetil quitosano

Figura 1.11. Reacción de cuaternización del quitosano.

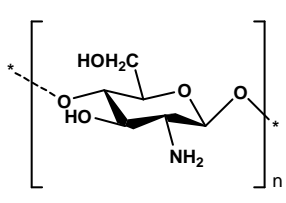

Quitosano

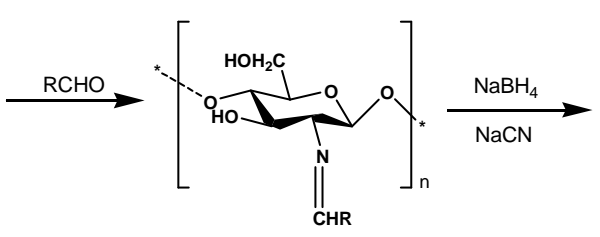

Base de Schiff

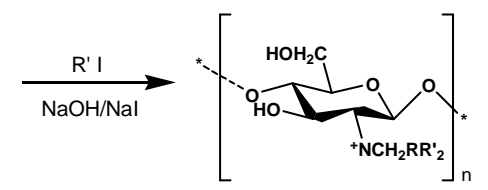

Quitosano cuaternario

$\mathrm{N}$-alquil quitosano

Figura 1.12. Reacción de alquilación del quitosano seguido de una cuaternización

El grado de cuaternización puede ser controlado experimentalmente mediante el tiempo de reacción y la concentración del agente alquilante, por lo que es posible obtener compuestos derivados del quitosano mono, di o trialquilados. 
Generalmente los productos obtenidos mejoran sustancialmente su solubilidad en agua con relación al quitosano de origen. Jia y colaboradores [97], sintetizaron y estudiaron derivados cuaternizados del quitosano en su acción antibacterial sobre la Escherichia coli, demostrando que ésta es mayor para altos pesos moleculares y apreciándose mayor efectividad para sustituyentes alquilos con mayores longitudes de cadena.

Una característica sumamente interesante de los derivados cuaternizados del quitosano es su carácter hidrófilo y sus aplicaciones en cuanto al transporte de nutrientes se refiere y un ejemplo de ello es el transporte de células intestinales de Caco-2 a través de mono capas de trimetil-quitosano (TMC). Thanou y colaboradores [98] han observado que este polímero es capaz de abrir las uniones compactas del epitelio intestinal a valores de $\mathrm{pH}$ fisiológico, donde el quitosano es insoluble, y por tanto inefectivo. En este caso loas autores han sugerido que un material con una alta densidad de carga como el TMC mejoraría sustancialmente la permeabilidad paracelular del epitelio intestinal; donde se espera que a corto plazo este material refuerce la permeación de fármacos macromoleculares hidrófilos como, por ejemplo, los péptidos y las proteínas.

Los derivados cuaternizados del quitosano han sido utilizados también como agente floculante en el tratamiento de aguas de desecho que contienen glutamato de sodio mostrando alta eficiencia en la eliminación de la turbidez en un intervalo amplio de pH. Por su parte, Kim y colaboradores [99] también han sintetizado una serie de derivados cuaternizados que han mostrado un alto poder floculante, independientemente del valor del $\mathrm{pH}$ y que se incrementa con el aumento de tamaño de la cadena alquílica. 


\subsubsection{Reacciones de entrecruzamiento}

Existen dos vías a partir de las cuales es posible obtener redes de quitosano: la vía física, donde la reticulación tiene lugar producto a las interacciones iónicas entre el quitosano y el agente entrecruzador y la vía química donde la reticulación tiene lugar a través de una reacción química mediante la formación de un enlace covalente entre el quitosano y el agente reticulante [100]. A continuación explicaremos más en detalle dichas dos vías.

Vía química: Existen varios agentes entrecruzantes capaces de reticular el quitosano. Entre los más estudiados se encuentran la epiclorhidrina, el etilenglicol glicidiléter, las carbodimidas, el glutaraldehído y el genipin. Aunque el glutaraldehído y las reacciones con los di-aldehídos [101 y 102] son los más frecuentemente utilizados. No obstante, en los últimos tiempos el genipin ha despertado el interés de muchos científicos debido a la toxicidad del glutaraldehído y a los posibles efectos que pueden generar los materiales entrecruzados con este reactivo una vez implantados en el organismo humano.

El glutaraldehído es una molécula bifuncional que reacciona con los grupos amina presente en la estructura del quitosano formando una base de Schiff [103] (ver figura 1.13). Estudios realizados por Fwu-Long y colaboradores [104-106] demuestran que el glutaraldehído es 1000 veces más tóxico que el genipin. 


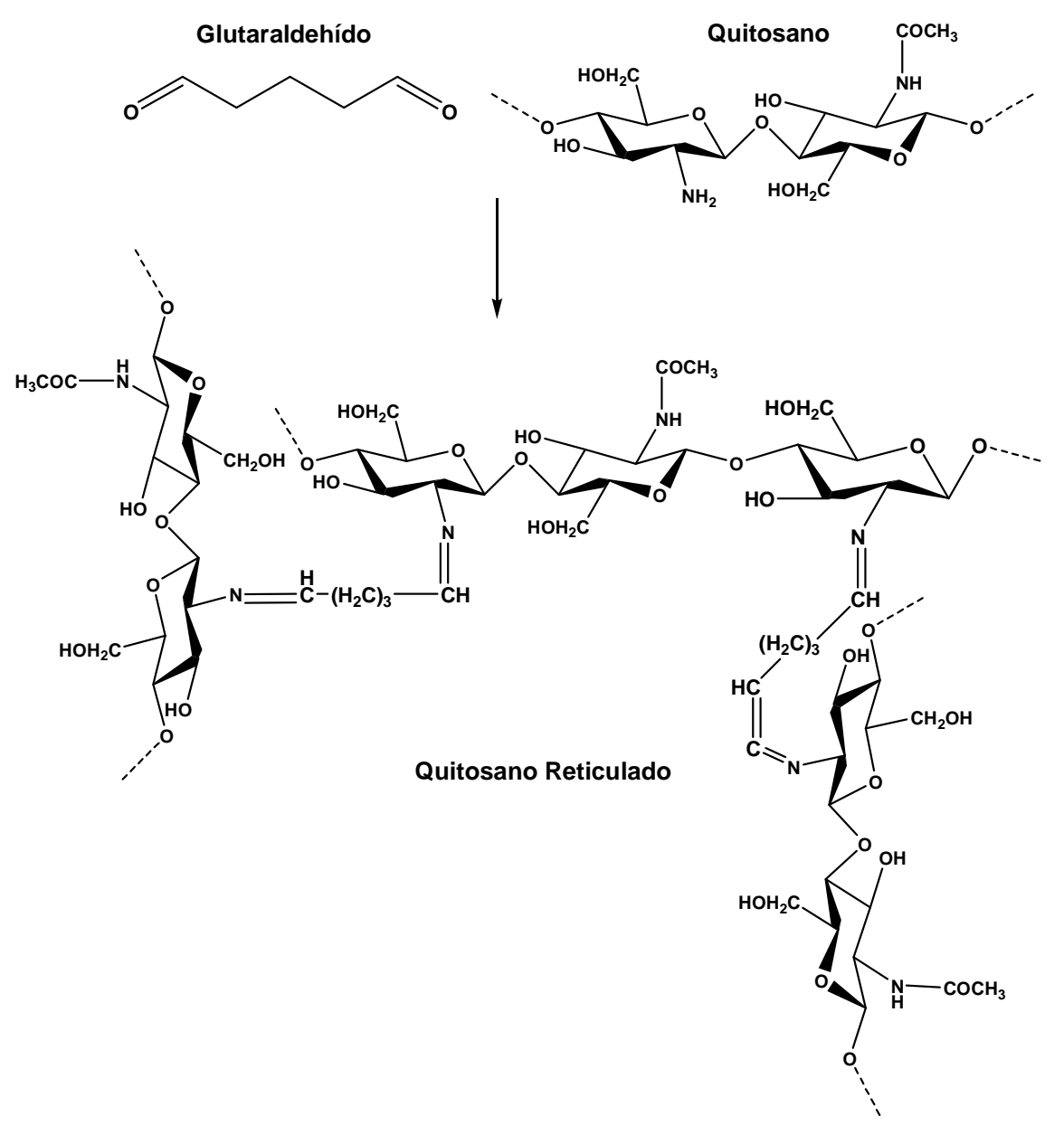

Figura 1.13. Estructura de una red de quitosano entrecruzada con glutaraldehído

El genipin es un compuesto natural, extraído del fruto de la gardenia jasminoides Ellis como se describe en la literatura [107 y 108]. El genipin reacciona con los grupos amina primario de aminoácidos, proteínas u otros compuestos que presenten ese grupo funcional, como es el caso del quitosano dando lugar a la formación de pigmentos de color azul [109 y 110]. La 
estructura propuesta por Fwu-Long para el quitosano entrecruzado con genipin se representa en la figura 1.14 .

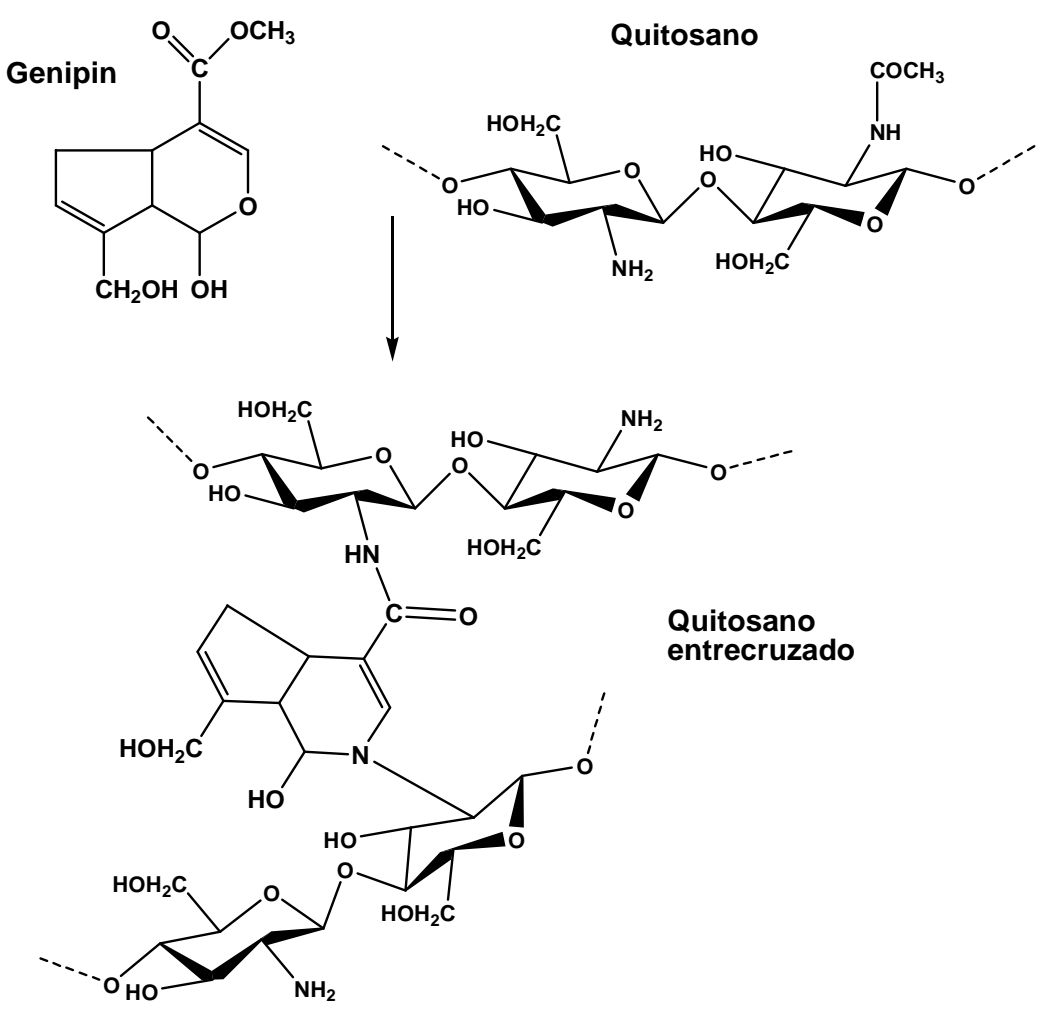

Figura 1.14. Estructura de una red de quitosano entrecruzada con genipin.

Vía física: El tripolifosfato de sodio (TPP) es el agente entrecruzante más utilizado en la obtención de redes de quitosano. El tripolifosfato se disocia en agua formando iones hidroxilo e iones fosfóricos por lo que el proceso de reticulación dependerá de la disponibilidad de los sitios catiónicos en el quitosano y de las especies cargadas negativamente, por lo que cabe esperar que el pH juegue un papel fundamental en el tipo de entrecruzamiento. 
A pH ácido, sólo están presentes los iones fosfóricos, por lo que la reticulación es predominantemente iónica (ver figura 1.15 (a)) sin embargo, a $\mathrm{pH}$ básicos co-existen los iones hidroxilo y los iones fosfóricos los cuales compiten entre sí por los sitios $\mathrm{NH}_{3}{ }^{+}$del quitosano. Los iones hidroxilo se unen a los grupos aminas y tiene lugar la deprotonación del quitosano (ver figura 1.15 (b)). El mecanismo de entrecruzamiento del quitosano con el TPP puede ser por deprotonación y/o por interacciones iónicas según las condiciones de $\mathrm{pH}[111]$. En la figura 1.16 se muestra la estructura de una red de quitosano entrecruzada con TPP a pH neutro.

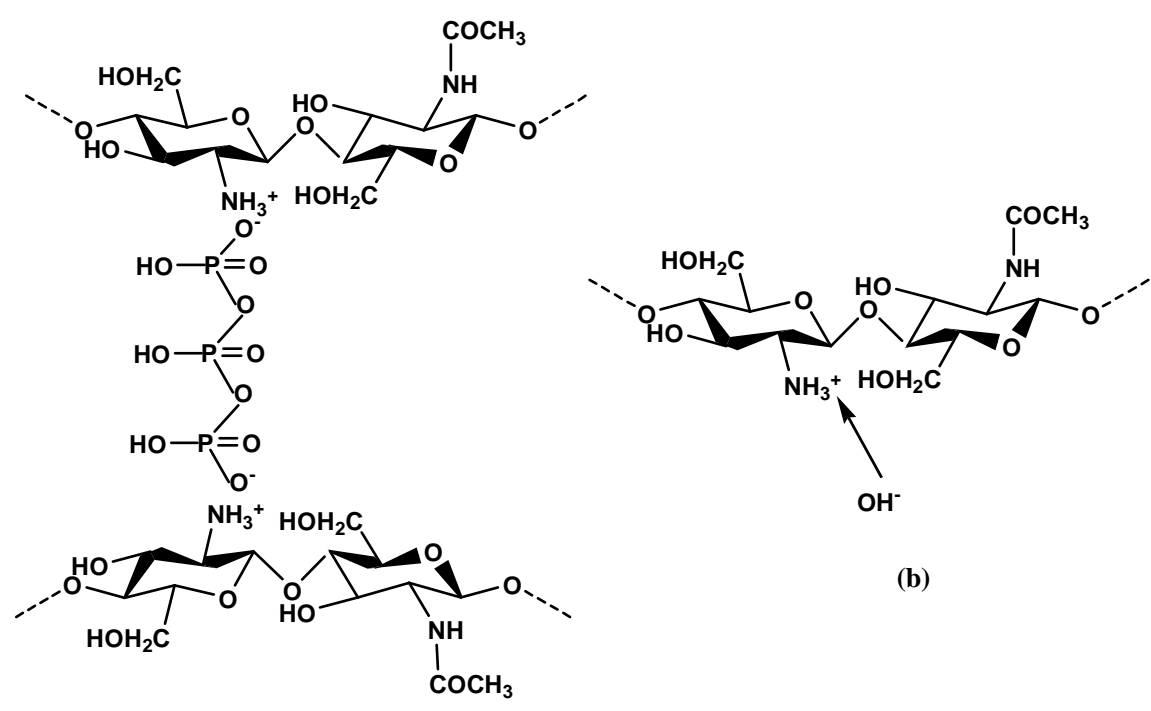

(a)

Figura 1.15. Estructura de una red de quitosano. (a) entrecruzamiento iónico y (b) deprotonación del grupo amina. 


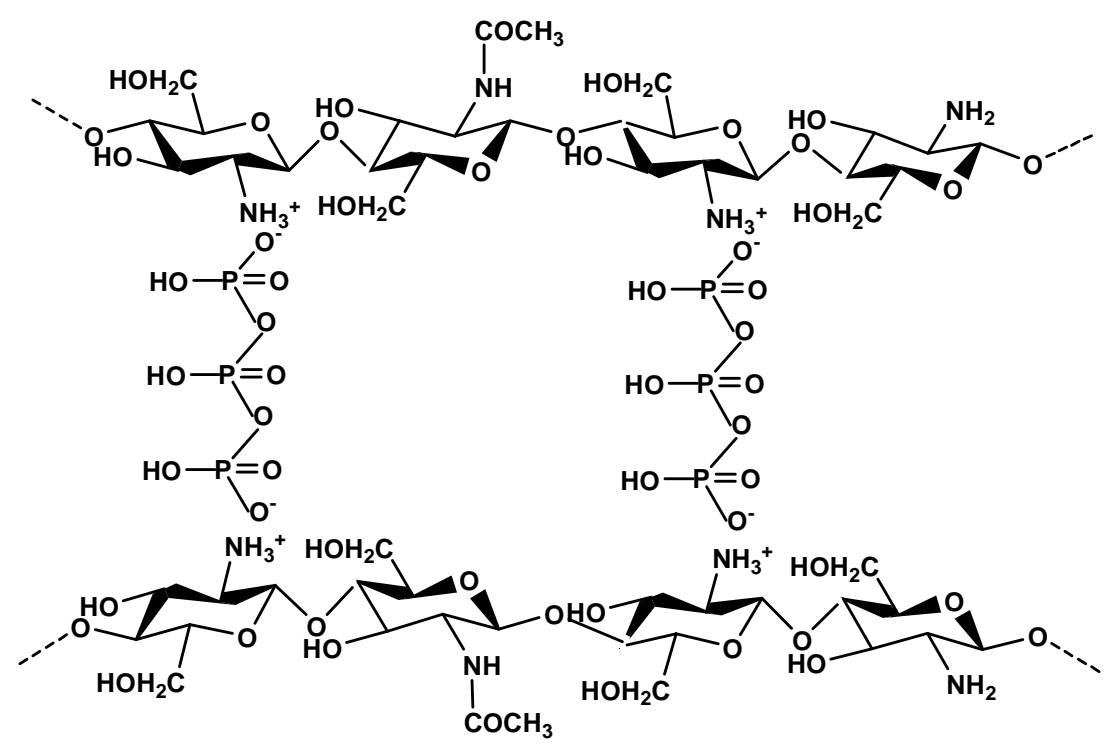

Figura 1.16. Estructura de una red de quitosano entrecruzada con TPP a pH neutro.

\subsubsection{Formación de policomplejos}

Los complejos polielectrólitos son formados por la atracción electrostática de dos polielectrólitos con cargas opuestas, aunque también puede existir interacciones de van der Waals, interacciones hidrofóbicas o por puente de hidrógeno [112]. Por su naturaleza policatiónica, el quitosano ha sido usado para la formación de complejos con proteínas acídicas en una variedad de fluidos biológicos, al igual que con muchas otras biomoléculas aniónicas como la heparina el alginato, el ácido hialurónico, el DNA, y otros ácidos nucleicos. Los complejos polielectrólitos son materiales de gran relevancia que han sido ampliamente utilizados en un sinnúmero de aplicaciones. 


\subsection{Mezclas de quitosano con otros polímeros}

El quitosano, como biopolímero natural, es un material con propiedades biológicas adecuadas, aunque en ocasiones sus aplicaciones se ven limitadas debido a su alto módulo elástico propio de su alta temperatura de transición vítrea y su cristalinidad [113]. Con el objetivo de modificar sus propiedades mecánicas y como alternativa a las modificaciones químicas, muchos autores han apostado por el desarrollo de nuevos materiales a partir de mezclas con otros polímeros tanto de origen natural como sintético. De esta manera podría obtenerse a través de métodos de procesamiento relativamente sencillos, materiales con propiedades mucho mejores que una simple superposición de las propiedades de cada uno de sus componentes. La formación de mezclas poliméricas constituye una alternativa más eficiente que la síntesis de nuevos monómeros o que las nuevas estrategias de polimerización.

Las mezclas entre polímeros naturales y sintéticos poseen un amplio rango de propiedades físico-químicas y técnicas de procesamiento relativamente sencillas que provienen de los polímeros sintéticos y una buena biocompatibilidad proveniente de los polímeros naturales.

En el caso específico del quitosano, este biopolímero ha sido frecuentemente utilizado en la formación de mezclas con polímeros solubles en agua tales como: la hidroxipropil celulosa, el polivinilalcohol y el polióxido de etileno [ $114 \mathrm{y}$ 115]. En estos casos se han obtenido membranas y fibras con buenas propiedades mecánicas. Sin embargo, en los últimos tiempos se han estudiado mezclas con poliésteres biodegradables para su utilización no sólo en aplicaciones biomédicas sino también en la química ambiental con el fin de minimizar los residuos de envases plásticos y con ello reducir la contaminación ambiental. 
La policaprolactona (PCL) es un poliéster alifático biodegradable, semi cristalino, con un punto de fusión relativamente bajo alrededor de $60^{\circ} \mathrm{C}$, con buenas propiedades mecánicas y con unas condiciones de procesamiento bastante sencillas. Muchos autores han estudiado las mezclas de PCL con varios polímeros tanto cristalinos [116] como amorfos [117], incluido el quitosano [1 18 y 119].

El principal problema para la formación de mezclas entre la PCL y el CHT radica en encontrar un solvente adecuado que sea común para los dos polímeros. La PCL es soluble en solventes orgánicos, mientras que el quitosano lo es en soluciones acuosas ácidas diluidas. Honma y colaboradores [120] estudiaron las propiedades térmicas de mezclas entre la PCL y el CHT preparadas mediante la técnica de evaporación de solvente, utilizando para disolver a ambos polímeros el 1,1,1,3,3,3 hexafluor 2-propanol, como solvente común, pero el gran inconveniente de este solvente es que es altamente tóxico y además es necesario tiempos muy largos para la preparación de las mezclas debido a su elevada temperatura de ebullición.

En los últimos años, Sarasam y colaboradores [121] han estudiado las propiedades físico-químicas y antibacteriales de mezclas de PCL y CHT en las que han utilizado como solvente el ácido acético glacial para la PCL y una solución acuosa de ácido acético $(0,5 \mathrm{M})$ para disolver el quitosano. En este caso, se obtuvieron mezclas aparentemente homogéneas en todo el rango de composiciones desde un 0\% de PCL hasta un 100\%. En el trabajo de esta Tesis Doctoral hemos estudiado, como se describirá con detalle más adelante la morfología, la respuesta biológica y la cinética de cristalización de la PCL en mezclas de PCL y CHT preparadas de manera análoga, pero partiendo de soluciones concentradas de ambos polímeros. Las mezclas obtenidas abarcan un rango de composiciones desde un 10\% hasta un 40\% de CHT en las 
muestras preparadas con una PCL de peso molecular $14 \mathrm{kDa}$ y hasta un $30 \%$ de CHT en las muestras donde se utilizó una PCL de peso molecular 48 kDa. En el estudio biológico se utilizó condrocitos primarios humanos y se analizó la influencia de la topografía del sustrato en la morfología, adhesión y proliferación celular. Los resultados obtenidos demuestran un cambio en la adhesión y morfología de la célula en la mezcla preparada con un $20 \%$ de quitosano. Estos resultados han aparecido publicados recientemente $[122 \mathrm{y}$ $123]$.

Teniendo en cuenta los resultados obtenidos podemos afirmar que tanto la PCL, como el CHT son de gran importancia en el desarrollo de nuevos materiales con propiedades físico-químicas muy variadas. A continuación se describirán las principales características de la policaprolactona.

\subsubsection{Principales características de la policaprolactona.}

La policaprolactona (PCL) pertenece a la familia de los poliésteres, es un polímero semicristalino, con un bajo punto de fusión $\left(60^{\circ} \mathrm{C}\right)$, una temperatura de transición vítrea alrededor de $\operatorname{los}-60^{\circ} \mathrm{C}[124]$ y se obtiene mediante una reacción de polimerización de apertura de anillo a partir de la $\varepsilon$-caprolactona, utilizando como catalizador el octanoato de estaño, tal y como se muestra en la figura 1.17 .

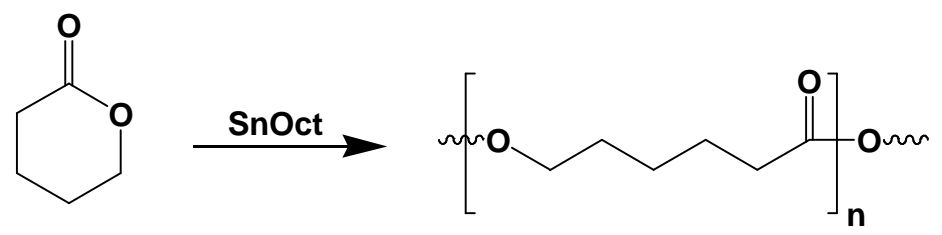

Figura 1.17. Síntesis por apertura de anillo de la policaprolactona. 
La estructura molecular de la PCL consta de un grupo éster polar y cinco grupos metilenos con características apolares. Los cuales le confieren a la molécula unas propiedades mecánicas similares a las de las olefinas. Por otra parte, su biodegradabilidad en medios biológicos "in vitro" e "in vivo" es consecuencia de la susceptibilidad de los enlaces ésteres a la hidrólisis.

La cinética de degradación de la PCL es más bien lenta debido a su cristalinidad y a su semejanza estructural con las olefinas. Estudios realizados por Pitt y colaboradores [125] demuestran que la degradación ocurre en dos etapas. En una primera etapa tiene lugar la escisión hidrolítica de las cadenas del polímero de manera aleatoria lo cual provoca una disminución del peso molecular. Y en una segunda etapa, fragmentos o porciones de bajo peso molecular y pequeñas partículas del polímero son desplazadas del sitio del implante ya sea mediante solubilización en los fluidos corporales o mediante fagocitosis, lo cual se manifiesta como una pérdida de peso. La completa degradación y eliminación de los homopolímeros de poli (caprolactona) pueden tardar aproximadamente de 2 a 4 años.

La velocidad de degradación de los materiales de PCL puede incrementarse notablemente mediante copolimerización o a través de la formación de mezclas con polímeros hidrófilos. Por ejemplo, la adición de ácido oleico o aminas terciarias pueden actuar como catalizadores del proceso de hidrólisis de las cadenas del polímero.

En la actualidad, numerosas investigaciones han demostrado el gran potencial que poseen los materiales basados en PCL en la biomedicina; un ejemplo de ello es el sistema capronor ${ }^{\circledR}$ [126], un dispositivo implantable de liberación controlada de anticonceptivos de 1 año de duración. Otro ejemplo, son las grapas biodegradables utilizadas para cerrar las heridas, los implantes 
dentales, los clavos y tornillos utilizados para fijar internamente los implantes en las fracturas de hueso, etc. La aplicación en la ingeniería tisular de la PCL y de sus mezclas con polímeros naturales, como es el caso del CHT será abordada más adelante, aunque en ocasiones la aplicación de la PCL es más restringida debido a su hidrofobicidad y a la ausencia de grupos funcionales bioactivos en su superficie [127 y 128].

\subsection{Ingeniería tisular}

La ingeniería tisular (TE) es una ciencia multidisciplinaria que aplica los principios y métodos de la ingeniería de materiales y la biología molecular hacia el desarrollo de sustitutos que restauren/reparen, mejoren o mantengan la función biológica de un tejido u órgano dañado [129]. Langer y Vacanti [130] publicaron que el enfoque mas común hacia el desarrollo de sustitutos biológicos está basado en tres componentes principales: las células, las moléculas bioactivas y los materiales poliméricos tri-dimensionales (scaffolds). Las células son las encargadas de sintetizar la matriz extracelular del tejido nuevo y restaurar la función de los tejidos dañados, mientras que el scaffold debe proporcionar un ambiente favorable para la adhesión, proliferación y diferenciación celular y las moléculas bioactivas deben facilitar y promover la regeneración del nuevo tejido.

Durante el proceso de regeneración, el scaffold no solo proporciona una estructura tri-dimensional temporal donde se va a formar el nuevo tejido sino que también controla la liberación de las moléculas bioactivas. El scaffold para llevar a cabo esa variedad de funciones en la ingeniería de tejido debe cumplir una serie de requerimientos, algunos de ellos son: 
1. Debe ser biocompatible con los tejidos

2. Debe tener una biodegradabilidad controlada con el fin de que el tejido sustituya eventualmente al scaffold.

3. No debe inducir ninguna respuesta adversa en el organismo.

4. Debe poseer unas propiedades mecánicas adecuadas según el tipo de aplicación.

5. Debe poseer una porosidad y una morfología apropiada para favorecer el transporte de células, gases, metabolitos, nutrientes y moléculas bioactivas tanto dentro del scaffold como entre éste y el medio circundante.

En este sentido, un gran número de polímeros biodegradables tanto de origen natural como sintético han sido estudiados en el desarrollo de scaffolds para su aplicación en la ingeniería de tejidos [131]. Entre los polímeros sintéticos una atención especial ha recibido los poliésteres, tales como el poli (ácido láctico), el poli (ácido glicólico), sus copolímeros [132] y la policaprolactona [133 y 134]. Dentro de los polímeros naturales, el quitosano es uno de los materiales con mayor potencial debido no solo a sus propiedades biológicas sino también a sus propiedades físicas y químicas las cuales pueden ser controladas bajo condiciones suaves y mediante técnicas de procesamiento relativamente sencillas [135]. A continuación describiremos con mas detalles las características de los scaffolds, como material soporte en el cultivo celular.

\subsubsection{Scaffolds, como material soporte en el cultivo celular}

El desarrollo y la evolución en el campo de los biomateriales conjuntamente con las nuevas tecnologías de la biología molecular responden a la imperiosa necesidad de contar con materiales funcionales en los que se pueda 
sembrar células y posteriormente crear un sustituto biológico que sustituya, mantenga o mejore las funciones biológicas de un tejido u órgano dañado. En este sentido, materiales tri-dimensionales porosos en forma de hidrogeles [136], de esponjas [137 y 138], de fibras [139], de telas [140] y en membranas [141] han sido evaluados en cultivos celulares. También, en los últimos tiempos, las preparación de micropartículas y posterior creación de un scaffold mediante técnicas de sinterización [142] y fusión [143] han sido evaluadas como materiales soporte en el cultivo de células capaces de imitar el entorno natural de los tejidos [ $\left[\begin{array}{lll}144 & \text { y } & 145\end{array}\right]$. La aplicación de scaffolds inyectables basados en la combinación de micropartículas y células constituyen una alternativa muy novedosa frente a la aplicación de scaffold con una estructura pre-definida en la regeneración de tejidos ya que es posible implantar o transplantar las células a través de procedimientos quirúrgicos mínimamente invasivos [146 y 147].

A continuación se describirán diferentes técnicas de obtención de scaffolds basados en quitosano y sus características como material soporte en el cultivo "in vitro" de células.

\subsubsection{Esponjas de quitosano}

Los materiales a base de quitosano presentan una serie de propiedades que lo hacen especial para su uso en la ingeniería de tejidos, como material soporte en el cultivo celular [148]. El quitosano tiene la habilidad de formar estructuras porosas con poros interconectados mediante varias técnicas de procesamiento entre las que podemos mencionar: (i) la liofilización (Freezedrying), en la cual la solución de quitosano es congelada y seguidamente liofilizada, obteniéndose una estructura porosa con un tamaño de poro que 
depende principalmente de la temperatura de congelación; otra de las técnicas utilizadas es (ii) la freeze-gelation [149], la cual consiste en la conjugación de dos procesos, el de congelación y gelificación de la solución de quitosano. En este caso, primeramente se congela la solución de quitosano y seguidamente se introduce en una solución hidroalcoholica de hidróxido de sodio previamente enfriada a $-20^{\circ} \mathrm{C}$ donde tiene lugar la gelificación. También es posible obtener estructuras porosas a través del (iii) proceso de formación interna de burbujas [150] en el cual la solución de quitosano se mezcla con carbonato cálcico formando un gel que puede ser moldeado de la forma que se desee.

\subsubsection{Micropartículas de quitosano.}

La preparación de micropartículas y su aplicación como scaffold en la ingeniería de tejido constituye una alternativa muy novedosa e interesante frente a los demás tipos de estructuras tridimensionales utilizadas con este fin, puesto que además de servir como soporte en el cultivo celular también sirve como sistema de liberación controlada de moléculas bioactivas [151]. Existen diversos métodos para la obtención de micropartículas de quitosano entre las que podemos mencionar el método de gelificación ionotrópica, en el cual los contra-iones utilizados se pueden dividir en tres grandes categorías:

(1) Interacciones con iones de bajo peso molecular donde se puede incluir los iones tri-polifosfato, pirofosfato, tetra-polifosfato, hexa-polifosfato, entre otros.

(2) Interacciones con especies hidrófobas tales como el alginato, la $\mathrm{K}$ carragenina, entre otros.

(3) Interacciones con iones de alto peso molecular entre los que se encuentra el laurel sulfato, el octil sulfato, entre otros. 
En este método, el quitosano disuelto en una solución de ácido acético es añadida gota a gota sobre la solución acuosa que contiene el contra-ión, posteriormente las micropartículas son obtenidas por filtración, se lavan con agua destilada y se secan [152-155].

Mediante el proceso de emulsificación y gelificación ionotrópica también es posible obtener micropartículas. En este caso, la solución de quitosano es añadida sobre una fase orgánica formando una emulsión agua en aceite (w/o) [156] y posteriormente se añade un contra-ión para que tenga lugar la gelificación del polímero. Las micropartículas son separadas de la solución mediante filtración y seguidamente se lavan y se secan para su posterior utilización.

Otras de las técnicas utilizadas en el proceso de obtención de micropartículas son la coacervación [157], la coacervación compleja [158 y 159], la precipitación y entrecruzamiento químico [160], el método de evaporación del disolvente [161], el spray-drying [162] y el método de emulsión y entrecruzamiento químico [163]. En este caso, el quitosano disuelto en una solución de ácido acético es añadido lentamente sobre aceite mineral que contiene el surfactante con el fin de formar una emulsión agua en aceite (w/o) y posteriormente se entrecruzan las micropartículas ya sea con glutaraldehído o con genipin [164]. Las micropartículas formadas se separan del medio mediante filtración y después se lavan y se secan.

\subsubsection{Características de los scaffolds de quitosano}

La formación de una estructura porosa con poros interconectados es de suma importancia en el cultivo celular, en los materiales con poros interconectados las células pueden migrar y penetrar dentro de los poros, 
favoreciendo de este modo el contacto y la proliferación celular, así como el transporte de nutrientes y desechos desde y hacia el medio circundante. La angiogénesis y la organización del tejido son procesos que se ven afectados tanto por la porosidad del material como por la morfología del poro [165].

La naturaleza catiónica del quitosano es otra de las propiedades innatas de gran importancia ya que le permite interactuar con los glicosaminoglicanos y proteoglicanos distribuidos ampliamente en el organismo humano, así como con otras especies cargadas negativamente a través de interacciones electrostáticas. En diversas aplicaciones en la ingeniería de tejidos esta propiedad es esencial debido a que un gran número de citokinas y factores de crecimiento son modulados por glicosaminoglicanos de naturaleza aniónica tales como la heparina y el sulfato de queratán. Un scaffold recubierto con un complejo de quitosano y glicosaminoglicano puede servir para retener y controlar factores o biomoléculas secretadas por las células. Nishikawa y colaboradores [166] reportaron que la estructura de un complejo formado entre el quitosano y glicosaminoglicanos sulfatados consiste en largas cadenas lineales, no ramificadas, con unidades disacáridas repetitivas que juegan un papel crucial en la modulación de la morfología, función y diferenciación celular.

Las propiedades mecánicas de los scaffolds basados en quitosano dependen tanto del tamaño del poro como de su orientación. El módulo elástico de membranas porosas en estado hinchado es mucho menor (entre 0.1 y $0.5 \mathrm{MPa}$ dependiendo ampliamente de la fracción en volumen de poros, mientras que las membranas no porosas tienen un módulo entre 5 y $7 \mathrm{MPa}$. Las membranas porosas de quitosano exhiben una curva de tensióndeformación típica de materiales compuestos en la cual se distinguen claramente dos regiones: a bajas deformaciones con valores de módulo pequeño 
y otra transición a grandes deformaciones cuando el poro colapsa y el valor del módulo se triplica. La resistencia a la tensión de estructuras porosas de quitosano tienen un valor entre 30 y $60 \mathrm{KPa}[165]$.

La degradación de los constructos célula/material juega un papel crucial en las aplicaciones a largo plazo debido a que la degradación afecta a varios procesos celulares entre los que se incluyen la proliferación celular, la regeneración del tejido y la respuesta a cuerpo extraño. Por ejemplo, en la ingeniería de tejidos del sistema esquelético, la degradación del scaffold debe ser lenta y además debe mantener sus propiedades mecánicas hasta que el tejido se regenere completamente.

Las propiedades hasta ahora descritas y muchas otras hacen del quitosano un material de gran interés en el campo de la ingeniería tisular. A continuación citaremos algunas de las aplicaciones del quitosano en la ingeniería de tejidos.

\subsubsection{Aplicaciones de los scaffolds de quitosano en la ingeniería de tejidos}

Los scaffolds de quitosano han sido utilizados en varios tipos de tejidos en los que se pueden incluir: el tejido óseo [167 y 168], el cartílago [169-171], el hígado [172], los vasos sanguíneos, en la regeneración de nervios [173] y en la regeneración de la piel entre otros. A continuación describiremos con más detalles su utilización en la regeneración del tejido cartilaginoso y el tejido óseo. 


\subsubsection{El tejido óseo}

El tejido óseo representa la parte más importante del esqueleto, posibilita la acción mecánica de los músculos, protege órganos vitales y alberga la médula ósea hematopoyética. Además sirve como reservorio de calcio, fósforo y otros iones. El hueso es una variedad de tejido conectivo mineralizado, formado por la matriz ósea y tres tipos de células principales: los osteoblastos, los osteocitos y los osteoclastos.

\section{- La matriz ósea}

La matriz ósea está formada por dos fases: una fase orgánica $(35 \%$ de matriz orgánica) y otra fase mineral (65\% de material inorgánico). La fase orgánica esta formada por colágeno tipo I y una pequeña proporción de otras proteínas como proteoglicanos, proteínas implicadas en la adhesión celular (osteonectina, sialoproteínas, trombospondina, etc.), osteocalcina y factores de crecimiento [174]. Por otra parte, la fase inorgánica está constituida principalmente de fosfato de calcio en forma de cristales de hidroxiapatita.

La matriz ósea es la responsable de las propiedades biomecánicas del hueso. Las fibras de colágeno le proporcionan flexibilidad y resistencia a la tracción mientras que las sales minerales le confieren dureza, rigidez y resistencia a la compresión.

\section{- Osteoblastos}

Los osteoblastos son células diferenciadas provenientes de las células osteoprogenitoras, encargadas de sintetizar y secretar la parte orgánica de la matriz ósea (colágeno tipo I, proteoglicanos, proteínas implicadas en la adhesión celular, osteocalcina y factores de crecimiento) y controlan el depósito 
de las sales minerales. Son células con una morfología poliédrica, con un citoplasma basófilo, con un aparato de golgi prominente y abundantes cisternas de retículo endoplasmático rugoso [175].

Los osteoblastos participan en la calcificación de la matriz ósea mediante la secreción de vesículas matriciales cargadas de fosfatasa alcalina, una enzima capaz de generar iones fosfato $\left(\mathrm{PO}_{4^{-}}{ }^{2-}\right)$, elevando la concentración de este ión en el medio extracelular y creando centros de nucleación para el depósito de sales minerales.

En los cultivos celulares tanto "in vivo" como"in vitro" los osteoblastos pasan por tres etapas funcionales [176 y 177]

(1) La proliferación celular y la síntesis de los componente orgánicos de la matriz ósea.

(2) La maduración de la matriz ósea en la que tienen lugar cambios en la composición y organización de la matriz que la hacen competente para ser mineralizada.

(3) La deposición de sales minerales (principalmente hidroxiapatita).

La identificación de las diferentes etapas en estudios "in vitro" coincide con la activación sucesiva de una serie de genes específicos como los que transcriben el colágeno tipo I, la fibronectina y factores de crecimiento que son detectados durante la proliferación y síntesis de la matriz ósea, posteriormente en la etapa de maduración de la matriz es posible detectar la fosfatasa alcalina y durante la deposición de componentes inorgánicos se produce la activación de glicoproteínas tales como la sialoproteína ósea, la osteocalcina y la osteopontina. 


\section{- Osteocitos}

Los osteocitos son células óseas maduras derivadas de los osteoblastos. Se encuentran insertos en cavidades de la matriz ósea llamadas lagunas osteocitarias y se conectan a través de las uniones gap (gap junctions) [178] con otros osteocitos vecinos a través de sus prolongaciones citoplasmáticas, albergadas en los canalículos de la matriz.

Tanto las lagunas osteocitarias como los calcóforos o canalículos matriciales se encuentra un líquido intersticial a través del cual es posible el intercambio de iones y metabolitos lo cual, posibilita una comunicación química y eléctrica entre las células.

Los osteocitos no segregan materiales de la matriz ósea y su función es la de mantener las actividades celulares del tejido óseo como el intercambio de nutrientes y productos de desecho.

Los osteocitos son células con una escasa actividad metabólica pero su preservación parece necesaria para que el tejido óseo mantenga sus propiedades biomecánicas. Los osteocitos teóricamente pueden detectar estrés mecánico y microlesiones del tejido óseo, comportamiento que se está estudiando, debido a que una preservación de estas células conllevaría a un buen proceso de remodelación ósea y con ello se evitarían muchas enfermedades como la osteoporosis y la osteoartritis.

\section{- Osteoclastos}

Los osteoclastos son células gigantes multinucleadas encargadas de la resorción de la matriz ósea, localizadas en la superficie del hueso. Los osteoclastos se forman por la fusión de células mononucleares derivadas de una célula hematopoyética y presentan muchas de las propiedades de los macrófagos. Los osteoclastos se caracterizan por tener una zona de su 
membrana arrugada en forma de cepillo rodeada de un citoplasma libre de orgánulos [179 y 180] con la que se adhiere a la superficie del hueso mediante moléculas de adhesión de la familia de las integrinas [181].

Debido a que las propiedades mecánicas de los scaffolds de quitosano son muy bajas para ser utilizados por si solos en la regeneración del tejido óseo, muchos investigadores han optado por la utilización de composites de quitosano con materiales que poseen buenas propiedades mecánicas como son las bio-cerámicas de fosfato de calcio, donde la hidroxiapatita y el $\beta$-fosfato tricálcico son excelentes candidatos para la regeneración del tejido óseo debido a la similitud que existe entre la composición química de las bio-cerámicas y los componentes inorgánicos de la matriz ósea del hueso [182-185].

Por otro lado, sus propiedades biológicas son adecuadas ya que promueve la proliferación celular y la deposición de sales minerales en cultivos “in vitro" de osteoblastos. Además el quitosano es biocompatible, (minimiza la respuesta inflamatoria) es biodegradable y tiene la capacidad de formar estructuras porosas (permite la osteoconducción) [186].

Otra de las aplicaciones de los scaffolds de quitosano en la ingeniería tisular es la relacionada con la regeneración de tejido cartilaginoso, utilizando cultivos primarios de condrocitos o incluso la diferenciación de células madre o mesenquimales a cartílago, por lo que para entender los procesos que tienen lugar referente a este tipo de tejido abordaremos a continuación sus principales características. 


\subsubsection{El tejido cartilaginoso}

El tejido cartilaginoso es uno de los principales tejidos de sostén, junto con el hueso. Al igual que otros tejidos conectivos está formado por células, los condrocitos y por abundante material intercelular que forma la matriz. Los condrocitos son redondos, presentan un retículo endoplasmático rugoso abundante y un complejo de golgi bien desarrollado. En la superficie celular presentan microvellosidades y se localizan en pequeñas lagunas diseminadas por el tejido cartilaginoso. La función de estas células es secretar las proteínas y los glicosaminoglicanos que forman la matriz extracelular [187].

Los condrocitos son células altamente especializadas, sintetizan todos los componentes de la matriz extracelular y regulan su metabolismo. Algunas de las características de este tipo de célula se describen a continuación:

- Son de forma esferoidal.

- No existe contacto entre ellos, al igual que los osteocitos.

- Sintetizan colágeno tipo II y grandes cantidades de agregados de proteoglicanos y proteínas no colaginasas.

- Presentan una actividad metabólica alta, pero debido a que la proporción de éstos en volumen es muy baja (1-5\%), la actividad total es baja [188].

Las propiedades del tejido cartilaginoso relacionadas con su papel fisiológico dependen de la estructura fisicoquímica de la matriz por lo que se puede dividir en tres tipos: (1) el cartílago hialino, el cual se encuentra rodeando a la mayoría de los huesos en las articulaciones, (2) el cartílago elástico que se localiza en la epiglotis, en el conducto auditivo externo y en el pabellón de la oreja y (3) el cartílago fibroso o fibrocartílago que se encuentra 
en los discos intervertebrales y en ciertos lugares de inserción del tendón al hueso.

\section{- Cartílago hialino}

El cartílago hialino que se encuentra en la superficie del cóndilo femoral donde se acomodan las cavidades glenoideas de la tibia se le conoce como cartílago articular.

El cartílago articular cumple dos funciones fundamentales: (1) amortiguar la sobrecarga de presión de las superficies articulares y (2) permitir el desplazamiento de las superficies óseas sin que se produzca fricción entre ellas [189].

La matriz extracelular también juega un papel de gran importancia en la regeneración del cartílago articular. Las principales funciones de la matriz [189 y 190] son: (i) proteger a los condrocitos de las tensiones mecánicas (ayuda a mantener su fenotipo), (ii) almacenar las citoquinas y factores de crecimiento necesarios para los condrocitos, (iii) controlar la concentración y velocidad de difusión de nutrientes y (iv) actuar como transductor de señales para las células.

El cartílago articular es el más abundante del organismo, es de color blanco azulado, es avascular [189] (no tiene vasos sanguíneos), nutriéndose a partir del líquido sinovial mediante difusión pasiva, y no tiene inervación, o sea no duele (la percepción del dolor se produce por las terminaciones nerviosas de la membrana sinovial y el hueso subcondral). Estructuralmente, el cartílago está compuesto principalmente, por una red de fibras de colágeno tipo II (aunque también están presentes otros tipos de colágeno) y proteoglicanos sintetizados por los condrocitos. Las fibras de colágeno forman más del 50\% del peso seco y se encargan del mantenimiento de la integridad del tejido 
mientras que los proteoglicanos son muy viscosos e hidrófilos y se encargan de la resistencia a la compresión. Excepto en las caras articulares, el cartílago está envuelto en un tejido conectivo denso llamado, pericondrio cuya integridad es esencial para la vida del cartílago.

En la matriz extracelular del cartílago predominan mayoritariamente las sustancias amorfas constituidas por los proteoglicanos, glicosaminoglicanos y glicoproteínas mientras que las fibras de colágeno tipo II son muy pequeñitas y se encuentran en menor proporción. La consistencia de este tejido viene dado por su sustancia amorfa.

\section{- Cartílago elástico}

El cartílago elástico tiene los mismos componentes que el cartílago hialino, tiene condrocitos, fibras de colágeno tipo II, glicosaminoglicanos, etc., pero además tiene fibras elásticas, las cuales se disponen en forma de redes muy finas alrededor del condrocito. El cartílago elástico está recubierto totalmente por pericondrio, es microscópicamente amarillo y se localiza en aquellas zonas donde se necesita soporte pero a la vez flexibilidad.

\section{- Cartílago fibroso}

Tiene las mismas características del cartílago hialino, pero además tiene unas fibras gruesas de colágeno tipo I, en este caso los condrocitos se ubican a lo largo de las fibras de colágeno, más o menos paralelos a las fibras lo que garantiza que el cartílago sea fuerte, pero a la vez tenga cierta elasticidad. A diferencia del cartílago hialino y elástico no esta recubierto por el pericondrio. 
Capítulo 2

Parte Experimental 


\subsection{Materiales}

\subsubsection{Polímeros}

- Quitosano (CHT), suministrado por Sigma Aldrich con un grado de desacetilación de un 75\%, determinado mediante espectroscopía UV [89] y un peso molecular de $150 \mathrm{kDa}$ determinado por métodos viscosimétricos a través de la ecuación de Mark-Houwink [95], utilizando como sistema de solventes, una solución de ácido acético, $\mathrm{CH}_{3} \mathrm{COOH}(0.1 \mathrm{M})$ y otra de cloruro de sodio, $\mathrm{NaCl}(0.2 \mathrm{M})$ a $25^{\circ} \mathrm{C}$.

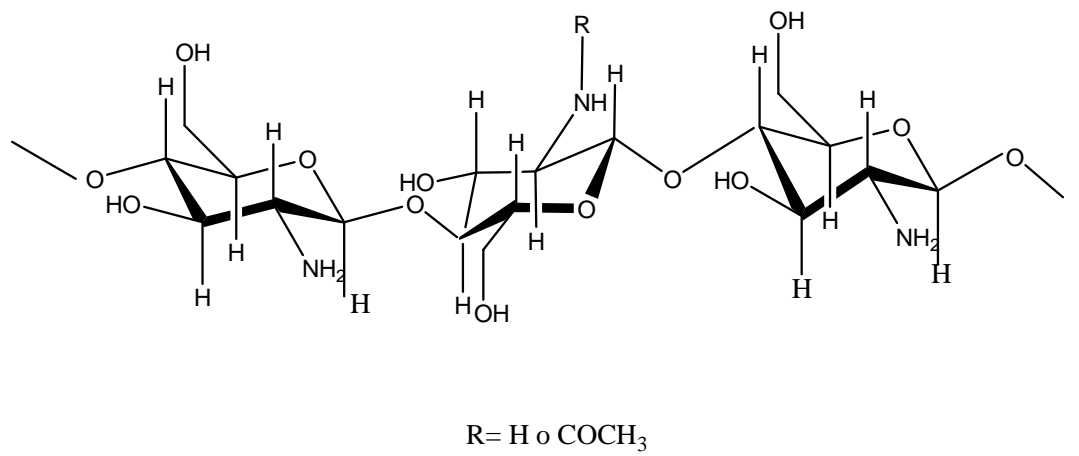

- Policaprolactona (PCL), suministrada por Polysciences con un peso molecular de 14 o $48 \mathrm{kDa}$, determinado por cromatografía de permeación de $\operatorname{gel}(\mathrm{GPC})$.<smiles>CCCOC(=O)CCCCCCC(=O)O</smiles> 
- Polimetacrilato de etilo (PEMA) y polióxido de etileno (PEO) en forma de micropartículas esféricas de $200 \mu \mathrm{m}$ de diámetro suministrados por Quimidroga, S. A. y Polysciences respectivamente, fueron utilizados como porógeno en la preparación de scaffolds.<smiles>CCOC(=O)C(C)(CC(C)(C)C)C(C)(C)C</smiles>

PEMA<smiles>CC(C)(C)CCOCCOC(C)(C)C</smiles>

PEO 


\subsubsection{Otros reactivos}

- Tripolifosfato de sodio $\left(\mathrm{Na}_{5} \mathrm{P}_{3} \mathrm{O}_{7}\right)$, suministrado por Sigma Aldrich.

- Hidróxido de sodio (NaOH), suministrado por Scharlau.

- Genipin, suministrado por Wako.

- Aceite mineral, suministrado por Sigma Aldrich.

- Tween 80, suministrado por Sigma Aldrich.

- Formalina y glutaraldehído, suministrados ambos por Sigma Aldrich.

\subsubsection{Solventes}

- Ácido acético glacial (HAc), utilizado como solvente de la policaprolactona y en soluciones acuosas al 1\% para disolver el quitosano, suministrado por Scharlau.

- Etanol absoluto (ETOH), utilizado como solvente del PEMA y en la preparación de los scaffolds y micropartículas de quitosano, suministrado por Scharlau.

- Agua destilada $\left(\mathrm{H}_{2} \mathrm{O}\right)$, suministrada por Scharlau, de conductividad 10 $\mu \mathrm{S}$.

2.1.4. Tipo de células y medios de cultivo utilizados en los ensayos biológicos

Células madre provenientes de médula ósea de cabras adultas (GBMSCs), suministradas por el laboratorio 3B's Research Group in 
Biomaterials, Biodegradables and Biomimetics, de la Universidad de Minho, Braga, Portugal fueron utilizadas en los ensayos de diferenciación osteogénico.

Condrocitos humanos provenientes de cartílago articular de pacientes sometidos a una artroplastia total de rodilla fueron aislados y utilizados en los ensayos in vitro.

Dulbecco's Modified Eagle's Medium (DMEM), enriquecido con un $1 \%$ de hidrógeno carbonato de sodio (NaHCO3) (ambos reactivos suministrados por Sigma-Aldrich), un $10 \%$ de suero bovino-fetal (FBS) y un $1 \%$ de antibiótico/antimicótico (reactivos suministrados por Gibco U.K) fue utilizado en la preparación del medio de cultivo utilizado para el mantenimiento y proliferación de las GBMSCs.

Minimal Essential Medium Eagle, modificación alfa, ( $\alpha$-MEM) enriquecido con dexametasona $\left(10^{-8} \mathrm{M}\right), 50 \mathrm{mgml}^{-1}$ de acido ascórbico, $\beta$ glicerol fosfato (10mM) (reactivos suministrados por Sigma-Aldrich), $1 \%$ de antibiótico/antimicótico y 10 \% de FBS fue utilizado en la preparación del medio de diferenciación osteogénico.

Dulbecco's Modified Eagle’s Medium (DMEM), enriquecido con un $1 \%$ de piruvato de sodio, $1 \%$ de glutamina (reactivos suministrados por Gibco, U.K), 1 \% de antibiótico/antimicótico, 1\% de ácido ascórbico y un 10 \% de FBS fue utilizado en la preparación del medio de cultivo para los ensayos "in vitro" de condrocitos.

El medio de cultivo DMEM, preparado sin rojo fenol y sin FBS se mezcló con el reactivo (3-(4,5-dimetiltiazol-2-il)-5-(3-carboximetoxifenil)-2(4sulfofenil)-2H tetrasolium) (MTS) (suministrado por Promega) en relación 5:1 para obtener el medio MTS utilizado en los ensayos de viabilidad celular. 


\subsection{Experimentos realizados}

2.2.1. Caracterización físico-química y evaluación de la respuesta biológica de mezclas poliméricas biodegradables de policaprolactona y quitosano

2.2.1.1. Preparación de mezclas de policaprolactona y quitosano.

Soluciones de quitosano (2\%) y policaprolactona de bajo y alto peso molecular, 14 y $48 \mathrm{kDa}(1.8 \%)$ fueron preparadas utilizando como disolvente para el quitosano, una solución de ácido acético al 1 \% y para la policaprolactona ácido acético glacial. Las mezclas de los dos polímeros fueron preparadas como se describe a continuación. Diferentes alícuotas de la solución de quitosano fueron añadidas a $20 \mathrm{ml}$ de la solución de PCL bajo constante agitación a una temperatura de $50^{\circ} \mathrm{C}$ hasta obtener una solución extremadamente viscosa. Seguidamente, las mezclas homogenizadas fueron mantenidas a temperatura ambiente hasta total evaporación del solvente. Los films homogéneos de PCL y CHT obtenidos fueron neutralizados en una solución de hidróxido de sodio $(0.1 \mathrm{M})$ para regenerar los grupos aminos libres presentes en la cadena polimérica del quitosano y evitar de esta manera una posible redisolución del CHT. Finalmente, las muestras fueron lavadas vigorosamente en agua destilada hasta $\mathrm{pH} 7$ y secadas en vacío a temperatura ambiente hasta su utilización. El porcentaje de CHT en las mezclas aparentemente homogéneas con la PCL de bajo peso molecular (18 kDa) varían des de un $0 \%$ hasta un $40 \%$ mientras que las preparadas con la PCL de alto peso molecular $(48 \mathrm{kDa}$ ) sólo es posible llegar hasta un $30 \%$, debido a que tiene lugar la separación de fases de los dos polímeros y no es posible preparar la 
mezcla. En la tabla 2.1 se reportan las composiciones de las mezclas preparadas.

Tabla 2.1 Composición de las mezclas de policaprolactona y quitosano.

\begin{tabular}{|c|c|c|}
\hline PCL (14 kDa) & CHT & PCL (48 kDa) \\
\hline 100 & 0 & 100 \\
\hline 90 & 10 & 90 \\
\hline 80 & 20 & 80 \\
\hline 70 & 30 & 70 \\
\hline 60 & 40 & \\
\hline
\end{tabular}

2.2.2. Cultivo in vitro de condrocitos humanos sobre mezclas biodegradables de policaprolactona y quitosano

\subsubsection{Aislamiento celular de condrocitos}

Los condrocitos han sido obtenidos a partir de cartílago articular humano procedente de pacientes sometidos a una artroplastia total de rodilla. Los condrocitos utilizados en el estudio biológico de las mezclas de PCL y CHT han sido aislados en el Centro de Biomateriales e Ingeniería Tisular siguiendo el protocolo descrito en [123] y los utilizados en los cultivos de los scaffolds tri-dimensionales de quitosano han sido aislados según [191] y nos lo ha suministrado el Instituto Municipal de Investigaciones Médicas de Barcelona. 


\subsubsection{Cultivo primario de condrocitos}

Las mezclas de policaprolactona y quitosano esterilizados con radiación gamma (25 kGy) fueron colocados en una placa de cultivo de 96 pocilllos y se acondicionaron con medio de cultivo 24 horas antes de realizar el experimento. Posteriormente, se añadió $40 \mu \mathrm{l}$ de la suspensión celular de condrocitos sobre cada muestra y se incubaron durante 1 hora a $37^{\circ} \mathrm{C}$ y $5 \% \mathrm{CO}_{2}$. Transcurrido este tiempo, $60 \mu \mathrm{l}$ de medio de cultivo fue añadido a cada pocillo y las muestras se mantuvieron durante 10 días a $37^{\circ} \mathrm{C}$ y $5 \% \mathrm{CO}_{2}$. Cada experimento se realizó por triplicado y se utilizó como control un pocillo vacío. El medio de cultivo se cambió cada tres días.

2.2.3. Materiales $3 D$ con estructura porosa basados en redes poliméricas semi-interpenetradas (semi-IPNs) de policaprolactona y quitosano

2.2.3.1. Preparación de las redes poliméricas semi-interpenetradas de policaprolactona y quitosano

La policaprolactona y el quitosano se disolvieron en ácido acético glacial y una solución de ácido acético al $1 \%$ respectivamente. Seguidamente, ambas soluciones fueron mezcladas en condiciones apropiadas y precipitadas en un exceso de una solución de tripolifosfato de sodio (0.3\%) bajo una agitación constante y vigorosa con el fin de obtener redes poliméricas semiinterpenetradas de PCL y CHT con un 10, 20 y un 30\% de quitosano. Las redes semi-interpenetradas fueron obtenidas en forma de polvo blanco, el cual se resuspendió en una solución de hidróxido de sodio con el objetivo de neutralizar las cadenas poliméricas de quitosano que no hubiera formado parte 
de la red. Finalmente las redes preparadas se lavaron con abundante agua hasta alcanzar un pH neutro y se secaron a vacío hasta peso constante.

\subsubsection{Preparación de scaffolds a partir de las semi-IPNs}

Scaffolds de PCL y CHT con diferente porosidad fueron preparados a partir de las redes semi-interpenetradas usando como porógeno micropartículas de polióxido de etileno (PEO) de 100-150 $\mu \mathrm{m}$. Para ello, las redes semi-interpenetradas de diferente composición preparadas en el apartado anterior (2.2.2.1.) fueron trituradas cuidadosamente $\mathrm{y}$ mezcladas con las partículas de PEO en diferentes proporciones (30 45 y un 55\%). Posteriormente, la mezcla fue trasvasada a un molde circular de $30 \mathrm{~mm}$ de diámetro y $1.5 \mathrm{~mm}$ de espesor, el cual fue colocado dentro de un horno a $90^{\circ} \mathrm{C}$ durante 1 hora con el fin de obtener el scaffold. Durante ese tiempo, tanto la PCL como el PEO fundieron y subsecuentemente durante el enfriamiento del molde, ambos polímeros cristalizaron de nuevo uniendo las partículas entre sí y formando una estructura de fases co-continuas: la red semi-interpenetrada PCL/CHT por una parte y el porógeno por otra. Finalmente, los scaffolds fueron sumergidos en agua durante 3 días con el objetivo de eliminar totalmente todo el porógeno. En la tabla 2.2 se muestra la composición de cada scaffold.

Tabla 2.2 Composición de los scaffolds de PCL y CHT.

\begin{tabular}{|l|l|}
\hline & PCL/CHT scaffolds \\
\hline S1 & $90 / 10$ \\
\hline S2 & $80 / 20$ \\
\hline S3 & $70 / 30$ \\
\hline
\end{tabular}




\subsubsection{Diferenciación osteogénica de células madre de médula ósea de cabra (GBMSCs) cultivadas en scaffolds de quitosano}

\subsubsection{Preparación de los scaffolds de quitosano}

Los scaffolds de quitosano fueron preparados mediante la combinación de las técnicas de freeze-gelation y disolución de las partículas de porógeno con el fin de obtener estructuras porosas con diferente distribución de tamaño de poro. Para ello, se preparó una solución de CHT al 4 \% en ácido acético al 1\% y se mezcló con 70, 77.5 y 85 \% en peso de micropartículas de polimetacrilato de etilo de $200 \mu \mathrm{m}$, que fueron utilizadas como porógeno. Posteriormente, la mezcla resultante fue congelada en nitrógeno líquido y finalmente se sumergió en una solución previamente enfriada a $-20^{\circ} \mathrm{C}$ de $\mathrm{NaOH}(1 \mathrm{M})$ y etanol absoluto, (en proporción 50/50) durante 3 días. Transcurrido este tiempo, las muestras obtenidas fueron lavadas con abundante agua hasta alcanzar $\mathrm{pH}$ neutro y posteriormente se llevó a cabo la extracción de las partículas de porógeno. Para ello, se utilizó un Soxhlet y como disolvente del PEMA, etanol absoluto. Finalmente, los scaffolds de CHT de $7 \mathrm{~mm}$ de diámetro y $3 \mathrm{~mm}$ de espesor fueron liofilizados para su posterior utilización. 


\subsubsection{Cultivo in vitro de GBMSCs y su diferenciación osteogénica en estructuras $3 D$ porosas de quitosano}

\subsubsection{Aislamiento de las GBMSCs}

Las células madre fueron aisladas de la médula ósea proveniente de la cresta íliaca de cabras adultas mediante una punción y cultivadas en DMEM suplementado con FBS y antibióticos basándose en la habilidad de adherencia de éstas sobre una superficie plástica a diferencia de las células hematopoyéticas u otro tipo de células no adherentes. Las GBMSCs fueron cultivadas hasta confluencia y subcultivadas dos veces antes de ser utilizadas en el experimento.

\subsubsection{Cultivo y osteoinducción de las GBMSCs en scaffolds de quitosano}

Los scaffolds de quitosano preparados como se ha descrito en el apartado (2.2.3.1.) fueron esterilizados con una mezcla de óxido de etileno y dióxido de carbono en proporción (12/88) en volumen, a una temperatura de $45^{\circ} \mathrm{C}$ y una presión de $50 \mathrm{kPa}$ durante 14 horas [192] y acondicionados en $\alpha$-MEM 24 horas antes de realizar el experimento.

Las GBMSCs cultivadas en frascos hasta un $80 \%$ de confluencia fueron subcultivadas hasta el pase 2 y desprendidas del frasco mediante tripsinización. La suspensión celular obtenida fue sembrada dentro de los scaffolds de quitosano a una densidad celular de $1 \times 10^{5}$ células/scaffold utilizando una jeringa, seguidamente las muestras fueron incubadas durante 1 hora con el fin de promover la adhesión celular dentro del scaffold. Transcurrido este tiempo, 
los constructos células/scaffold fueron transferidos a una nueva placa de 48 pocillos con el objetivo de evaluar únicamente las células adheridas dentro del scaffold y $800 \mu \mathrm{l}$ de medio de cultivo osteogénico fue añadido a cada pocillo para inducir la diferenciación celular. El experimento se llevo a cabo por triplicado durante 28 días, extrayendo los constructos a los tiempos 3, 7, 14, 21 y 28 para evaluar la viabilidad y proliferación celular. El medio osteogénico fue renovado cada tres días. Scaffolds sin células fueron procesados bajo las mismas condiciones y utilizados como referencia.

2.2.6. Materiales tridimensionales porosos a base de quitosano para la regeneración de cartílago articular

\subsubsection{Preparación de scaffolds de quitosano}

Los scaffolds de quitosano fueron preparados de manera análoga a la descrita en el apartado 2.2.4.1. En este caso, se utilizó un 70 \% de PEMA como porógeno, obteniendo materiales con un tamaño de poro medio de $140 \mu \mathrm{m}$.

\subsubsection{Cultivo primario de condrocitos en scaffolds de quitosano.} Ensayos estáticos y dinámicos

Los scaffolds de quitosano previamente esterilizados con oxido de etileno fueron colocados en una placa de cultivo de 48 pocillos y acondicionados en medio de cultivo 24 horas antes e realizar la siembra. Los condrocitos utilizados en este experimento fueron aislados de cartílago articular humano proveniente de pacientes sometidos a una artroplastia total de rodilla cedidos por el IMIM de Barcelona. En este caso, la suspensión celular sembrada dentro 
de los materiales con la ayuda de una jeringa correspondía a una densidad celular de $1 \times 10^{6}$ células/scaffold. Posteriormente, las muestras fueron incubadas durante 1 hora a $37^{\circ} \mathrm{C}$ y $5 \% \mathrm{CO}_{2}$ con el objetivo de promover la adhesión celular. Seguidamente, una parte de las muestras (constructos células/scaffold) fueron transferidas a una nueva placa de cultivo y $800 \mu \mathrm{l}$ de medio de cultivo fueron añadidos a cada pocillo, consiguiendo de esta manera llevar a cabo el experimento en condiciones estáticas. Por otra parte, el resto de los constructos células/scaffold fueron transferidos a cuatro vasos que conforman un bioreactor en suspensión (MCS-125, techne, Cambridge, UK) y se fijaron en dos etapas las condiciones dinámicas del cultivo: una primera etapa de adhesión celular en la cual se agita el medio a 60 rpm durante intervalos de 5 minutos y 15 minutos en condiciones estáticas (0 rpm) durante las primeras 72 horas. En la segunda etapa el medio se mantiene en constante agitación a $80 \mathrm{rpm}$ durante 28 días. El medio de cultivo se renovó cada tres días y se realizaron todos los ensayos por triplicado. Los constructos fueron extraídos a las 17 horas (el cual estimamos como tiempo cero), 7, 14 y 28 días de cultivo.

2.2.7. Scaffolds a base de micropartículas de quitosano como soporte en el cultivo celular de GBMSCs

\subsubsection{Preparación de micropartículas de quitosano entrecruzadas con genipin}

Las micropartículas de quitosano fueron preparadas utilizando el método de emulsión, en este caso, agua en aceite y posterior reacción de entrecruzamiento. Para ello, se preparó una solución de $\mathrm{CHT}$ al $2 \%$ en una 
solución de ácido acético al 1\%, la cual se dejó gotear lentamente sobre $100 \mathrm{ml}$ de aceite mineral que contenía un $1 \%$ de tween 80 , utilizado como surfactante. Posteriormente, para llevar a cabo el entrecruzamiento de las micropartículas se añadió una solución acuosa de genipin a diferentes concentraciones (20 y 40 $\mathrm{mM})$. Finalmente, la emulsión se mantuvo durante 17 horas en ausencia de luz y bajo constante agitación a $1750 \mathrm{rpm}$. Transcurrido este tiempo, las micropartículas entrecruzadas de quitosano fueron recogidas mediante centrifugación.

\subsubsection{Cultivo in vitro de GBMSCs sobre micropartículas de quitosano entrecruzadas con genipin}

Las micropartículas de quitosano fueron previamente esterilizadas en etanol antes de realizar el cultivo con las GBMSCs. Posteriormente las micropartículas fueron transferidas a una placa de 48 pocillos no tratada (suministradas por Nunc, referencia 150787) para evitar la adhesión celular al pocillo y acondicionadas en medio de cultivo, DMEM, sin FBS 24 horas antes de realizar la siembra.

Se añadió la suspensión celular con una densidad de 1 x $\quad 10^{5}$ células/pocillo y se mantuvo el cultivo en contacto con las micropartículas durante 14 días a $37^{\circ} \mathrm{C}$ y $5 \% \mathrm{CO}_{2}$. El medio de cultivo utilizado fue DMEM suplementado con FBS y se renovó cada 2 días. Los constructos células/micropartículas fueron extraídos a $\operatorname{los} 7$ y 14 días para evaluar la viabilidad, adhesión y proliferación celular. 


\subsection{Técnicas experimentales}

\subsubsection{Técnicas y métodos de caracterización de materiales}

\section{- Espectroscopía infrarroja de transformada de fourier (FTIR)}

Se caracterizaron las muestras mediante FTIR aplicando la técnica de reflexión total atenuada (FTIR-ATR) y reflectancia difusa (SDR-FTIR), usando un Thermo Nicolet Nexus FTIR. Los espectros fueron obtenidos por la acumulación de 64 barridos en un rango de $650-4000 \mathrm{~cm}^{-1}$ con una resolución de $4 \mathrm{~cm}^{-1}$.

\section{- Calorimetría diferencial de barrido (DSC)}

Las medidas de calorimetría diferencial de barrido se realizaron en el equipo Pyris 1 (PerkinElmer), utilizando nitrógeno como gas de purga con un flujo de $20 \mathrm{ml} / \mathrm{min}$. La temperatura del equipo fue calibrada con indio y zinc. La entalpía de fusión del indio fue usada para calibrar el flujo de calor. De manera excepcional, en los ensayos de cristalización isotérmica y en los barridos dinámicos enfriando, el equipo fue calibrado utilizando la temperatura de la transición esméctica-nemántica $\left(\mathrm{T}_{\mathrm{s}-\mathrm{n}}\right)$ del cristal líquido, 4 ciano-4’octiloxi bifenilo (M24) y la temperatura de fusión del indio. Para ello la temperatura de la transición de la fase esméctica-nemántica fue medida a diferentes velocidades de calentamiento y enfriamiento (con el equipo calibrado según procedimiento habitual) para demostrar que la extrapolación de los resultados durante el enfriamiento y el calentamiento coinciden en un mismo valor cuando las velocidades de enfriamiento y calentamiento tienden a cero [193]. Por otra 
parte, la temperatura onset del indio fue medida sólo a diferentes velocidades de calentamiento. Las medidas de las muestras fueron realizadas con la calibración habitual del equipo y posteriormente los datos de la escala de temperatura fueron corregidos teniendo en cuenta la dependencia de la temperatura $T_{\mathrm{s}-\mathrm{n}} \mathrm{y}$ la temperatura de fusión del indio con la velocidad de los barridos experimentales.

\section{- Análisis dinámico mecánico (DMA)}

El análisis dinámico mecánico se realizó en el equipo Seiko DMS2 10, a la frecuencia de $1 \mathrm{~Hz}$ en el modo de tensión. La dependencia con la temperatura del módulo de almacenamiento $\left(\mathrm{E}^{\prime}\right)$ y la tangente de pérdida $(\tan \delta)$ fueron medidos en el intervalo de temperaturas de $-120{ }^{\circ} \mathrm{C}$ hasta $100{ }^{\circ} \mathrm{C}$ a una velocidad de $2{ }^{\circ} \mathrm{C} / \mathrm{min}$.

\section{- Análisis termogravimétrico (TGA)}

La estabilidad térmica de las muestras fue evaluada mediante un equipo TA-Instrument, modelo SDT-Q600 utilizando portamuestras de alúmina. Las masas de las muestras estaban en el rango de 5-10mg. Los valores de la perdida de masa se midieron en función de la temperatura en el intervalo entre 30 y $750^{\circ} \mathrm{C}$ con una velocidad de calentamiento de $10^{\circ} \mathrm{C} / \mathrm{min}$. Los experimentos fueron llevados a cabo en atmósfera de nitrógeno a un flujo de $50 \mathrm{ml} / \mathrm{min}$ con el objetivo de evitar una degradación oxidativa de las muestras. 
- Microscopía electrónica de barrido (SEM)

La morfología de las muestras fueron examinadas mediante el microscopio electrónico de barrido Jeol JSM-5410; previamente todas las muestras fueron recubiertas por una capa fina de oro. Las micrografías fueron tomadas con un voltaje de $15 \mathrm{kV}$ para obtener imágenes de alta resolución.

\section{- Tomografía micro-computarizada $(\mu-C T)$}

La información cualitativa de la arquitectura de los scaffolds de quitosano fue obtenida por análisis de imágenes mediante técnicas de $\mu$-CT, usando el equipo Scanco 20 (Scanco Medicals, Switzerland) con un nivel de penetración de rayos $\mathrm{X}$ de $50 \mathrm{kV}$. El barrido de rayos $\mathrm{X}$ fue adquirido en modo de alta resolución. El software Mimicss (Materialise, Belgium), fue utilizado para visualizar las secciones en $2 \mathrm{D}$ realizadas a los scaffolds. Se tomaron datos de 150 a 160 cortes separados por 7 micras lo que nos permitió realizar una reconstrucción tridimensional.

\section{- Ensayos de compresión de los scaffolds de quitosano}

Los ensayos de compresión se realizaron en el equipo seiko TMA/6000, con un palpador de cuarzo de $3.5 \mathrm{~mm}$ de diámetro. Las medidas se han realizado en estado seco y en inmersión (en DMEM) a $37^{\circ} \mathrm{C}$. Para ello, se aplicó una rampa de tensión a una velocidad de $20 \mathrm{mN} / \mathrm{min}$ hasta un valor de 500 y $2000 \mathrm{mN}$ registrándose la deformación en la muestra. El módulo deYoung aparente se ha obtenido a partir de la pendiente de la región lineal en 
la curva de tensión-deformación, después de sustraer la región de "acoplamiento" del palpador a la muestra (siguiendo la norma "ASTM D162104a, Standard Test Method for Compressive Properties of Rigid Cellular Plastics"). Se han realizado 10 medidas para cada muestra.

\section{- Microscopía de fuerza atómica (AFM)}

Las imágenes de microscopía de fuerza atómica fueron adquiridas mediante el equipo Nanoscope III del grupo de instrumentos digitales (VeecoMetrology) utilizando una punta comercial MPP-21100 con un radio de 10$12,5 \mathrm{~nm}$ y una frecuencia de resonancia de aproximadamente $100 \mathrm{kHz}$. Todas las muestras fueron analizadas en modo tapping, utilizando una relación entre la amplitud de vibración libre y la de contacto de 0.7. Las imágenes adquiridas corresponden a diferentes localizaciones y áreas.

\section{- Microscopía confocal láser de barrido (CLSM)}

Las imágenes de CLSM fueron adquiridas con un microscopio confocal con láser invertido Leica TCS SP2 AOBS (Leica Microsystems Heidelberg $\mathrm{GmbH}$, Mannheim, Germany), usando un objetivo de aceite 63x (PlanApochromat-Lambda Blue 1.4 N.A). La distribución de la fase del quitosano en las muestras fue visualizada debido a sus características fluorescentes a una longitud de onda de excitación de 488 nm y en un rango de emisión de 502-508 nm. 


\section{- Determinación de la energía superficial de los materiales}

La energía superficial de las muestras fue calculada a partir de medidas de ángulo de contacto utilizando para ello un goniómetro (Contact Angle System OCA) asociado al software Sca20 (Dataphysics Instruments GmbH, Germany). Agua, glicerol, diiodo metano y formamida fueron los líquidos utilizados para calcular el ángulo de contacto. La energía superficial fue determinada utilizando la metodología de Owens-Wendt [194] a partir de la siguiente ecuación.

$$
(1+\cos \theta) \gamma_{l}=2\left(\gamma_{s}^{d} \gamma_{l}^{n d}\right)^{1 / 2}+2\left(\gamma_{s}^{n d} \gamma_{l}^{n d}\right)^{1 / 2}
$$

Donde $\theta$ es el ángulo de contacto, $\gamma_{1}$ es la energía superficial del líquido puro, $\gamma_{\mathrm{s}}$ es la energía superficial del sustrato. Los superíndices "d" y "nd" corresponden a las contribuciones dispersas y no-dispersas de la energía superficial respectivamente.

\section{- Estudio de hinchamiento de las muestras}

La capacidad de absorción de agua de las muestras se llevó a cabo mediante la hidratación de estas en fluido biológico simulado [195] (SBF) a $37^{\circ} \mathrm{C}$. Transcurridos intervalos regulares de tiempo las muestras fueron extraídas del SBF y pesadas en una balanza. El hinchamiento es expresado como la cantidad de agua absorbida por unidad de masa de polímero seco (xerogel). 


$$
w=\frac{m_{\text {water }}}{m_{\text {xerogel }}}
$$

Los valores de hinchamiento reportados son los promedios de tres medidas realizadas.

- Adsorción de laminina sobre diferentes sustratos. Evaluación mediante AFM

La laminina (L-2020, $1 \mathrm{mg} / \mathrm{ml}$, suministrada por Sigma, Steinheim, Germany) fue adsorbida sobre la superficie de diferentes sustratos a través de la inmersión de estos en una solución fisiológica $(\mathrm{NaCl} 0.9 \%)$ de la proteína a una concentración de $2 \mu \mathrm{g} / \mathrm{ml}$ durante 10 minutos. Posteriormente la superficie de la muestra se expuso a un flujo de nitrógeno durante unos minutos hasta que se secó.

\section{- Estudio de degradación de los scaffolds de quitosano}

El estudio de degradación "in vitro" de los scaffolds de quitosano se llevó a cabo en una solución buffer fosfato (PBS, pH 7.4) que contiene $10 \mu \mathrm{g} / \mathrm{ml}$ de lisozima y $0.02 \%$ de azida de sodio a $37^{\circ} \mathrm{C}$ durante 45 días. La concentración de lisozima empleada corresponde a la concentración de esta enzima presente en el suero humano [76]. En detalle, tres réplicas de cada muestra/scaffold fueron pesadas inicialmente, en su estado seco, y posteriormente introducidas en $5 \mathrm{ml}$ de la solución de lisozima y colocadas en un baño termostático a $37^{\circ} \mathrm{C}$ y con agitación orbital a 50 rpm durante todo el período de estudio. La solución 
de la enzima fue renovada cada tres días con el fin de garantizar una continua actividad enzimática. A los 7, 14, 35 y 45 días las muestras fueron extraídas y lavadas con agua destilada, seguidamente se deshidrataron en soluciones hidroalcohólicas y finalmente se pesaron hasta peso constante. El porcentaje de degradación se calculó a partir de la diferencia de peso de los scaffolds secos antes y después del tratamiento con lisozima.

\subsubsection{Técnicas de caracterización biológica.}

\section{- Citotoxicidad celular}

Los ensayos de citotoxicidad celular in vitro fueron realizados siguiendo la norma ISO 10993 para la evaluación biológica de los materiales estudiados en este trabajo, en específico para el caso de las micropartículas de quitosano entrecruzadas con genipin obtenidas mediante el método de emulsión agua en aceite. Para ello, utilizamos células de tipo fibroblástica de la línea celular L929 y como control positivo el látex (donde las células se mueren) y como control negativo un pocillo vacío. El experimento se basa principalmente en valorar la adhesión, morfología y viabilidad de las células L929 que han sido cultivadas con un medio de cultivo que previamente ha estado en contacto con las micropartículas de quitosano entrecruzadas con genipin durante 24 horas, bajo constante agitación y a $37^{\circ} \mathrm{C}$ en condiciones estériles. Para ello, las células L929 se siembran en una placa de 96 pocillos y a las 24 horas de cultivo se cambia el medio y se añade el medio que ha estado en contacto con las micropartículas, en el caso del control positivo el medio que ha estado en contacto con el látex y en el control negativo se añade medio de cultivo normal. Posteriormente se incuban las placas y se mantiene el mismo medio de 
cultivo los 14 días que dura el experimento. La adhesión, morfología y viabilidad celular se analiza a las 24 horas, 3, 7 y 14 días de cultivo.

\section{- Viabilidad celular}

La viabilidad celular fue analizada mediante el ensayo de MTS, un método colorimétrico que determina el número de células vivas debido a la bioreducción del reactivo de Owen's, (3-(4,5-dimetiltiazol-2-il)-5-(3carboximetoxifenil)-2(4-sulfofenil)-2H tetrasolium), (sustrato MTS) por la acción de las co-enzimas NADPH (Nicotiamida-Adenina Dinucleotido fosfato) o NADH producidas en las enzimas deshidrogenasas presentes en las células metabolicamente activas. Como consecuencia se obtiene un producto coloreado, el formazán, el cual es soluble en el medio de cultivo y puede ser cuantificado midiendo la absorbancia a $490 \mathrm{~nm}$.

Los constructos células/scaffold extraídos a los diferentes períodos de tiempo se lavan dos veces con PBS y se transfieren a una placa de 96 pocillos. Posteriormente, el medio de cultivo sin rojo fenol y sin FBS se mezcla con el reactivo MTS en proporción 5:1 y se añade a cada pocillo hasta cubrir totalmente los constructos. Seguidamente, se incuba a $37^{\circ} \mathrm{C}$ y $5 \% \mathrm{CO}_{2}$ durante 3 horas. Transcurrido el tiempo de incubación, se realizan lecturas de absorbancia en un lector de multiplacas (VICTOR ${ }^{3} \mathrm{TM}$, PerkinElmer) a $490 \mathrm{~nm}$. La absorbancia medida es directamente proporcional al número de células vivas presentes en el cultivo. 


\section{- Cuantificación del ácido desoxirribonucleico (DNA)}

El contenido de DNA de las células cultivadas sobre los materiales fue determinado mediante ensayos fluorimétricos, utilizando el kit PicoGreen (Molecular Probes). Para ello, los constructos células/scaffold extraídos después de cada tiempo de incubación fueron transferidos a microtubos (eppendorf) que contenían $1 \mathrm{ml}$ de agua miliQ estéril y congelados a $-80^{\circ} \mathrm{C}$ hasta su utilización, con el objetivo de facilitar la extracción del DNA debido a la ruptura de la membrana nuclear de la célula. Posteriormente, los constructos fueron descongelados a temperatura ambiente y sonicados durante 15 minutos. En la cuantificación del DNA se siguió el procedimiento descrito por el fabricante. Soluciones estándar fueron preparadas diluyendo la solución de DNA comercial $(100 \mu \mathrm{g} / \mathrm{ml})$, hasta obtener un rango de concentraciones de o a $2 \mu \mathrm{g} / \mathrm{ml}$. Posteriormente, $28,7 \mu \mathrm{l}$ de la solución de las muestras sonicadas y de las soluciones estándar fueron mezcladas con 71,3 $\mu \mathrm{l}$ de PicoGreen y $100 \mu \mathrm{l}$ del buffer TE $1 x$ (10 mM Tris-HCl y $1 \mathrm{mM}$ EDTA) en una placa opaca de 96 pocillos. Posteriormente, las placas fueron incubadas durante 10 minutos protegidas de la luz y se realizaron las medidas de fluorescencia en un lector de multiplacas (VICTOR ${ }^{\mathrm{T}_{\mathrm{TM}}}$, PerkinElmer) a una longitud de onda de excitación de $490 \mathrm{~nm}$ y una de emisión de $520 \mathrm{~nm}$. Cada muestra fue analizada por triplicado. La concentración de DNA fue obtenida a partir de una curva de calibración y con la medida de fluorescencia de cada muestra.

\section{- Adhesión y morfología celular}

La adhesión y la morfología de las células cultivadas en los scaffolds fueron evaluadas mediante microscopía electrónica de barrido (SEM). Para 
ello, los constructos extraídos después de cada tiempo de cultivo fueron lavados dos veces con PBS y tratados con una solución de glutaraldehído al $2,5 \%$ a $4^{\circ} \mathrm{C}$ durante 1 hora con el fin de fijar las células. Después de una hora, los constructos fueron lavados nuevamente con PBS y deshidratados en soluciones hidro-alcohólicas de diferentes concentraciones (10,30, 50, 70, 80, $90 \%$ y etanol absoluto) en intervalos de 10 minutos. Una vez terminado, las muestras fueron secadas a temperatura ambiente y recubiertas con oro para su posterior análisis.

\section{- Diferenciación y des-diferenciación celular}

Análisis de marcadores específicos de condrocitos y osteoblastos fueron detectados mediante ensayos immunocitoquímicos utilizando la técnica de microscopía confocal láser de barrido (CLSM). Para ello, los constructos se fijaron con formalina a $4^{\circ} \mathrm{C}$ durante 1 hora, posteriormente se lavaron con PBS $\mathrm{y}$ se permeabilizaron con una solución al 0,1\% de triton $\mathrm{x}-100$ en PBS 1x. Seguidamente, las muestras fueron incubadas en una solución de bloqueo (SB) que contiene suero bovino fetal (FBS) al $10 \%$ en PBS $1 \mathrm{x}$ durante 2 horas a temperatura ambiente, para evitar uniones inespecíficas de los anticuerpos. Transcurrido dicho tiempo los constructos fueron incubados en la solución del anticuerpo primario (Ac I) durante 24 horas a $4^{\circ} \mathrm{C}$ (ver Tabla 2.3). Finalmente se lavaron en PBS dos veces y se incubaron con el anticuerpo secundario (Ac II) correspondiente (suministrados por Invitrogen) en relación 1:200 (Ac II/SB) durante 2 horas a temperatura ambiente y protegido de la luz. Después del período de incubación las muestras se lavaron tres veces con PBS en intervalos de 5 minutos y se montaron las muestras en portaobjetos utilizando medio de montaje con DAPI (4,6- diamidino-2-fenilindol diclorhidrato) para 
teñir los núcleos de color azul. En la tabla 2.3 se reportan los anticuerpos primarios y secundarios utilizados en los ensayos immunocitoquímicos. También se han realizado tinciones del citoesqueleto de actina utilizando la bodipy FL phallacidin (Invitrogen, referencia RB-48).

Tabla 2.3 Anticuerpos primarios (Ac I) y secundarios (Ac II) utilizados en los ensayos immunocitoquímicos.

\begin{tabular}{|c|c|c|c|c|}
\hline \multicolumn{2}{|c|}{ Ac I } & Dilución & Ac II & Casa comercial \\
\hline $\begin{array}{c}\text { Anti-human } \\
\text { collagen } \\
\text { type II }\end{array}$ & $\begin{array}{c}\text { Mouse, } \\
\text { monoclonal }\end{array}$ & $1 / 6$ & $\begin{array}{l}\text { Alexa } 488 \\
(\alpha-\text { mouse })\end{array}$ & $\begin{array}{c}\text { Chemicon } \\
\text { International }\end{array}$ \\
\hline Ki-67 & $\begin{array}{c}\text { Mouse, } \\
\text { monoclonal }\end{array}$ & $1 / 50$ & $\begin{array}{l}\text { Alexa } 488 \\
(\alpha-\text { mouse })\end{array}$ & Dakocytomation \\
\hline $\begin{array}{l}\text { Anti-human } \\
\text { aggrecan }\end{array}$ & $\begin{array}{c}\text { Mouse, } \\
\text { monoclonal }\end{array}$ & $1 / 50$ & $\begin{array}{l}\text { Alexa } 488 \\
(\alpha-\text { mouse })\end{array}$ & Invitrogen \\
\hline $\begin{array}{c}\text { Anti-human } \\
\text { Collagen } \\
\text { type I }\end{array}$ & $\begin{array}{c}\text { Rabbit, } \\
\text { Polyclonal }\end{array}$ & $1 / 40$ & $\begin{array}{l}\text { Alexa } 647 \\
(\alpha-\text { rabbit })\end{array}$ & $\begin{array}{l}\text { Chemicon, } \\
\text { International }\end{array}$ \\
\hline $\begin{array}{l}\text { Anti-human } \\
\text { ALP }\end{array}$ & $\begin{array}{c}\text { Mouse, } \\
\text { monoclonal }\end{array}$ & $1 / 50$ & $\begin{array}{l}\text { Alexa } 555 \\
(\alpha-\text { mouse })\end{array}$ & R\&D Systems \\
\hline $\begin{array}{l}\text { Anti-human } \\
\text { osteocalcin }\end{array}$ & $\begin{array}{c}\text { Mouse, } \\
\text { monoclonal }\end{array}$ & $1 / 10$ & $\begin{array}{l}\text { Alexa } 555 \\
(\alpha-\text { mouse) }\end{array}$ & R\&D Systems \\
\hline
\end{tabular}

\subsubsection{Análisis estadístico de los resultados}

Los resultados fueron analizados estadísticamente mediante ensayos de ANOVA de un factor. Los valores obtenidos son expresados como un valor 
Capítulo 2

promedio y su desviación estándar. Se consideró un nivel de significación estadística con $\mathrm{p}=0.05$. 
Capítulo 3

Resultados y discusión 


\subsection{Propiedades físico-químicas de filmes poliméricos biodegradables de policaprolactona de bajo peso molecular y quitosano. Cinética de cristalización.}

Los filmes biodegradables de policaprolactona (PCL) y quitosano (CHT) fueron preparados mediante la técnica de evaporación de solvente, para ello la PCL se disolvió en ácido acético glacial (HAc) y el quitosano en una solución acuosa de ácido acético de concentración 0.1M. La mezcla de ambos polímeros se produce en una mezcla de HAc y agua cuya composición varía en dependencia de la composición de los filmes que se deseen obtener. En este caso, se obtuvieron filmes con un 10, 20, 30 y un 40 \% de quitosano. En este estudio, se ha utilizado una PCL de bajo peso molecular ( $14 \mathrm{kDa})$ con el fin de facilitar la homogeneidad de los filmes teniendo en cuenta que el agua es un no-solvente de la PCL. Cuando la PCL y el CHT en sus respectivos solventes se mezclan para formar el film, en la mezcla de los dos solventes o durante la homogenización y evaporación de éste, puede tener lugar una separación de fases líquido-líquido.

En la preparación de los filmes las mezclas de las disoluciones de ambos polímeros eran claramente homogéneas, excepto en el caso de la mezcla que contenía un $40 \%$ de quitosano donde se observó una turbidez, lo cual es indicativo de una separación de fases, aunque finalmente se obtuvo un film aparentemente homogéneo. En las mezclas poliméricas con un mayor porcentaje de quitosano la separación de fases era totalmente evidente y los filmes obtenidos eran muy heterogéneos por lo que decidimos analizar las propiedades físico-químicas de las mezclas poliméricos que contenían hasta un $40 \%$ de quitosano. 
La morfología de las mezclas de PCL/CHT fue examinada mediante SEM (Figura 3.1), después de eliminar uno de los dos componentes en un solvente adecuado. Para ello, se ha utilizado cloroformo para disolver la fase de la PCL y una solución acuosa de ácido acético 0.1 M para la fase del quitosano. Todos los filmes después de eliminar la fase de la PCL presentaban una estabilidad dimensional excepto el film con un $10 \%$ de quitosano donde se obtuvieron pequeños agregados los cuales fueron filtrados y examinados mediante SEM.

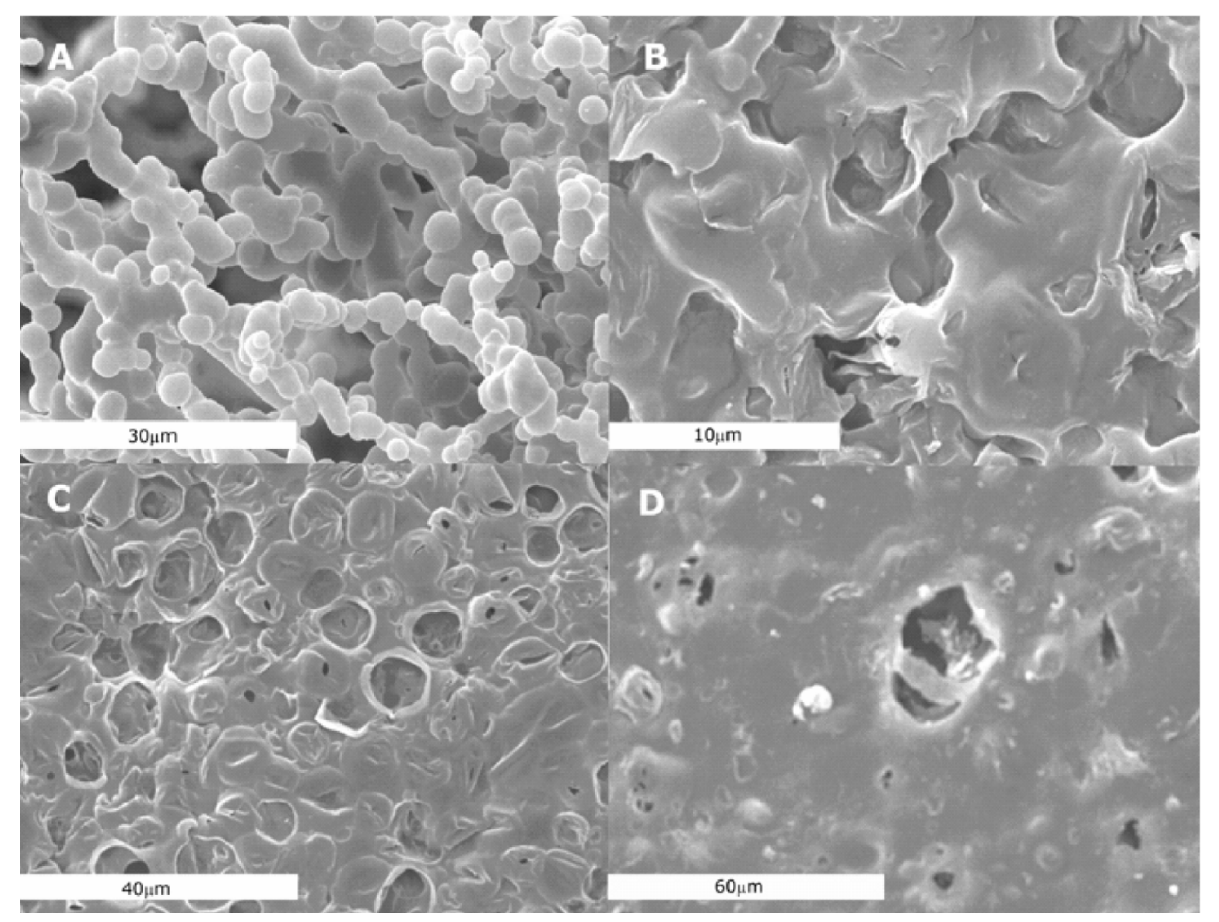

Figura 3.1. Microfotografías de SEM de las mezclas de PCL y CHT con diferentes composiciones, después de extraer la fase de PCL (A) $10 \%$ de CHT, (B) $20 \%$, (C) $30 \%$ y (D) $40 \%$ de CHT. 
Las imágenes de SEM de la mezcla que contiene un $10 \%$ de CHT, después de eliminar la fase de PCL, revela una estructura de pequeños dominios de CHT que consisten en partículas alrededor de $1 \mu \mathrm{m}$ adheridas entre sí formando una red tri-dimensional. Sin embargo, la cantidad de CHT en la mezcla no es suficientemente alta como para permitir una continuidad de esta red en toda la muestra.

Las mezclas con mayores contenidos de quitosano preservan su integridad, después de eliminar la fase de PCL y en las imágenes de SEM se observa la presencia de huecos que representan dominios dispersos de PCL (Figura 3.1C y D), excepto en la mezcla con un $20 \%$ de quitosano (Figura 3.1B) donde se observa que se forman fases co-continuas. El que la fase de quitosano sea continua con sólo un contenido del $20 \%$ de este componente se explica por la capacidad de las partículas de quitosano para agregarse.

También, se analizaron las imágenes obtenidas después de disolver la fase de quitosano (Figura 3.2). Como se puede apreciar, en la mezcla con un $90 \%$ de PCL se observa la formación de esferulitas (Figura 3.2A), pero sin embargo un detalle curioso lo encontramos al ampliar una única esferulita en la que se observan pequeños huecos (Figura 3.2B), los cuales se corresponden con la fase de CHT extraída, se trata de pequeños dominios de CHT de aproximadamente $1 \mu \mathrm{m}$ que aparecen alrededor de la laminilla cristalina de la PCL, embebidos en las esferulitas. En las mezclas con un $80 \%$ de policaprolactona los dominios de CHT se localizan en los espacios entre las esferulitas (Figura 3.2C) y el film preserva su integridad después de extraer la fase del CHT. Las muestras con un 70 y un 60\% de PCL se disgregan totalmente al disolver la fase del quitosano lo que demuestra que en estas composiciones la PCL forma agregados dispersos en la mezcla. 


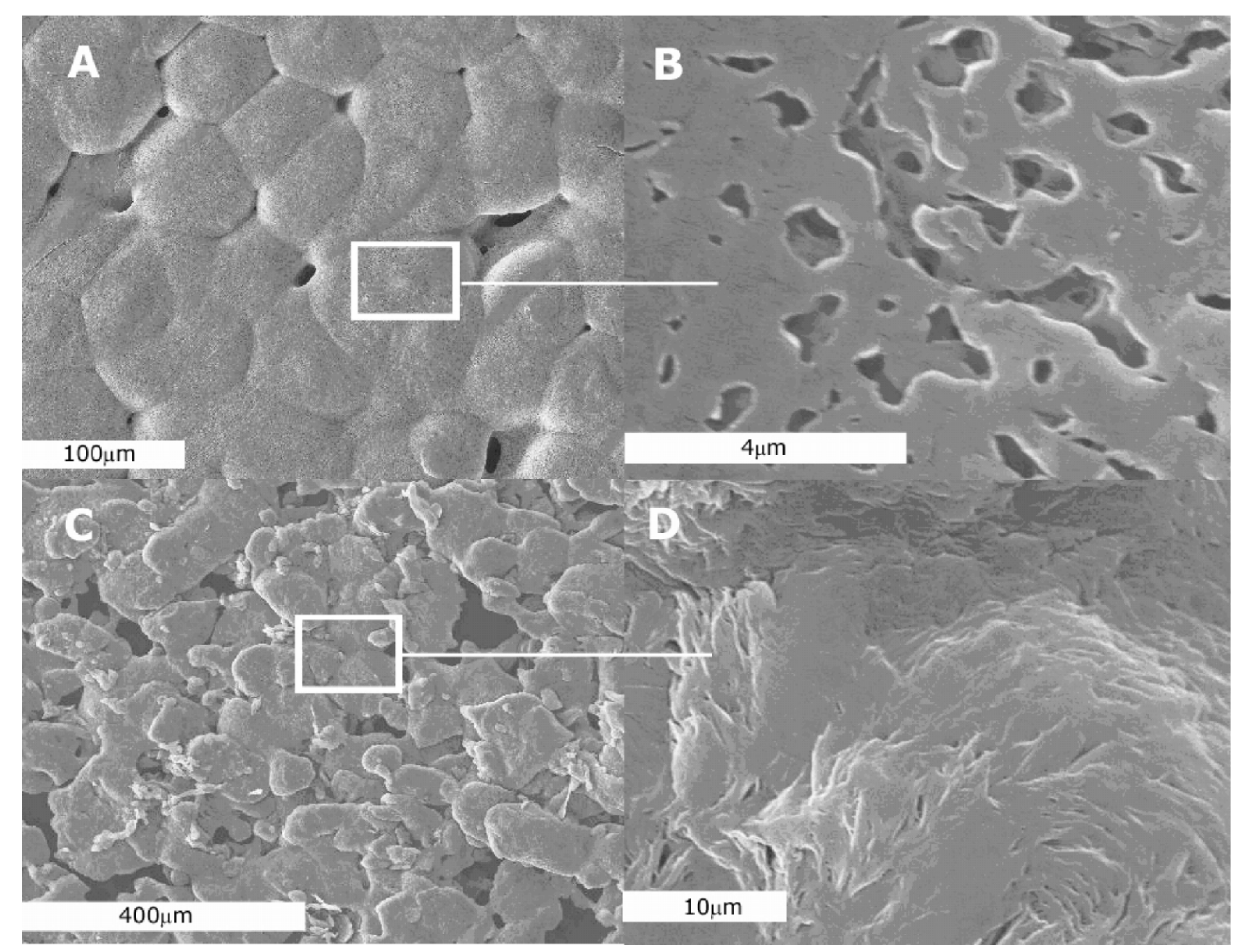

Figura 3.2. Micrografías de SEM de las mezclas, después de extraer la fase de CHT. (a y b) $90 \%$ de PCL, (c y d) 80\% de PCL. Las imágenes b y d son ampliaciones de a y c respectivamente.

También se analizaron las posibles interacciones entre los dos polímeros mediante espectroscopía infrarroja. En la figura 3.3 se muestra el espectro obtenido tanto para las mezclas como para sus polímeros puros. 


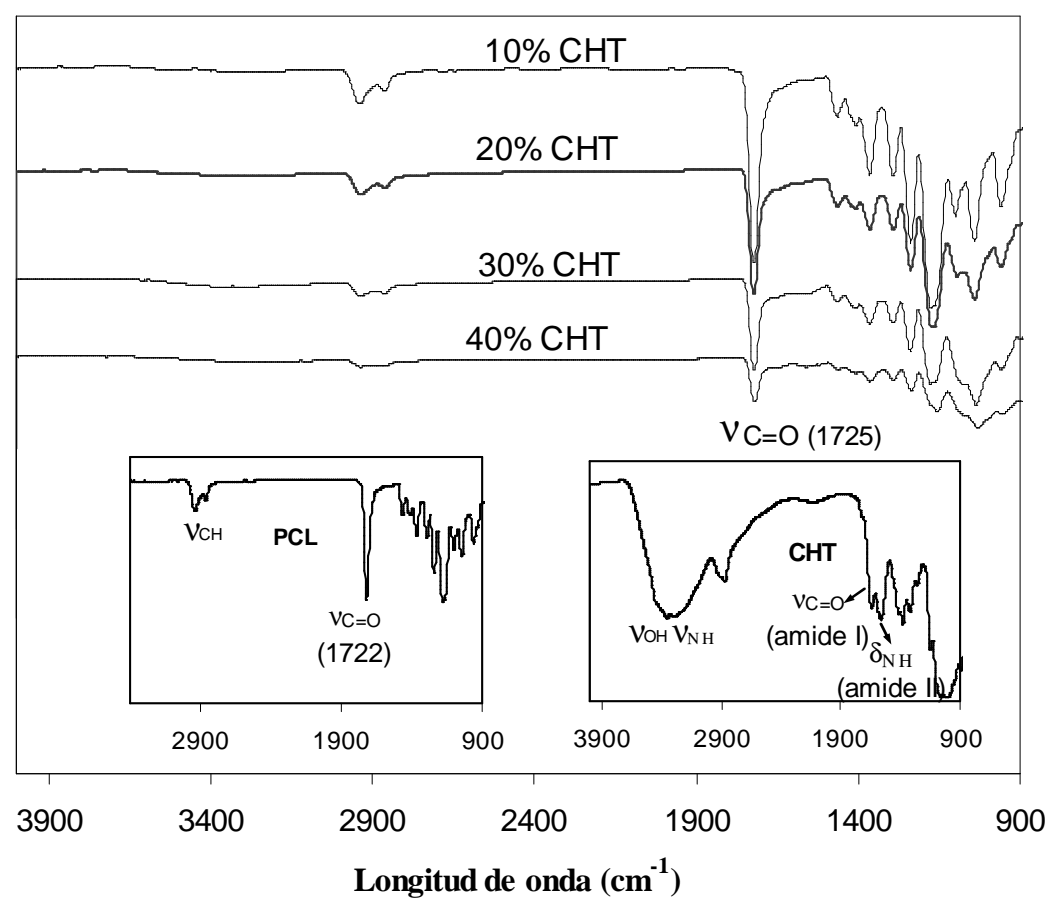

Figura 3.3. Espectro FTIR de las mezclas de PCL/CHT con diferentes composiciones y sus polímeros puros.

En el espectro se indican los picos característicos de los grupos funcionales presentes en la estructura del CHT y de la PCL. El pico correspondiente a las vibraciones del grupo carbonilo de la PCL aparece sobre los $1722 \mathrm{~cm}^{-1} \mathrm{y}$ en el quitosano los dos picos característicos son las vibraciones de amida primaria y la deformación del grupo amina primaria localizados 1650 y $1590 \mathrm{~cm}^{-1}$ respectivamente. Estos picos también aparecen en los espectros de las mezclas, aunque su intensidad varía en dependencia de la composición de las mezclas. 
El grupo carbonilo de la PCL puede interactuar con los grupos hidroxilo y los grupos amina presentes en la estructura del quitosano y formar enlaces éster y amidas. Sin embargo, no se observa ningún desplazamiento en estos picos respecto a los correspondientes componentes puros, lo cual es indicativo de que no existe una interacción mutua a nivel molecular.

Con el objetivo de evaluar las propiedades mecánicas de las mezclas se realizaron ensayos dinámico-mecánicos. Las mezclas con un 10\% de CHT no fueron ensayadas debido a que la muestra es muy frágil y no fue posible sujetarla con las mordazas del equipo. En la figura 3.4 se representa la dependencia del módulo de almacenamiento y la tangente de pérdida con la temperatura. 


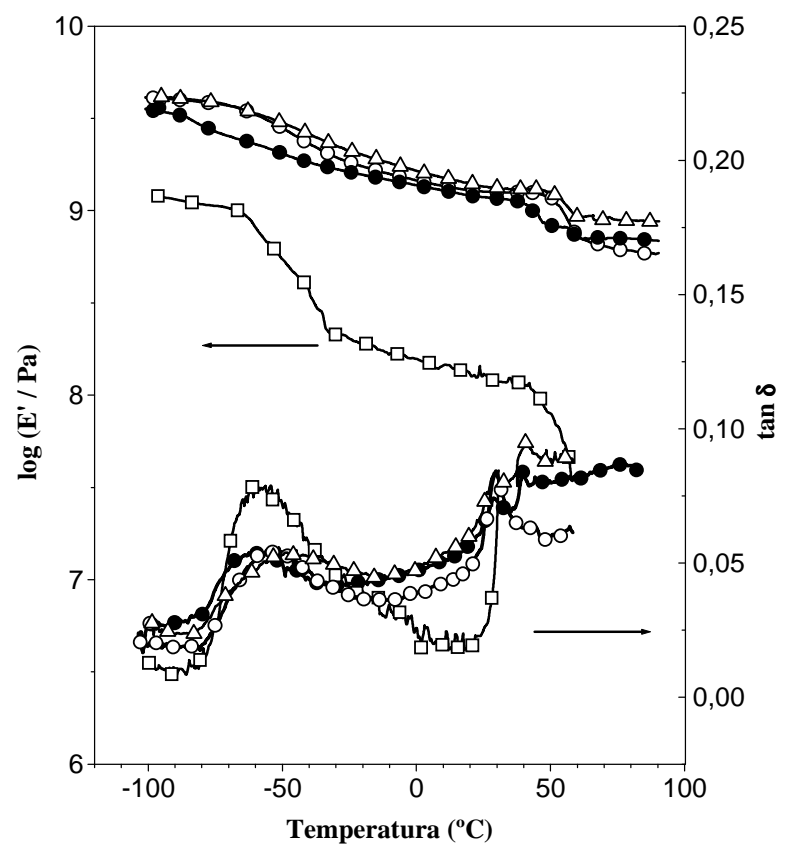

Figura 3.4. Dependencia del módulo elástico y la tangente de pérdida con la temperatura para las mezclas con un $20 \%$ de $\mathrm{CHT}(\mathbf{0}), 30 \%$ de $\mathrm{CHT}(\bullet)$ y un $40 \%$ de CHT $(\Delta)$. La medida correspondiente a una PCL de $48 \mathrm{kDa}(\square)$ ha sido representada para comparar.

Como se observa en la figura 3.4 a bajas temperaturas, el módulo de almacenamiento en todas las mezclas se encuentra alrededor de $10^{9.5} \mathrm{~Pa}$, un valor característico de polímeros semicristalinos en el estado vítreo. Luego se observa una caída del módulo entre -70 y $30^{\circ} \mathrm{C}$, la cual coincide con la relajación principal, asociada a la transición vítrea de la PCL y una segunda caída del módulo como consecuencia del proceso de fusión de los cristales de la PCL. Un detalle curioso, es que las muestras que contienen a partir de un $20 \%$ de CHT mantienen su integridad incluso por encima de la temperatura de fusión del la PCL. En cierta medida los resultados obtenidos se relacionan con 
la morfología de las mezclas ya que las muestras con un $20 \%$ de CHT presentan una estructura co-continua y las que contienen una mayor cantidad de quitosano, los agregados dispersos de la PCL modifican poco las propiedades de la matriz rígida de quitosano, la cual es la responsable de que una vez superada la temperatura de fusión de la PCL las muestras mantengan su módulo.

No es posible comparar los procesos de relajación de la fase de PCL en las mezclas con los de la PCL pura ya que su bajo peso molecular hace que se parezca más a una cera, apenas consistente mecánicamente. No obstante, en la figura 3.4 se ha incluido la medida dinámico-mecánica de una PCL de peso molecular $48 \mathrm{kDa}$. Como se puede observar no existen cambios en la achura del pico correspondiente a la relajación principal de la PCL a medida que aumenta el contenido de quitosano en las mezclas. Por otra parte, la caída del módulo que tiene lugar sobre los $50^{\circ} \mathrm{C}$ se corresponde con la fusión de los cristales de PCL. Resulta interesante remarcar que en las mezclas después de que la PCL se encuentra fundida el valor del módulo elástico se mantiene alto alrededor de $10^{9} \mathrm{~Pa}$, lo cual corrobora la continuidad de la fase de quitosano. El comportamiento de las mezclas con un 30 y un $40 \%$ de CHT es muy similar entre sí a excepción de un pequeño cambio en el valor del módulo elástico y en la forma del pico de la tangente de pérdida en la zona de la relajación principal.

La influencia del quitosano en el proceso de cristalización de la PCL en las mezclas fue analizada mediante calorimetría diferencial de barrido, para ello se realizaron experimentos de cristalización isoterma a diferentes temperaturas y barridos de enfriamiento a diferentes velocidades de enfriamiento.

En los experimentos de cristalización isoterma, el proceso de cristalización de la PCL en las mezclas se midió en el intervalo de temperaturas 
comprendido entre 34 y $46^{\circ} \mathrm{C}$ cada $2^{\circ} \mathrm{C}$ partiendo desde $70^{\circ} \mathrm{C}$, temperatura en la que toda la PCL presente en las mezclas se encuentra fundida, y enfriando a $40^{\circ} \mathrm{C} / \mathrm{min}$ hasta la temperatura de cristalización determinada. Cuando la temperatura de cristalización es inferior a $34^{\circ} \mathrm{C}$ una gran parte de la $\mathrm{PCL}$ cristaliza durante el enfriamiento. En la figura 3.5 se muestran las isotermas de cristalización de la PCL en cada una de las mezclas y de la PCL pura a la temperatura de $40^{\circ} \mathrm{C}$ respectivamente.

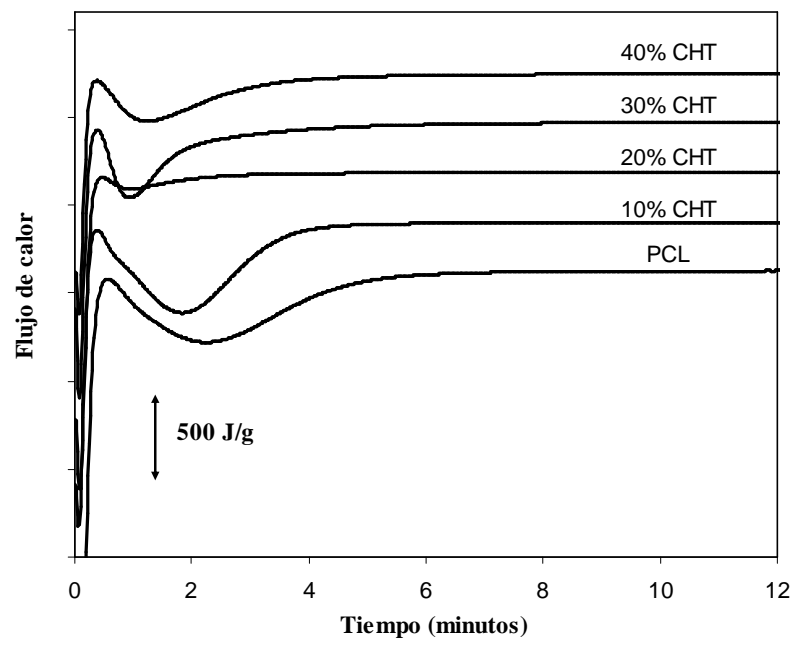

Figura 3.5. Isotermas de cristalización de la PCL pura y en las mezclas con diferentes contenidos de quitosano.

Como se puede observar en la figura 3.5 el comportamiento de las isotermas de cristalización de la $\mathrm{PCL}$ en las mezclas a $40^{\circ} \mathrm{C}$ varía en dependencia del contenido de quitosano. A medida que aumenta la cantidad de quitosano, el pico de cristalización de la PCL se desplaza hacia tiempos más cortos, si lo comparamos con la PCL pura y la entalpía de cristalización 
disminuye significativamente en las mezclas que contienen a partir de un $20 \%$ de quitosano.

La fracción cristalina calculada a partir del área bajo la curva de cristalización isoterma, referida a la masa de PCL en la mezcla con respecto a la entalpía de fusión de un cristal de PCL pura [196] se representa en la figura 3.6.

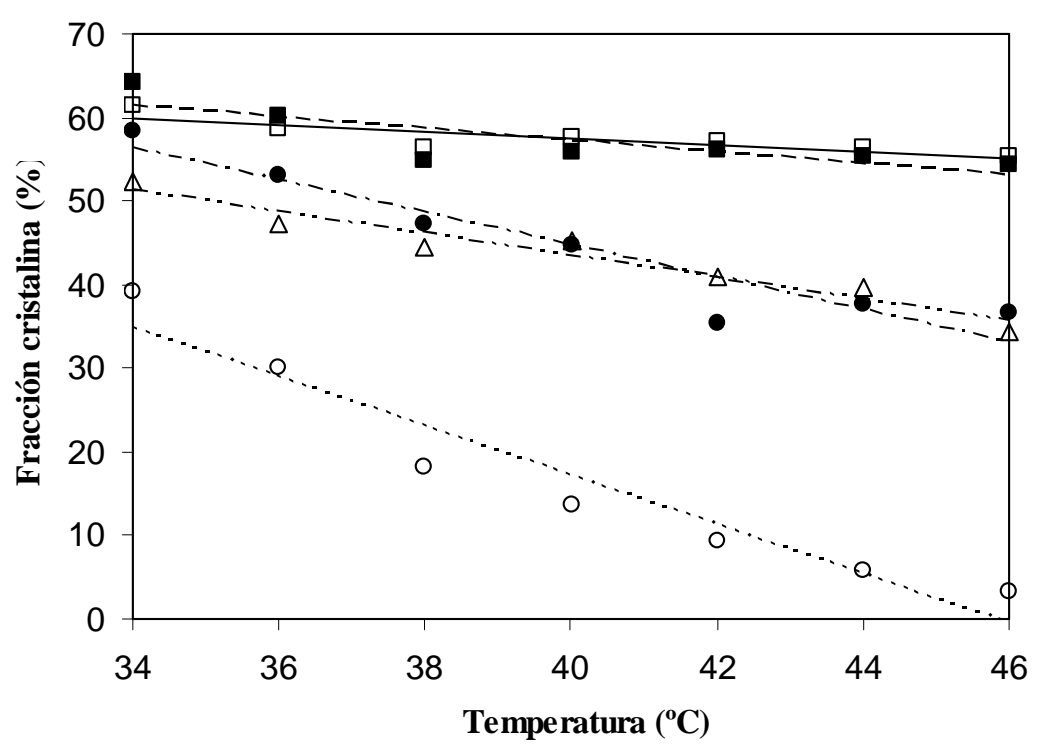

Figura 3.6. Fracción cristalina de la PCL en cada una de las mezclas en función de la temperatura de cristalización. PCL pura (), $10 \%$ de CHT (घ), $20 \%$ de CHT (०), $30 \%$ de $\operatorname{CHT}(\bullet)$ y $40 \%$ de $\operatorname{CHT}(\Delta)$.

Como se puede apreciar la cristalinidad de la PCL en la mezcla que contiene un $20 \%$ de CHT es muy pequeña con respecto a la de la PCL pura y a la obtenida en otras mezclas. El peculiar comportamiento de cristalización de la PCL en esta mezcla hay que atribuirlo a la morfología de la mezcla en la que la co-continuidad de las fases de PCL y CHT produce una mezcla muy íntima de los dos componentes y consecuentemente pequeños espacios para el 
crecimiento de los cristales de PCL. Es de destacar que la fracción cristalina de la PCL en esta mezcla varía de forma más marcada con la temperatura que en otras mezclas.

El tiempo necesario para alcanzar la mitad de la cristalinidad total en el experimento isotérmico, $\mathrm{t}_{1 / 2}$, es representado en la figura 3.7 con respecto a la temperatura de cristalización.

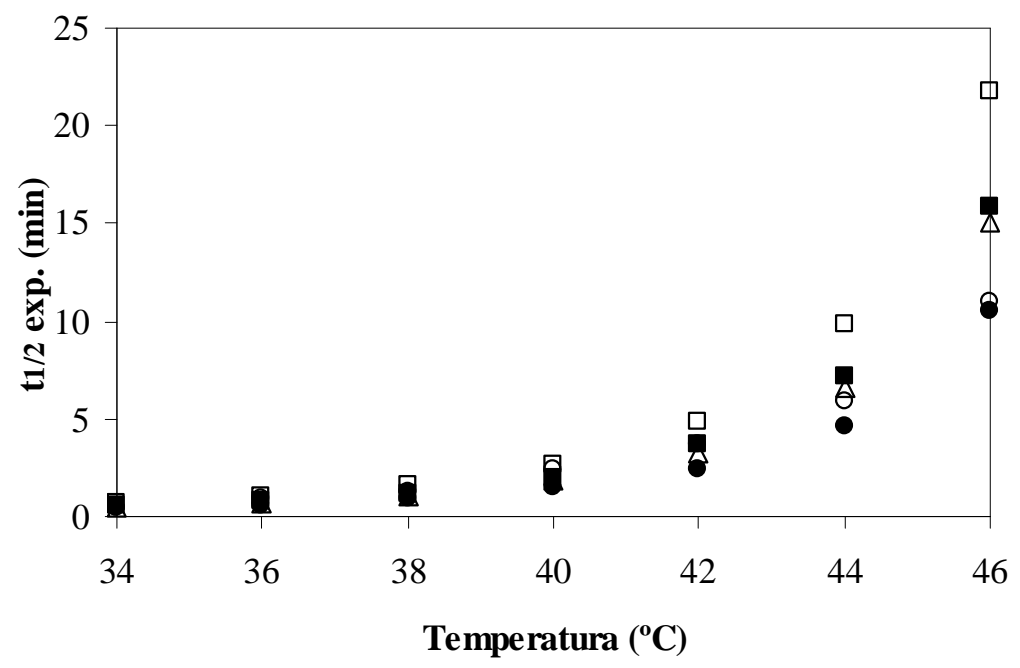

Figura 3.7. Variación de $t_{1 / 2}$ en función de la temperatura de cristalización. PCL pura (口), $10 \%$ de $\operatorname{CHT}(\bullet), 20 \%$ de $\operatorname{CHT}(\circ), 30 \%$ de $\operatorname{CHT}(\bullet)$ y $40 \%$ de $\operatorname{CHT}(\Delta)$.

Como se muestra en la figura 3.7 el valor de $t_{1 / 2}$ es siempre más pequeño en la mezcla con un 30\% de CHT que en el resto de las mezclas preparadas, lo cual es indicativo de que el proceso de cristalización de la PCL es mucho más rápido.

En la figura 3.8 se representan los termogramas de calentamiento medidos para cada una de las mezclas y para la PCL pura después del proceso de cristalización a $40^{\circ} \mathrm{C}$. 


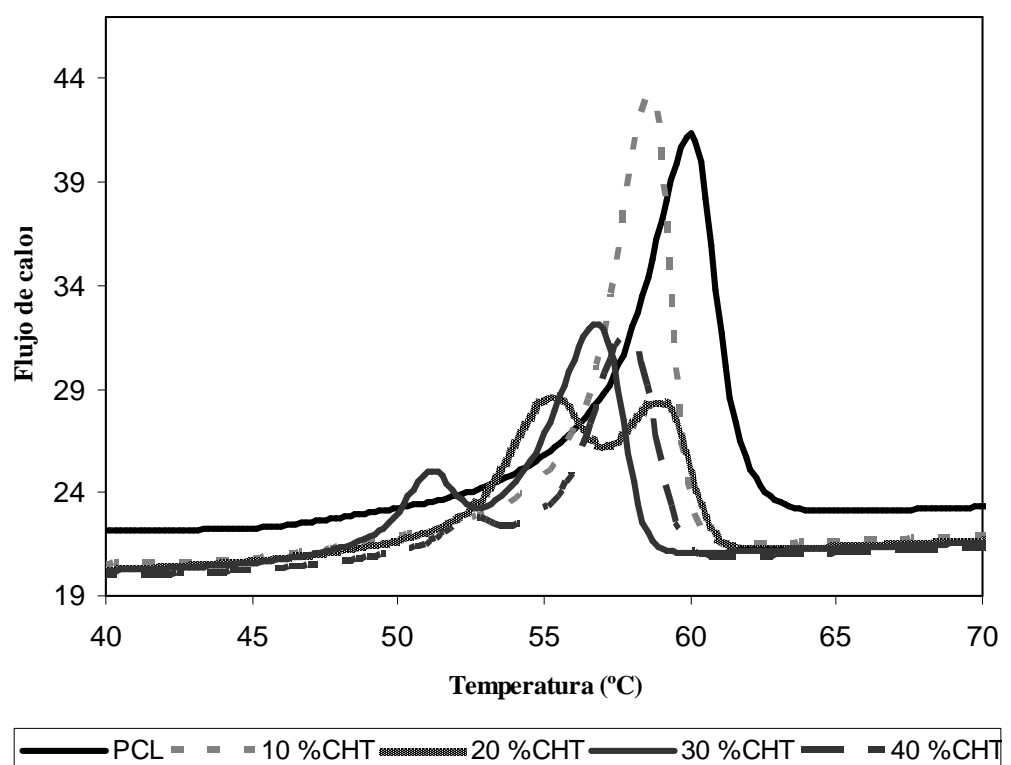
PCL pura.

Figura 3.8. Termogramas de calentamiento de cada una de las mezclas y de la

Como se observa en la figura 3.8 los cristales de PCL en la mezcla con un $10 \%$ de CHT funden a más baja temperatura si lo comparamos con el pico de fusión de la PCL pura, lo cual nos sugiere que el tamaño de cristalita es más pequeño. En el proceso de fusión de la PCL en las mezclas con un mayor contenido de CHT se observa la aparicion de dos picos lo cual puede ser debido a que existan cristales de diferentes tamaños y en cualquier caso, estos son más pequeños que en la muestra de PCL pura y otra posibilidad es que una vez fundido los cristales más pequeños, estos vuelvan a cristalizar debido a que están por debajo de la temperatura de fusión de la PCL y entonces se puede producir una superposición de picos de cristalización y fusión. 
Posteriormente se caracterizó la influencia del CHT en la cinética de cristalización de la PCL en las mezclas sobre la base de la teoría general de Avrami [197] según la siguiente ecuación:

$$
1-\frac{v_{c}}{v_{\infty}}=\exp \left(-K(T) t^{n}\right)
$$

donde $v_{c}$ representa la fracción en volumen del cristal, $v_{\infty}$ es la fracción en volumen del cristal a tiempo infinito, $t$ es el tiempo, $n$ es el exponente de Avrami que depende de mecanismos de nucleación y crecimiento del cristal y $K$ es un parámetro que depende de la temperatura según la ecuación de Lauritzen y Hoffman [198]:

$$
K(T)=A \exp \left(\frac{-B}{\left(T-T_{\infty}\right)}\right) \exp \left(\frac{-C}{T\left(T_{m}-T\right)}\right)
$$

donde $T_{\infty}$ es la temperatura a la cual cesan los movimientos conformacionales, usualmente se estima un valor aproximado que suele ser $50^{\circ} \mathrm{C}$ por debajo de la temperatura de transición vítrea, $T_{m}$ es la temperatura de fusión en equilibrio y A, B y C son constantes.

El flujo de calor por unidad de masa de muestra en los ajustes de las medidas realizadas en los experimentos de cristalización isotérmica fue calculado como $\frac{d q}{d t}(t)=\Delta h^{0} \frac{d w_{c}}{d t}$, en la que $w_{c}$ es la fracción másica de cristal que se calcula a partir de la cristalinidad $\mathrm{v}_{\mathrm{c}}$ (ecuación (1)) haciendo uso de las 
densidades de las fases cristalinas y amorfas de la PCL $\left(\rho_{\mathrm{c}}\right.$ y $\left.\rho_{\mathrm{a}}\right)$, según la siguiente ecuación: $w_{c}=\frac{\rho_{c} v_{c}}{\rho_{a}+\left(\rho_{c}-\rho_{a}\right) \nu_{c}}$

Para determinar el valor del exponente de Avrami, $n$ y el valor de $K(T)$ se utilizó una rutina de ajustes por mínimos cuadrados no lineal. Según los resultados obtenidos hemos encontrado una pequeña dependencia, no sistemática del valor de $\mathrm{n}$ con la temperatura debido a la correlación existente entre los dos parámetros en la ecuación. En los ajustes hemos asumido un valor promedio para el exponente de avrami y hemos utilizado como parámetro variable el valor de $K$.

En la figura 3.9 se muestran las isotermas de cristalización medidas para la PCL pura a diferentes temperaturas y para cada una de las mezclas a $34^{\circ} \mathrm{C}$.

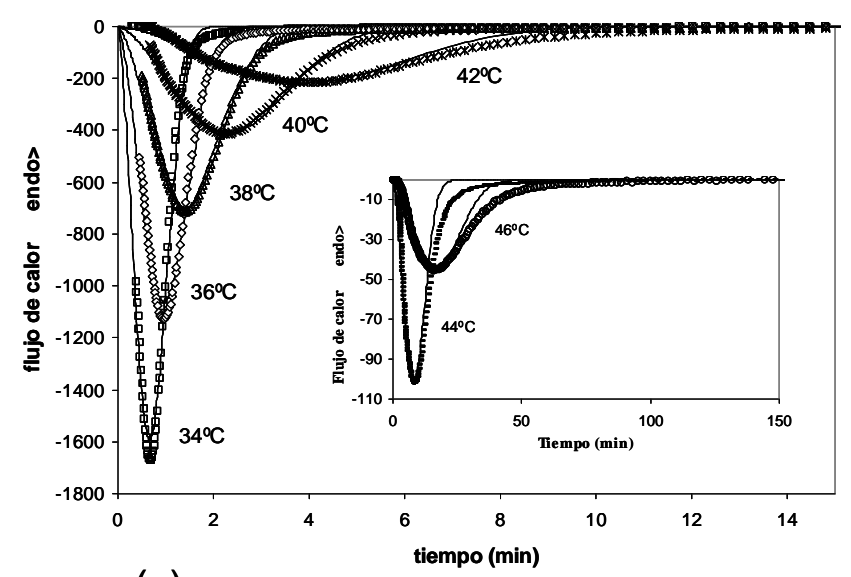

(a) 


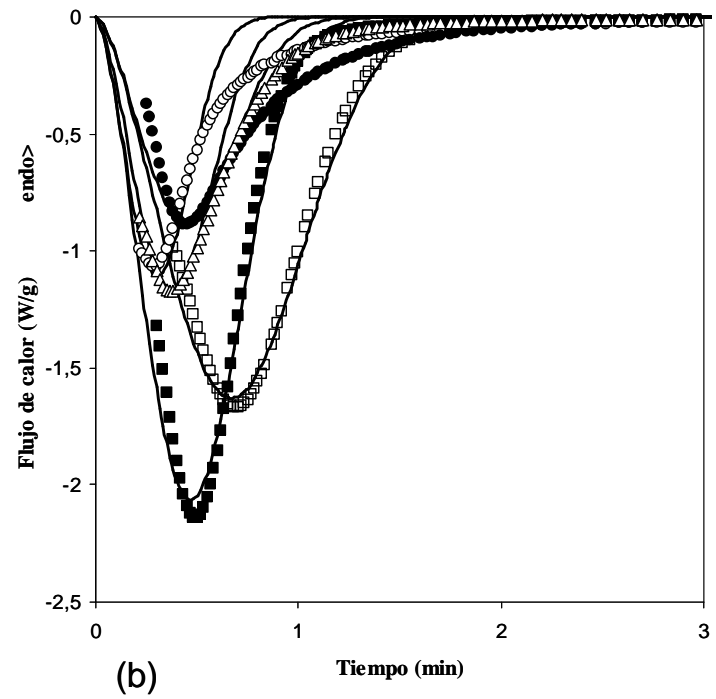

Figura 3.9. Isotermas de cristalización de la PCL a diferentes temperaturas (a) e isotermas obtenidas a $34^{\circ} \mathrm{C}$ para las mezclas de PCL/CHT con $10 \% \mathrm{de} \mathrm{CHT}(\mathbf{\square}), 20 \%$ de $\operatorname{CHT}(\circ), 30 \%$ de $\operatorname{CHT}(\bullet), 40 \%$ de $\operatorname{CHT}(\Delta)$ y para la PCL pura $(\square)(b)$. La línea sólida en (a y b) representa las curvas calculadas según la teoría de Avrami.

Como se puede apreciar en la figura 3.9a el ajuste del modelo para la PCL pura es bastante aceptable en el intervalo de temperatura entre 34 y $42^{\circ} \mathrm{C}$, mientras que en las isotermas medidas a altas temperaturas $\left(44 \mathrm{y}_{4}^{\circ} \mathrm{C}\right)$ se observan desviaciones significativas justo en la cola a tiempos muy altos, por lo que resulta difícil el poder reproducir los resultados experimentales con el modelo.

El modelo ajusta igualmente bien para la mezcla que contiene un $10 \%$ de CHT (figura 3.9b), utilizando el mismo exponente de avrami obtenido para la PCL pura $(n=2.5)$, aunque con un ligero incremento $(n=3)$, el ajuste es también bueno, pero teniendo en cuenta que en la ecuación de Avrami la constante cinética $K(T)$ depende en gran medida del valor de $n$, hemos preferido 
mantenerlo constante para que el análisis de la dependencia de $\mathrm{K}(\mathrm{T})$ con el incremento de CHT en las mezclas sea más consistente.

Las isotermas medidas en las mezclas que contienen un 20\% de CHT son muy diferentes a las de la PCL pura y a las isotermas obtenidas para las mezclas que contienen 30 y $40 \%$ de CHT tal y como se muestra en la figura 3.9b donde se observa además que los ajustes del modelo son muy pobres y sólo una pequeña parte de la curva (alrededor del punto máximo del pico de cristalización) puede ser reproducida por el modelo. El pico de cristalización experimental es mucho más ancho que el que reproduce el modelo y para tiempos muy largos la curva calculada se aparta completamente de la experimental.

En el caso de las mezclas con un 30 y un $40 \%$ de CHT los picos de cristalización no son tan anchos como en la mezcla con un 20 \% de CHT, pero para tiempos muy largos el ajuste del modelo de Avrami presenta desviaciones. Estas desviaciones pueden explicarse teniendo en cuenta que la teoría de Avrami predice un crecimiento de cristales a partir de un número fijo de núcleos fijos de ristalización y a una velocidad constante lo cual no coincide con los procesos naturales de cristalización, los cuales son mas complejos y durante el crecimiento de los cristales estos chocan entre sí, además se van creando nuevos núcleos de cristalización durante el proceso.

Como ya dijimos antes, la ventana de temperaturas experimentales (34$46^{\circ} \mathrm{C}$ ) utilizadas no es posible extenderla hasta más bajas temperaturas debido a que tiene lugar el proceso de cristalización de la PCL durante el enfriamiento antes de llegar a la temperatura de cristalización elegida. Consecuentemente, el valor de $K(T)$ medido en el rango de temperaturas experimentales disminuye con el incremento de la temperatura (Figura 3.10), lo cual corresponde con que la velocidad del proceso de cristalización isoterma disminuye con el incremento 
de la temperatura de cristalización. En los experimentos analizados sólo es posible representar la parte de la campana que corresponde con las altas temperaturas según la predicción a partir de la ecuación (2). Para el caso de la PCL pura el valor del exponente de Avrami obtenido es de 2.5.

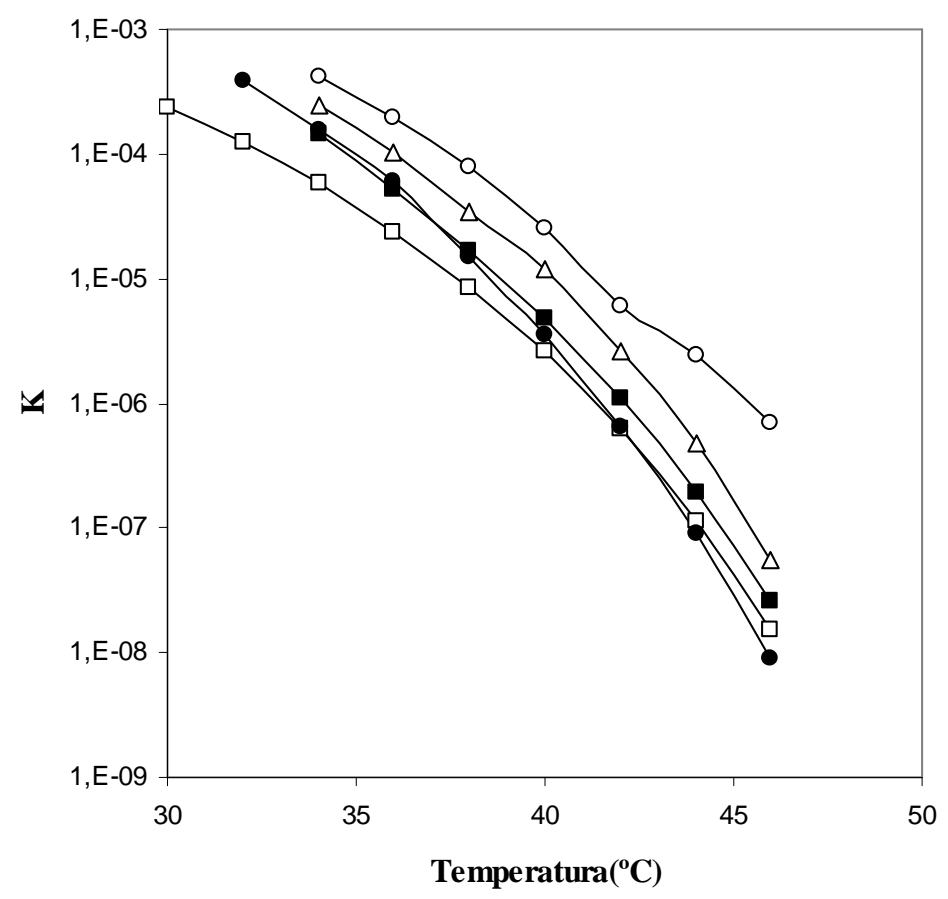

Figura 3.10. Curvas de $\mathrm{K}(\mathrm{T})$ en función de la temperatura para la PCL pura ( $\square$ ) y las mezclas que contienen $10 \%$ de $\operatorname{CHT}(\bullet), 20 \%$ de $\operatorname{CHT}(0), 30 \%$ de $\operatorname{CHT}(\bullet)$ y 40 $\%$ de $\operatorname{CHT}(\Delta)$.

Como se muestra en la figura 3.10 el valor de $K(T)$ obtenido para la mezcla que contiene un $10 \%$ de CHT es ligeramente mayor que el medido en la PCL pura, lo cual nos indica que el proceso de cristalización es más rápido. Todavía crece $\mathrm{K}(\mathrm{T})$ en la mezcla con el $20 \%$ de CHT y después disminuye para valores mayores del contenido de quitosano, pero manteniéndose por encima 
del calculado en la PCL. Este comportamiento es paralelo al que se puede observar en la Figura 3.9b respecto al desplazamiento del pico del flujo de calor exotérmico que acompaña a la cristalización.

En la mezcla con un $10 \%$ de CHT, el CHT tiene un efecto nucleante y acelera el proceso de cristalización isotermo de la PCL como se muestra directamente en la evolución de $t_{1 / 2}$. La nucleación tiene dos orígenes posibles, una nucleación heterogénea originada en la superficie de impurezas, en este caso en la superficie de las partículas de CHT y una nucleación tri-dimensional homogénea formada por las cadenas de la PCL. A altas temperaturas, domina la nucleación heterogénea y la presencia de CHT en las mezclas es más importante; sin embargo a medida que disminuye la temperatura de cristalización, el número de núcleos de cristalización de PCL aumenta y la diferencia entre la velocidad de cristalización entre la mezcla y el polímero puro es menor. La modificación de la velocidad de cristalización es también aparente en la evolución del factor K(T) en la ecuación de Avrami.

En la figura 3.11 se muestran los termogramas de enfriamiento de la PCL pura y las mezclas medidos a $10^{\circ} \mathrm{C} / \mathrm{min}$. A simple vista se puede deducir que el CHT influye notablemente en el proceso de cristalización de la PCL, por lo que nos hemos planteado realizar un estudio más exhaustivo de la cinética de cristalización no-isotérmica y determinar los parámetros que la caracterizan utilizando la teoría de Avrami. Para ello, el procedimiento utilizado para ajustar los termogramas resulta similar al propuesto en la referencia [199]. Los barridos de enfriamiento fueron simulados por una serie de escalones de temperatura de medio grado seguidos de etapas isotermas durante un tiempo determinado $\Delta t$ calculado de forma que la temperatura disminuya a una 
velocidad media como la que se ha fijado experimentalmente. Resulta, por lo tanto que $\Delta t=0.5 / \beta$ siendo $\beta$ la velocidad de enfriamiento.

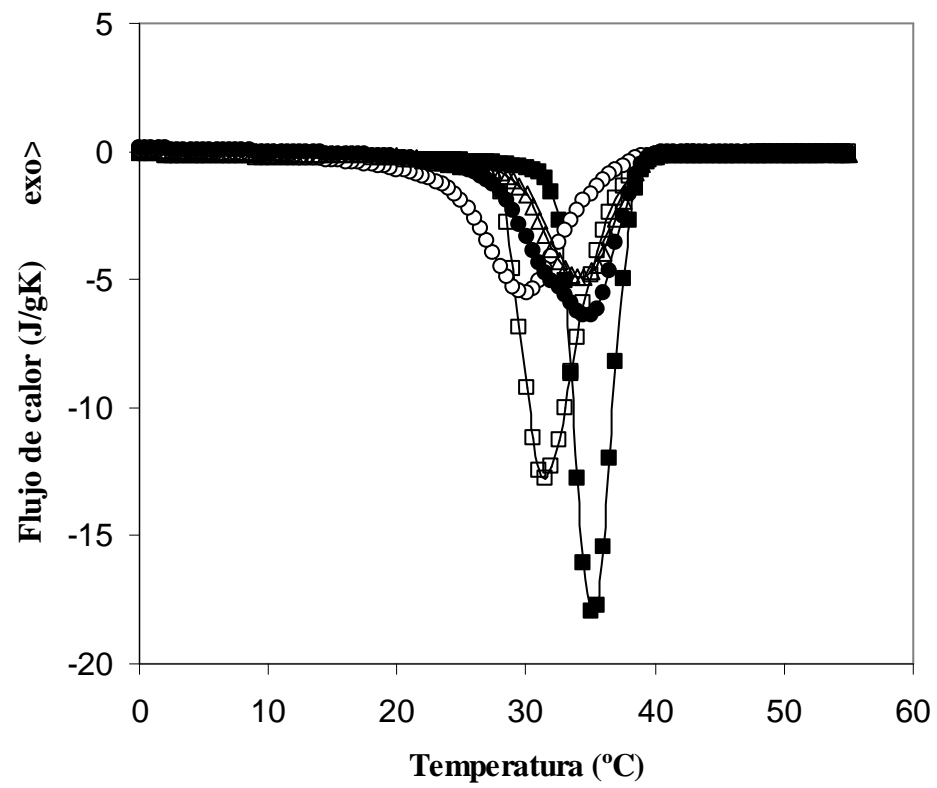

Figura 3.11. Termogramas de enfriamiento obtenidos a $10^{\circ} \mathrm{C} / \mathrm{min}$ de la PCL pura () y de las mezclas que contienen $10 \%$ de $\operatorname{CHT}(\bullet), 20 \%$ de CHT (०), $30 \%$ de $\operatorname{CHT}(\bullet)$ y $40 \%$ de $\operatorname{CHT}(\Delta)$.

Para aplicar la ecuación de Avrami (1) a la evolución de la fracción cristalina durante una de las etapas isotermas a $T_{i}$, comprendida entre dos saltos de temperatura, hay que tener en cuenta que el material tiene ya una fracción cristalizada cuando se inicia el proceso a $T_{i}$. La fracción cristalizada después del salto de temperatura de $T_{i-1}$ a $T_{i}$ se considera igual a la que el material tenía al final de la etapa isoterma a la temperatura $T_{i-1}$ y que llamamos $v_{v_{i-i} .}$. Sin embargo, la ecuación (1) se aplica a un proceso que se inicia con el material completamente amorfo. Para resolver este problema se calculó un 
tiempo ficticio $t_{f ; i}$ definido como el tiempo que tendría que haber transcurrido para que en un proceso de cristalización isotermo que se inicia con el material amorfo a la temperatura $T_{i}$ el material alcance la fracción cristalina $v_{c_{i-1}-\text {. }}$

$$
t_{f i c, i}=\left\{-\frac{1}{K\left(T_{i}\right)} \ln \left(1-\frac{v_{c, i-1}}{v_{\infty}}\right)\right\}^{1 / n}
$$

Y la fracción cristalina al final de la etapa isoterma a la temperatura $T_{i}$ se puede representar calculando con la ecuación (1) la fracción cristalina en el instante de tiempo $t_{f i c i}+\Delta t$. Por lo tanto,

$$
v_{c, i}=v_{\infty}\left[1-\exp \left(-K(T)\left(t_{f i c, i}+0.5 / \beta\right)^{n}\right)\right]
$$

El flujo de calor fue calculado identificando el calor total emitido por la muestra durante la etapa isoterma a la temperatura $T_{i}$ con el área debajo de la curva de flujo de calor normalizado entre $T_{i-1}$ y $T_{i}$ aproximada por un trapecio.

$$
\dot{q}_{N}\left(T_{i}\right)=\frac{2 \Delta v_{c} \rho \Delta h^{s l}}{T_{i-1}-T_{i}}-\dot{q}_{N}\left(T_{i-1}\right)
$$

donde $\Delta h^{l}$ es la entalpía de fusión (tomada como $139.5 \mathrm{~J} / \mathrm{g}$ de acuerdo con $[196])$ y $\rho$ es la densidad de la fase cristalina $\left(\rho=1.1175 \mathrm{~g} / \mathrm{cm}^{s}\right.$ según $\left.[200]\right)$ $\dot{q}_{N}=\dot{Q} / m \beta, \dot{Q}$ es el flujo de calor exotérmico, $m$ es la masa de la muestra y $\beta$ es la velocidad de enfriamiento.

Los termogramas medidos a 5 velocidades de enfriamiento diferentes $\left(40,20,10,5 \mathrm{y}^{\circ} \mathrm{C} / \mathrm{min}\right.$ ) (Figura 3.12$)$ fueron ajustados simultáneamente 
utilizando las ecuaciones (2), (4) y (5). Para ello, asumimos como el valor de $T_{\infty}$ , la temperatura correspondiente a $50^{\circ} \mathrm{C}$ por debajo de la temperatura de transición vítrea de la PCL, $\left(T_{\infty}=163 \mathrm{~K}\right)$, y la temperatura de fusión en el equilibrio como $T_{m}=339 \mathrm{~K}$.

Los resultados experimentales no contienen información suficiente acerca de la parte correspondiente a las mas bajas temperaturas de la curva de $K(T)$ por la misma razón que hemos explicado anteriormente en los ajustes isotermos. Esto significa que es posible obtener termogramas muy similares con diferentes valores de $\mathrm{B}$ diferentes combinaciones del resto de parámetros. Esta correlación entre los parámetros del modelo se salvó fijando el valor de B en los ajustes mínimo cuadráticos, se tomó $\mathrm{B}=1000 \mathrm{~K}$ para todas las muestras. Ello introduce una gran incertidumbre en los valores obtenidos de cada uno de los demás parámetros de ajuste: A y C en la ecuación (2) y el exponente de Avrami n. Sin embargo, las distintas combinaciones de A y C encontradas para diferentes valores de $\mathrm{B}$ determinan prácticamente la misma curva de $\mathrm{K}(\mathrm{T})$ mediante la ecuación (2) de forma que los resultados expresados en la forma de una curva de $\mathrm{K}(\mathrm{T})$ calculada mediante el ajuste de los termogramas de enfriamiento experimentales son precisos y permiten comparar las cinéticas de cristalización de las diferentes muestras. 

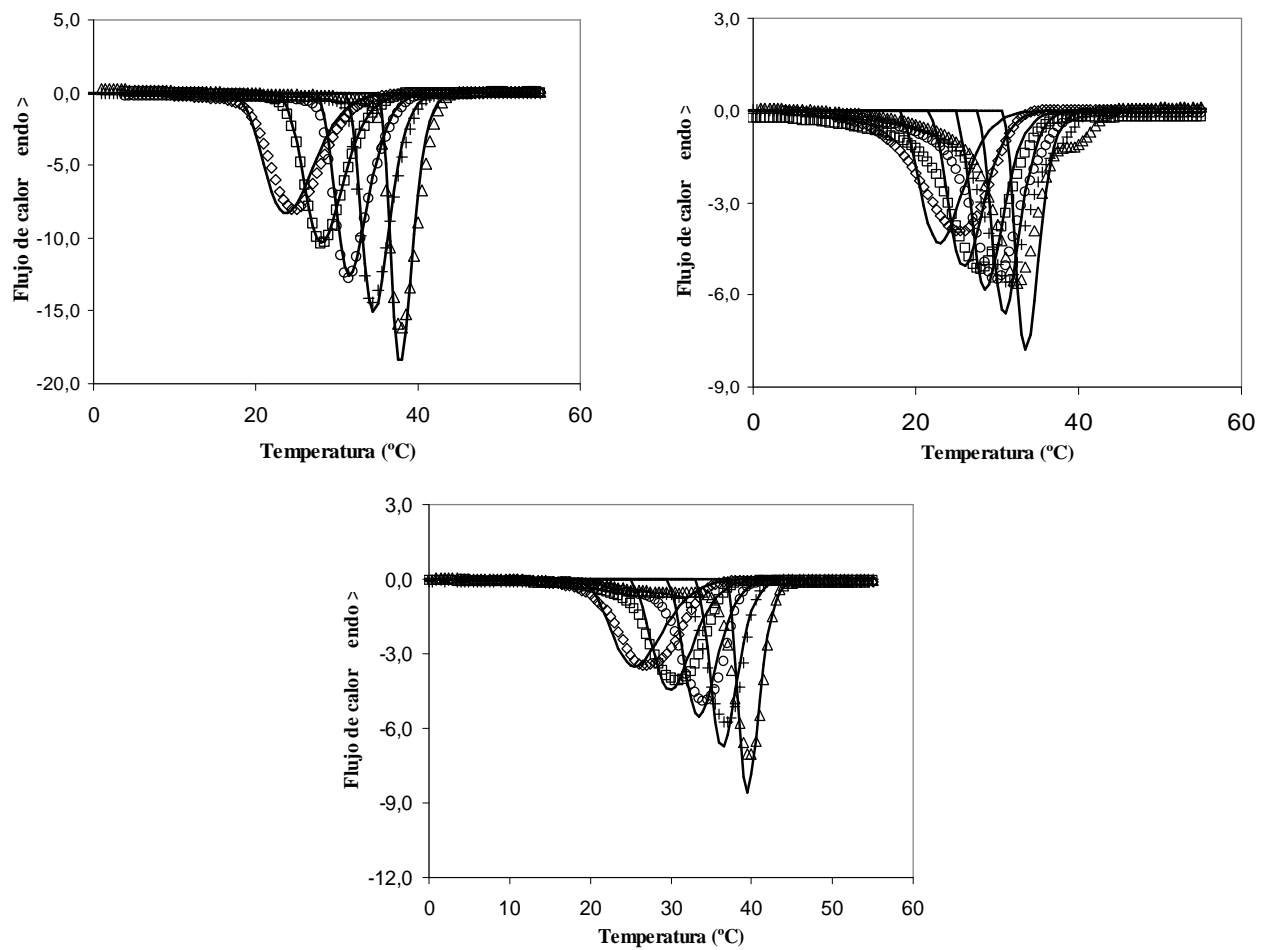

Figura 3.12. Termogramas de enfriamiento de la PCL pura (a) y las mezclas que contienen $20 \%$ de CHT (b) y $40 \%$ de CHT (c) medidos a diferentes velocidades de enfriamiento $(\Delta) 2^{\circ} \mathrm{C} / \mathrm{min},(+) 5^{\circ} \mathrm{C} / \mathrm{min},(\circ) 10^{\circ} \mathrm{C} / \mathrm{min},(\square) 20^{\circ} \mathrm{C} / \mathrm{min} \mathrm{y}(\diamond) 40^{\circ} \mathrm{C} / \mathrm{min}$.

En el caso de la PCL el ajuste es muy bueno (figura 3.12a). El valor del exponente de Avrami $(\mathrm{n}=2.5)$ es igual al encontrado en los experimentos isotérmicos. Los ajustes realizados en los termogramas de enfriamiento de la mezcla con un 10\% de CHT, con un exponente de Avrami de $n=2.5$, es muy similar al de la PCL pura y curiosamente un comportamiento análogo fue obtenido para las mezclas con un 30 o un $40 \%$ de CHT (figura 3.12c) aunque en la mezcla con un $30 \%$ el pico de cristalización es un poco más ancho que el que predice el modelo. 
La misma serie de parámetros reproduce los picos de cristalización medidos a diferentes velocidades de enfriamiento. No obstante, el comportamiento de la mezcla con un $20 \%$ de CHT es nuevamente peculiar, como se observa en la figura 3.12b el pico de cristalización es más ancho que el que predice el modelo y la dependencia de la temperatura máxima de la exoterma con la velocidad de enfriamiento es difícilmente reproducible.

La curva de $\mathrm{K}(\mathrm{T})$ con la temperatura en el experimento dinámico se representa en la figura 3.13. Las mezclas que contienen un 10 y un $20 \%$ de CHT presentan un valor de $\mathrm{K}(\mathrm{T})$ ligeramente menor que el obtenido para la PCL pura, aunque las curvas tienden a converger a bajas temperaturas.

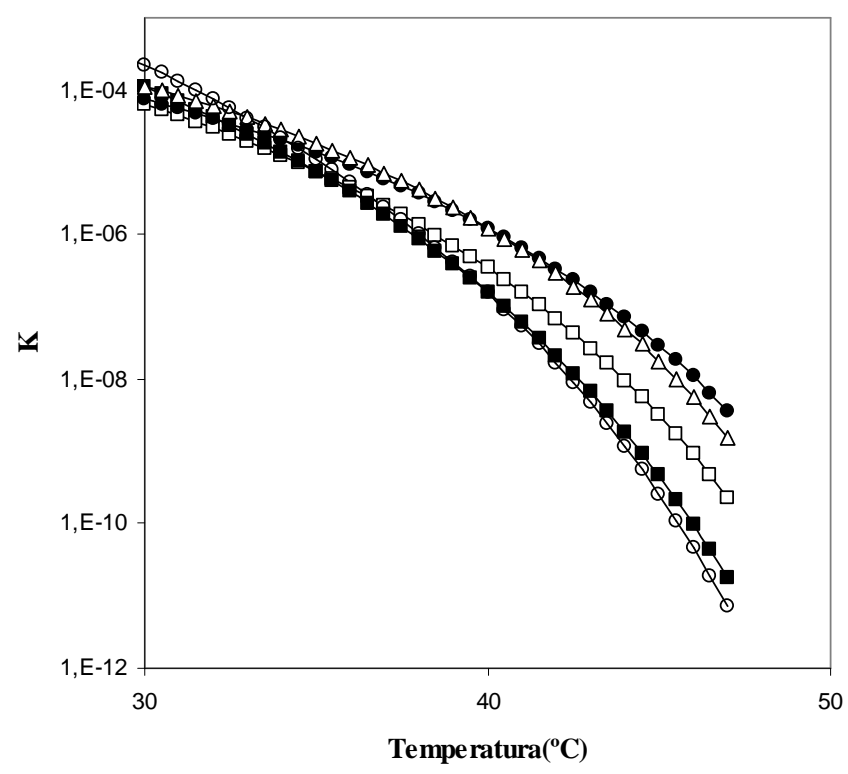

Figura 3.13. Curvas de $\mathrm{K}(\mathrm{T})$ en función de la temperatura para la PCL pura ( $\square$ ) y las mezclas que contienen $10 \%$ de $\operatorname{CHT}(\boldsymbol{\bullet}), 20 \% \operatorname{de} \operatorname{CHT}(\circ), 30 \% \operatorname{de~} \operatorname{CHT}(\bullet)$ y 40 $\%$ de $\operatorname{CHT}(\Delta)$. 
Una vez analizados los resultados individuadamente en cada uno de los experimentos, podemos decir que las partículas de quitosano en la mezcla con un $10 \%$ de CHT actúan como agente de nucleación en el proceso de cristalización de la PCL. Los resultados obtenidos por ambos métodos han sido descritos fehacientemente haciendo uso de la teoría de Avrami con un exponente igual a 2.5. El exponente de Avrami esta relacionado con la nucleación y los mecanismos de crecimiento de los cristales, un exponente igual a 3 es característico de una nucleación térmica con un crecimiento esférico, sin embargo un exponente igual a 2 viene asociado a un mecanismo de crecimiento bi-dimensional. Incluso, aunque en la teoría de Avrami no se considera un valor de exponente que no sea un número entero, el valor obtenido en este estudio se considera el más apropiado teniendo en cuenta que los cristales de PCL en las mezclas crecen rodeados de una fase de quitosano; Incluso si hubiéramos empleado un exponente igual a 3 para realizar los ajustes, hubiéramos mantenido el valor de 2.5, debido a que la comparación para $\mathrm{K}(\mathrm{T})$ se puede realizar de una manera más adecuada.

\subsection{Morfología, propiedades y evaluación biológica de mezclas poliméricas biodegradables de policaprolactona de alto peso molecular y quitosano}

La formación de mezclas poliméricas entre la PCL y los polímeros hidrófilos, en este caso el quitosano, nos permiten modular la capacidad de absorción de agua controlando la fracción de quitosano en las muestras. Las mezclas de policaprolactona y quitosano utilizadas en los estudios biológicos fueron preparadas siguiendo el mismo procedimiento descrito en el apartado anterior, pero esta vez utilizamos una PCL de alto peso molecular $(48 \mathrm{kDa})$. 
La morfología de las mezclas de PCL y CHT, donde coexisten las dos fases, así como la de sus componentes puros fue examinada mediante SEM (Figura 3.14). La mezcla con un $10 \%$ de CHT (figura 3.14B) mantiene la morfología típica de esferulitas como en la PCL pura (figura 3.14A). Sin embargo, en las mezclas con un $20 \%$ de CHT (figura 3.14C) la morfología es diferente, no es posible distinguir las esferulitas y en las que contienen un $30 \%$ de CHT (Figura 3.14D) la superficie es más irregular y está compuesta por pequeños agregados adheridos entre sí.

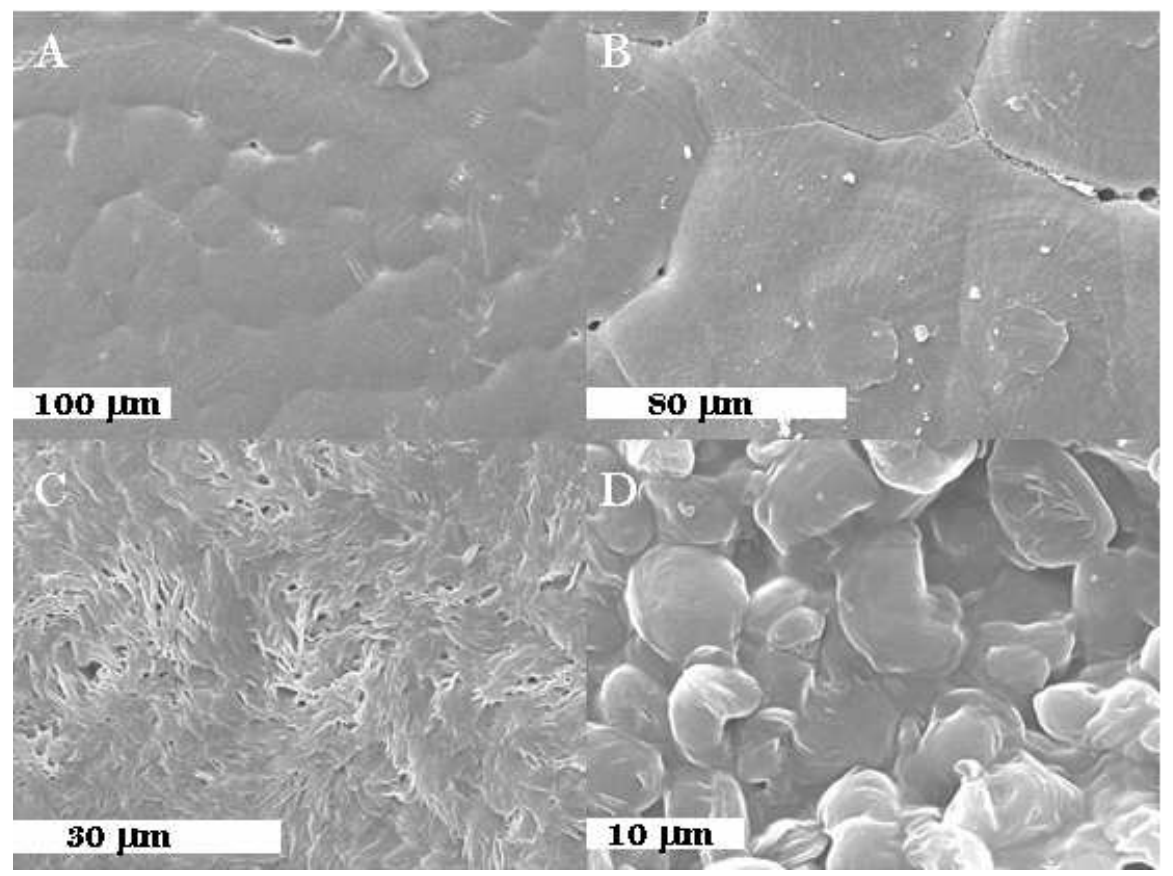

Figura 3.14. Microfotografías de SEM de las mezclas de PCL/CHT. (A) PCL pura, (B, C y D) corresponden a las mezclas con 10, 20 y $30 \%$ de CHT.

Para analizar más en detalles tanto la morfología como la topografía de las mezclas se utilizó la técnica de microscopía de fuerza atómica (AFM). En la figura 3.15 se muestran las imágenes de la fase obtenida a diferentes 
ampliaciones en el modo "tapping". En las mezclas con un $10 \%$ de CHT la fase de quitosano está bien distribuida en la matriz de PCL en forma de dominios nanométricos intra e inter-esferulíticos (figura 3.15A). A medida que aumenta el contenido de CHT en las mezclas los nano-agregados de CHT tienden a colapsarse y forman una fase co-continua. En las muestras con un $20 \%$ de

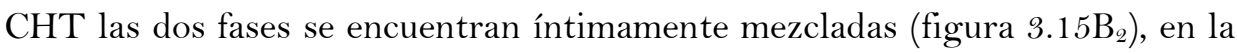
imagen de la figura $3.15 \mathrm{~B}_{1}$ se logra distinguir la fase de la PCL compuesta por laminillas ordenadas de las esferulitas y una fase continua de nano-agregados de quitosano. En las mezclas que contienen un $30 \%$ de CHT no se distingue ninguna esferulita aislada (Figura $3.15 \mathrm{C}_{1}$ ).y los nano-agregados de CHT se localizan entre las esferulitas de la PCL. 

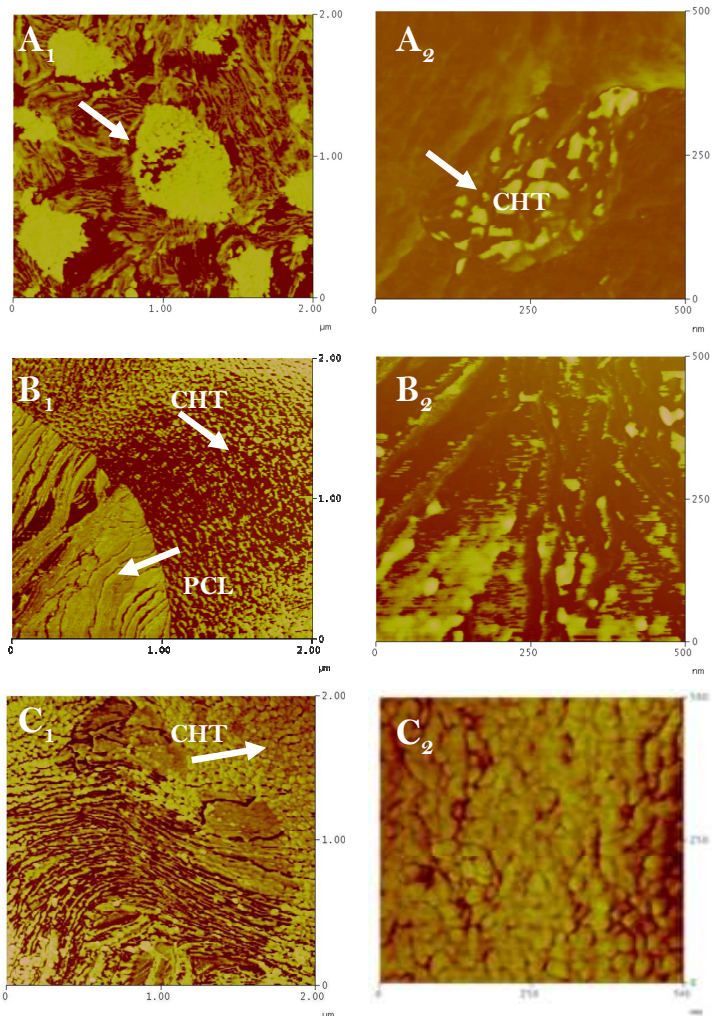

Figura 3.15 Imágenes de AFM en fase de las mezclas de PCL/CHT. (A) mezcla con un $10 \%$ de CHT, (B) con un $20 \%$ de CHT y (C) con un $30 \%$ de CHT. El área escaneada es de 2 × $2 \mu \mathrm{m}(1)$ y 500 x $500 \mathrm{~nm}(2)$. La escala de $100^{\circ}$ es la misma para todas las imágenes.

Como técnica complementaria y aprovechando las características fluorescentes del quitosano (emite fluorescencia de color verde) utilizamos la microscopía confocal de barrido para visualizar la distribución de cada una de las fases en la mezcla. En la figura 3.16 se representan las imágenes obtenidas tanto para las mezclas como para los polímeros puros. En la imagen de la PCL, que se muestra como control, no se observa ninguna señal fluorescente, mientras que el quitosano puro se ilumina en todas su superficie. 


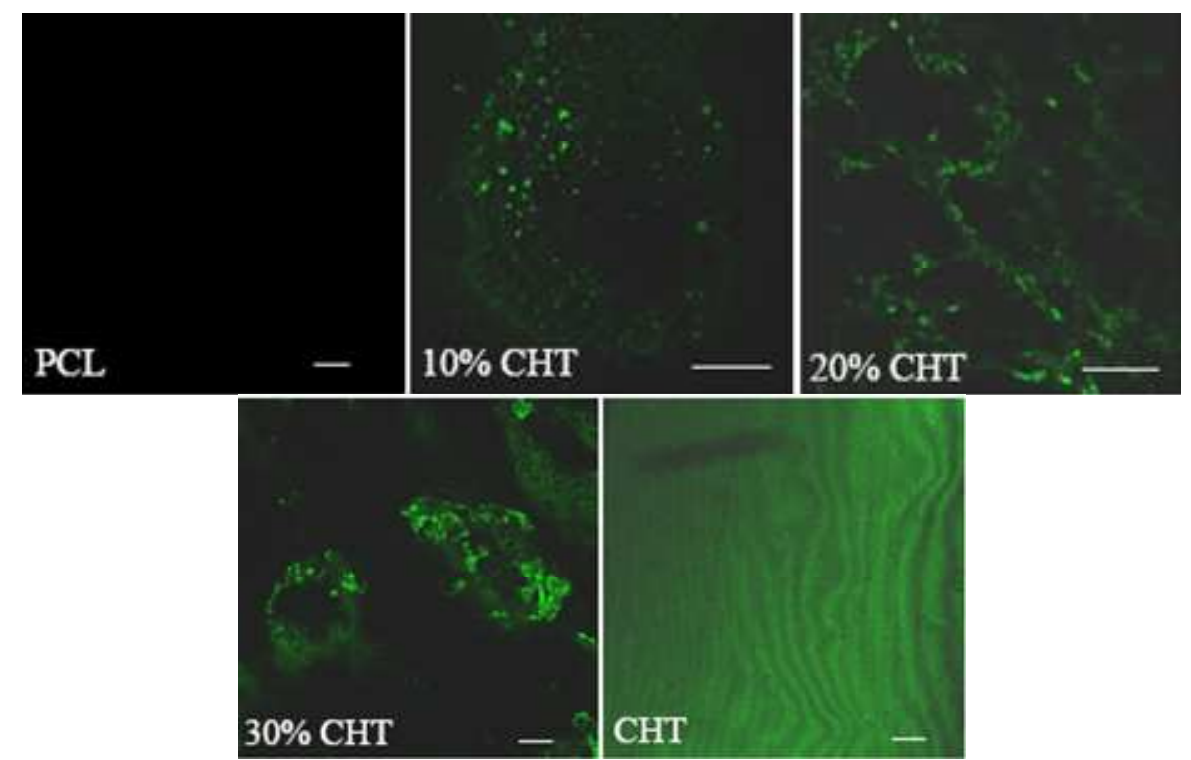

Figura 3.16. Imágenes de CLSM de las mezclas y los polímeros puros. El área de color verde corresponde a la fase de quitosano en las mezclas. Las dimensiones de la barra corresponden a $20 \mu \mathrm{m}$.

Como se aprecia en la figura 3.16 las imágenes de CLSM revelan resultados muy similares a los obtenidos por SEM y AFM. En la muestra con un $10 \%$ de CHT se observan puntos verdes aislados, sin embargo en las mezclas con un $20 \%$ de CHT se puede apreciar la presencia de manchas verdes que tienden a formar una red continua y en las mezclas con un $30 \%$ de CHT aparecen grandes agregados de CHT.

Con el objetivo de evaluar la influencia del quitosano, como componente hidrófilo, sobre la capacidad de absorción de agua de las mezclas se realizaron estudios de hinchamiento en fluido biológico simulado a $37^{\circ} \mathrm{C}$ siguiendo el procedimiento descrito en la parte experimental. Como era de esperar, el incremento del contenido de CHT en las mezclas se traduce en un aumento de la absorción de agua desde un 0.3 en las muestras de PCL hasta un 1.2 en las 
mezclas con un $30 \%$ de CHT. También hemos determinado la absorción de agua por gramo de quitosano y hemos obtenido un valor de 1.9 que es aproximadamente constante independientemente de la composición de la mezcla. En la tabla 3.1 se resumen los valores del grado de hinchamiento en el equilibrio, conjuntamente con los valores de energía superficial obtenidos para cada mezcla.

La energía superficial de las mezclas fue calculada a partir de las medidas del ángulo de contacto a través del Método de Owens and Wendt como se ha descrito en la parte eperimental. Los resultados obtenidos demuestran que existe una dependencia no-monótona de la energía superficial con la cantidad de CHT en las mezclas. La mezcla que contiene un 20\% de CHT presenta un valor máximo (Tabla 3.1).

Tabla 3.1. Valores obtenidos del grado de hinchamiento y la energía superficial de las mezclas con diferentes composiciones y sus polímeros puros.

\begin{tabular}{|c|c|c|}
\hline Mezclas & $\begin{array}{c}\text { Grado de hinchamiento } \\
\text { (g de agua/g de polímero) }\end{array}$ & $\begin{array}{c}\text { Energía Superficial } \\
(\mathrm{mN} / \mathrm{m})\end{array}$ \\
\hline PCL & $0.34 \pm 0.03$ & $37.8 \pm 0.8$ \\
\hline $10 \%$ CHT & $0.55 \pm 0.02$ & $40.8 \pm 0.8$ \\
\hline $20 \%$ CHT & $0.82 \pm 0.02$ & $43.4 \pm 0.9$ \\
\hline $30 \%$ CHT & $1.14 \pm 0.02$ & $38.2 \pm 0.7$ \\
\hline CHT & $1.90 \pm 0.01$ & $34.9 \pm 0.7$ \\
\hline
\end{tabular}

La relación monótona entre la capacidad de absorción de agua y la cantidad de CHT en las mezclas no se corresponde con la energía superficial de las muestras. Los valores de la energía superficial muestran un máximo para 
las mezclas que contienen un $20 \%$ de $\mathrm{CHT}$ y disminuye tanto para las mezclas con mayores como con menores contenidos de CHT. Este comportamiento es un buen ejemplo en el cual la hidrofilicidad, que es la afinidad de los sistemas hacia la absorción de agua y la energía superficial (medida por el ángulo de contacto) no pueden ser usadas para explicar la misma magnitud física y no siempre esta relacionada una con la otra como aparece ampliamente argumentado en la literatura [201]. Este comportamiento puede ser debido a la distribución de los dominios hidrófilos e hidrófobos en los diferentes sustratos.

Las propiedades mecánicas de las mezclas han sido evaluadas mediante ensayos dinámico-mecánicos. En la figura 3.17 se muestra el módulo de almacenamiento y la tangente de pérdida en función de la temperatura.

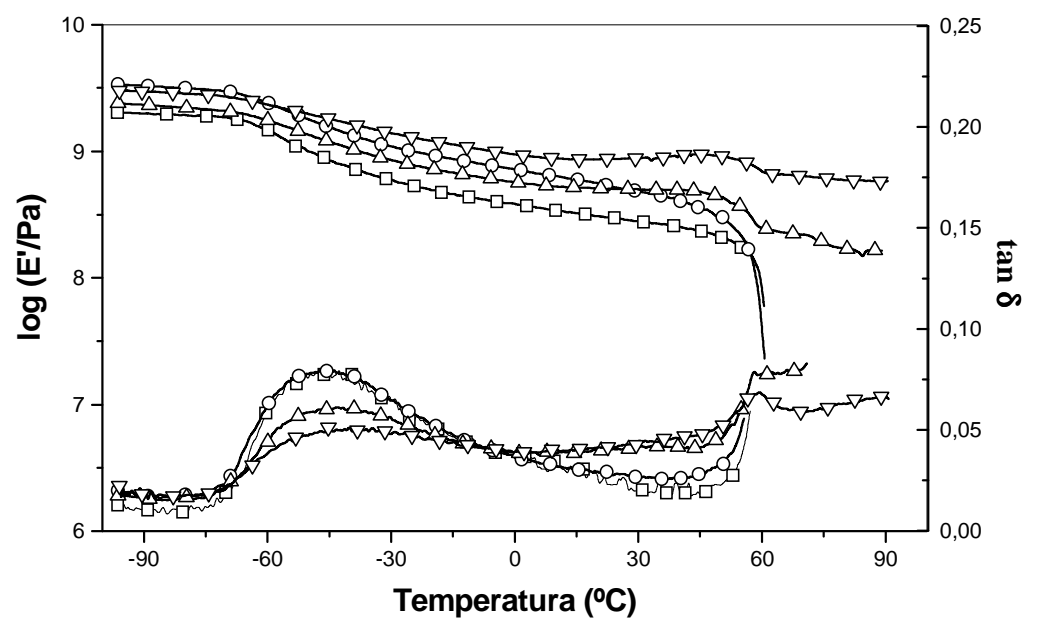

Figura 3.17. Dependencia del módulo elástico y la tangente de pérdida con la temperatura, medida a la frecuencia de $1 \mathrm{~Hz}$ en las mezclas de PCL y CHT. PCL pura $(\square), 10 \%$ de $\operatorname{CHT}(\circ), 20 \%(\Delta)$ y $30 \%$ de $\operatorname{CHT}(\nabla)$. 
Como se puede apreciar en la figura 3.17 la relajación principal asociada a la temperatura de transición vítrea $\left(\mathrm{T}_{\mathrm{g}}\right)$ de la PCL es bastante ancha cubriendo un intervalo de temperatura de $70^{\circ} \mathrm{C}$, donde el máximo de la tangente de pérdida está localizado en $-40^{\circ} \mathrm{C}$. Este resultado sugiere la existencia de pequeños dominios distribuidos dentro del material con tiempos de relajación cuantitativamente diferentes, los cuales pueden ser una consecuencia de las regiones confinadas dentro de las cristalitas. Por encima de los $50^{\circ} \mathrm{C}$ el módulo elástico disminuye bruscamente debido al proceso de fusión de los cristales de PCL, por encima de la temperatura de fusión el material fluye sin mantener ninguna consistencia mecánica debido al relativamente bajo peso molecular del polímero que hace que no haya un número de puntos de entrelazamiento ("entanglements") suficiente para dotar al fundido de una estructura tridimensional capaz de resistir esfuerzos. Al añadir el CHT en las mezclas el módulo aumenta. En las mezclas que contienen un 10 \% de CHT se observa prácticamente el mismo comportamiento que en la PCL pura. La fusión de la PCL produce un flujo irreversible del material. No obstante, esto no ocurre con las mezclas que contienen a partir de un $20 \%$ de CHT donde se obtiene una estabilidad mecánica a temperaturas por encima de la temperatura de fusión de la PCL (el módulo elástico es aún muy alto, alrededor de $10^{9} \mathrm{~Pa}$ ), lo cual sugiere la co-continuidad de la fase de CHT en las mezclas.

Una vez analizadas las características físico-químicas de las mezclas nos propusimos evaluar su respuesta biológica. Para ello, se realizaron cultivos celulares "in vitro" de condrocitos durante 3 y 10 días.

En la figura 3.18 se muestran los resultados obtenidos de los ensayos de MTT sobre las diferentes muestras después de 3 y 10 días de cultivo. La 
viabilidad y proliferación celular no presentan diferencias significativas en las mezclas respecto a los polímeros puros, después de 3 días de cultivo. Sin embargo, después de 10 días de cultivo la proliferación celular sobre la PCL pura es incluso mayor que en el control. En los sustratos de quitosano el número de células viables es mucho más pequeño comparado con la PCL y con el control.

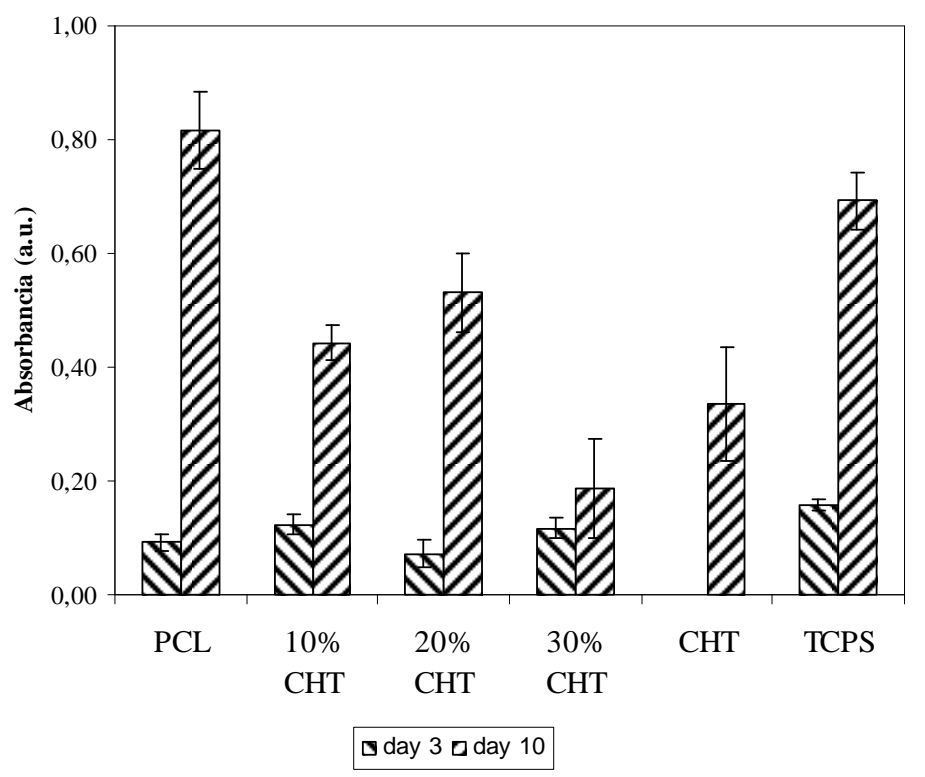

Figura 3.18. Viabilidad y proliferación celular medido mediante el ensayo colorimétrico MTT después de 3 y 10 días de cultivo. Los valores representados es el promedio con un intervalo de confianza igual a 0.05.

En el caso de las mezclas que contienen 10 y $20 \%$ de quitosano los resultados muestran diferencias significativas $(\alpha=0.05)$. El número de células en las mezclas con un $30 \%$ de CHT es muy similar al obtenido para el quitosano puro. Los resultados obtenidos nos indican que al mezclar el CHT con la PCL en ciertas proporciones es posible incrementar tanto la adhesión como la proliferación celular y a su vez mejorar la hidrofilicidad de los 
sustratos, una propiedad muy deseable en muchas aplicaciones biomédicas (el sustrato tiene que ser capaz de suministrar un transporte adecuado de nutrientes desde el medio circundante y poder eliminar los desechos celulares).

En la figura 3.19 se muestran las imágenes de SEM de los condrocitos sobre los diferentes sustratos.
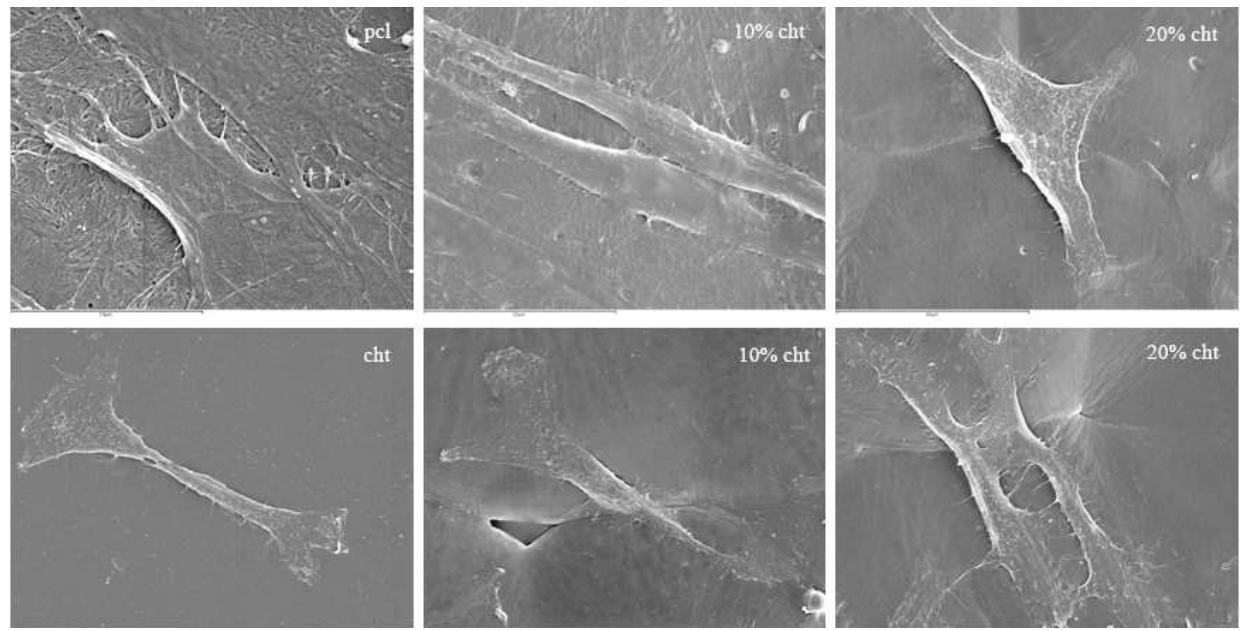
mezclas.

Figura 3.19. Imágenes de SEM de la morfología del condrocito en las diferentes

La morfología de los condrocitos cambia de acuerdo a la superficie del material. Las células sobre la mezcla que contiene un $20 \%$ de CHT adoptan una conformación más extendida con una mayor cantidad de filopodias, lo cual nos sugiere una gran adhesión celular. Este resultado está correlacionado con los ensayos de MTT y los valores de energía superficial del sistema, además la presencia de filopodias está también relacionada con la nano/microtopografía de las muestras [202 y 203], lo cual sugiere una fuerte interacción entre las células-proteínas y el sustrato. 
Para comprender los resultados obtenidos se realizaron ensayos de adsorción de laminina, una proteína de la matriz extracelular, cuya adsorción y conformación sobre sustratos sintéticos depende en gran medida de la superficie química del material así como de la distribución de dominios hidrófilos e hidrófobos [204-209] en la superficie de las muestras. A pesar de que en los cultivos realizados las proteínas que se adsorben sobre el material desde el medio de cultivo son otras, hemos realizado la adsorción de laminina como un ejemplo del comportamiento de unas de las proteínas de la ECM sobre diferentes sustratos.

En la figura 3.20 se muestra la conformación de la laminina sobre los dos sustratos (PCL y CHT). Como se puede observar, la laminina muestra una conformación globular sobre los sustratos hidrófilos que pasa a una conformación extendida con interacciones entre diferentes moléculas de proteínas dando lugar a un recubrimiento co-continuo sobre el material. La conformación de la laminina no se pudo observar sobre las mezclas a causa de las interferencias entre la distribución de los dominios de quitosano en la mezcla y la señal de la proteína. 

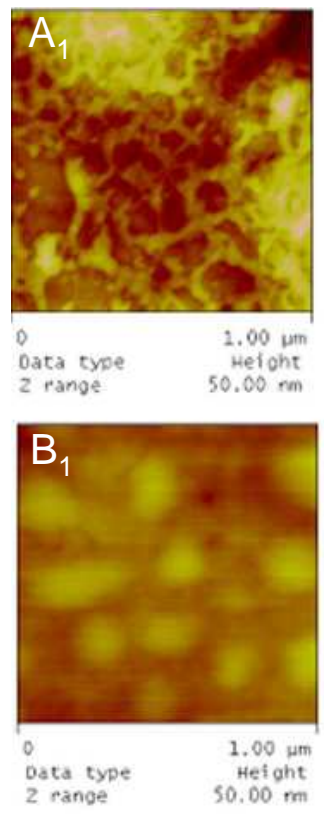
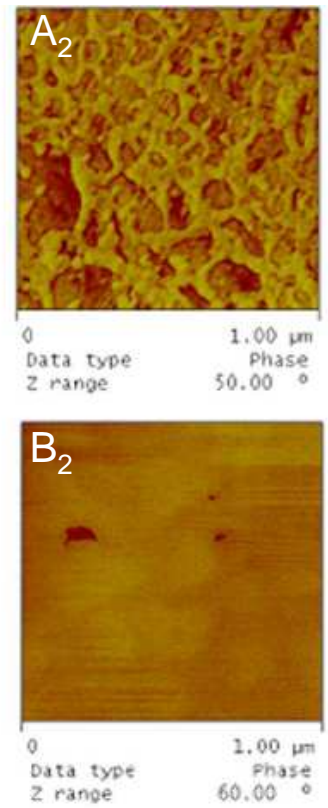
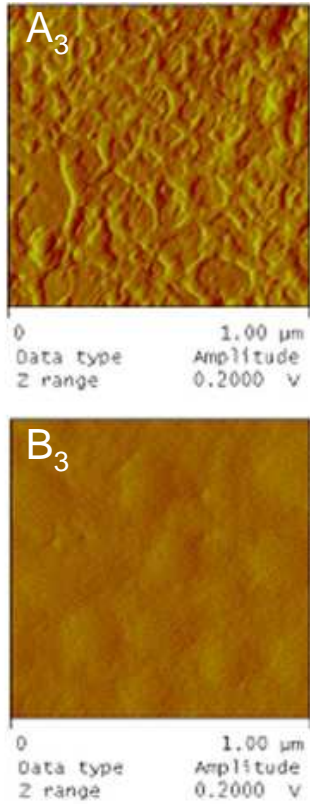

Figura 3.20. Imágenes de AFM de la laminina sobre PCL (A) y CHT (B). El subíndice (1) pertenece a la imagen en altura, el (2) en fase y el (3) en amplitud. El área escaneada es de 1 x $1 \mu \mathrm{m}$.

La laminina presenta una morfología diferente si comparamos las muestras de CHT y PCL (globular y extendida respectivamente, Figura 3.20) la cual esta relacionada con la función biológica del material. La interacción entre los dominios de la proteína y la membrana celular está regulada por muchos receptores celulares (principalmente las integrinas). Varios de estos receptores reconocen específicamente secuencias de péptidos en las proteínas y su vinculación está fuertemente relacionada con la cantidad, distribución y orientación espacial en el sustrato. En [210] se ha observado diferentes conformaciones de la laminina sobre sustratos con una densidad de grupos hidroxilo controlada, la cual esta correlacionada con los resultados obtenidos en cultivos "in itro" de células progenitoras neurales, donde los mejores resultados han sido obtenidos en los sustratos donde la laminina adoptaba una 
conformación extendida [211]. La densidad de la proteína así como su conformación modifica la unión a los receptores celulares y por consiguiente los resultados biológicos en los sustratos.

\subsection{Preparación de scaffolds macroporosos a partir de la formación de redes semi-interpenetradas de policaprolactona y quitosano}

Las redes semi-interpenetradas de PCL y CHT fueron preparadas precipitando la mezcla de ambos polímeros en un solución precipitante de uno de ellos. En este caso, En este caso, se mezcló una disolución de PCL con otra de CHT y se vertió sobre una solución de tripolifosfato de sodio, que actúa reticulando las cadenas de quitosano. De esta forma se obtiene una red de quitosano en la que quedan atrapadas las de PCL. Se forma por lo tanto una red semi-interpenetrada ya que sólo uno de los dos componentes poliméricos está en forma de red. La formación de la red de quitosano actúa como agente compatibilizador, tendiendo a evitar la separación de fases que ya se vió en los apartados anteriores es la tendencia termodinámica de las mezclas PCL-CHT. Sin embargo, la tendencia a la separación de fases en mezclas de polímeros es tan fuerte que incluso con el impedimento que supone la formación de redes, los dos componentes suelen encontrar espacios para formar agregados nanométricos separados en la mayoría de los sistemas poliméricos multicomponentes. En nuestro caso la miscibilidad entre la PCL y el CHT y sus interacciones durante la formación de las semiIPNs han sido caracterizadas mediante las técnicas DSC, TGA, FTIR y DMA.

Mediante la técnica de calorimetría diferencial de barrido (DSC) se estudio la influencia del contenido de CHT en las semiIPNs de PCL/CHT sobre las propiedades térmicas de la PCL. En la figura 3.21 se representa el 
termograma de cristalización obtenido a una velocidad de enfriamiento de $10^{\circ} \mathrm{C} / \mathrm{min}$.

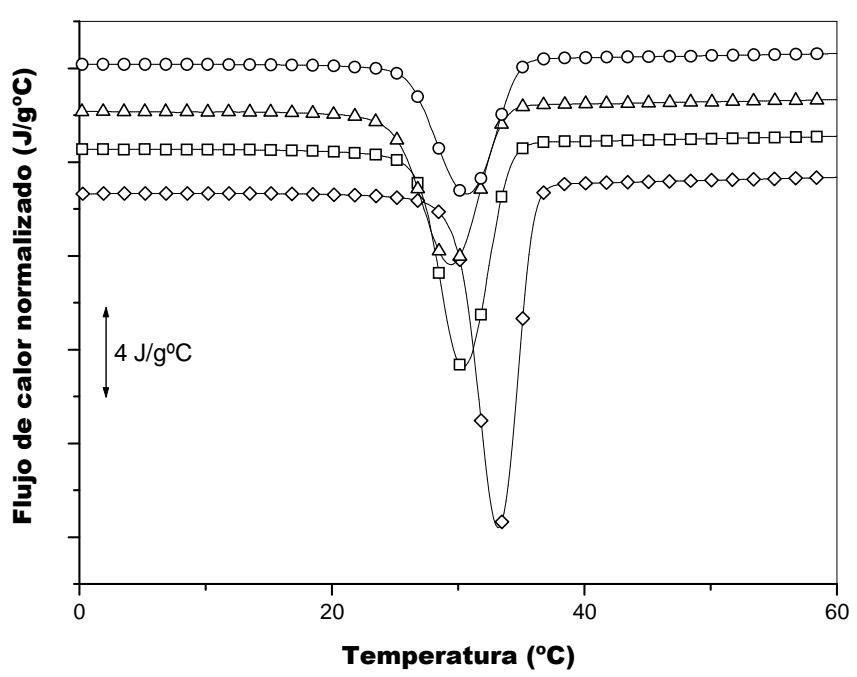

Figura 3.21. Termogramas de enfriamientos para la PCL pura $(\diamond)$ y las semiIPNs con un $10 \%(\square), 20 \%(\Delta)$ y $30 \%$ (०) de CHT.

La principal característica observada es el desplazamiento del pico exotérmico hacia bajas temperaturas debido a la cristalización de la PCL en las semiIPNs con respecto al de la PCL pura. En la tabla 3.2 se resumen diferentes parámetros obtenidos tanto en los termogramas de calentamiento como en los de enfriamiento. ( $T_{c}$, temperatura de cristalización, $T_{m}$, temperatura de fusión, determinada en el mínimo el pico exotérmico medido en enfriamiento y en el máximo del pico de fusión endotérmico respectivamente, $\Delta \mathrm{H}_{\mathrm{c}}$, entalpía de cristalización, $\Delta \mathrm{H}_{\mathrm{m}}$, entalpía de fusión, ambas determinadas por gramo de PCL en la muestra y $\chi_{c}$, el grado de cristalinidad). 
La fracción de PCL que ha cristalizado en las semiIPNs fue calculada utilizando la siguiente ecuación:

$$
x_{c}=\frac{\Delta H_{f}}{w_{P C L} \Delta H_{f}^{0}}
$$

donde, $\Delta H_{f}$ es la entalpía de fusion asociada al pico endotérmico de la PCL en los termogramas de DSC, mientras que $\Delta H_{f}^{0}=139.5 \mathrm{~J} / \mathrm{g}[196]$ representa la entalpía de fusión de un cristal y $w_{P C L}$ es la fracción en peso de la PCL en las semilPNs.

Tabla 3.2. Propiedades térmicas de las SemilPNs. $\Delta H_{c}$, entalpía de cristalización, $\Delta \mathrm{H}_{\mathrm{m}}$, entalpía de fusión, $\mathrm{T}_{\mathrm{c}}$, temperatura de cristalización, $\mathrm{T}_{\mathrm{m}}$, temperatura de fusión y $\chi_{c}$, el grado de cristalinidad.

\begin{tabular}{cccccc}
\hline $\begin{array}{c}\text { SemiIPNs } \\
\text { PCL/CHT }\end{array}$ & $\boldsymbol{\Delta} \mathbf{H}_{\mathrm{c}}(\mathbf{J} / \mathbf{g})$ & $\boldsymbol{\Delta} \mathbf{H}_{\mathrm{f}}(\mathbf{J} / \mathbf{g})$ & $\mathbf{T}_{\mathrm{m}}\left({ }^{\mathbf{o}} \mathbf{C}\right)$ & $\mathbf{T}_{\mathrm{c}}\left({ }^{\mathbf{o}} \mathbf{C}\right)$ & $\chi_{\mathrm{c}}(\mathbf{\%})$ \\
\hline PCL & 57,8 & 65,4 & 57,0 & 32,5 & 46,9 \\
\hline $10 \%$ CHT & 45,6 & 46,9 & 56,7 & 29,9 & 37,4 \\
\hline $20 \%$ CHT & 37,9 & 41,0 & 56,4 & 28,8 & 36,8 \\
\hline $30 \%$ CHT & 32,8 & 35,1 & 56,6 & 30,0 & 36,0 \\
\hline
\end{tabular}

La cristalinidad de la PCL en las semiIPNs (cristalizada desde el fundido) es significativamente menor que en la PCL pura, lo cual sugiere que una parte de las cadenas de PCL no forman parte de la estructura cristalina probablemente porque se encuentran dispersas en la red de quitosano. Dicho comportamiento concuerda con los resultados obtenidos por Honma y colaboradores [120], los cuales proponen que la dismiución de la cristalinidad viene dada por una posible interacción por puente de hidrógeno entre los 
grupos funcionales de la PCL y el quitosano, interacciones que tiene lugar en la fase amorfa por lo que la cristalinidad es suprimida.

Los espectros de SDR-FTIR de los polímeros puros y las semiIPNs de PCL/CHT se muestran en la figura 3.22. En el espectro del CHT se observan las bandas de los $3450 \mathrm{~cm}^{-1}$ que se atribuyen a las vibraciones de valencia de los grupos $-\mathrm{NH}_{2} \mathrm{y}-\mathrm{OH}$ y las bandas características de amina I localizada a los $1655 \mathrm{~cm}^{-1}$. Por otro lado, el espectro de la PCL muestra una banda a los 1725 $\mathrm{cm}^{-1}$ que es la banda característica de de las vibraciones del grupo carbonilo de la estructura química de la PCL. Los espectros SDR-FTIR de las semiIPNs $\mathrm{PCL} / \mathrm{CHT}$ exhiben cambios notables si lo comparamos con los espectros de los componentes puros (ver figura 3.22a). La banda del grupo carbonilo de la PCL se desplaza hacia mayores longitudes de ondas (desde 1725 a $1748 \mathrm{~cm}^{-1}$ ) y aparece un hombro a los $1710 \mathrm{~cm}^{-1}$ con el incremento del contenido de CHT en las semiIPNs. Este hombro se atribuye a las interacciones por puente de hidrógeno entre el grupo carbonilo de la PCL y los grupos funcionales del CHT $\left(-\mathrm{NH}_{2}\right.$ y $\left.-\mathrm{OH}\right)$ (ver figura 3.22b). Senda y colaboradores [212] observaron un comportamiento similar en las mezclas de PCL/quitina y PCL/CHT. Es importante también destacar la aparición de la banda a los $1640 \mathrm{~cm}^{-1}$ atribuida a la formación de $\mathrm{NH}_{3}+$ junto con la banda de los $1200 \mathrm{~cm}^{-1}$ atribuida al grupo $\mathrm{P}=\mathrm{O}$ del tripolifosfato de sodio, usado como agente entrecruzante, donde se ven más claramente en el espectro SDR-FTIR de las semiIPNs con un $30 \%$ de CHT. 


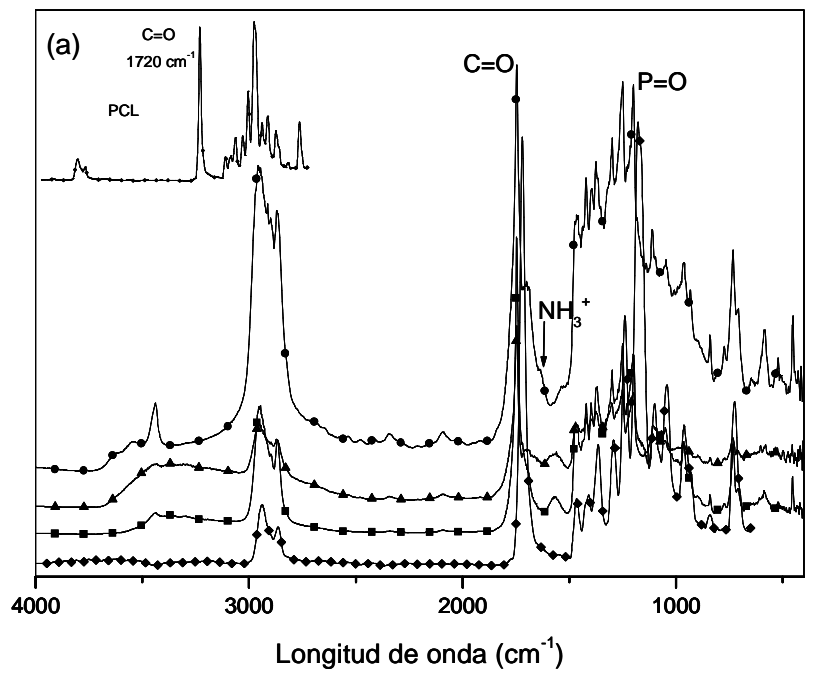

(b)<smiles>COC(C)(C)CCCCCCOC(C)(C)C</smiles>

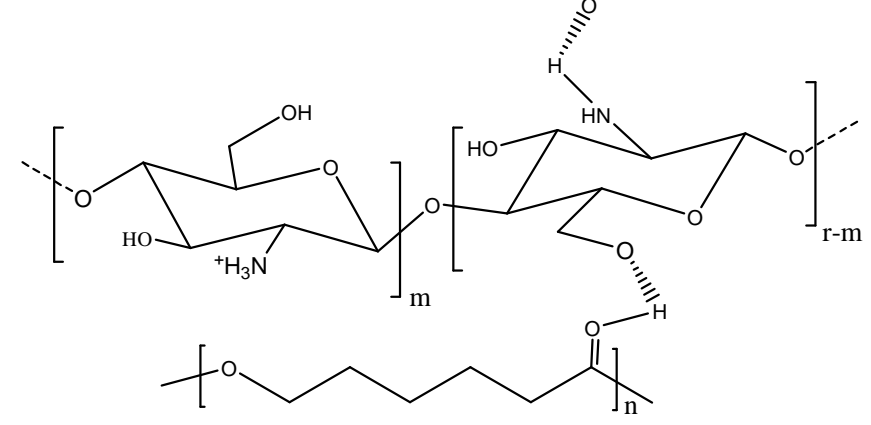

Figura 3.22. Espectros SDR-FTIR de los semiIPNs de PCL y CHT con diferentes composiciones (a) y la posible interacción por puente de hidrógeno entre los grupos funcionales de la PCL y el CHT (b). 
El estudio de degradación térmica de las semiIPNs y los polímeros puros se llevó a cabo mediante la técnica de análisis termogravimétrico (TGA) a una velocidad de calentamiento de $10^{\circ} \mathrm{C} / \mathrm{min}$ y en atmósfera de nitrógeno. En la figura 3.23 se muestran la pérdida de peso y su derivada para los polímeros puros y las semiIPNs. En el gráfico de la derivada de peso en función de la temperatura (Figura 3.23b) sólo se han representado los resultados para los polímeros puros y la semiIPN que contiene un $30 \%$ de quitosano. 

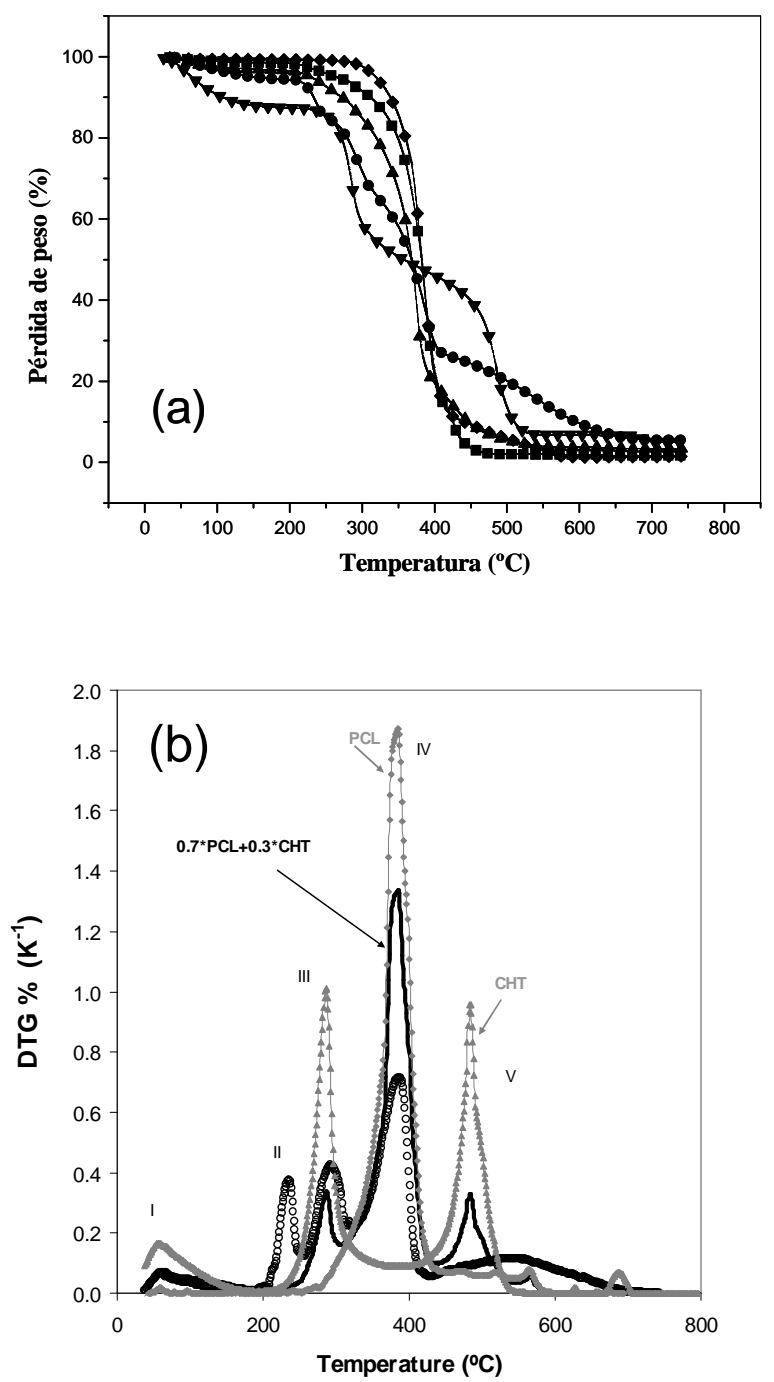

Figura 3.23. Representación de la pérdida de masa con la temperatura para los polímeros puros (PCL $(\diamond)$ y CHT $(\nabla)$ ) y las semiIPNs de PCL/CHT con un $10 \%(\square)$, $20 \%(\Delta)$ y $30 \%(0)$ de quitosano (a) y la derivada de la pérdida de masa respecto a la temperatura para la PCL ( $\diamond$ gris), el CHT ( $\Delta$ gris) y la semiIPN que contiene un $30 \%$ de CHT (O) (b). La línea continua en (b) representa la suma de los termogramas de la PCL y el CHT multiplicada por 0.7 y 0.3 respectivamente. 
El termograma de la PCL muestra un paso de degradación entre los 283 y $448^{\circ} \mathrm{C}$ con un máximo de temperatura de degradación localizado en $386^{\circ} \mathrm{C}$, el cual es atribuible a la ruptura de cadenas [213] llamado estado IV en la figura 3.23b. Por otra parte, en la curva de la derivada de la pérdida de peso del CHT muestra tres estados diferentes I, III y V. El primer estado (I) está localizado entre 60 y $140^{\circ} \mathrm{C}$ con un pico centrado en $110^{\circ} \mathrm{C}$ el cual es usualmente asociado con la pérdida de agua [214], el segundo estado (II) comienza a los $240^{\circ} \mathrm{C}$ y alcanza el valor máximo a los $298^{\circ} \mathrm{C}$ y el último estado (V) el pico máximo se localiza a los $550^{\circ} \mathrm{C}$. Los dos últimos estados o etapas de degradación pueden ser atribuidos a procesos complejos que incluyen la deshidratación de los anillos sacarídicos, la depolimerización y la descomposición de las unidades acetiladas y desacetiladas [2 15 y 216].

En la curva de pérdida de peso correspondiente a cada una de las semiIPNs (Figura 3.23a) se muestran las principales características de sus componentes puros, excepto para la muestra que contiene un $30 \%$ de CHT donde aparece un nuevo pico alrededor de $\operatorname{los} 220^{\circ} \mathrm{C}$ (pico II, en la figura 3.23b). Al comparar el termograma experimental de la semiIPN con un $30 \%$ de CHT con el resultado de la suma de los termogramas de los componentes puros, multiplicado por la fracción en peso de la PCL en la muestra (línea continua en la figura 3.23b) obtuvimos que el pico I y III aproximadamente coincide con la pérdida de peso de la fase de quitosano y el pico IV es evidentemente menos intenso que el correspondiente a la degradación de la PCL por lo que la pérdida de peso correspondiente al pico II que aparece nuevo en el termograma de las semiIPNs puede que se corresponda con la degradación de las cadenas de PCL que debido a la interacción con las unidades de quitosano degradan a más baja temperatura. 
Una vez caracterizada las semiIPNs preparamos scaffolds macroporosos de PCL y CHT. La base del procedimiento utilizado en la fabricación de los scaffolds consiste en que las cadenas de PCL fundan y durante el proceso de recristalización se creen uniones entre las partículas de las semiIPNs de PCL y CHT. De esta manera, los scaffolds obtenidos presentan una cierta porosidad, incluso sin utilizar porógeno, debido al aire que queda entre las partículas de PCL/CHT. La porosidad en este caso está entre un 20 y un $30 \%$ (ver tabla 3.3). Un dato muy curioso es que aunque la porosidad es bastante pequeña, los poros están bien interconectados como se muestran en la figura 3.24 A, B y C para las muestras que contiene $10 \%, 20 \%$ y $30 \%$ de quitosano.

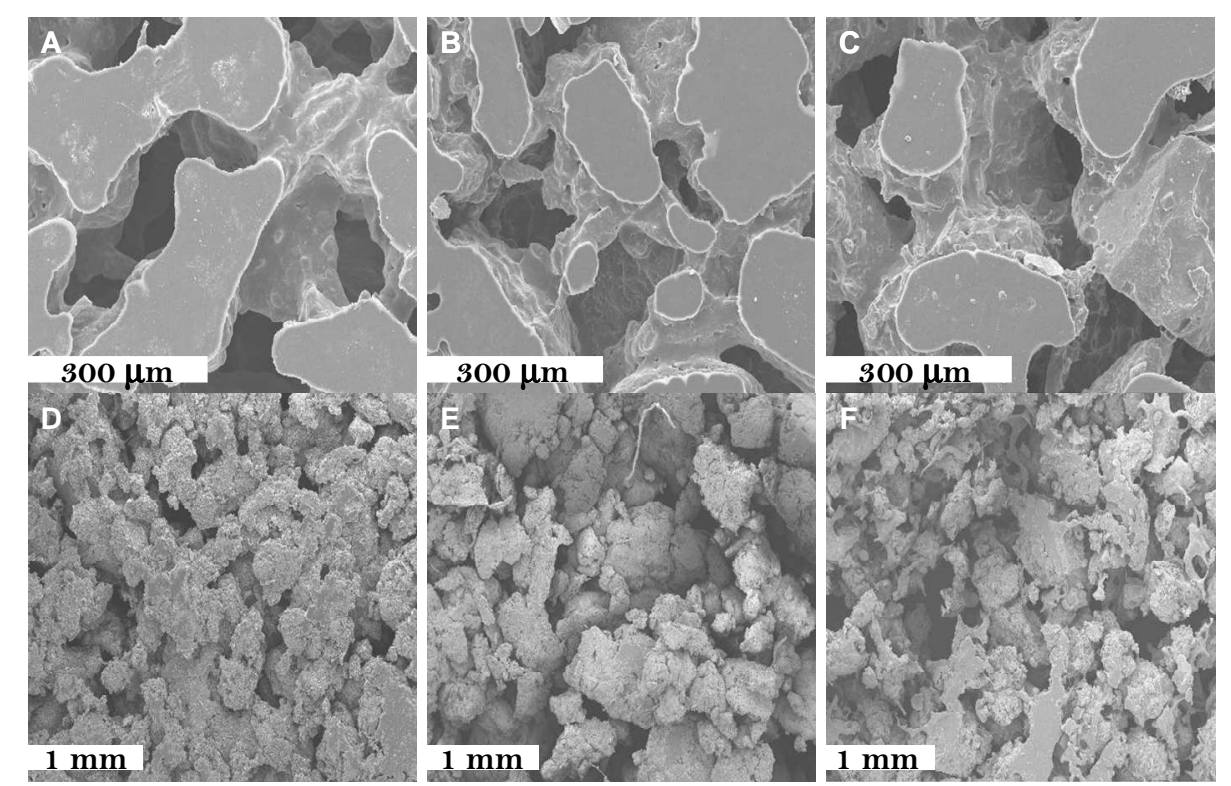

Figura 3.24. Microfotografías de SEM de los scaffolds de PCL/CHT con un 10 $\%$ de $\operatorname{CHT}(\mathrm{A}), 20 \%$ de $\mathrm{CHT}$ (B) y $30 \%$ de $\mathrm{CHT}(\mathrm{C})$. Las imágenes D, E y F corresponden a los scaffolds preparados con un $55 \%$ de porógeno. 
La estructura porosa de los scaffolds presenta poros bien interconectados con un diámetro de alrededor de $100 \mu \mathrm{m}$, pero la porosidad es muy pequeña para ser utilizados en aplicaciones en la ingeniería de tejidos. Por consiguiente con el objetivo de obtener scaffolds macroporosos, microesferas de polióxido de etileno), (PEO) han sido utilizadas como porógeno. El punto de fusión del PEO y el de la PCL se encuentran en el mismo rango de temperaturas. En la obtención de los scaffolds, las partículas de PCL/CHT (semiIPN) y las microesferas de PEO se mezclan y se calientan hasta $90^{\circ} \mathrm{C}$ (temperatura en la que tanto la PCL como el PEO se encuentran en estado fundido) y posteriormente la mezcla se enfría, durante el enfriamiento recristalizan los dos materiales produciendo fases co-continuas, donde una de las fases consiste en la semiIPN PCL/CHT sinterizada y la otra fase es el PEO. La fase del PEO se disuelve en agua dejando una fracción en volumen adicional de poros interconectados de acuerdo a la cantidad añadida en un inicio. En la tabla 3.3 se muestra la dependencia de la porosidad de los scaffolds con la fracción en peso de PEO añadida durante el proceso de sinterización.

Cuando la cantidad de PEO utilizada con las partículas de PCL/CHT es mayor que un $55 \%$ en peso durante el tratamiento térmico para la obtención del scaffolds tanto el PEO como la PCL recristalizan haciendo posible la unión entre las partículas de las semiIPNs por lo que al eliminar el porógeno se obtiene un material macroporoso como se muestra en la figura $3.24 \mathrm{D}, \mathrm{E}$ y $\mathrm{F}$ (nótese la diferencia en los aumentos con que se han tomado las microfotografías con respecto a las imágenes de las muestras preparadas sin porógeno). Aún así, los scaffolds presentan una estructura de poros abiertos e interconectados. La forma esférica de las micropartículas de PEO se ha perdido durante los procesos de fusión y recristalización en la obtención del scaffold, por lo que la forma de los poros es un poco irregular. Como se muestra en la 
tabla 3.3 la porosidad de los scaffolds aumenta con el incremento de la cantidad de porógeno, alcanzando valores entre un 60 y un $65 \%$ en dependencia del contenido de quitosano en las muestras y hasta una cantidad máxima de PEO de un $55 \%$ en peso porque cuando se utilizan mayores contenidos de PEO se obtienen scaffolds sin integridad mecánica, debido a que al aumentar la temperatura hasta $90^{\circ} \mathrm{C}$ las partícula de PCL/CHT se mantiene dispersas en la fase fundida del PEO y no se adhieren unas a otras durante el enfriamiento.

En la figura 3.25 se muestran los cortes transversales de los scaffolds de PCL/CHT. En las imágenes obtenidas se observa una microporosidad y micropartículas esféricas de quitosano de tamaño alrededor de $2 \mu$ m incluidas en el scaffold. Dicha morfología fue encontrada en mezclas de PCL/CHT [123] obtenidas por precipitación a partir de una co-solución de PCL y CHT en ácido acético acuoso.

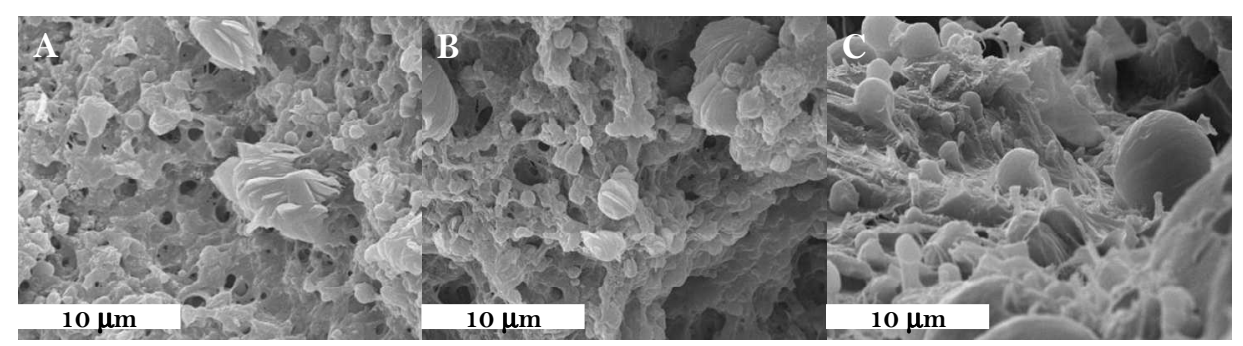

Figura 3.25. Microfotografías de SEM de la microporosidad de los scaffolds de $\mathrm{PCL} / \mathrm{CHT}$ con un $10 \%$ (A), $20 \%$ (B) y $30 \%$ (C) de CHT.

También se determinó la influencia del componente hidrófilo sobre la capacidad de absorción de agua de los materiales. Para ello se realizaron estudios de hinchamiento en SBF durante 6 días a $37^{\circ} \mathrm{C}$ y se determinó la ganancia de peso en función del tiempo.

Los ensayos de absorción de agua fueron realizados en inmersión en SBF teniendo en cuenta que el quitosano es un policatión por lo que el experimento 
podría ser más representativo del comportamiento de este material en el medio de cultivo o en el sitio del implante. La absorción de agua depende tanto de la porosidad como del contenido de quitosano en las muestras ya que la policaprolactona es un polímero hidrófobo. En la tabla 3.3 se resumen los valores de la capacidad de absorción de agua de los scaffolds, la cual aumenta con el incremento del contenido de CHT. A pesar de las pequeñas diferencias en la porosidad de las muestras, de manera general todos los scaffolds absorben 2 gramos de agua por gramo de quitosano presente en la muestra.

Tabla 3.3. Contenido de agua en el equilibrio y porosidad de las semiIPNs de $\mathrm{PCL} / \mathrm{CHT}$.

\begin{tabular}{|c|c|c|c|c|c|}
\hline \multirow{2}{*}{ Scaffolds de PCL/CHT } & \multicolumn{4}{c|}{ Porosidad (\%) } \\
\cline { 2 - 6 } & Absorción de agua & \multicolumn{3}{c|}{ Cantidad de PEO } \\
\hline & (g de agua / g de polímero seco) & 0 & 30 & $\mathbf{4 5}$ & $\mathbf{5 5}$ \\
\hline $\mathbf{1 0} \%$ CHT & $0,22 \pm 0.01$ & 21 & 34 & 51 & 58 \\
\hline $\mathbf{2 0} \%$ CHT & $0.39 \pm 0.02$ & 33 & 32 & 54 & 61 \\
\hline $\mathbf{3 0} \%$ CHT & $0,58 \pm 0.03$ & 25 & 37 & 60 & 64 \\
\hline
\end{tabular}

Las propiedades mecánicas de los scaffolds preparados sin porógeno a partir de las semiIPNs de PCL/CHT con diferentes composiciones fueron medidas haciendo uso de la técnica de DMA a la frecuencia de $1 \mathrm{~Hz}$. En la figura 3.26 se muestra la dependencia del módulo de almacenamiento y la tangente de pérdida con la temperatura para los scaffolds de PCL/CHT. 


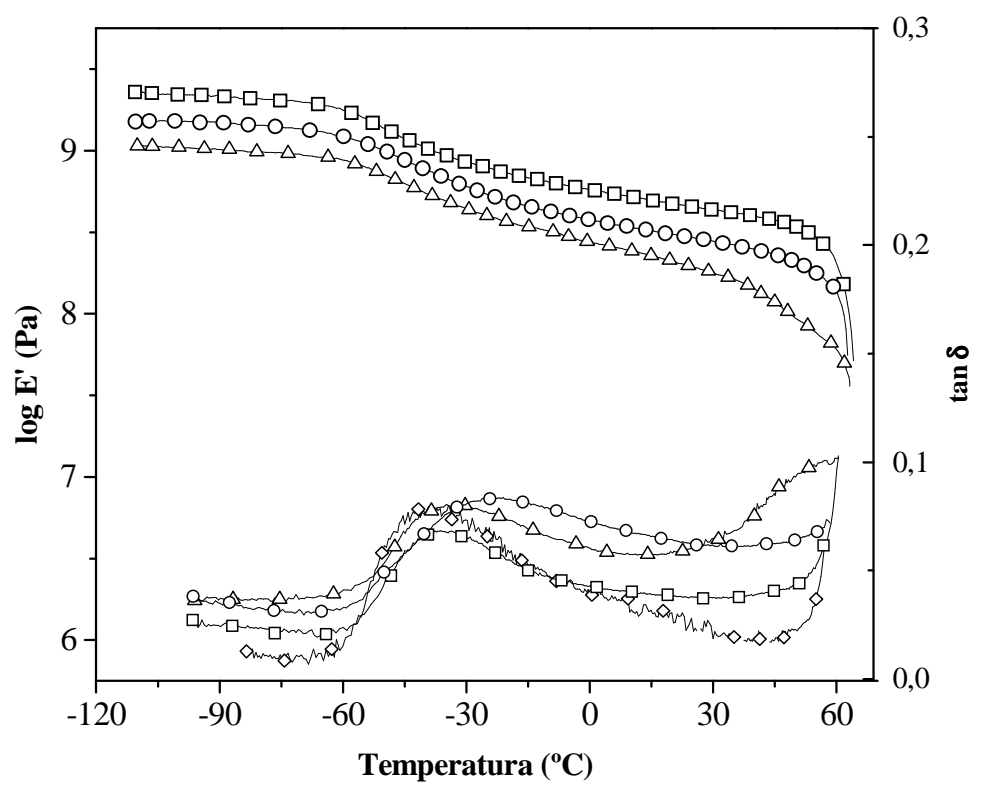

Figura 3.26. Dependencia del módulo elástico y la tangente de pérdida con la temperatura para los scaffolds de PCL/CHT con un $10 \%(\square), 20 \%(\Delta)$ y un $30 \%(0)$ de CHT. La curva de tangente de pérdida de la PCL pura $(\diamond)$ ha sido representada para comparar.

El análisis dinámico-mecánico es muy sensible para el estudio de la transición vítrea en sistemas complejos. En este caso, la relajación principal dinámico-mecánica de la fase amorfa de la PCL asociada con la $\mathrm{T}_{\mathrm{g}}$ se ve claramente en la tangente de pérdida como un pico ancho alrededor de $-40^{\circ} \mathrm{C}$ y una caída del módulo elástico.

El módulo elástico tiene un valor alto que oscila entre $10^{9}$ y $10^{9.5} \mathrm{~Pa}$ a bajas temperaturas cuando la parte amorfa de la PCL está en el estado vítreo en dependencia del contenido de quitosano y la porosidad de los scaffolds. Este 
valor prueba que las partículas de PCL/CHT (semiIPNs) están bien adheridas formando un material continuo. Alrededor de $-50^{\circ} \mathrm{C}$, tiene lugar la transición vítrea de la PCL y el valor del módulo cae ligeramente, pero aún así en el estado de goma, el valor del módulo se mantiene alto debido al refuerzo de las cadenas de CHT. Posteriormente cuando la PCL funde, alrededor de $\operatorname{los} 60^{\circ} \mathrm{C}$, la muestra fluye debido a que la unión entre las partículas de PCL/CHT se ha perdido.

Una interpretación del valor absoluto del módulo elástico es difícil, porque no sólo depende del CHT rígido y su conectividad en las semiIPNs, sino también de la porosidad de las muestras. Es por ello, que el módulo de almacenamiento de las muestras que contienen un $10 \%$ de CHT es mayor que en las muestras que contienen un 20 y un $30 \%$ de CHT, un comportamiento contrario al esperado. No obstante y como se observa en la tabla 3.3 la porosidad de las muestras con un $10 \%$ de CHT es menor que en los scaffolds con un mayor contenido de CHT.

El desplazamiento de la $\mathrm{T}_{\mathrm{g}}$ o del pico de la tangente de pérdida asociada a la relajación principal, $\mathrm{T}_{\alpha}$, con respecto a la de sus componentes puros es un criterio bien aceptado de miscibilidad o de interacción de las interfases entre los componentes en las mezclas poliméricas o composites. En el caso de los scaffolds de PCL/CHT (preparados a partir de las semiIPNs) la relajación principal $\alpha$ se desplaza hacia altas temperaturas haciéndose cada vez más ancha y disminuyendo en intensidad a medida que aumenta el contenido de CHT en las muestras. Este comportamiento corrobora la existencia de una interacción entre las fases de la PCL y CHT, lo cual sugiere que los movimientos conformacionales de las cadenas de PCL en el estado amorfo son afectados por 
las cadenas vecinas de quitosano. Dicho resultado concuerda con los obtenidos en los espectros SDR-FTIR y en los ensayos de termogravimetría.

\subsection{Scaffolds porosos de quitosano. Proliferación y diferenciación de las GBMSCS}

\subsubsection{Caracterización de los scaffolds}

Los scaffolds de quitosano utilizados en este estudio han sido preparados mediante la combinación de dos técnicas: la freeze-gelation y la posterior disolución de micropartículas de un porógeno (leaching out technique). En este caso, se obtuvieron scaffolds de quitosano con una estructura de micro y macroporosidad. La técnica de freeze-gelatión crea una estructura microporosa de tamaño de poro alrededor de $10 \mu \mathrm{m}$, determinada por la separación de fases sólido-líquido que tiene lugar durante el proceso de congelación. La disolución acuosa de quitosano a $\mathrm{pH}$ ácido se congela formándose una estructura continua de cristales de agua cuyas formas y dimensiones varían con la velocidad de enfriamiento y también con la concentración de la disolución original o las características de la transmisión de calor en el molde o recipiente que contiene la disolución. Cuando posteriormente se introduce la muestra sólida en la disolución de hidróxido de sodio, los cristales de agua se disuelven al mismo tiempo que se neutraliza el ácido acético de la disolución original, de forma que el quitosano se vuelve insoluble a una temperatura a la que no tiene movilidad suficiente para deformarse, por lo que el espacio que ocupaban los cristales de agua acaban siendo poros en el scaffold que se obtiene finalmente. El tamaño de esos poros es insuficiente para muchas aplicaciones en ingeniería tisular, aún cuando la estructura porosa obtenida por este procedimiento suele estar bien 
interconectada. Para aumentar el tamaño de poro se creó la estructura macroporosa utilizando micropartículas de polimetacrilato de etilo (PEMA) de diámetro de partícula alrededor de $200 \mu \mathrm{m}$, como porógeno. Estas microesferas se mezclan con la disolución de quitosano inicial, antes de congelarla y son eliminadas posteriormente por disolución una vez se ha eliminado el agua y el quitosano se ha vuelto insoluble. En este trabajo hemos preparado scaffolds con diferentes cantidades de porógeno que varían entre un 70 y un $85 \%$. La morfología de los scaffolds fue examinada mediante SEM (Figura 3.27).
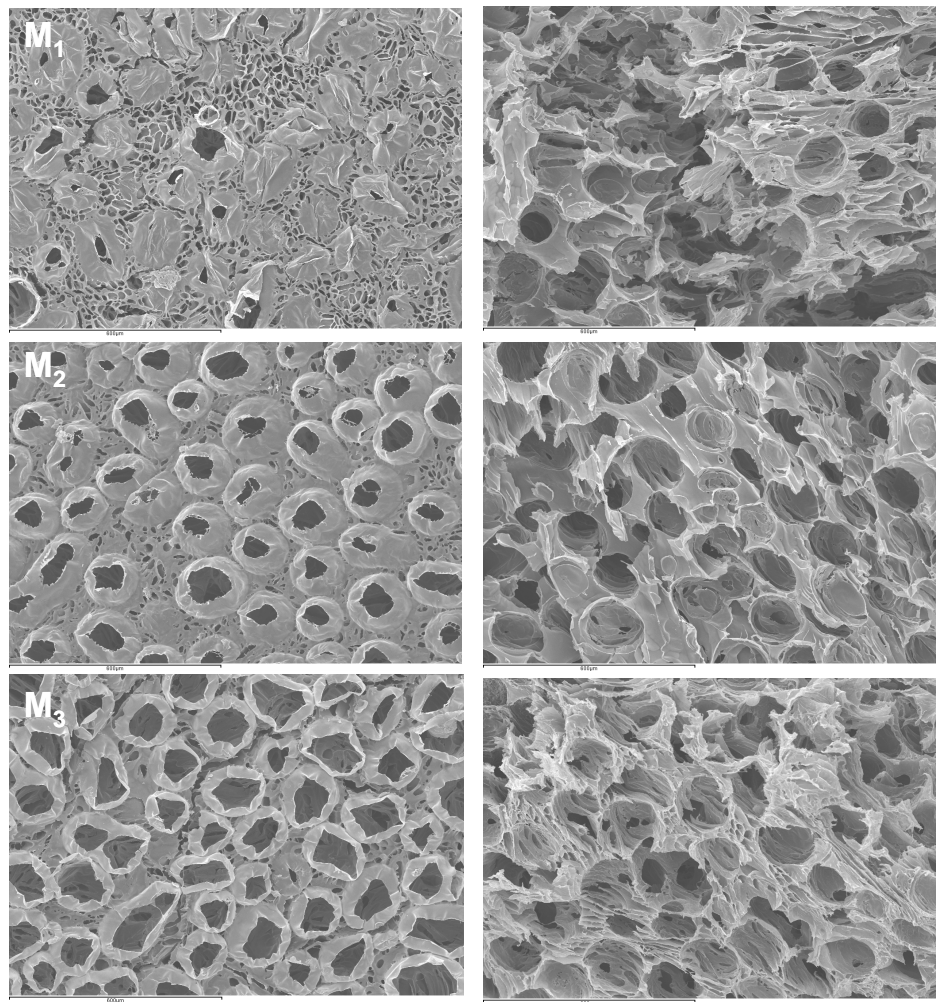

Figura 3.27. Micrografías de SEM de los scaffolds de quitosano con diferentes cantidades de porógeno. $\mathrm{M}_{1}(70 \%), \mathrm{M}_{2}(77.5 \%)$ y $\mathrm{M}_{3}(85 \%)$. Las imágenes de la izquierda son de superficie y los cortes transversales de las muestras se representan en las imágenes de la derecha. 
En las imágenes de SEM se observa una estructura micro y macroporos en la superficie de los scaffolds. La densidad de poros grandes aumenta con el incremento en el contenido de porógeno. Realizando cortes transversales pudimos ver una microestructura de poros abiertos e interconectados.

La estructura interna de los materiales fue caracterizada mediante técnicas de tomografía micro-computarizada $(\mu-\mathrm{CT})$, la cual nos permite obtener una medida cuantitativa del tamaño de poro y la interconectividad. En la figura 3.28 se muestran las imágenes de los cortes bidimensionales y la reconstrucción tri-dimendional de los scaffolds obtenidos con un $70 \%$ de porógeno.
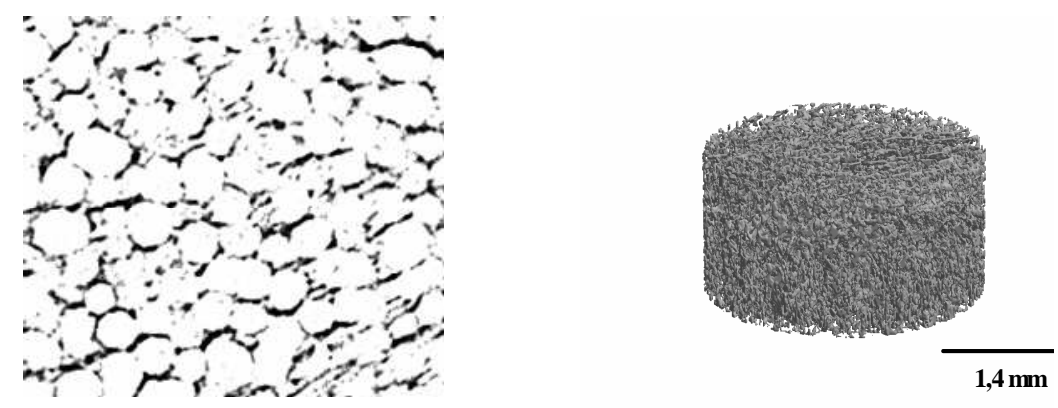
porógeno.

Figura 3.28. Imágenes de $\mu$-CT de los scaffolds de quitosano con un $70 \%$ de

Como se observa en la figura 3.28 los scaffolds tienen una estructura altamente porosa con poros interconectados de geometría esférica. A partir de las imágenes de los cortes transversales no fue posible detectar diferencias entre los scaffolds con diferente cantidad de porógeno. La porosidad obtenida para todas las muestras fue de un $85 \%$, suma del volumen de los microporos y de los macroporos. Hay que notar que el volumen de microesferas de porógeno que se añade inicialmente no se traduce directamente en un volumen de 
macroporos en el scaffolds finalmente obtenido. Durante el proceso de extracción del porógeno se produce una contracción de la estructura del quitosano, como se demostrará por la diferencia entre el diámetro de los macroporos y el de las microesferas de porógeno. Este proceso de contracción es el que parece conducir a una misma porosidad del scaffold independientemente de la cantidad de porógeno utilizada.

La distribución de tamaño de poros en los scaffolds se obtuvo mediante el análisis de las imágenes de los cortes bidimensionales y haciendo uso de una herramienta de software propia EsTra [ 217 y 218$]$ desarrollada bajo el entorno de MATLAB y adaptada para su uso en el análisis de biomateriales [219] como soporte en la regeneración tisular. En la figura 3.29 se representa la distribución de tamaño de poro de los scaffolds preparados con diferentes cantidades de porógeno.

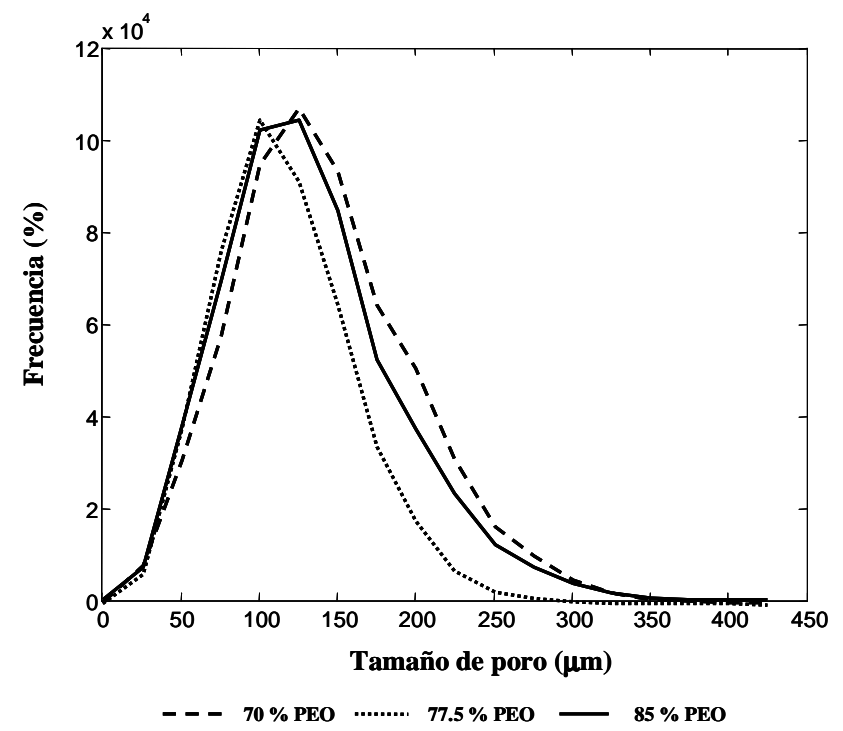

Figura 3.29. Distribución de tamaño de poro para los scaffolds de CHT con diferentes cantidades de porógeno. 
En la figura 3.29 se observa que la distribución de tamaño de poro es prácticamente similar para todos los scaffolds preparados. El tamaño de poro promedio para todos los scaffolds preparados oscila entre 120 y $140 \mu \mathrm{m}$ (ver tabla 3.4).

\subsubsection{Ensayos de biodegradación "in vitro" de los scaffolds de quitosano}

Los estudios de biodegradación "in vitro" de los scaffolds fueron realizados en una solución de buffer fosfato de $\mathrm{pH} 7.4$ que contenía $10 \mu \mathrm{g} / \mathrm{ml}$ de lisozima de acuerdo con la concentración de esta enzima en el suero humano.

En la figura 3.30 el perfil de degradación de cada muestra. Como se puede apreciar, al cabo de los 45 días todos los scaffolds se han degradado hasta un $10 \%$ en peso. No existen diferencias significativas entre los scaffolds con un mayor contenido de porógeno, como era de esperar ya que la porosidad de todos ellos es prácticamente la misma.

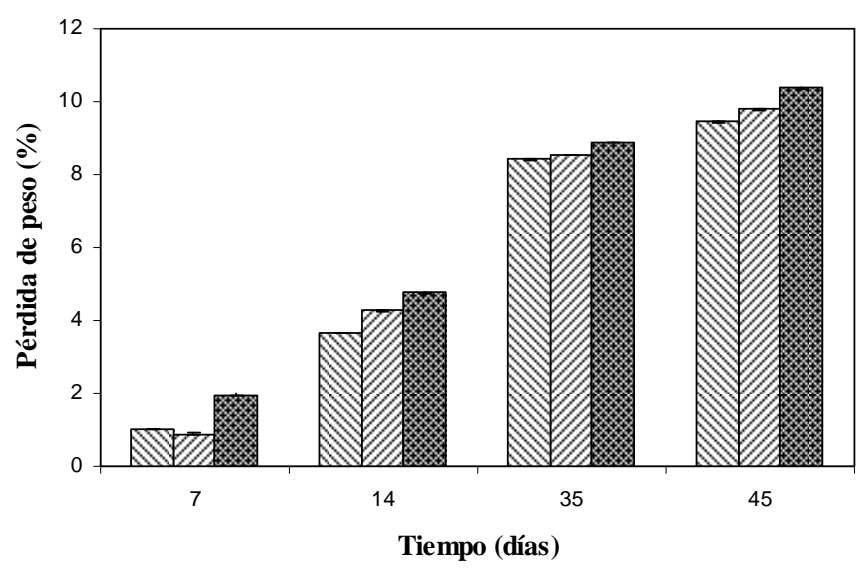

Figura 3.30. Perfil de degradación de los scaffolds de quitosano. 
La velocidad de degradación enzimática del quitosano depende en gran medida del grado de desacetilación [220], disminuyendo dicha velocidad con el incremento de esta característica (el grado de desacetilación). El quitosano utilizado en este trabajo tiene un grado de desacetilación de un $75 \%$. Los resultados obtenidos en este caso, concuerdan con otros estudios descritos en la literatura [220 y 221].

\subsubsection{Determinación de las propiedades mecánicas de los scaffolds mediante ensayos de compresión.}

En un ensayo de compresión, el comportamiento típico de un material poroso tridimensional pasa por 4 etapas fundamentales: (1) una etapa inicial de contacto de la muestra con las mordazas, (2) seguida de una zona de comportamiento elástico lineal, (3) para pasar a una zona donde se producen con poco aumento de la tensión, grandes deformaciones (zona de plateau), producido por un mecanismo llamado "buckling" (donde las paredes del scaffolds se empiezan a doblar) y finalmente (4) la última etapa donde la deformación aumenta debido al colapso o densificación de la estructura porosa del material [222 y 223].

Los ensayos de compresión fueron realizados en estado seco y en inmersión (medio de cultivo, DMEM) con el fin de evaluar las propiedades mecánicas del material en las condiciones de cultivo. En las figuras 3.31 y 3.32 se representan las curvas de tensión-deformación de los scaffolds de quitosano preparados con un $77.5 \%$ de porógeno, en el estado seco e hinchado. La figura 3.31 muestra claramente dos de las cuatro etapas descritas teóricamente para 
un material poroso, sin embargo al realizar una ampliación de la curva en la zona de bajas deformaciones hasta un $70 \%$ se puede apreciar tres etapas, una primera zona lineal hasta un 30 \% de deformación aproximadamente en la cual hemos determinado el módulo elástico entre un 5 y un $15 \%$ de deformación, luego se observa un punto de inflexión o cambio de pendiente donde el material entra en la zona de plateau y alrededor del $60 \%$ de deformación empieza la densificación del material. La curva de tensión-deformación en compresión obtenida para el material en el estado hinchado (figura 3.32) es aparentemente similar a la del estado seco. Las curvas obtenidas para el resto de materiales presentaban un comportamiento similar.

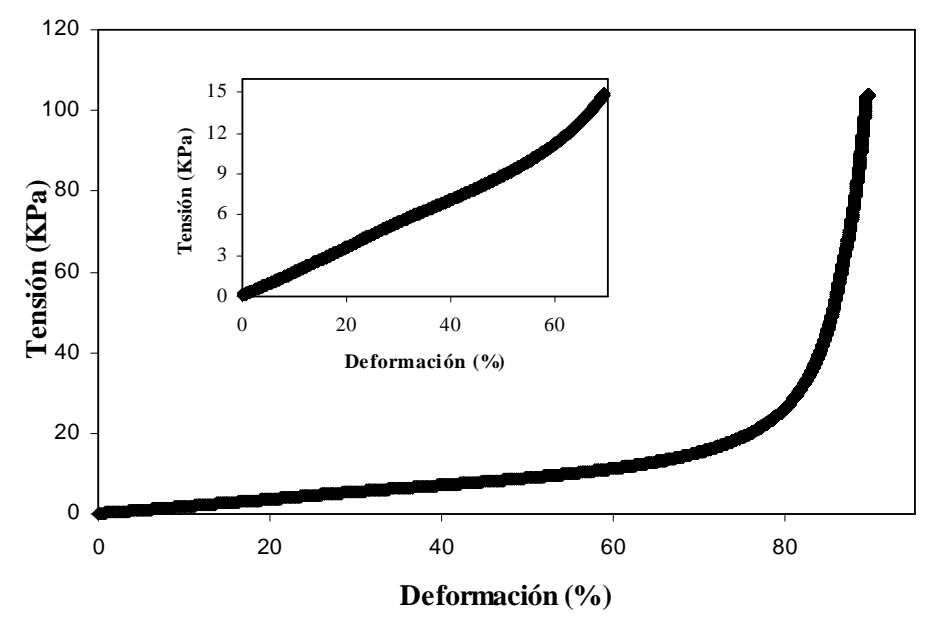

Figura 3.31. Curva experimental de tensión-deformación obtenida, en el estado seco, para los scaffolds de CHT preparados con un $77.5 \%$ de porógeno. 


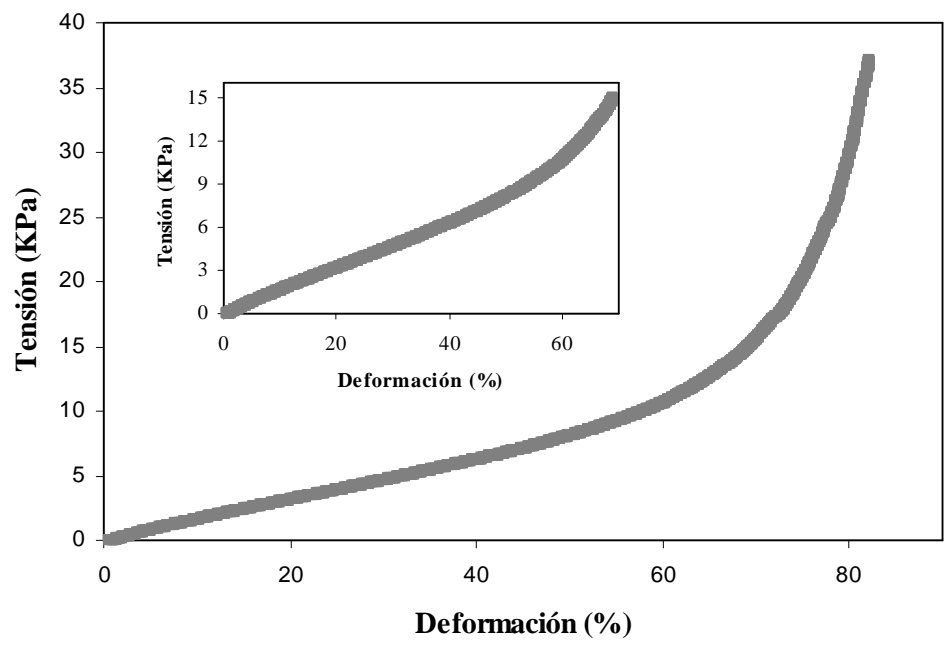

Figura 3.32. Curva experimental de tensión-deformación obtenida, en el estado hinchado, para los scaffolds de CHT preparados con un $77.5 \%$ de porógeno.

A partir de la pendiente de la zona lineal determinamos el valor del módulo de Young aparente. En la tabla 3.4 se muestra el valor del módulo de Young aparente en el estado seco e hinchado, la porosidad obtenida mediante $\mu$-CT y el tamaño de poro promedio obtenido por la herramienta-software EsTra para todos los scaffolds preparados con diferentes cantidades de porógeno $70 \%$ (M1), $77.5 \%$ (M2) y un $85 \%(\mathrm{M} 3)$. 
Tabla 3.4. Valores de la porosidad medida en los ensayos de $\mu$-CT, tamaño de poro medido en la herramienta-software EsTra y el módulo elástico aparente en el estado seco, $\mathrm{E}_{\mathrm{d}}$, e hinchado, $\mathrm{E}_{\mathrm{s}}$, determinado a partir de las curvas de tensióndeformación.

\begin{tabular}{|c|c|c|c|c|}
\hline Muestras & $\begin{array}{c}\text { Porosidad } \\
(\mu-\mathrm{CT})\end{array}$ & $\begin{array}{c}\text { Tamaño de } \\
\text { poro }(\mu \mathrm{m})\end{array}$ & $\mathrm{E}_{\mathrm{d}}(\mathrm{MPa})$ & $\mathrm{E}_{\mathrm{s}}(\mathrm{MPa})$ \\
\hline M1 & 0.849 & $142 \pm 58$ & $0.21 \pm 0.07$ & $0.021 \pm 0.003$ \\
\hline M2 & 0.823 & $117 \pm 44$ & $0.19 \pm 0.05$ & $0.020 \pm 0.004$ \\
\hline M3 & 0.842 & $133 \pm 55$ & $0.24 \pm 0.05$ & $0.018 \pm 0.002$ \\
\hline
\end{tabular}

Como se puede observar tanto la porosidad como el tamaño de poro y los valores de los módulos son muy similares en todos los materiales. El valor del módulo en el estado seco es 10 veces mayor que en el estado hinchado, lo cual sugiere una plastificación de las cadenas de quitosano.

\subsubsection{Cultivo"in vitro" de GBMSCs, viabilidad celular, adhesión, proliferación y producción de la matriz extracelular.}

En esta parte del trabajo nos propusimos estudiar la adhesión, proliferación y diferenciación a tejido óseo de células madre provenientes de médula ósea de cabra, GBMSCs, en los scaffolds de quitosano. Para ello, teniendo en cuenta que no existían diferencias entre cada uno de los scaffolds preparados con diferentes cantidades de porógeno en cuanto a porosidad, distribución de tamaño de poro y propiedades mecánicas hemos seleccionado el 
scaffold preparado con un $70 \%$ de porógeno para realizar los estudios biológicos.

En los scaffolds se inyectaron $50 \mu \mathrm{l}$ de una suspensión celular que contenía 1 x $10^{5}$ células y los constructos células-scaffold fueron incubados durante 1 hora con el objetivo de promover la adhesión celular. Transcurrido ese tiempo, los constructos fueron transferidos a una nueva placa de cultivo para poder analizar exclusivamente las células adheridas al scaffold y se añadió $800 \mu \mathrm{l}$ de medio de diferenciación osteogénico. El experimento se llevó a cabo por triplicado durante 28 días, extrayendo los constructos a los tiempos 3, 7, 14, 21 y 28 días.

La figura 3.33 muestra las micrografías de SEM de las superficies de los scaffolds de CHT, sembrados con GBMSCs y cultivados en medio osteogénico durante 4 tiempos (3, 7, 21 y 28 días). 


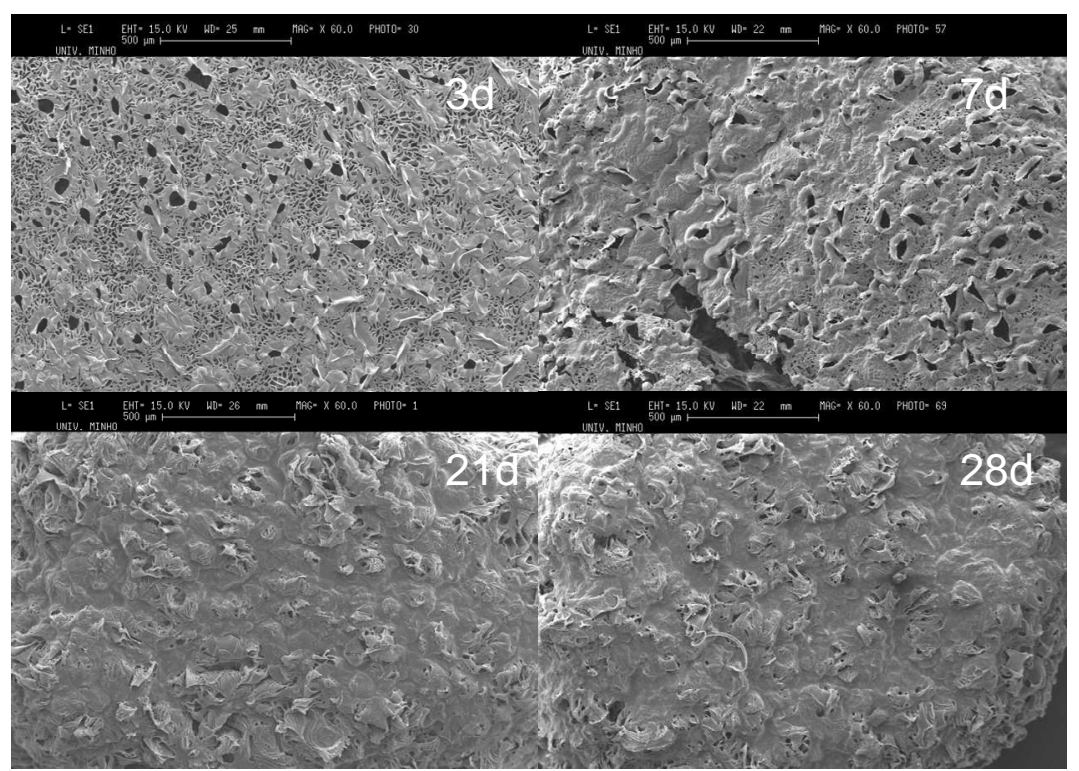

Figura 3.33. Micrografías de SEM de las superficies de los scaffolds de CHT, sembrados con GBMCs, cultivados en medio osteogénico durante 3, 7, 21 y 28 días. La escala de las imágenes corresponde a $500 \mu \mathrm{m}$.

Como podemos observar, la densidad celular se incrementa con el tiempo de cultivo llegando a cubrir totalmente la superficie del scaffold al cabo de los 21 días, lo cual nos sugiere una adecuada proliferación de las células en el material poroso de CHT.

La morfología de las células se observa con mayor precisión en las imágenes tomadas a mayores magnificaciones de cortes transversales de los scaffolds de CHT al día 28 (figura 3.34). 


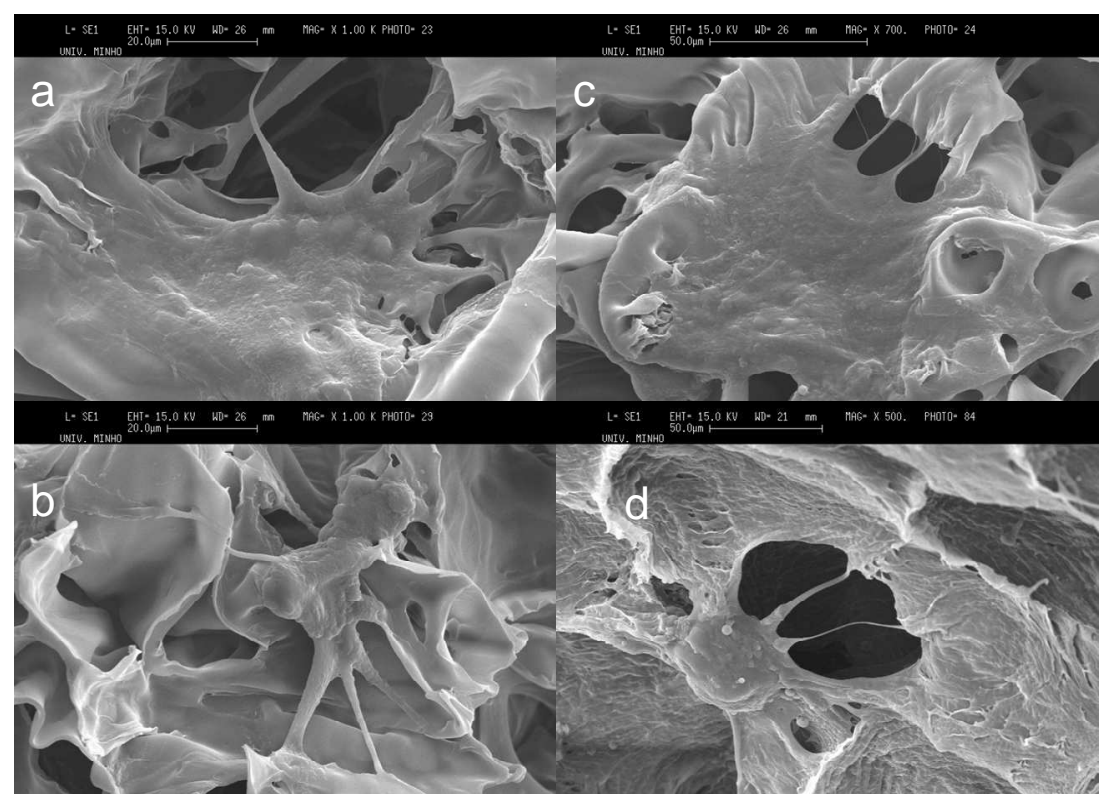

Figura 3.34. Micrografías de SEM de cortes transversales de los scaffolds de CHT, sembrados con GBMCs y extraídos a los 28 días. La escala de las imágenes a y b corresponde a $20 \mu \mathrm{m}$ y las imágenes c y d corresponden a $50 \mu \mathrm{m}$.

En la figura 3.34 se puede observar como en el interior del scaffold las células están bien extendidas, adheridas a la pared de los poros con múltiples filopodias, favoreciendo el contacto intercelular $\mathrm{y}$ formando puentes intercelulares entre los poros.

Además se puede observar claramente en la figura 3.35 la formación de matriz extracelular en los scaffolds de CHT a partir de los 14 días de cultivo. 


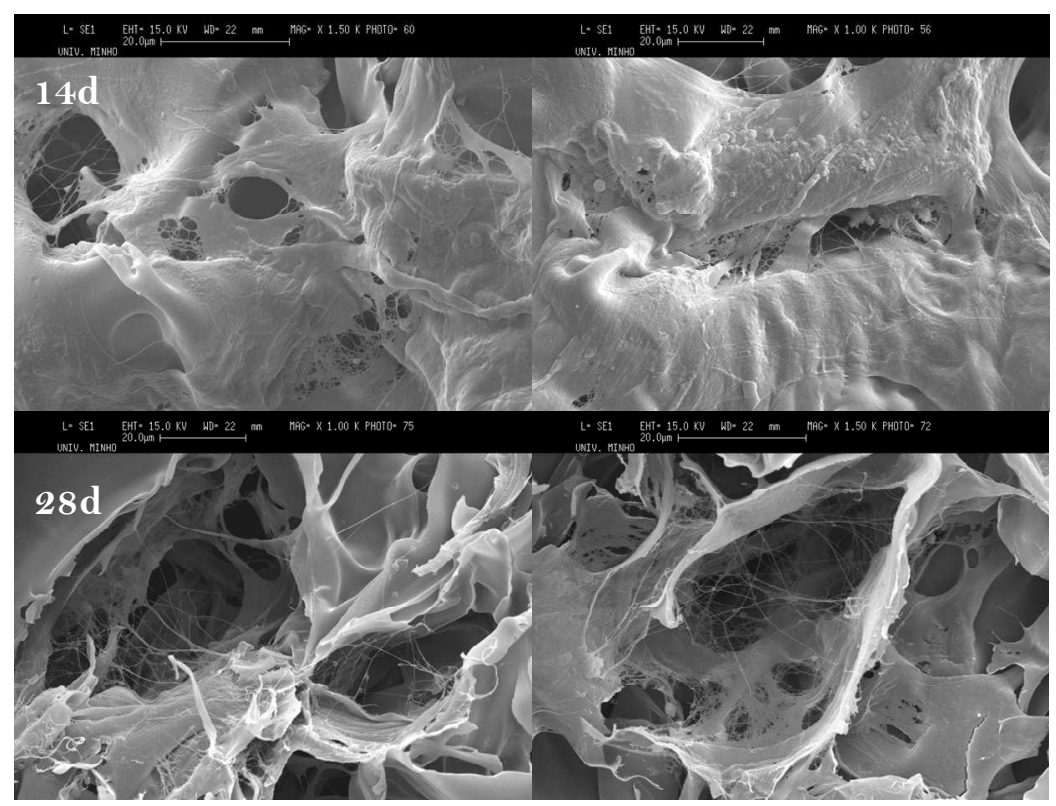

Figura 3.35. Micrografías de SEM de los scaffolds de CHT, sembrados con GBMCs, extraídos a los 14 días de cultivo y cortes transversales de los constructos células-scaffold a los 28 días. La escala de las imágenes corresponde a $20 \mu \mathrm{m}$.

Para evaluar la viabilidad celular de los scaffolds de quitosano sembrados con GBMSCs se utilizo el ensayo de MTS a los 3, 7, 14, 21 y 28 días de cultivo. En la figura 3.36 se representa el número de células viables en función del tiempo. 


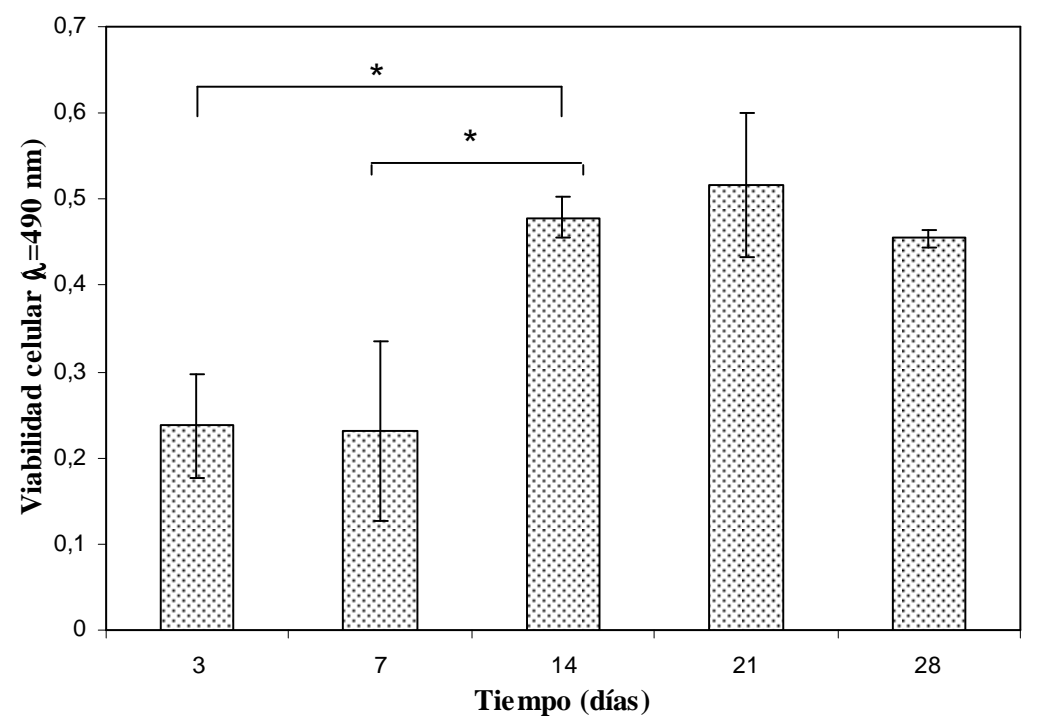

Figura 3.36. Viabilidad celular en los scaffolds de quitosano cultivados durante $3,7,14,21$ y 28 días de cultivo. $* p<0.05$.

Los resultados obtenidos en los ensayos de viabilidad celular muestran un continuo incremento en el número de células viables hasta el día 14 de cultivo, obteniéndose diferencias significativas entre el día 7 y 14 donde se duplica el número de células. A partir del día 14, la viabilidad celular se mantiene aproximadamente constante durante los días 21 y 28 ( $\mathrm{p}<0.05)$.

Un comportamiento similar fue observado en los ensayos de cuantificación del contenido de DNA en los scaffolds (figura 3.37), donde el número de células se triplica (del día 3 de cultivo al día 14) demostrando una buena proliferación celular. 


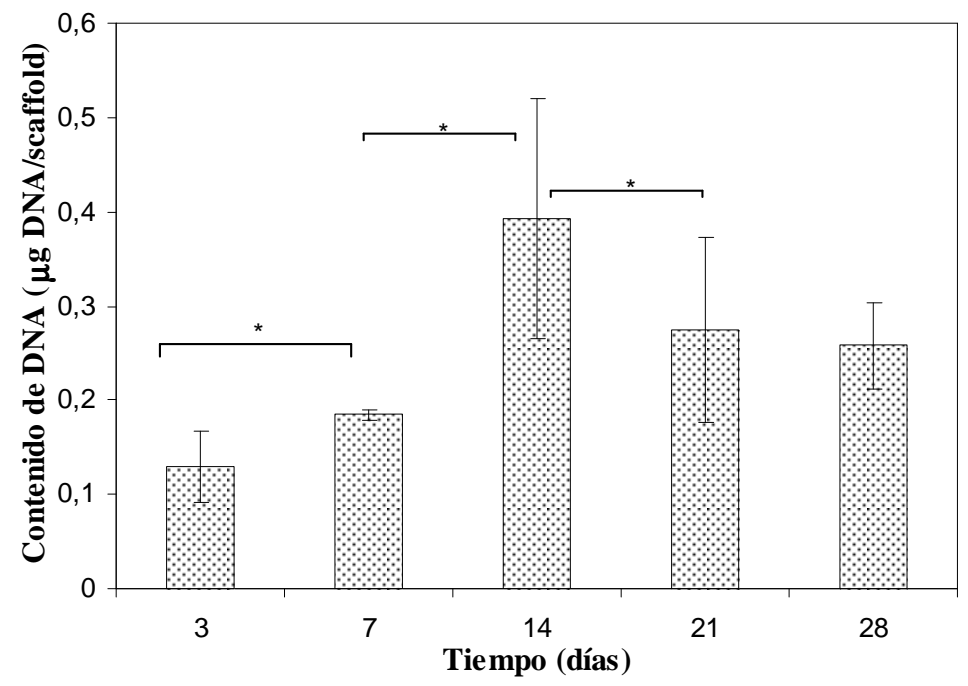

Figura 3.37. Cuantificación de DNA de las GBMSCs para scaffolds de CHT después de 3, 7, 14, 21 y 28 días de cultivos en medio osteogénico. $* p<0.05$.

Otro de los objetivos en esta parte del trabajo era determinar si las GBMSCs cultivadas en los scaffolds de quitosano en medio de diferenciación osteogénico se habían diferenciado a osteoblastos, las células del tejido óseo. En los modelos de diferenciación osteogénico "in vitro" con el transcurso del tiempo de cultivo en medio de diferenciación, tienen lugar cambios en los niveles de expresión de moléculas asociadas al fenotipo osteoblástico y diferentes combinaciones de marcadores específicos de este tipo de célula [224]. Generalmente, la diferenciación a osteoblastos tiene lugar en tres etapas. Una primera etapa de proliferación celular, seguida de una etapa de maduración y una tercera etapa de mineralización de la matriz extracelular (ECM). Durante la etapa de proliferación la expresión de colágeno tipo I es relativamente alta y después disminuye [225 y 226] mientras que durante la maduración y la síntesis de la matriz extracelular son expresados marcadores específicos del fenotipo osteoblástico como la fosfatasa alcalina (una 
glicoproteína presente en la superficie de la célula que se detecta en los primeros estadíos del proceso de diferenciación y que está involucrada en el proceso de mineralización) y la osteocalcina (una matriz proteica que regula la actividad de los osteoclastos). La fosfatasa alcalina en la primera etapa presenta niveles altos pero luego disminuye cuando empieza la mineralización [226 y 227]. La osteocalcina aparece aproximadamente con la mineralización [228].

En este estudio, para comprobar si las GBMCs se habían diferenciado a osteoblastos se realizaron ensayos inmunocitoquímicos para detectar la expresión de marcadores específicos de este tipo de célula como el colágeno tipo I, la fosfatasa alcalina (ALP) y la osteocalcina. Para ello, se realizaron los ensayos inmunocitoquímicos sobre cortes transversales de los constructos células-scaffold extraídos a los 14, 21 y 28 días de cultivo. En la figura 3.38 se muestran las imágenes de CLSM de cada uno de los marcadores a los 14 días de cultivo.

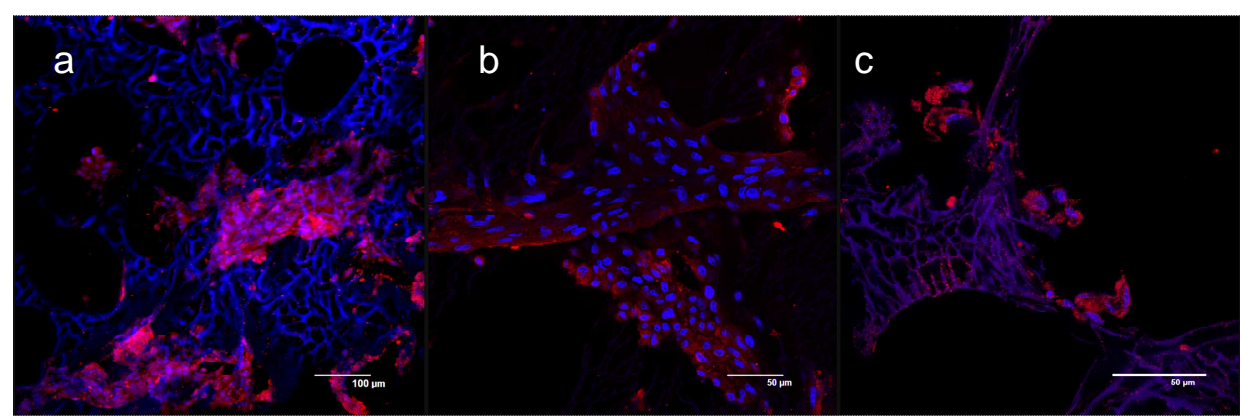

Figura 3.38. Análisis de inmunofluorescencia de marcadores de osteoblastos, en las GBMSCs cultivadas en los scaffolds de CHT. Las imágenes a, b y c corresponden al colágeno tipo I, osteocalcina y ALP respectivamente a los 14 días de cultivo.

En la figura 3.38a se muestra el colágeno tipo I en color rojo y los núcleos de las células en color azul. El colágeno es detectado tanto en las células que están adheridas al material como las que están dentro de los poros. 
El quitosano es fluorescente en las mismas frecuencias que el DAPI por lo que podemos apreciar la estructura porosa del material y su tri-dimensionalidad. La fosfatasa alcalina localizada en la superficie de las células también se puede apreciar en color rojo en la imagen (c) de la figura 3.38. La osteocalcina también da positivo a los 14 días de cultivo por lo que analizando todos los resultados en conjunto podemos decir que las GBMSCs se han diferenciado a osteoblastos, las células del tejido óseo y que se encuentran en la etapa de mineralización de la matriz extracelular.

Una vez caracterizado los scaffolds y concluido los estudios biológicos podemos decir que los scaffolds de quitosano a pesar de promover la proliferación y diferenciación celular a células de tejido óseo sus propiedades mecánicas no son las más adecuadas para este tipo de aplicación. No obstante, consideramos que estos materiales poseen un enorme potencial y pueden ser utilizados en otras aplicaciones de la ingeniería de tejidos.

\subsubsection{Cultivo "in vitro" de condrocitos en condiciones estáticas y dinámicas en scaffolds de quitosano.}

Teniendo en cuenta los resultados obtenidos tanto en el estudio biológico como en los ensayos mécanicos de los scaffolds de CHT descritos en el apartado 3.4.4 nos planteamos realizar ensayos biológicos con los mismos materiales, (scaffolds de CHT) pero esta vez utilizando condrocitos humanos primarios ya que pensamos que de acuerdo a las propiedades de estos materiales, su uso en la regeneración del cartílago articular es la aplicación más apropiada. Para ello, nos hemos propuesto realizar los estudios biológicos tanto en condiciones estáticas como en dinámicas (utilizando un bioreactor de flujo con agitación intermitente) y analizar sí en estas condiciones las células son capaces de mantener su fenotipo. 
Para dar cumplimiento a este objetivo, se inyectaron $50 \mu \mathrm{l}$ de una suspensión celular que contenían $1 \times 10^{6}$ células en los materiales $3 \mathrm{D}$ y los constructos (células-scaffold) fueron incubados durante 1 hora (en condiciones estáticas) con el objetivo de promover la adhesión celular. Transcurrido ese tiempo, una parte de los constructos fueron transferidos a una nueva placa de cultivo y se añadió $800 \mu \mathrm{l}$ de medio de cultivo (ver apartado 2.1.4.). Por otra parte, el ensayo dinámico se llevo a cabo en un bioreactor con agitación intermitente, donde se introdujeron el resto de los constructos y fueron agitados a $60 \mathrm{rpm}$ de manera intermitente en intervalos de 5 minutos y en estático (o rpm) durante otros 15 minutos en las primeras 72 horas, para pasar a agitación continua el resto del tiempo de cultivo. El experimento se llevó a cabo por triplicado durante 28 días, extrayendo los constructos a las 17 horas (el cual estimamos como tiempo cero), 7, 14 y 28 días.

La figura 3.39 muestran las micrografías de SEM de la superficie de los constructos a las 17 horas (tiempo 0), 14 y 28 días de cultivo en condiciones estáticas y dinámicas. 


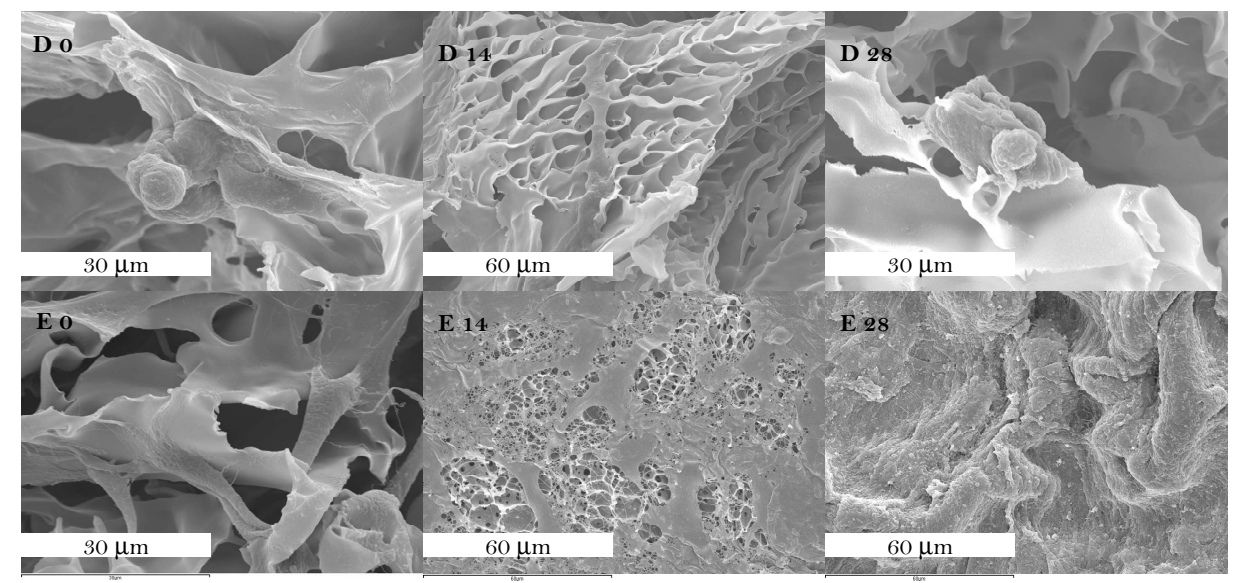

Figura 3.39. Micrografías de SEM de la superficie de los constructos a las 17 horas (tiempo 0), 14 y 28 días de cultivo en condiciones estáticas (Eo, E14 y E28) y dinámicas (Do, D14 y D28).

Como se puede observar en los ensayos estáticos las células presentan una buena adhesión celular, con una morfología plana y expandida, además a medida que aumenta el tiempo de cultivo se ve una gran proliferación celular, llegando a cubrir el cultivo la estructura tridimensional de los scaffolds. En el caso de los ensayos dinámicos, la morfología de las células es distinta, donde las células tienen una forma esférica con una pobre adhesión y a tiempos de cultivos mayores (14 y 28 días) no se observa gran diferencia con el tiempo o lo cual nos sugiere que existe una baja proliferación en los cultivos.

En la figura 3.40 se muestran las imágenes de los cortes transversales de los scaffolds a las 17 horas (tiempo 0), 14 y 28 días de cultivo en condiciones estáticas y dinámicas. 


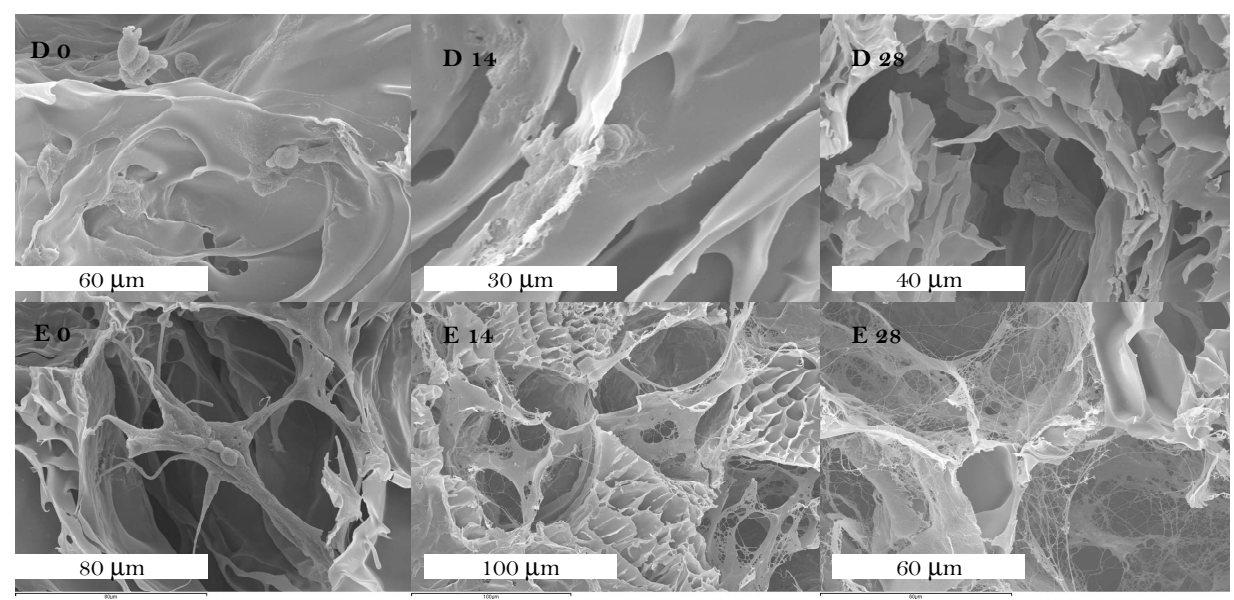

Figura 3.40. Micrografías de SEM de los cortes transversales de los constructos a las 17 horas (tiempo 0), 14 y 28 días de cultivo en condiciones estáticas (EO, E14 y E28) y dinámicas (Do, D14 y D28).

Pudimos observar como las células en los cultivos estáticos han podido migrar por el interior del scaffolds, presentando buena adhesión, proliferación y morfología plana e incluso hemos podido ver la formación de matriz extracelular a los 28 días de cultivos. Éste comportamiento no ha sido el mismo para los cultivos realizados en dinámico donde se observan muy pocas células, con una morfología esférica.

La figura 3.41 representa los resultados obtenidos en los ensayos de MTS de los constructos tanto en condiciones dinámicas como estáticas a las 17 horas (tiempo 0), 14 y 28 días de cultivo. 


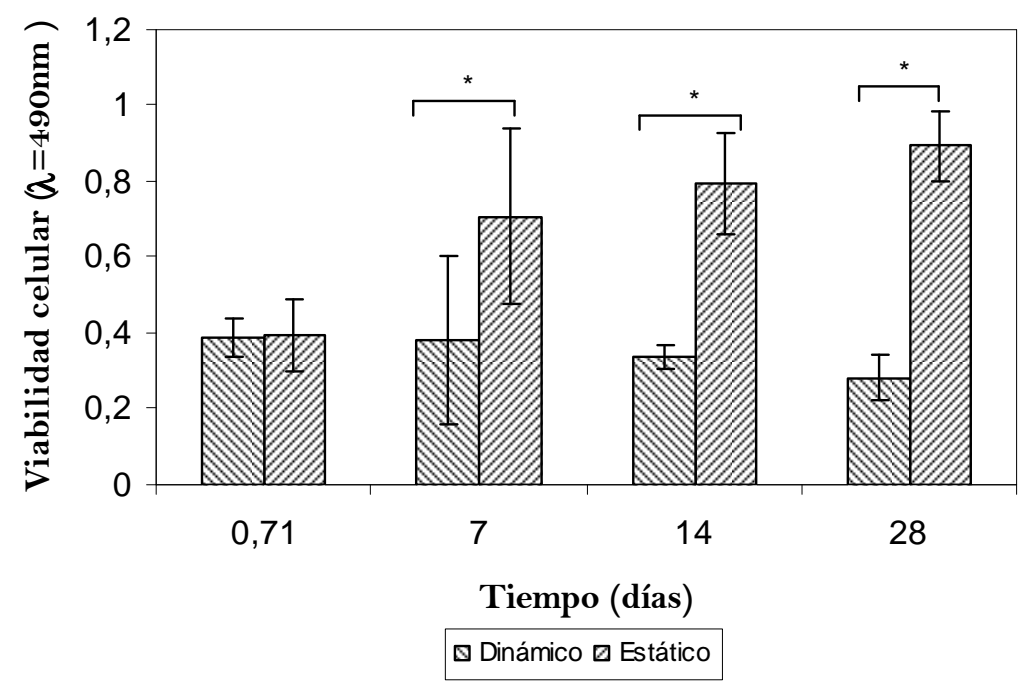

Figura 3.41.Viabilidad celular de los constructos (scaffold/células) a las 17 horas (tiempo 0), 14 y 28 días de cultivo en condiciones estáticas y dinámicas. $* p<0.05$

De la figura anterior se observa como aumenta el número de células con el tiempo de cultivo en el ensayo estático, no siendo así en el ensayo dinámico donde el comportamiento es el contrario. Si comparamos ambos estudios podemos ver como el número de células viables en ambos ensayos (dinámico y estático) es prácticamente la misma a tiempo o y a tiempos mayores existen diferencias significativas ( $p<0.05$, test de ANOVA) entre ambos, lo cual concuerda con los resultados obtenidos en las imágenes de SEM.

Teniendo en cuenta las diferencias observadas en cuanto a la morfología de las células y los resultados obtenidos en el ensayo de MTS entre el cultivo en estático y en el bioreactor, nos planteamos analizar la composición de la matriz extracelular en cada caso, para ello se realizaron ensayos inmunocitoquímicos de los siguientes marcadores: colágeno tipo I, colágeno 
tipo II y agrecano. Además utilizamos como marcador de proliferación el Ki-67 y realizamos tinciones para detectar la formación del citoesqueleto de actina.

Los condrocitos son las células encargadas de sintetizar la matriz extracelular del cartílago hialino, donde los principales componentes de dicha matriz son los proteoglicanos y el colágeno tipo II. Las fibrillas de colágeno adoptan un patrón morfológico en forma de malla o red concéntrica que rodea a los grupos isogénicos (agrupación de condrocitos que descienden de una misma célula por el proceso de mitosis del crecimiento intersticial) y los proteoglicanos que son proteínas complejas y que se sitúan en los intersticios de la red colágena del cartílago [229 y 230].

En primer lugar, tal como ya se vió en los cultivos de células madre en medio osteogénico, la autofluorescencia del quitosano permite observar en el microscopio confocal la morfología de los scaffolds mejor que en el microscopio electrónico de barrido. La figura 3.38 muestra claramente las secciones de los macroporos perfectamente circulares, y esto es un hecho a destacar porque significa que en el proceso de fabricación del scaffold la contracción es isótropa, no distorsiona la estructura de los poros. Se aprecian también con mucha claridad las laminillas de quitosano que forman la matriz del scaffold dejando espacios entre ellas del orden de las $10 \mu \mathrm{m}$, como ya hemos mencionado antes. Claramente los macroporos están interconectados y permiten que cuando se siembran las células inyectando una suspensión de condrocitos en el centro del scaffold con la jeringuilla de precisión, el flujo recorra el scaffold completo y permita que sea completamente invadido. El comportamiento de los condrocitos en cultivo estático y dinámico es muy diferente. Es interesante cómo en el caso del cultivo estático las células están distribuidas por todo el 
volumen de forma más o menos uniforme, como se ve en la imagen de la figura 3.42, más adelante veremos que hay signos de que las células se adhieren a las paredes de los poros, mientras que en el cultivo dinámico las células se agrupan y parecen separadas de las paredes del poro.
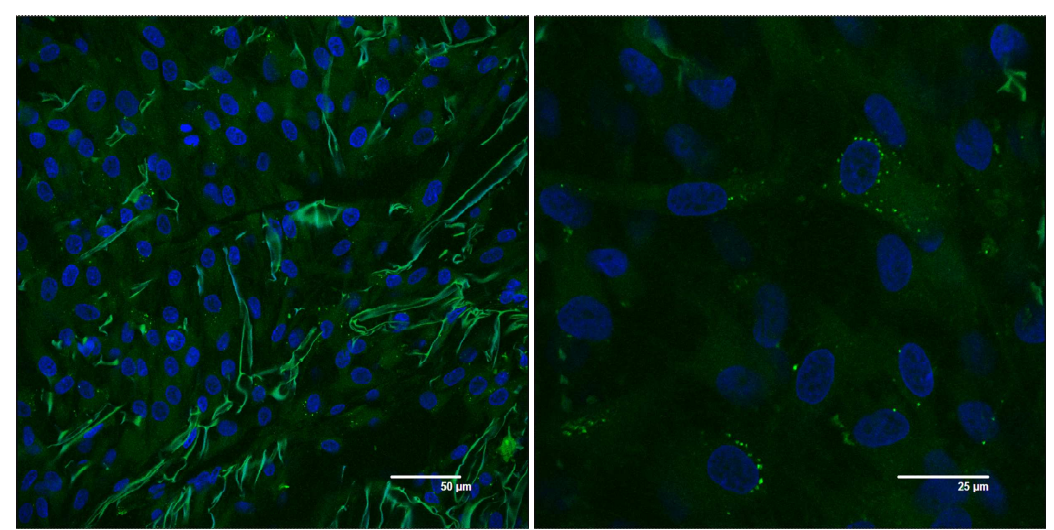

Figura 3.42. Análisis de inmunofluorescencia de agrecanos de condrocitos primarios cultivados en materiales 3D en condiciones estáticas a los 14 días de cultivo.

Existe la duda de si las células que se mantienen en el cultivo estático durante todo el tiempo proliferan dentro de los poros o no lo hacen. El ensayo de MTS y la medida de DNA indican que hay proliferación, con un aumento continuo del número de células al menos hasta los 14 días, pero puede ser que este aumento se deba a la proliferación de las células que forman la capa externa que recubre el scaffold y que se observa en SEM (ver la figura 3.36). Esa capa exterior puede decirse que se trata de células que se conservan como si se hubieran cultivado en monocapa, proliferando hasta confluencia en periodos de tiempo del orden de 14 días. Podría ser, sin embargo, que las células que ocupan el interior del scaffold por el hecho de encontrarse las células en un entorno tridimensional acercasen más su comportamiento al de las células "in vivo". Hay varias características del comportamiento de los 
condrocitos cultivados en monocapa: por una parte la adhesión de la célula al sustrato se inicia por el reconocimiento por las integrinas de la célula de secuencias de adhesión de las proteínas que se hayan adsorbido sobre el sustrato (en el caso de las células del interior del scaffold, las paredes de los poros), el agrupamiento de estas integrinas y la formación de adhesiones focales y la polimerización del citoesqueleto de actina. Cuando se realizaron las tinciones de F-actina en las secciones transversales del scaffold se observa (figura 3.43) la formación del citoesqueleto en una serie de células que hay que pensar que se encuentran adheridas a la pared del poro.
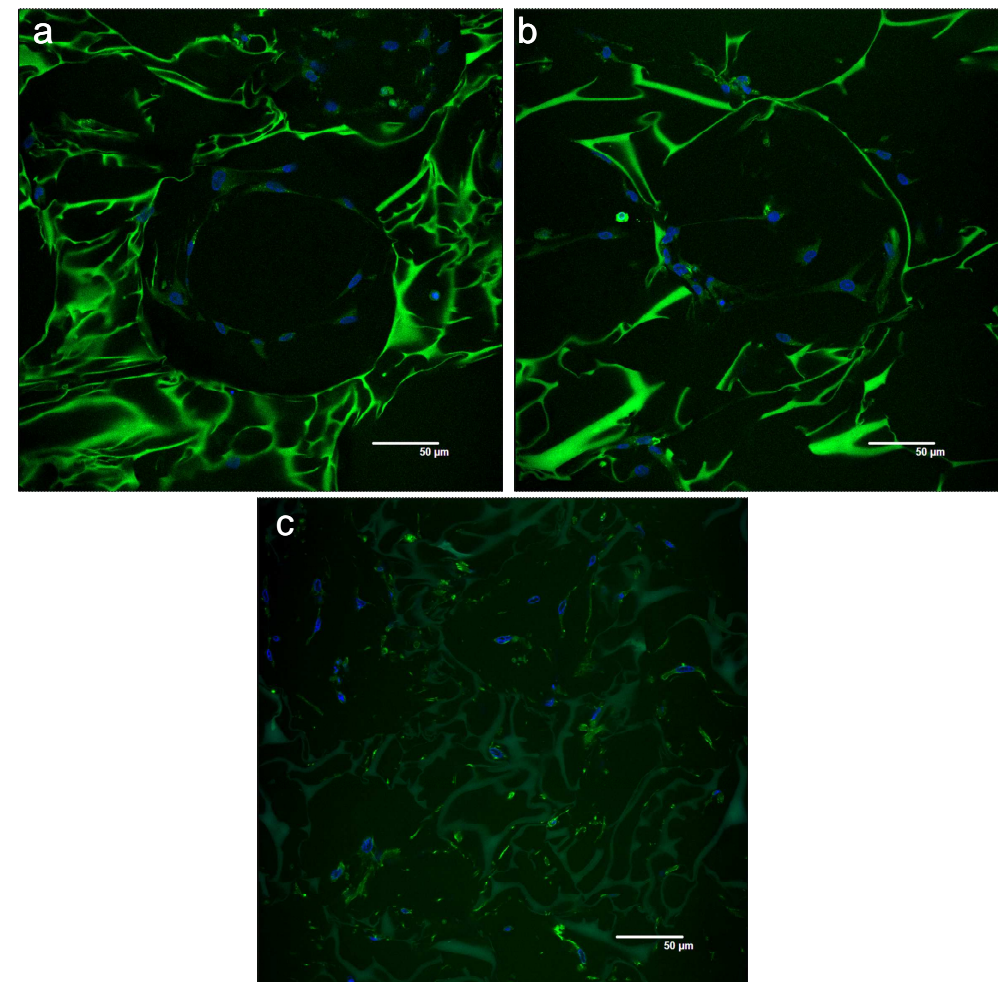

Figura 3.43. Análisis de inmunofluorescencia del citoesqueleto de actina de condrocitos primarios cultivados en materiales $3 \mathrm{D}$ en condiciones estáticas a los 7 (a), 14 (b) y 28 (c) días de cultivo. 
Por otra parte, estas células adheridas al sustrato proliferan, y de hecho se observan células en el interior del poro Ki67 positivas (figura 3.44), es decir que se encuentran en el ciclo de proliferación.

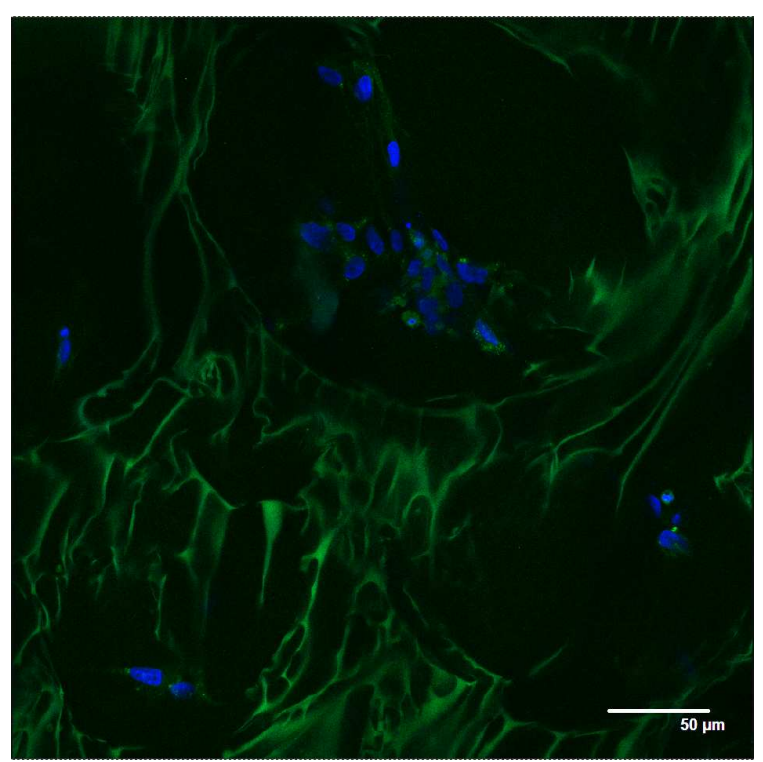

Figura 3.44. Análisis de inmunofluorescencia de Ki-67 de condrocitos primarios cultivados en materiales 3D en condiciones estáticas a los 14 días de cultivo.

Otra de las características de estas células proliferativas es su desdiferenciación, produciendo colágeno tipo I que no se encuentra en el cartílago hialino "in vivo". Es muy interesante observar cómo en el scaffold cultivado en condiciones estáticas hay zonas en las que claramente las células expresan colágeno tipo I a los 14 días de cultivo (figura 3.45a y 3.45b), pero muchas otras que no lo hacen. No obstante, a los 28 días de cultivo se observa claramente que las células sintetizan en abundancia el colágeno tipo I, recubriendo todos los poros del material (figura $3.45 \mathrm{c}$ y $3.45 \mathrm{~d}$ ). 

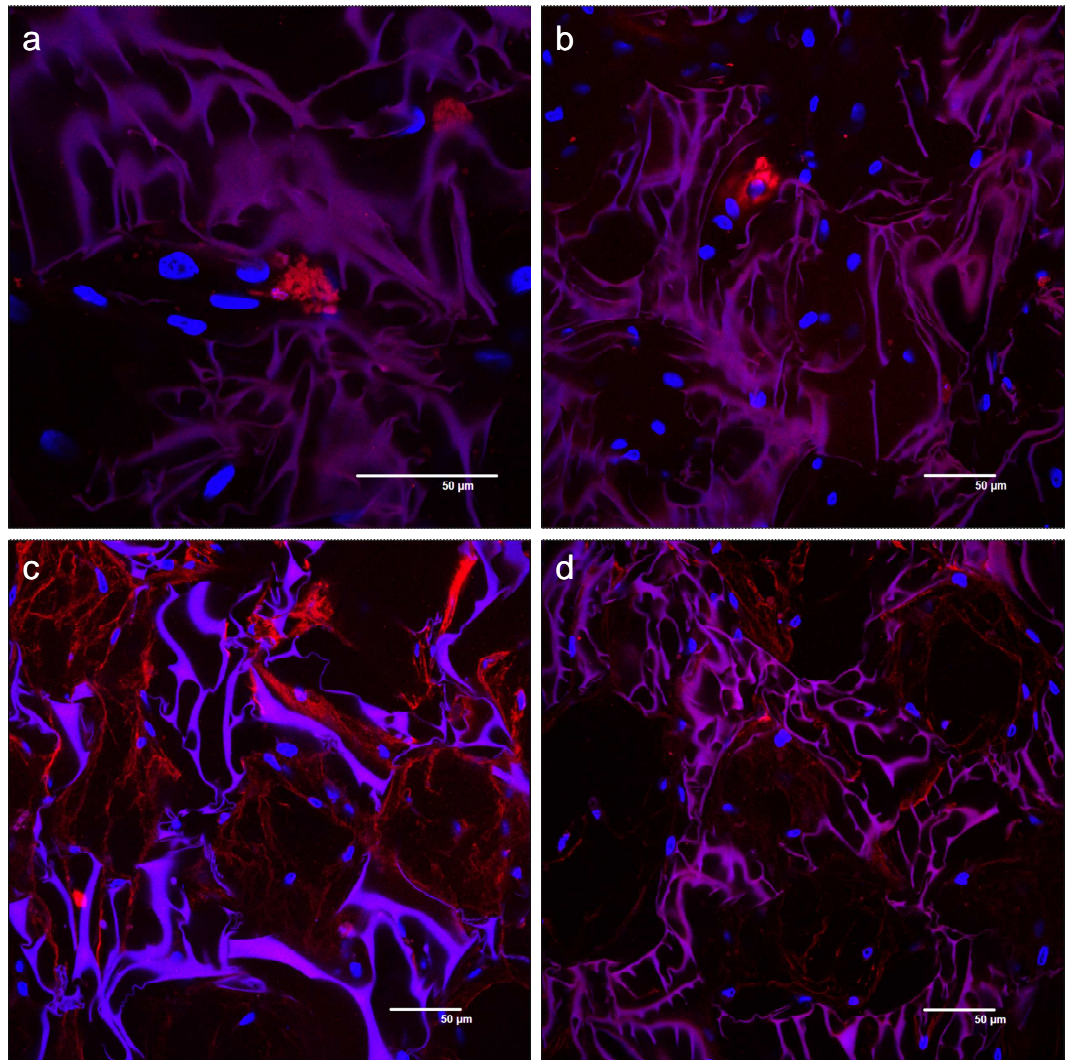

Figura 3.45. Análisis de inmunofluorescencia de colágeno tipo I de condrocitos primarios cultivados en materiales 3D a los 14 (a y b) y 28 (c y d) días de cultivo en condiciones estáticas.

Por otro lado también se encuentra expresión de colágeno tipo II en estos scaffolds (figura 3.46). Hay que tener en cuenta que los condrocitos no expresan simultáneamente colágeno tipo I y colágeno tipo II. Todo ello nos lleva a pensar que una parte de las células que se siembran en el scaffold se adhieren a las paredes y esas células se comportan como si estuvieran en monocapa, pero otras no están adheridas y ocupan el interior de los poros, adquiriendo un comportamiento diferenciado. 

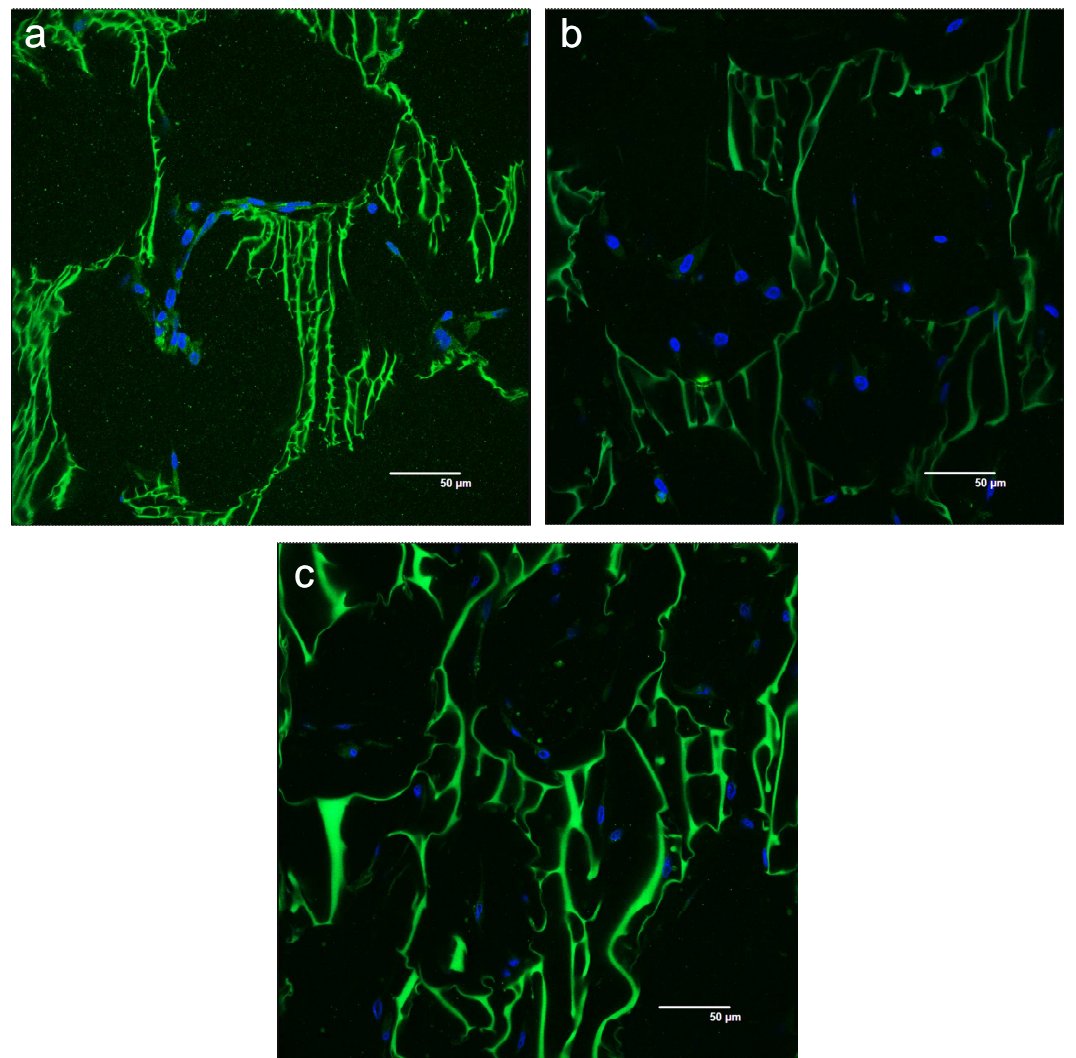

Figura 3.46. Análisis de inmunofluorescencia de colágeno tipo II de condrocitos primarios cultivados en materiales 3D a $\operatorname{los} 7$ (a), 14 (b) y 28 (c) días de cultivo en condiciones estáticas.

El proceso de siembra es el mismo para los cultivos en estático y en el bioreactor. $\mathrm{Al}$ pasar los soportes al bioreactor el primer efecto claro es que el flujo del medio de cultivo alrededor de las muestras evita la formación de la capa de células (figura 3.39) y matriz extracelular que recubre el scaffold en el cultivo estático. Por otra parte, las diferencias encontradas en las células del interior del scaffold respecto a las del cultivo estático muestran que el medio de cultivo fluye por el interior del scaffold y somete a las células a esfuerzos cortantes que tienen un efecto en la diferenciación celular [231 y 232]. Como 
se ve en las figuras 3.47 y 3.48, las células forman agregados que se parecen a los que forman los condrocitos cultivados en "pellets", en ausencia de soportes [233 y 234]. Estos agregados no parecen tener contacto con las paredes de los poros. Las células en ellos expresan claramente agrecano (figura 3.47) y colágeno tipo II (figura 3.48) y no colágeno tipo I y por lo tanto parecen adquirir el fenotipo propio de las células del cartílago hialino: También es claro que no desarrollan el citoesqueleto de F-actina ni se encuentran células Ki67 positivas, es decir en proliferación.
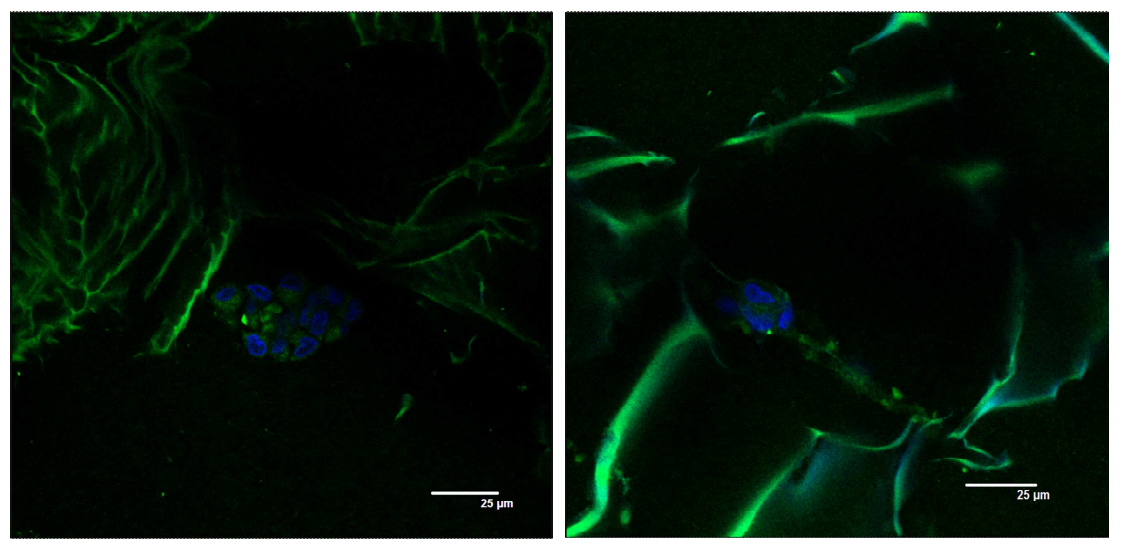

Figura 3.47. Expresión de agrecanos de condrocitos primarios cultivados en materiales $3 \mathrm{D}$ a los 7 y 14 días de cultivo en el bioreactor. 

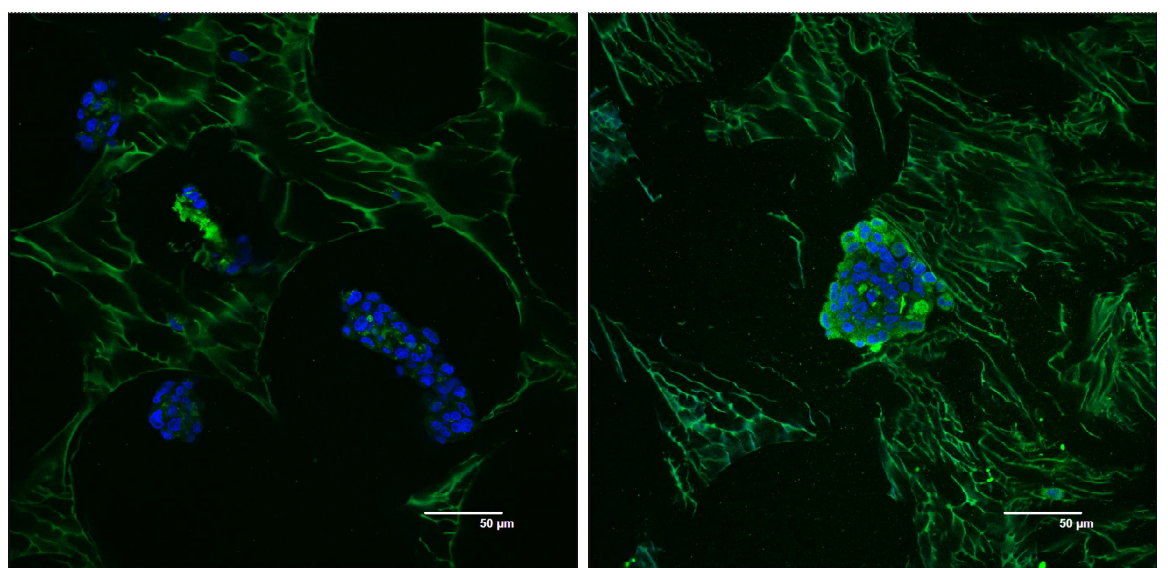

Figura 3.48. Expresión de colágeno tipo II de condrocitos primarios cultivados en materiales $3 \mathrm{D}$ a los 7 y 14 días de cultivo en el bioreactor.

Estos resultados revelan el gran papel que la acción mecánica juega en la diferenciación de los condrocitos. En el cartílago hialino, un tejido altamente hidratado debido a su alto contenido de proteoglicanos, las cargas de compresión que actúan en la articulación tienen por una parte un efecto directo del que las células se protegen aislándose en lagunas rodeadas por la matriz extracelular de alto módulo elástico que apantalla las elevadas cargas mecánicas, pero por otra tienen también un efecto de impulso de flujo de fluidos a través del tejido que suministra nutrientes y ejerce un efecto de estímulo mecánico quizás similar al que se produce en el bioreactor. 


\subsection{Proliferación y adhesión de GBMSCs sobre las micropartículas de quitosano}

En esta parte del trabajo el objetivo fundamental fue desarrollar constructos tri-dimensionales mediante la combinación de micropartículas de quitosano y células madre para el transplante de células mediante una estrategia de mínima invasión en el organismo humano.

Este planteamiento se presenta como una alternativa muy prometedora frente a los inconvenientes y dificultades que a menudo surgen en la implantación de scaffolds 3D sembrados con células. Las micropartículas pueden ser utilizadas conjuntamente con células en la regeneración de tejidos, teniendo como expectativa que dichas partículas puedan aglomerarse después de una implantación como consecuencia de la proliferación celular y la producción de matriz extracelular, jugando el importante papel de un material tridimensional.

Desde hace varios años el quitosano ha sido utilizado en la producción de scaffolds para la ingeniería tisular [235 y 236], simultáneamente, las partículas de quitosano han sido preparadas para su uso en los sistemas de liberación de moléculas terapéuticas [237]. Es por ello, que en esta parte del trabajo usaremos las micropartículas de quitosano para probar el concepto anteriormente descrito.

Las micropartículas de quitosano fueron preparadas por el método de emulsión [238 y 239] como se describe en el apartado 2.2.5.1 de la parte experimental utilizando una solución de genipin como agente entrecruzante en dos concentraciones diferentes, 20 y $40 \mathrm{mM}$. La morfología de las 
micropartículas obtenidas fue examinada mediante imágenes de microscopía óptica (figura 3.49). Las micropartículas presentan una superficie lisa, tienen una geometría esférica, son de color azul y tienen un tamaño promedio igual a $70 \pm 20 \mu \mathrm{m}$ y $60 \pm 10 \mu \mathrm{m}$ para las micropartículas entrecruzadas con 20 y $40 \mathrm{mM}$ de genipin respectivamente.
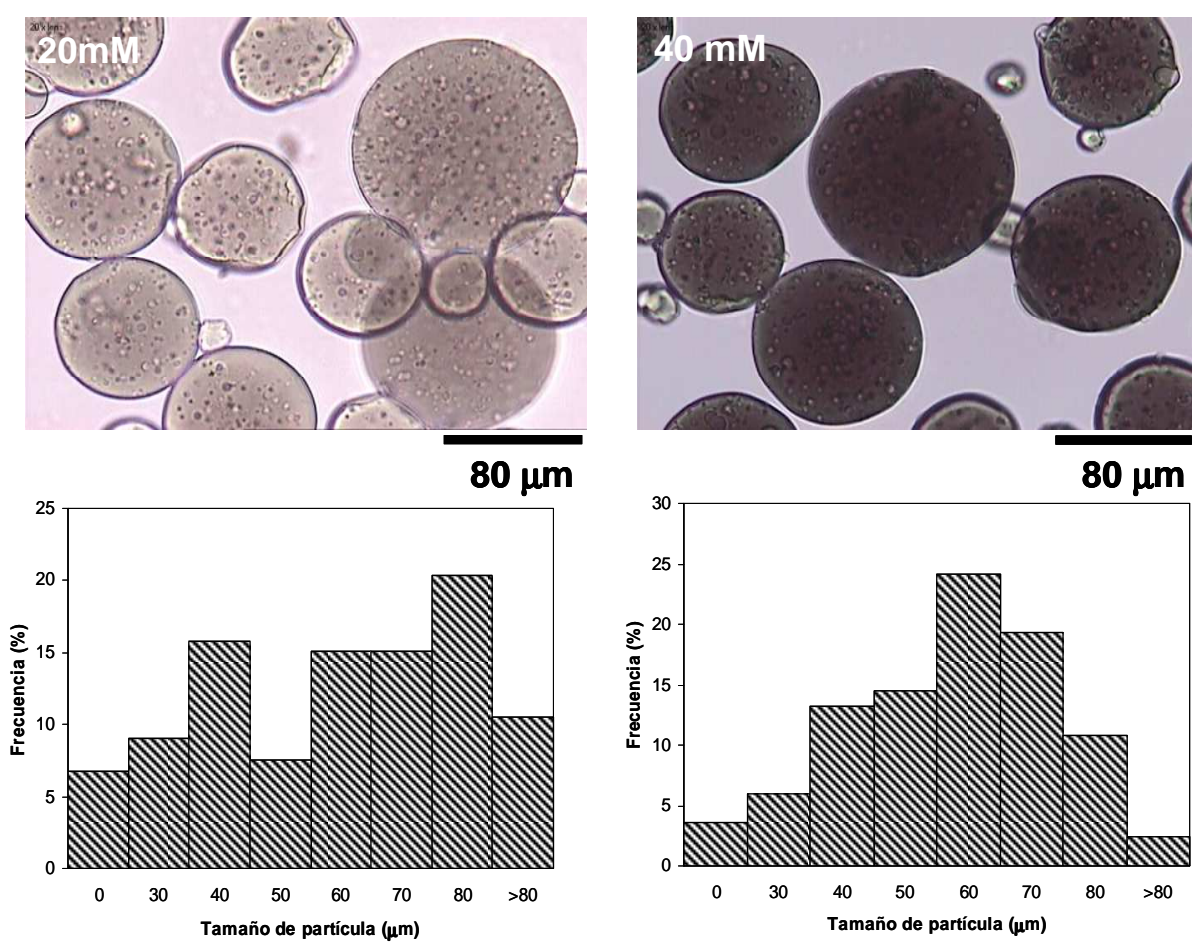

Figura 3.49. Morfología de las micropartículas entrecruzadas con una solución de 20 y $40 \mathrm{mM}$ de genipin y sus respectivos histogramas con el tamaño de partícula.

Una vez obtenida las micropartículas y antes de realizar los cultivos celulares realizamos los ensayos de citotoxicidad celular "in vitro" siguiendo el procedimiento descrito en la parte experimental según la norma ISO 10993. 
En la figura 3.50 se muestran las imágenes de microscopía óptica de las células L929 que han sido cultivadas con el medio que ha estado en contacto con las micropartículas de quitosano entrecruzadas con diferentes concentraciones de genipin y el control positivo y negativo a los 14 días de cultivo.
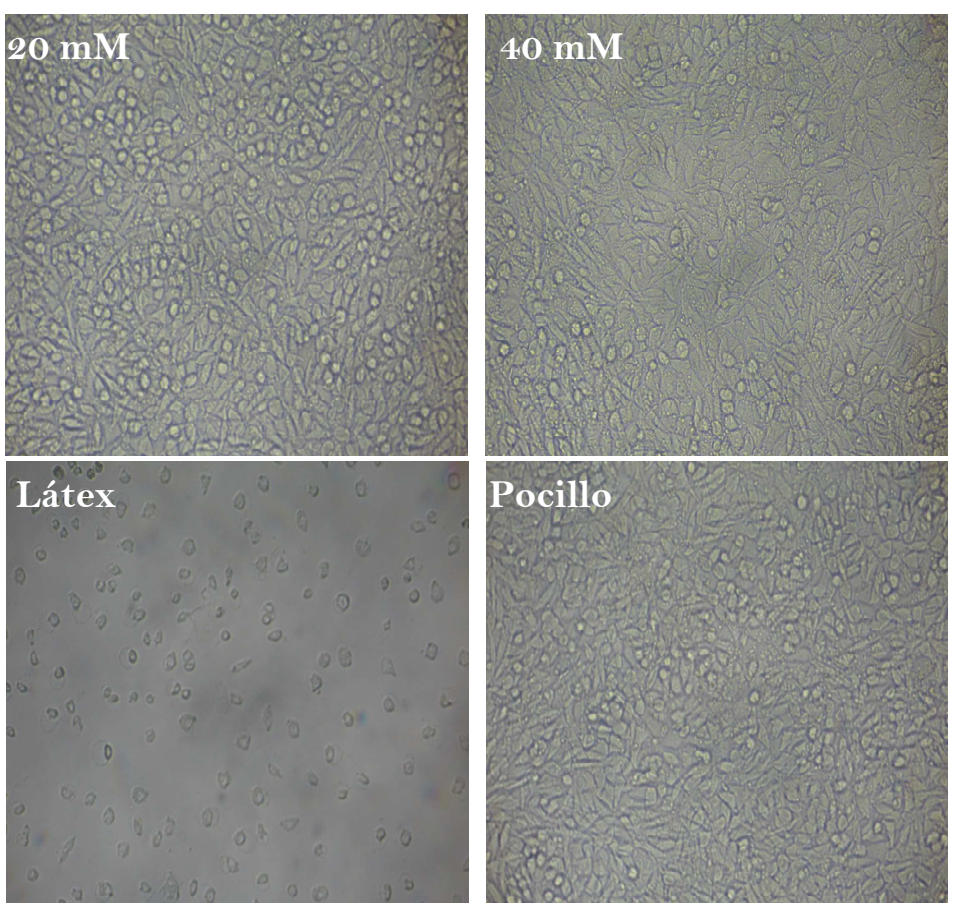
cultivo.

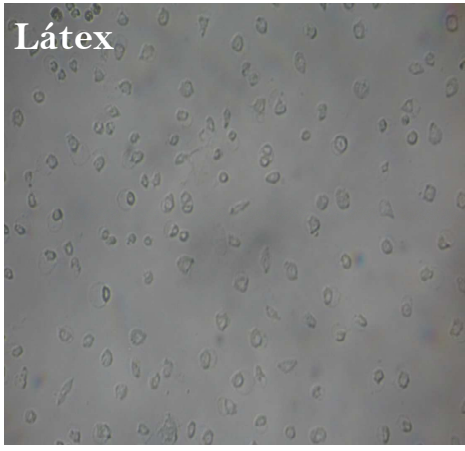

Figura 3.50. Imágenes de microscopía óptica de las células L929 a los 14días de

Como se puede observar las células en el control positivo se despegan del pocillo y adoptan una morfología redondeada, sin embargo las que han sido cultivadas con el medio de las micropartículas presentan una morfología extendida, típica de los fibroblastos y muy similar a la observada en el control negativo. 
La viabilidad celular fue evaluada mediante los ensayos de MTS a las 24 horas, 3, 7 y 14 días de cultivo. En la figura 3.51 se muestra el número de células viables en función del tiempo.

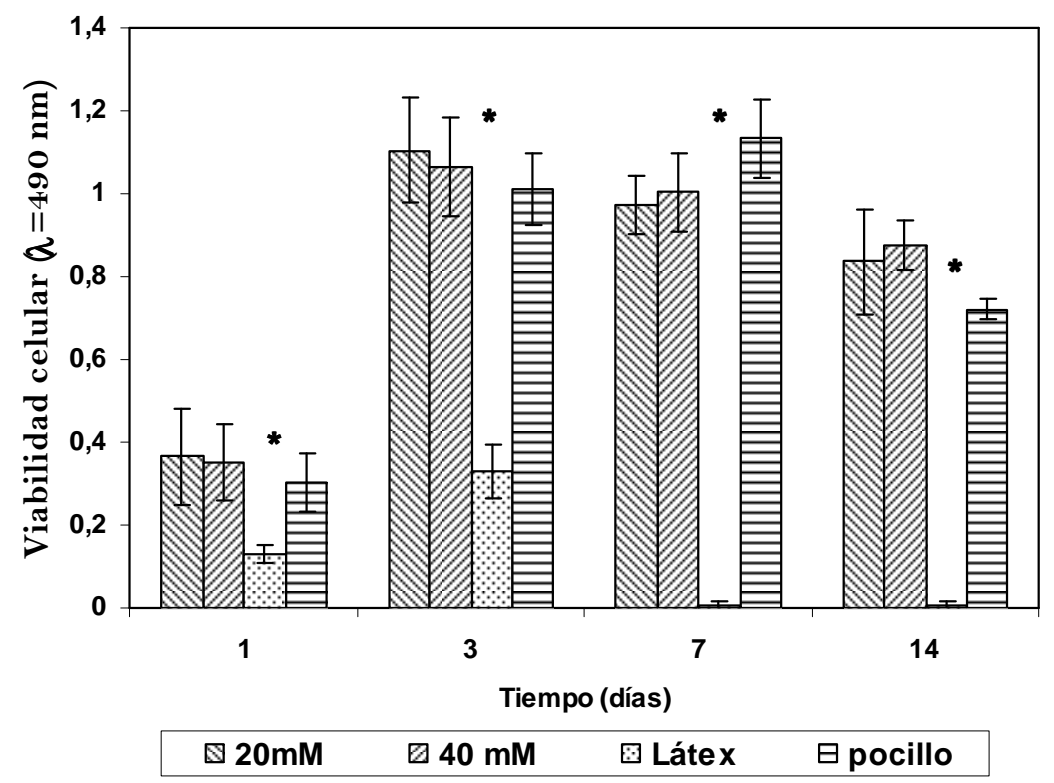

Figura 3.51. Viabilidad celular a las 24 horas, 3, 7 y 14 días de cultivo. *p< 0.05.

Los resultados obtenidos muestran una disminución significativa en el número de células viables en contacto con el látex, lo cual sugiere que el material es altamente tóxico para las células provocando la muerte celular. Por otro lado, el número de células viables en contacto con las micropartículas de quitosano entrecruzadas con 20 y $40 \mathrm{mM}$ de genipin se incrementa con el tiempo de cultivo, a niveles muy similares a los obtenidos en el control negativo por lo que hay proliferación y podemos decir que las micropartículas son biocompatibles. 
Para analizar la respuesta biológica de las micropartículas, se utilizaron las GBMSCs, las cuales fueron sembradas sobre las micropartículas a dos tiempos de cultivos ( 7 y 14 días).

Se evaluó la viabilidad y proliferación celular mediante el ensayo de MTS (Figura 3.52) demostrando que el quitosano crea un ambiente adecuado para la adhesión celular. El número de células viables es mayor en las micropartículas reticuladas con una solución de $20 \mathrm{mM}$ de genipin que las entrecruzadas con una mayor concentración (40mM). Dicho comportamiento puede ser explicado teniendo en cuenta que la reacción de reticulación con genipin ocurre químicamente a través de los grupos amina por lo que parece ser que un mayor número de grupos aminos libres favorece la proliferación celular [240].

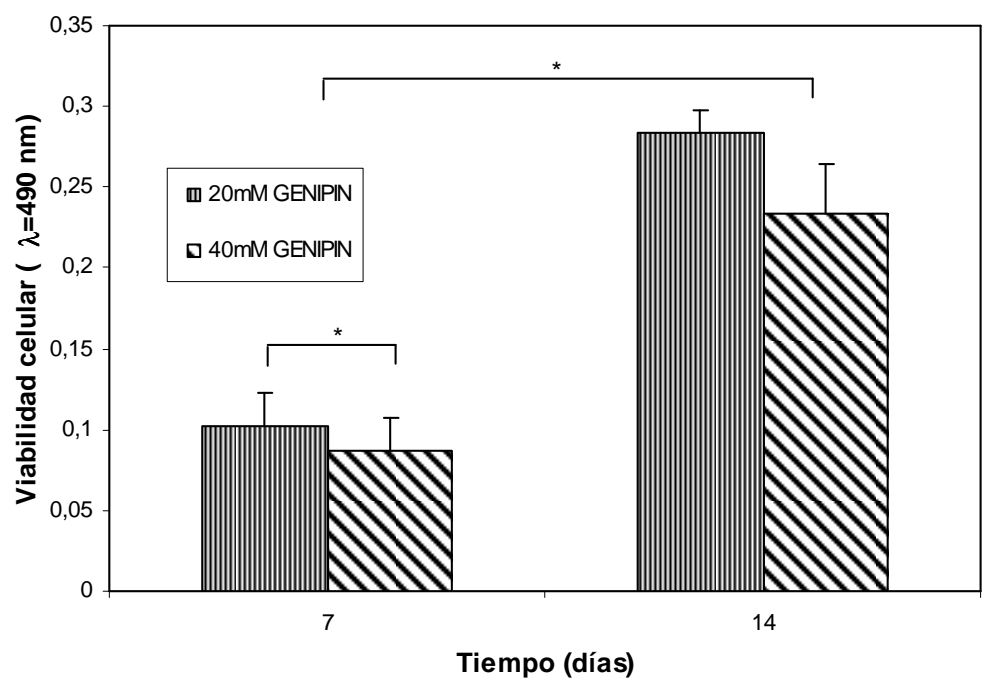

Figura 3.52. Viabilidad celular en las micropartículas de quitosano entrecruzadas con una solución de genipin de 20 y $40 \mathrm{mM}$ cultivados con las GBMSCs durante 7 y 14 días. $* p<0.05$. 
Mediante las imágenes de SEM se analizó la morfología y la adhesión de las células sobre las micropartículas de quitosano reticuladas con genipin. Como se muestra en la figura 3.53 después de los 7 días de cultivos las células están bien adheridas, observándose una gran proliferación, la formación de puentes celulares y pequeños agregados de células y partículas.

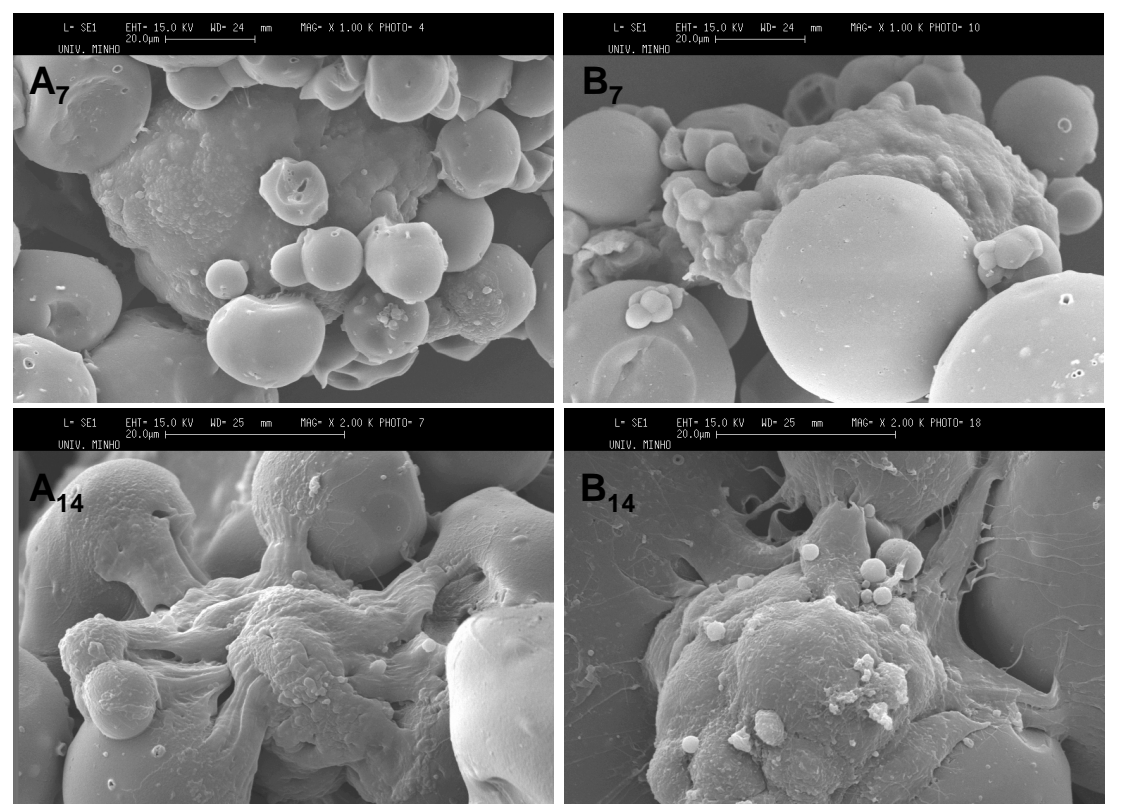

Figura 3.53. Micrografías de SEM de las GBMSCs sobre las micropartículas de quitosano entrecruzadas con $20 \mathrm{mM}$ (A) y $40 \mathrm{mM}$ (B) de genipin a los 7 y 14 días de cultivo.

Es de destacar que las células son de igual tamaño o mayores que las microesferas con una morfología extendida observándose la extensión de las filopodias sobre la superficie de las micropartículas. Por otro lado podemos decir que las células unen a estas micropartículas, brindándole al constructo final (células-micropartículas) un importante papel hacia la obtención de un material tridimensional que pueda ser utilizado en la ingeniería tisular. A 
Capitulo 3

diferencia de los scaffolds convencionales, este sistema es muy dinámico debido a que las micropartículas pueden ser desplazadas durante la proliferación celular permitiendo una expansión natural del tejido. 


\section{Conclusiones}


1. Se ha logrado preparar mezclas de PCL/CHT con diferentes contenidos de quitosano. En la morfología de las mezclas con un $90 \%$ de PCL se observa la formación de nanoagregados de quitosano alrededor de la laminilla cristalina de la PCL e incluso embebidos en las esferulitas. Las mezclas con un $20 \%$ de quitosano forman fases cocontinuas y en las muestras con un mayor contenido de quitosano la PCL se aprecia en forma de agregados dispersos en la mezcla. Las propiedades mecánicas de las mezclas de PCL/CHT son mejores que la de la PCL pura, las muestras que contienen a partir de un $20 \%$ de quitosano mantienen su integridad incluso por encima de la temperatura de fusión de la PCL.

2. Los resultados obtenidos en la cinética de cristalización de la PCL en las mezclas preparadas con PCL de bajo peso molecular, tanto en los experimentos isotérmicos como en los no-isotérmicos medidos a diferentes velocidades de enfriamiento han sido descritos fehacientemente haciendo uso de la teoría de Avrami con un exponente igual a 2.5. En las mezclas con un 10 \% de quitosano, el CHT actúa como agente nucleante en el proceso de cristalización de la PCL. Las mezclas que contienen a partir de un $20 \%$ de CHT la entalpía de cristalización disminuye significativamente, sí lo comparamos con la de la PCL pura.

3. La morfología de las mezclas de PCL/CHT preparadas con PCL de alto peso molecular analizada mediante AFM y microscopía confocal revela una distribución de dominios hidrófobos (la fase de la PCL) e hidrófilos (la fase del quitosano) en las diferentes muestras. A medida 
que aumenta el contenido de quitosano en las mezclas aumenta la capacidad de absorción de agua. Sin embargo, no existe una relación monótona entre la hidrofilicidad y la energía superficial de las muestras. En los cultivos "in vitro" de condrocitos sobre las mezclas se obtienen mejores resultados en cuanto a viabilidad y proliferación celular en las mezclas con un $20 \%$ de CHT que en las demás mezclas.

4. Se ha descrito un nuevo método para la obtención de scaffolds macroporosos de PCL y CHT a partir de la formación de redes poliméricas semi-interpenetradas de PCL y CHT. Durante la formación de las semiIPNs ambos polímeros interactúan entre sí a través de enlaces por puente de hidrógeno como ha sido demostrado en los espectros SDR-FTIR, en las medidas dinámico-mecánicas y en los estudios de degradación térmica. Los scaffolds macroporosos de PCL y CHT obtenidos mediante procesos de sinterización de las partículas de PCL y CHT (semiIPNs) y las microesferas de PEO utilizado como porógeno revela una estructura de poros abiertos e interconectados con una porosidad máxima de un $65 \%$.

5. Se han preparado scaffolds de quitosano utilizando diferentes cantidades de microesferas de PEMA como porógeno. La morfología de los scaffolds revela una estructura de micro y macroporosidad con poros de geometría esférica y altamente interconectados. La porosidad de todos los scaffolds es aproximadamente igual a un $85 \%$ y el tamaño de poro promedio oscila entre 120 y $140 \mu \mathrm{m}$ independientemente de la cantidad de porógeno utilizada. 
6. En los cultivos "in vitro" de células madre provenientes de médula ósea de cabra (GBMSCs) el número de células se incrementa con el tiempo de cultivo. A partir de los 14 días de cultivo las células se empiezan a diferenciar a osteoblastos, las células del tejido óseo según los resultados obtenidos en los ensayos inmunocitoquímicos.

7. En el cultivo de condrocitos en condiciones estáticas se aprecian células dispersas, muchas de ellas adheridas a las paredes de los poros y desarrollan el citoesqueleto de actina. Hay células que expresan colágeno tipo I y también hay células proliferando, Ki-67 positivas. También se observa expresión de colágeno tipo II y agrecano. El aumento con el tiempo del número de células probablemente es debido en mayor medida a las células que recubren el scaffold.

8. En el bioreactor, el flujo del medio de cultivo a través del scaffold y la acción de la fuerza centrífuga cambia el comportamiento: desaparece la cubierta exterior de células y matriz extracelular, las células se agrupan, tienen forma más redondeada, no se observa proliferación ni células Ki67 positivas, la expresión de colágeno tipo I es marginal y no se ha observado citoesqueleto de actina.

9. Se ha desarrollado un scaffold inyectable basado en micropartículas de quitosano y células madre (GBMSCs) para la regeneración de tejidos mediante métodos mínimamente invasivos. Las micropartículas de quitosano entrecruzadas con una solución de genipin fueron preparadas mediante el método de emulsión agua en aceite (w/o). El tamaño de partícula promedio es de $70 \mu \mathrm{m}$. En el estudio biológico, se 
ha demostrado que las micropartículas entrecruzadas de quitosano son biocompatibles y que la densidad de entrecruzamiento afecta ligeramente la viabilidad celular. Las células se extienden sobre la superficie de las micropartículas, uniéndolas entre sí formando un constructo tri-dimensional donde las micropartículas actúan como soporte del tejido. 


\section{Abreviaturas}

HA Ácido hialurónico

GAG Glicosaminoglicanos

CHT Quitosano

CS Sulfato de condroitina

$\mathrm{T}_{\mathrm{g}} \quad$ Temperatura de transición vítrea

SEM Microscopía electrónica de barrido

DTGA Análisis termogravimétrico

DMA Análisis dinámico mecánico

DSC

Calorimetría diferencial de barrido

FTIR Espectroscopía infrarroja de transformada de fourier

SDR-FTIR Reflectancia difusa-

$\Delta \mathrm{H}_{\mathrm{c}} \quad$ Entalpía de cristalización

$\Delta \mathrm{H}_{\mathrm{m}} \quad$ Entalpía de fusión

ALP Fosfatasa alcalina

Tris-EDTA Tris-ácido etilendiaminotetracético

$\tan \delta \quad$ Tangente de pérdida

a-MEM Minimal Essential Medium Eagle, modificación alfa

DMEM Dulbecco's Modified Eagle's Medium 
FBS

GBMCs

$\beta-\mathrm{TCP}$

ECM

$\mathrm{T}_{\mathrm{m}}$

PCL

$E^{\prime}$

semiIPNs

RNA

TE

bFGF

BMP-2

rhBMP-2

TGF- $\beta 1$

TGF- $\beta$

PDGF-BB

BDNF

DD

FBS

\section{Suero bovino-fetal}

Células mesenquimales provenientes de médula ósea de cabras adultas

$\beta$-fosfato tricálcico

Matriz extracelular

Temperatura de fusión

Poli ( $\varepsilon$-caprolactona)

Módulo de Young

Redes poliméricas semi-interpenetradas

Acido ribonucleico

Ingeniería de tejidos

Basic fibroblast growth factor

Bone morphogenetic protein-2

Recombinant human bone morphogenetic protein-2

Transforming growth factor- $\beta 1$

Transforming growth factor

Platelet-derived growth factor-BB

Brain derived neutrophic factor

Grado de desacetilación

Suero bovino-fetal 
DMEM Dulbecco’s Modified Eagle’s Medium

$\alpha$-MEM Minimal Essential Medium Eagle, modificación alfa

MTS 3-(4,5-dimetiltiazol-2-il)-5-(3-carboximetoxifenil)-2(4sulfofenil)-2H tetrasolium

TMC Trimetil-quitosano

PBS Solución salina de buffer fosfato

DNA Ácido desoxirribonucleico

Tris-EDTA Tris-ácido etilendiaminotetracético

BS Solución de bloqueo

DAPI 4',6-diamidino-2-fenilindol

ANOVA Análisis de varianza

Col I Colágeno tipo I

PEMA Poli etil metacrilato

PEO Poli óxido de etileno

SDR-FTIR Técnica de reflectancia difusa en FTIR

HAc Acido acético

TGA Análisis termogravimétrico

u-CT Tomografía micro-computarizada 


\section{Referencias}

[1] Ratner B.D., Biomaterials Science: An Introduction to Materials in Medicine. Academic Press, San Diego, (1996).

[2] Herrero J.E., Biological Biomaterials. En Anales de Química, Int. Ed. 93 S32, (1997).

[3] Stegemann J.P., Kazsuba S.N., Rowe S.L., Tissue engineering, 13,2601, (2007).

[4] Nishinari K., Takahashi R., Curr. Opin. Colloid Interface Sci., 8, 396 (2003).

[5] Mano J.F., Silva G.A., Azevedo H.S., Malafaya P.B., Sousa R.A., Silva S.S., Boesel L.F., Oliveira J.M., Santos T.C., Marques A.P., Neves N.M., Reis R.L., J. R. Soc. Inteface, 4, 999, (2007)

[6] Liao Y.H., Jones S.A., Forbes B., Martin G.P., Brown M.B., Drug Deliv., 12, 327 (2005).

[7] Ji Y., Ghosh K., Li B.Q., Sokolov J.C., Clark A.F., Rafailovich M.H., Macromol. Biosci., 6, 811 (2006).

[8] Nam H.S., An J., Chung D.J., Kim J.H., Chung C.P., Macromol. Rest., 14, 530 (2006).

[9] Xu X.L., Lou J., Tang T.T., Ng K.W., Chang J.H., Yu C.F., Dai K.R., J. biomed. Mater. Res., Part B, Appl. Biomater., 75B, 289 (2005).

[10] Chung C., Mesa J., Miller G.J., Randolph M.A., Gill T.J., Burdick J.A., Tissue Eng., 12, 2665 (2006).

[11] Giani E., Andreassi A., Taweucci P., Alessandrini C., Fimiani M., Andreassi L., Biomaterials, 20, 1689 (1999). 
[12] Hennrich K., Heimburg D.V., Rendchen R., Bartolo C.D., Milella E., Pallua N., Biomaterials, 26, 7025 (2005).

[13] Chih-Ta L., Ching-Ping H., Yu-Der L., Biomacromolecules, 7, 2200, (2006) [14] Gilbert M.E., Kirker K.R., Gray S.D., Ward P.D., Szakacs J.G., Prestwich G.D., Laringo-scope, 114, 1406 (2004).

[15] Kirker K.R., Luo Y., Nielson J.H., Shelby J., Prestwich G.D., Biomaterials, 17, 3661 (2002).

[16] Keskin D.S., Tezcaner A., Korkusuz P., Korkusuz F., Hasirci V., Biomaterials, 26, 4023 (2005).

[17] Park Y.J., Lee Y.M., Lee J.Y., Seol Y.J., Chung C.P., Lee S.J., J. Control. Release, 67, 385 (2000).

[18] Lee J.E., Kim K.E., Kwon I.C., Ahn H.J., Lee S.H., Cho H., Kim H.J., Seong S.C., Lee M.C., Biomaterials, 25, 4163 (2004).

[19] Cai S., Liu Y., Shu X.Z., Prestwich G.D., Biomaterials, 26, 6054 (2005).

[20] Fan H., Hu Y., Zhang C., Li X., Lu R., Qin L., Zhu R., Biomaterials, 27, 4573 (2006).

[21] Chang C.H., Liu H.C., Lin C.C., Chou C.H., Lin F.H., Biomaterials, 24, 4853 (2003).

[22] Chang C.H., Kuo T.F., Lin C.C., Chou C.H., Chen K.H., Lin F.H., Biomaterials, 27, 1876 (2006).

[23]. Peter M.G, in: A. Steinbuchel, R.H. Marchessault (Eds.), Biopolymers for Medical and Pharmaceutical Applications, Wiley- VCH, Weinheim, 2005, pp. 419-512.

[24] Hejazi R., Amiji M., J. Control. Release, 89, 151 (2003).

[25] Hon D.N., in: S. Dumitriu (Ed.), Polysaccharides in Medicinal Applications, Marcel Dekker, New York, 1996, pp. 631-649. 
[26] Mangione M.R., Giacomazza D., Bulone D., Martorana V., Cavallaro G., San Biagio P.L., Biophys. Chemist., 1 13, 129 (2005).

[27] Bartkowiak A., Hunkeler D., Colloid Surf., B Biointerfaces, 21, 285 (2001).

[28] Sjoberg H., Persson S., Caram-Lelham N., J. Control. Release, 59, 391 (1999).

[29] Tapia C., Corbalan V., Costa E., Gai M.N., Yazdani-Pedran M., Biomacromolecules, 6, 2389 (2005).

[30] Brown R.M., J. polym. Sci., A, Polym. Chem., 42, 487 (2004).

[31] Saxena I.M., Brown R.M., Ann. Bot., 96, 9 (2005).

[32] Martson M., Viljanto J., Hurme T., Saukko P., Eur.Surg. Res., 30, 426 (1998).

[33] Muller F.A., Muller L., Hofman I., Greil P., Wenzel M.M., Staudenmaier R., Biomaterials, 27, 3955 (2006).

[34] Pulkkinen H., Tiitu V., Lammentausta E., Hamalainen E.R., Kiviranta I., Lammi M.J., Biomed. Mater. Eng., 16, 529 (2006).

[35] Holmbom J., Ekholm E., Martson M., Liiho M., Salonen J., Penttinen R., Bone, 30, 55 (2002).

[36] Muller F.A., Jonasova L., Cromme P., Zollfrank C., Greil P., Biomimetic apatite formation on chemically modified cellulose templates, in: M.A. Barbosa, F.J. Monteiro, R. Correia, B. León (Eds.), Bioceramics 16, vol. 254-6, Trans Tech Publishers, Switzerland, 2004, pp. 1111-1114.

[37] Entcheva E., Bien H., Yin L.H., Chung C.Y., Farrell M., Kostov Y., Biomaterials, 25, 5753 (2004).

[38] Stevens M.M., Qanadilo H.F., Langer R., Prasad Shastri V., Biomaterials, 25, 887 (2005).

[39] Grant G.T., Morris E.R., Rees D.A., Smith P.J.C., Tom D., FEBS Lett., 32, 195 (1973). 
[40] George M., Abraham T.E., J. Control. Release, 114, 1 (2006).

[41] King A.H., Brown seaweed extracts (alginates). In M. Glicksman (ed).

Food hydrocolloids, Vol II. Boca Raton, FL: CRC Press, pp. 115-188, (1983).

[42] Kuo C.K., Ma P.X., Biomaterials, 22, 511 (2001).

[43] Pongjanyakul T., Puttipipatkhachorn S., Int. J. Pharm., 331, 61(2007).

[44] Grunder T., Gaissmaier C., Fritz J., Stoop R., Hortschansky P., Osteoarthr. Cartil., 12, 559 (2004).

[45] Liao I.C., Wan A.C.A., Yim E.K.F., leong K.W., J. Control. Release, 104, 347 (2005).

[46] Xu X.L., Lou J., Tang T.T., ng K.W., Zhang J.H., Yu C.F., Dai K.R., J.

Biomed. Mater. Res., B Appl. Biomater., 75, 289 (2005).

[47] Mierisch C.M., Cohen S.B., Jordan L.C., Robertson P.G., Balian G., Diduch D.R., Arthroscopy, 18, 892 (2002).

[48] Gruber H.E., Hoelscher G.L., Leslie K., Ingram J.A., Hanley E.N., Biomaterials, 27, 371 (2006).

[49] Gruber H.E., Leslie K., Ingram J.A., Norton H.J., Hanley E.N., Spine J., 4, 44 (2004).

[50] Gruber H.E., Fisher E., Desai B., Stasky A., Hoelscher G., Hanley E.N., Exp. Cell Res., 235, 13 (1997).

[51] Vogelin E., Baker J.M., Gates J., Dixit V., Constantinescu M.A., Jones M.F., Exp. Neurol., 199, 348 (2006).

[52] Ravi Kumar M.N.V., React. Funct. Polymers, 46, 1, (2000).

[53] Naessens M., Cerdobbel A., Soetaert W., Vandamme E.J., J. Chem. Technol. Biotechnol., 80, 845 (2005).

[54] Amott S., Fulmer A., Scott W.E., Dea I.C., Moorhouse R., Ree D.J., J. Mol. Biol., 90, 269 (1974).

[55] Rees D.A., Adv. Carbohydr. Chem.., 24, 267 (1969). 
[56] Domard A., Int. J. Biol. Macromol., 9, 98 (1987).

[57] Anthonsen M.W., Smidsred O., Carbohydr. Polym., 26, 303 (1995).

[58] Sannan T., Kuda K., Iwakura Y., Macromol. Chem., 177, 3589 (1976).

[59] Värum K.M., Ottey M.H., Smidsred O., Carbohydr. Polym., 25, 65 (1994).

[60] Sugano M., Watanabe S., Kishi A., Izume M., Ohtakara A., Lipids, 23, 187 (1988).

[61] Klokkevold P.R., Subar P., Fukuyama H., Bertolami C.N., J. Oral Maxilof. Surg., 50, 41 (1992).

[62] Muzzarelli R., Tarsi R., Filippini O., Giovanetti E., Biagini G., Varaldo P., Antimicrob. Agents Chemother., 34, 2019 (1990).

[63] Bowler P., Duerden B., Armstrong D., Clin. Microbiol. Rev., 14, 244 (2001).

[64] Morimoto M., Hiroyuki S., Shigemasa Y., Trends Glycosci. Blycotechnol., 14, 205 (2002).

[65] Aimin C., Chunlin H., Juliang B., Tinyin Z., Zhichao D., Clin. Orthop., 366, 239 (1999).

[66] Begin A., Van Calsteren M., Int. J. Biol. Macromol., 26, 63 (1999).

[67] Lloyd L., Kennedy J., Methacanon P., Paterson M., Knill C., Carbohydr.

Polym., 37, 315 (1998).

[68] Dykes P., Heggie R., Hill S., J. Wound Care, 10, 7 (2001).

[69] Dykes P., Heggie R., J. Wound Care, 12, 260 (2003).

[70] Ueno H., Mori T., Fuginaga T., Adv. Drug Deliv. Rev., 52, 105 (2001).

[71] Kojima K., Okamoto Y., Miyatake K., Fujise H., Shigemasa Y., Minami S., J. Vet. Med. Sci.,, 66, 1595 (2004).

[72] Mori T., Murakami M., Okumura M., Kadosawa T., Uede T., Fuginaga T., J. Vet. Med. Sci., 67, 51 (2005).

[73] Khan T., Peh K., Ching H., J. Pharm. Pharmaceut. Sci., 3, 303 (2000). 
[74] Chatelet C., Damour O., Domard A., Biomaterials, 22, 261 (2001).

[75] Azevedo H.S., Reis R.L., Understanding the enzymatic degradation of biodegradable polymers and strategies to control their degradation rate, in biodegradable systems in medical functions, design, processing, testing and applications, Reis R.L. and Roman J.S., Eds., CRC Press, Boca Raton, 2004.

[76] Henry J.B., Clinical Diagnosis and Management by Laboratory Methods, 18th edition. Saunders, Philadelphia, p. 1371 (1991).

[77] Temei A., Kazokoglu H., Taga Y., Ann. Ophthalmol., 23, 191 (1991).

[78] Amano K., Ito E., Eur. J. Biochem., 85, 97 (1978).

[79] Berger L.R., Weiser R.S., Biochim. Biophys. Acta, 26, 517 (1957).

[80] Banjard S.H., Blake C.C., Swan F.L., I. D. A., In Lysozyme, eds. Osserman E.F., Canfield R.E., and Beychok S., Academic Press Inc., New York, p. $71(1974)$.

[81] Cohen J.S., Nature, 223, 43 (1969).

[82] Nordtveit R.J., Värum K.M., Smidsred O., Carbohydr. Polym., 29, 163 (1996).

[83] Hirano S., Tsuchida H., Nagao N., Biomaterials, 10, 574 (1989).

[84] Paradossi G., Chiessi E., Venanzi M., Pispisa B., Palleschi A., Int. J. Biol. Macromol., 14, 73 (1992).

[85] Lee K.Y., Ha W.S., Park W.H., Biomaterials, 16, 1211 (1995).

[86] Kamiyama K., Onishi H., Machida Y., Biol. Pharm. Bull., 22, 179 (1999).

[87] Raymond L., Morin F.G., Marchessault R.H., Carbohydr. Res., 243, 331 (1993).

[88] Baxter A., Dillon M., Taylor K.D.A., Roberts G.A.F., Int. J. Biol. Macromol., 14, 166 (1992).

[89] Da Silva R.M.P., Mano J.F., Reis R.L., Macromol. Chem. and Physics, 209, 1463 (2008). 
[90] Domard A., Int. J. Biol. Macromol., 9, 98 (1987).

[91] Niola F., Basora N., Chornet E., Vidal P.F., J. Therm. Anal., 28, 189 (1983).

[92] Rathke T.D., Hudson S.M., J. Polym. Sci., Polym. Ed., 31, 749 (1993).

[93] Wu A.C.M., Methods Enzimol., 161, 447 (1988).

[94] Muzarelli R.A.A., Lough C., Emanuelli M., Carbohydr. Res., 164, 433 (1987).

[95] Hiemenz P., Timothy L.P., Polymer Chemistry. Second ed. Boca Raton: CRC P, 336, 338 (2007).

[96] Sieval A.B., Thanou M., Kotze A.F., Verhoef J.C., Brussee J., Junginger H.E., Carbohydr. Polym., 36, 157 (1998).

[97] Jia Z., Shen D., Xu W., Carbohyd. Research, 333 (1), 1 (2001).

[98] Thanou M., Kotze A.F., Scharringhausen T., Lueben H.L., de Boer A.G., Verhoef J.C., Junginger H.E., J. Control. Release, 64, 15 (2000).

[99] Kim C., Jung B., Choi K., Kim J., Kongopo Hwahak, 7(1), 118 (1996).

[100] Kálal J., Švec F., Maroušek V., J. Polymer Sci. Polym. Symp.,47, 155, (1974).

[101] Roberts G.A.F., Taylor K.E., Makrom. Chem., 190, 951 (1989).

[102] Mi F.L., et al., Carbohydr. Polym., 41, 389 (2000).

[103] Crescenzi V., Imbriaco D., Lárez C., Dentini M., Ciferri A., Macromol. Chem. Phys., 196, 2873 (1995).

[104] Fwu-Long M., Hsing-Wen S., Hsing-Shing S., J. Polym. Sci. Polym. Chem., 38, 2804 (2000).

[105] Fwu-Long M., Yu-Chiun T., Hsiang-Fa L., Hsing-Wen S., Biomaterials, 23, 181 (2002).

[106] Nishi C., Nakajima N., Ikada Y., J. Biomed. Mater. Res., 29, 829 (1995). 
[107] Tsai T.H., Westly J., Lee T.F., Chen C.F., J. Liq. Chromatogr., 17, 2199 (1994).

[108] Fujikawa S., Yokota T., Koga K., Kumada J., Biotechnol. Lett., 9, 697 (1987).

[109] Touyama R., Takeda Y., Inoue K., Kawamura I., Yatsuzuka M., Ikumoto T., Shingu T., Yokoi T., Inouye H., Chem. Pharm. Bull., 42, 668 (1994).

[110] Fujikawa S., Fukui Y., Koga K., Tetrahedron Lett., 28, 4699 (1987).

[111] Bhumkar D.R., pokharkar V.B., AAPS PharmaScitech, 7, 1 (2006).

[112] Schatz C., Lucas J., Viton C., Domard A., Pichot C., Langmuir, 20, 7766 (2004).

[113] Madihally S.V., Matthew H.W.T., Biomaterials, 20, 1133 (1999).

[114] Mucha M., React. Funct. Polym., 38, 19 (1998).

[115] Mucha M., Pawlak A., Thermochim. Acta, 27, 69 (2005).

[116] Cheung Y.W., Stein R.S., Lin J.S., Wignall G.D., Macromolecules, 27, 2520 (1994).

[117] Koenig M., Huang S., Polymer, 36, 1877 (1995).

[118] Olabarrieta I., Forsstrom D., Gedde U., Hedenqvist M., Polymer, 42, 4401 (2001).

[119] Tomonori H., Toshihiko S., Yoshio I., Polym. Int., 52, 1839 (2003).

[120] Honma T., Senda T., Inoue Y., Polym. Int., 52, 1839 (2003).

[121] Sarasam A.R., Krishnaswamy R.K., Madihally S.V., Biomacromolecules, 7, 1131 (2006).

[122] García Cruz D.M., Gómez Ribelles J.L., Salmerón Sánchez M., J. Biomed. Mater. Res., Appl. Biomater., 85, 303 (2008). 
[123] García Cruz D.M., Coutinho D.F., Costa Martinez E., Mano J.F., Gómez Ribelles J.L., Salmerón Sánchez M., J. Biomed. Mater. Res., Appl. Biomater., 87, 544 (2008).

[124] Brode G.L., Koleske J.V., J. Macromol. Sci. Chem., 6, 1109 (1972)

[125] Pitt G., Poly( $\alpha$-caprolactone) and its copolymers. In: Biodegradable

Polymer as Drug Delivery Systems. M. Chasin, R. Langer (Eds.). Marcel Dekker, New York, p. 71 (1990).

[126] Engelberg I., Kohn J., Biomaterials, 12, 292 (1991).

[127] Zhu Y., Gao,C.Y., Shen J.Y., Biomaterials, 23, 4889 (2002).

[128] Mei N., Chen G., Zhou P., Chen X., Shao Z.Z., J. Biomater. Appl., 19, 323 (2005).

[129] Shalak R., Fox C.P., Preface In: Shalak R., Fox C.P., eds. Tissue Engineering. New York: Alan R. Liss, p. 26 (1988).

[130] Langer R., Vacanti J.P., Tissue Engineering. Science, 260, 920 (1993).

[131] Watanabe J., Ishihara K., Sci. Technol. Adv. Mater., 4, 539 (2003).

[132] Wu Y.C., Shaw S.Y., Lin H.R., Lee T.M., Yang C.Y., Biomaterials, 27, 896 (2006).

[133] Sarasam A., Madihaly S.V., Biomaterials, 26, 5500 (2005).

[134] Wiliams J.M., Adewunmi A., Scheck R.M., Flanagan C.L., Krebsbach

P.H., Feinberg S.E., Biomaterials, 26, 4817 (2005).

[135] Krajewska B., Sep. Purif. Technol., 41, 305 (2005).

[136] Ashton R.S., Banerjee A., Punyani S., Schaffen D.V., Kane R.S., . Biomaterials, 28, 5518 (2007).

[137] Izquierdo R., Garcia-Giralt N., Rodriguez M.T., Cáceres E., García S.J., Gómez Ribelles J.L., Monleón Pradas M., Monllau J.C., Suay J. J. Biomed. Mater. Res., 85, 25 (2008). 
[138] Escobar Ivirico J.L, Costa Martínez E., Salmerón Sánchez M., Muñoz Criado I., Gómez Ribelles J.L., Monleón Pradas M., J. Biomed. Mater. Res., 83, 266 (2007).

[139] Chew S.Y., Mi R., Hoke A., Leong K.W., Biomaterials, 29, 653 (2008).

[140] Rodríguez Hernández J.C., Serrano Aroca A., Gómez Ribelles J.L., Monleón Pradas M., J. Biomed. Mater. Res., 84, 541 (2008).

[141] Costa Martínez E, Escobar Ivirico JL, Muñoz Criado I, Gómez Ribelles JL, Monleón Pradas M, Salmerón Sánchez M., J. Mater. Sci., 18, 1627 (2007).

[142] Borden M., Attawia M., J. Biomed. Mater. Res., 61, 421 (2002).

[143] Jaklenec A., Wan E., Murray M.E., Mathiowitz E., Biomaterials 29, 185 (2008).

[144] Silva G.A., Coutinho O.P., Ducheyne P., Reis R.L., J. Tissue Eng. and Reg. Med., 1, 97 (2007).

[145] Curran S.J., Chen R., Curran J.M., Hunt J.A., Tissue Engineering, 11, $1312(2005)$.

[146] Sun-Woong K., Oju J., Byung-Soo K., Tissue Engineering, 11, 438, (2005).

[147] Garkhal K., Verma S., Tikoo K., Kumar N., J. Biomed. Mater. Res. Materials in Medicine, 82, 747, (2007).

[148] In-Yong K., Seog-Jin S., Hyun-Seuk M., Mi-Kyong Y., In-Young P., Bom-Chol K., Chong-Su C., Biotechnol. Adv., 26, 1 (2008).

[149] Ho M.H., Kuo P.Y., Hsieh H.J., Hsien T.Y., Hou L.T., Lai J.Y., Wang D.M., Biomaterials, 25, 129 (2004).

[150] Chow K.S., Khor E., Biomacromolecules, 1, 61 (2001).

[151] Sinha V.R., Singla A.K., Wadhawan S., Kaushik R., Kumria R., Bansal K., Dhawan S., Int. J. Pharma., 274, 1 (2004).

[152] Sezer A.D., Akbuga J., Int. J. Pharm., 121, 113 (1995). 
[153] Aydin, Z., Akbuga, J., Int. J. Pharm., 131, 101 (1996).

[154] Acikgoz M., Kas H.S., Orman M., Hincal A.A., J. Microencapsul., 13, 141 (1996).

[155] Bodmeier R., Paeratakul O., J. Pharm. Sci., 78, 964 (1989).

[156] Berthold A., Cremer K., Kreuter J., J. Control. Release, 39, 17 (1996).

[157] Ohya Y., Takei T., Kobayashi H., Ouchi T., J. Microencapsul., 10, 1 (1993).

[158] Chellat F., Tabrizian M., Dumitriu S., Chorne, E., Rivard C.H.,

Yahia L., J. Biomed. Mater. Res., 53, 592 (2000).

[159] De S., Robinson D., J. Control. Release, 89, 101 (2003).

[160] Aggarwal A., Kaur S., Tiwary A.K., Gupta S., J. Microencapsul., 18, 819 (2001).

[161] Lim S.T., Martin G.P., Berry D.J., Brown M.B., J. Control Release, 66, 281 (2000).

[162] Filipovic-Grcic J., Perissutti B., Moneghini M., Voinovich D., Martinac A., Jalsenjak I., J. Pharm. Pharmacol., 55, 921 (2003).

[163] Denkbas E.B., Seyyal M., Piskin E., J. Microencapsul., 16, 741 (1999).

[164] Mi F.L., Tan Y.C., Liang H.F., Sung H.W., Biomaterials, 23, 181 (2002).

[165] Madihaly S.V., Matthew H.W.T., Biomaterials, 20, 1133 (1999).

[166] Nishikawa H., Ueno A., Nishikawa S., Kido J., Oishi M., Inoue H., J. Endod, 26, 169 (2000).

[167] Seol Y-J., Lee J-Y., Park I-J., et al., Biotechnology Letters, 26, 1037, (2004).

[168] Malafaya P.B., Pedro A.J., Peterbauer A., Gabriel C., Redl H., Reis R.L., J. Mater. Sci. Materials in Medicine, 16, 1077, (2005).

[169] Suh J.K.F., Matthew H.W.T., Biomaterials, 21, 2589, (2000).

[170] Nettles D.L., Elder S.H., Gilber J.A., Tissue Engineering, 8, 1009, (2002). 
[171] Oliveira S.M, Amaral I.F., Barbosa M.A., Teixeira C.C., Tissue Engineering Part A, 14, 1, (2008).

[172] Jieliang L., Jilun P., Liguo Z., Xinji G., Yaoting Y., J. Biomed. Mater. Res. Materials in Medicine, 67, 938 (2003).

[173] Yi-Cheng H., Yi-You H., Chun-Chieh H., Hwa-Chang L., J. Biomed. Mater Res. Appl. Biomaterials, 74, 659, (2005).

[174] Termine J.D., Bone Matrix Proteins and Mineralization Process. En: Favus MJ. ed. Primer on the Metabolic Bone Diseases and Disorders of Mineral Metabolism, Second Edition New York: Raven Press, pp. 2 1(1993).

[175] Puzas J.E., The osteoblast. En: Primer on the metabolic bone diseases and disorders of mineral metabolism, second edition.Favus M.J. ed. New York: Raven Press, pp. 15 (1993).

[176] Lian J.B., Stein G.S., Crit. Rev. Oral Biol. Med., 3, 269 (1992).

[177] Stein G.S., Lian J.B., Endocr. Rev., 14, 424 (1993).

[178] Baron R., Anatomy and biology of bone matrix and cellular elements.

Chapter 1. American society for bone and mineral research, Washington DC, pp. 1 (2003).

[179] Gurley A.M., Roth S.I., Bone. En Sternberg SS, ed. Histology for Pathologists. New York: Raven Press, pp. 61 (1992).

[180] Mundy G.R., Bone Resorbing Cells. En: Primer on the Metabolic Bone Diseases and Disorders of Mineral Metabolism, Second Edition. Favus M.J., ed. New York: Raven Press, pp. 25 (1993).

[181] Parfitt A.M., J. Cell Biochem., 55, 273 (1994).

[182] Martino A.D., Sittinger M., Risbud M.V., Biomaterials, 26, 5983 (2005).

[183] Zhang Y., Ni M., Zhang M., Ratner B., Tissue Eng., 9, 337 (2003).

[184] Zhang Y., Zhang M., J. Biomed. Mater. Res., 62, 378 (2002). 
Referencias

[185] Zhao F., Yin Y., Lu W.W., Leong J.C., Zhang W., Zhang J., Biomaterials, 23, 3227 (2002).

[186] Kawakami T., Antoh M., Hasegawa H., Yamagishi T., Ito M., Eda S., Biomaterials, 13, 759 (1992).

[187] Chen E.S., Frenkel S.R., Di Cesare P.E ., Am. J. Orthop., 28, 31 (1999).

[188] Mankin H.J., J. Bone Joint Surg., 64A, 460 (1982).

[189] Buckwalter J.A., Mankin H.J., J. Bone Joint Surg., 79A, 600 (1997).

[190] Buckwalter J.A., Mankin H.J., J. Bone Joint Surg., 79A, 612 (1997).

[191] Pérez Olmedilla M., García-Giralt N., Monleón Pradas M., Benito Ruiz

P., Gómez Ribelles J.L., Cáceres Palou E., Monllau García J.C., Biomaterials, 27, 1003, (2006).

[192] Reis R.L., Mendes S.C., Cunha A.M., Bevis M.J., Polym. Inter., 43, 347, (1997).

[193] Höhne G.W.H., Schawe J., Schick C., Temochim. Acta, 22 1, 129 (1993).

[194] Owens D.K., Wendt R.C., J. Appl.Polym. Sci., 13, 1741, (1969).

[195] Kokubo T., Takadama H., Biomaterials, 27, 2907 (2006).

[196] CrescenziV., Manzini G., Calzolari G., Borri C., Eur. Polym. J., 8, 449 (1972).

[197] Avrami M., J. Chem. Physics., 8, 212 (1940).

[198] Lauritzen J.I., Hoffman J.D., J. Res. Nat. Bur. Std.,64A, 73, (1960).

[199] Hernández Sánchez F., Molina MateoJ., Romero Colomer F.J., Salmerón Sánchez M., Gómez Ribelles J.L., Mano J.F., Biomacromolecules, 6, 3283 (2005).

[200] Toshio Y., Kazuo N., Masatsugu M., Toshiro M., Pure Appl. Chem., 74, 869 (2002).

[201] Nisbet D.R., Pattanawong S., Nunan J., ShenW., Horne M.K., Finkelstein D.I., Forsythe J.S., J. Colloid Interface Sci., 299, 647 (2006). 
[202] Schakenraad J.M., Busscher H.J., Wildevuur C.H.R., Arends J., J. Biomed. Mater. Res., 20, 773 (1986).

[203] Dalby M.J., Childs S., Riehle M.O., Johnstone H.J.H., Affrossman S., Curtis A.S.G., Biomaterials, 24, 927 (2003).

[204] García A.J., Vega M.D., Boettiger D., Mol. Biol. Cell, 10, 785 (1999).

[205] Raghavachari M., Tsai H.M., Kottke-Marchant K., Marchant R.E., Colloids Surf. Biointerf., 19, 315 (2000).

[206] Arakawa H., Umemura K., Ikai A., Nature, 358, 171 (1992).

[207] Bergkvist M., Carlsson J., Oscarsson S., J. Biomed. Mater. Res., 64A, 349 (2003).

[208] Sherrat M.J., Holmes D.F., Shuttleworth C.A., Kielty C.M., Biophys. J., 86, $3211(2004)$.

[209] Sherrat M.J., Bax D.V., Chaudhry S.S., Hodson N., Lu J.R., Saravanapavan P., Kielty C.M., Biomaterials 26, 7192 (2005).

[210] Rodríguez Hernández J.C., Salmerón Sánchez M., Soria J.M., Gómez Ribelles J.L., Monleón Pradas M., Biophys. J., 93, 202 (2007).

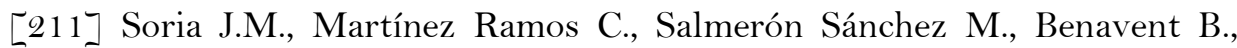
Campillo Fernandez A., Gómez Ribelles J.L., Garcia Verdugo J.M., Monleón Pradas M., Barcia J.A., J. Biomed. Mater. Res., 79A, 495 (2006).

[212] Senda T., He Y., Inoue Y., Polym. Inter., 51, 33 (2001).

[213] Sivalingam G., Karthik R., Madras G., J. Anal. Appl. Pyrol., 70, 631 (2003). 
[214] Peniche C., Argüelles-Monal W., Davidenko N., Sastre R., Gallardo A., Román J. S., Biomaterials, 20, 1869 (1999).

[215] Peniche C., Argüelles-Monal W., Román J. S., Polym. Degrad. Stab., 39, 21 (1993).

[216] Garcia I., Peniche C., Nieto J. M., J. Thermal Analysis, , 21, 189 (1983).

[217] Nieto Charques L., Moratal Pérez D., Martí Bonmatí L., EsTra: Análisis de la Estructura Trabecular. Herramienta de ayuda al diagnóstico de enfermedades óseas basada en un análisis estructural tridimensional a partir de imágenes de resonancia magnética. Herramienta-software registrada en el Centro de Transferencia Tecnológica de la Universidad Politécnica de Valencia, (2006).

[218] Nieto Charques L., Proyecto Fin de Carrera titulado "EsTra: Análisis de la Estructura Trabecular. Herramienta de ayuda al diagnóstico de enfermedades óseas basada en un análisis estructural tridimensional a partir de imágenes de resonancia magnética". Escuela Técnica Superior de Ingenieros de Telecomunicación, Universidad Politécnica de Valencia, (2006).

[219] Alberich Bayarri A., Proyecto Fin de Carrera titulado "Análisis estructural y mecánico mediante elementos finitos de la microarquitectura trabecular a partir de imágenes de resonancia magnética de alta resolución para una ayuda al diagnóstico, tratamiento y prevención de la osteoporosis. Aplicación del análisis estructural y mecánico a andamiajes sustitutivos de biopolímeros de hueso trabecular". Escuela Técnica Superior de Ingenieros de Telecomunicación, Universidad Politécnica de Valencia, (2007).

[220] Freier T., Koh H.S., Kazazian K., Shoichet M.S., Biomaterials, 26, 5872 (2005). 
[221] Cunha-Reis C., TuzlaKoglu K., Baas E., Yang Y., El Haj A., Reis R.L., J. Mater. Sci., 18A, 195 (2007).

[222] Hutmacher D.W., Biomaterials, 21, 2529 (2000)

[223] Gibson L.J., Ashby M.F. Cellular solids. Structure and properties.

Second Edition, Chapter 5, Cambridge University Press (1997)

[224] Owen T.A., Aronow M., Shalhoub V., Barone L.M., Wilming L., Tassinari M.S., Kennedy M.B., Pockwinse S., Lian J.B., Stein G.S., J. Cell. Physiol., 143, 420 (1990).

[204] Owen T.A., Aronow M.S., Barone L.M., Bettencourt B., Stein G.S., Lian J.B., Endocrinology, 128, 1496 (1991).

[225] Coelho M.J., Cabral A.T., Fernandez M.H., Biomaterials, 21, 1087 (2000).

[226] Zernik J., Twarog K., Upholt W.B., Differentiation, 44, 207 (1990).

[227] Boivin G., Morel G., Lian J.B., Anthoine-Therrier C., Dubois P.M., Meunier P.J., Virchows Archiv. Pathol. Anat. Histopathol., 41 7, 505 (1990).

[228] Pockwinse S.M., Wilming L.G., Conlon D.M., Stein G.S., Lian J.B., J. Cell. Biochem., 49, 310 (1992).

[229] Bhosale A.M., Richardson J.B., Br. Med. Bulletin, 87, 77, (2008).

[230] Hunter W., Phil. Trans. Roy. Soc., 42B, 514, (1943).

[231] Cormier J.T., Zur Nieden N.I., Rancourt D.E., Kallos M.S., Tissue Engineering, 12, 3233, (2006).

[232] Freed L.E., Guilak F., Guo X.E., Gray M.L., Tranquillo R., Holmes J.W., Radisic M., SeftonM.V., Kaplan D., Vunjak-Novakovic G., Tissue Engineering, 12, 3285, (2006). 
Referencias

[233] Johnstone B., Hering T.M., Caplan A.I., Goldberg V.M., Yoo J.U., Exp.

Cell Res., 238, 265, (1998).

[234] DeLise A.M., Fischer L., Tuan R.S., Osteoarthritis Cartilage, 8, 309, (2000).

[235] Tuzlakoglu K., Alves C.M., Mano J.F., Reis, R.L., Macromol. Biosc., 4, 811 (2004)

[236] Oliveira J.M., Rodrigues M.T., Silva S.S., Malafaya P.B., Gomes M.E., Viegas C.A., Dias I.R., Azevedo J.T., Mano J.F., Reis R.L., Biomaterials, 27, 6123 (2006).

[237] Prabaharan M., Mano J.F., Drug Delivery, 12, 41(2005).

[238] Denkbas E.B., Seyyal M., Piskin E., J. Microencapsul., 16, 741 (1999).

[239] Al-Helw A.A., Al-Angary A.A., Mahrous G.M., Al-Dardari M.M., J. Microencapsul., 15, 373 (1998).

[240] Amaral I.F., Cordeiro A.L., Sampaio P., Barbosa M.A., J. Biomater. Sci.

Polymer Edn., 18, 469, (2007). 


\section{Apéndice}

Algunos de los resultados presentados en este trabajo han sido realizados en colaboración con las siguientes personas:

Dra. Elisa Costa Martínez

- Evaluación de la respuesta biológica de las mezclas de policaprolactona y quitosano.

Dr. Manuel Ricardo Mendes Pereira da Silva de la Universidad de Minho en Braga, Portugal.

- Determinación del grado de desacetilación del quitosano mediante espectroscopía ultravioleta (UV).

Dr. David Morátal Pérez

- Determinación de la distribución del tamaño de poro de los scaffolds de quitosano.

Dr. José Antonio GómezTejedor

- Determinación de las propiedades mecánicas de los scaffolds de quitosano. 